InternationaI Telecommunication Union

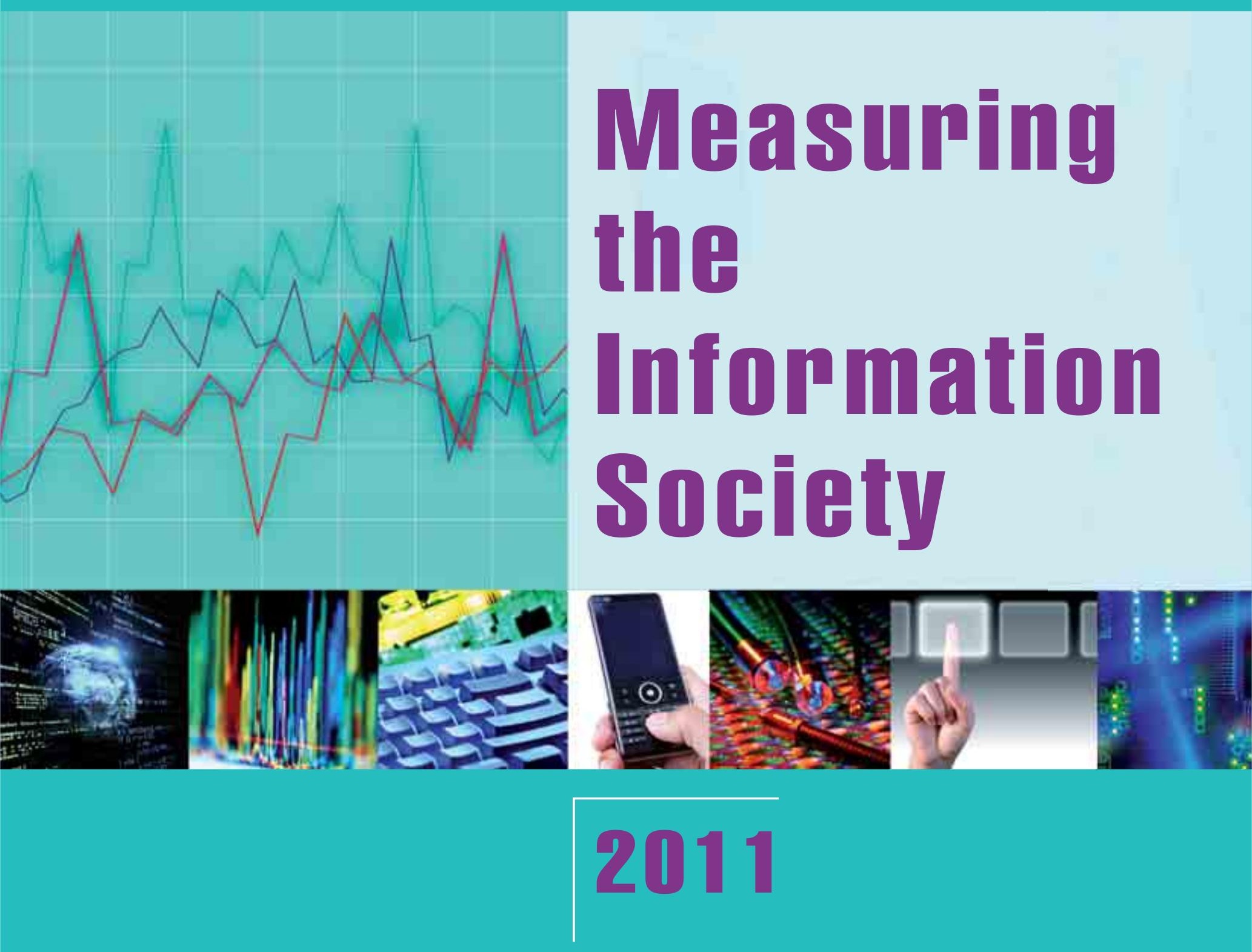

(1) 

I nternational Telecommunication Union

\section{Measuring the \\ Information Society}
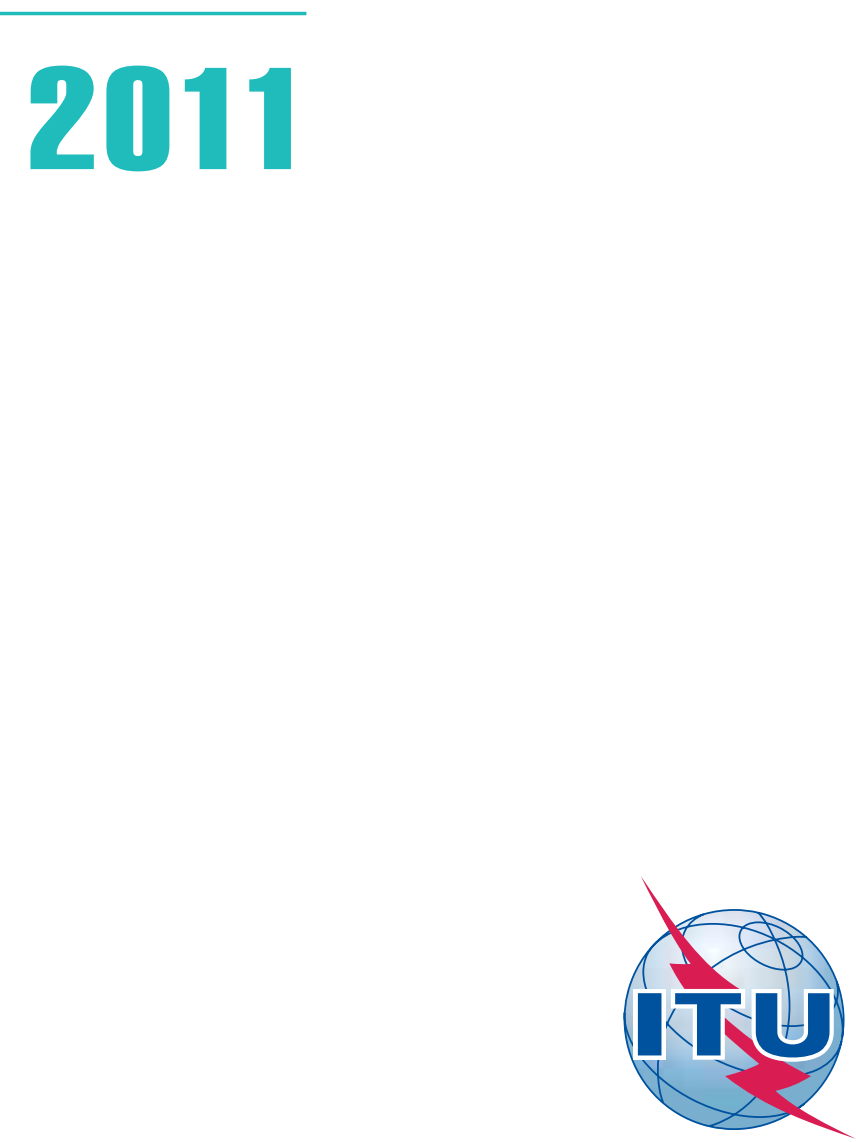
(C) 2011 ITU

International Telecommunication Union

Place des Nations

CH-1211 Geneva Switzerland

Original language of publication: English.

All rights reserved. No part of this publication may be reproduced, stored in a retrieval system, or transmitted in any form or by any means, electronic, mechanical, photocopying, recording, or otherwise, without the prior permission of the International Telecommunication Union.

ISBN 92-61-13801-2 


\section{Foreword}

I am pleased to present the 2011 edition of Measuring the Information Society. Each year, this publication features the latest ICT Development Index (IDI) and ICT Price Basket (IPB) - two benchmarking tools to monitor information society developments worldwide. While the IDI captures progress made in regard to ICT infrastructure, use and skills, the IPB is a powerful tool in monitoring the affordability of ICT services and in explaining why some countries have moved faster than others in their ICT development. The report also takes an in-depth look at broadband development and presents new data on subscriptions, speed and bandwidth. An analysis of Internet user statistics reveals some of the key challenges and opportunities that need to be addressed to bring more people online in developing countries.

Over the past two years, the world has witnessed continuous growth of ICT services and uptake worldwide. All 152 economies included in the IDI have improved their scores, confirming the continuous spread of ICTs and the growing global information society. While most of the leading IDI countries are still from the developed world, it is encouraging to see that the most dynamic performers are developing countries. The majority of these are middleincome countries, however, and most of the least developed countries remain at the bottom of the index. The report shows that while ICT and income levels are closely related, income constraints can be overcome by strong policy measures. A number of countries have succeeded in reaching higher IDI levels than would be expected given their income levels. This should encourage all countries to proactively promote ICT policies and create an enabling environment that allows the sector to grow.

The affordability of ICT services is key to bringing more people into the information age. Our latest IPB compares 2008 and 2010 tariffs for fixed-telephony, mobile-cellular telephony and fixed-broadband Internet services at global and regional levels, and highlights the difference in prices between developed and developing regions. Covering 165 economies, it is the only price basket to monitor the affordability of ICT services worldwide. The results show that ICT prices continue to fall, in particular fixed-broadband prices, which dropped by more than 50 per cent over the past two years. While this is extremely encouraging, broadband is still too expensive in many developing countries, where it costs on average more than 100 per cent of monthly income, compared with 1.5 per cent in developed countries. Countries without affordable broadband access run the risk of falling behind in the global information society, and I hope that this report will prompt policy-makers to look into ways of lowering ICT prices.

The ICT for development debate is witnessing an obvious shift: the focus is no longer on the mobile-cellular miracle, but on the need for high-speed broadband Internet access. The report shows that wireless-broadband Internet access is the strongest growth sector, with prepaid mobile broadband mushrooming in many developing countries and Internet users shifting from fixed to wireless connections and devices. The emergence of new mobile devices, such as smartphones and tablet computers, is accelerating this process, but they are still too expensive in developing countries and there is a need to develop more affordable models and products. Furthermore, the availability of bandwidth and capacity will increasingly determine the use and beneficial impact of ICTs. As this report shows, a digital divide is unfolding between those with high-speed/capacity/quality access (as is the case in many high-income countries) and those with lower speed/capacity/quality access (as is the case in many lowincome countries). While the potential development impact of bringing people from developing countries online via wireless access is enormous, high-end users from the business sector and public and private organizations continue to rely on high-speed fixed-broadband connections. Policy-makers should act swiftly to facilitate the spread of broadband and ensure that broadband services are fast, reliable and affordable.

The policy focus is often on enhancing ICT infrastructure and access. The full ICT development impact will only be felt, however, once people are using the technologies effectively. As more and more countries collect Internet user data, they provide valuable insights into who is currently online. The report shows that the Internet usage 
divide runs along gender, education, income and age lines, and there are significant differences between people living in rural and urban areas of developing countries. A promising way of bringing more people from developing countries online is by targeting the younger generation. Social networking and user-created content has become one of the main online activities in which young people especially are actively engaging. Given that 47 per cent of the population in developing countries are under 25 years of age, there is an incredible potential in terms of increasing the number of Internet users. Providing Internet access in schools starting at primary level is key once students have started using the Internet they will strive to continue to do so irrespective of their age, gender, income or final school qualification.

To ensure that the information society will be truly global and inclusive, much needs to be done to bring its benefits to the poorest in our societies. This means that future policy action needs to address issues that are related not only to access, but also to:

- price;

- bandwidth;

- speed and quality of service;

- skills;

- content and language; and

- applications targeted to low-end users.

In order to effectively monitor trends and assess progress, there is need for continuous development of reliable indicators. Measuring the Information Society is a key contribution to this process. I trust that the data and analysis provided will be useful to policy-makers, the ICT industry, academia, market analysts and others who are monitoring global ICT developments.

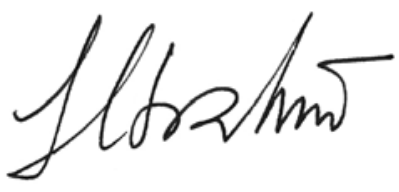

Brahima Sanou

Director

Telecommunication Development Bureau (BDT)

International Telecommunication Union 


\section{Acknowledgements}

The 2011 edition of Measuring the Information Society was prepared by the ICT Data and Statistics Division within the Telecommunication Development Bureau of ITU. The team included Susan Teltscher (Head of Division), Vanessa Gray, Esperanza Magpantay, Doris Olaya, Ivan Vallejo and Sonya Buracond (during her internship at ITU). Christoph Stork (consultant to ITU) provided substantive inputs to Chapter 5 of the report. Olivier Poupaert, Nathalie Rollet, and Ekaterina Bonacheva (during her internship at ITU) contributed to the data collection and Michael Minges (consultant to ITU) compiled and prepared the data set on international Internet bandwidth. Helpful comments and suggestions were received from Martin Adolph (ITU/TSB) and Sergio Buonomo (ITU/BR), as well as colleagues in the ITU Regional Office for Asia and the Pacific. The work was carried out under the overall direction of Cosmas Zavazava, Chief a.i., Project Support and Knowledge Management Department, Telecommunication Development Bureau.

The report includes data received from Eurostat, the United Nations Population Division and Wireless Intelligence, as well as purchasing power parity conversion factors received from the World Bank and fibre-optic access data provided by the Fiber-to-the-Home Council, which is greatly acknowledged.

ITU also appreciates the cooperation of countries that have provided data included in the ICT Development Index and ICT Price Basket.

The report was edited by the ITU English Translation Section, led by Anthony Pitt. The desktop publishing was carried out by Nathalie Rollet, and the cover was designed by Simon de Nicola. Administrative support was provided by Herawasih Yasandikusuma. 



\section{Table of contents}

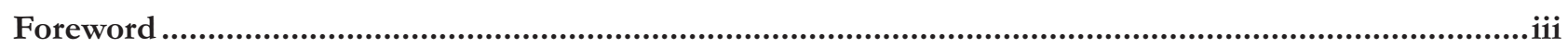

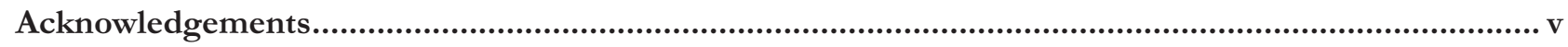

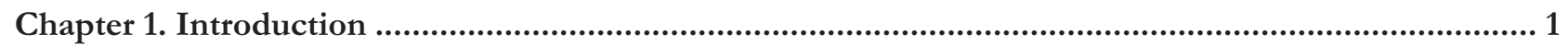

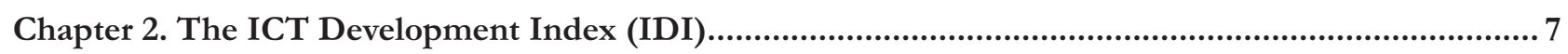

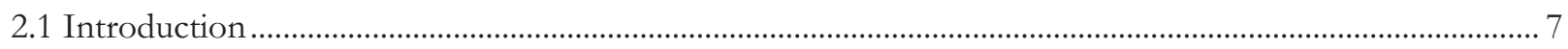

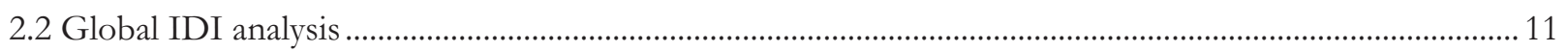

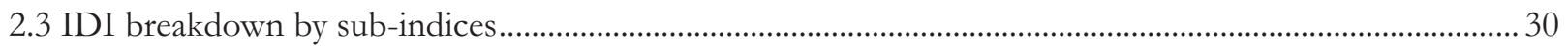

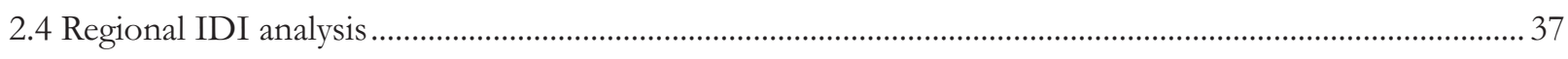

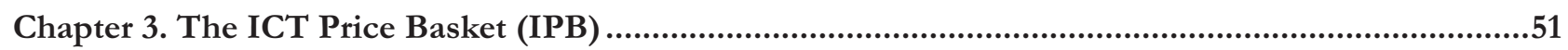

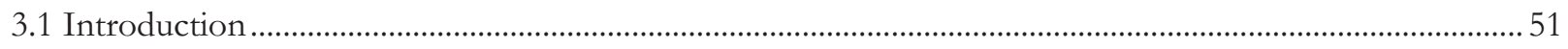

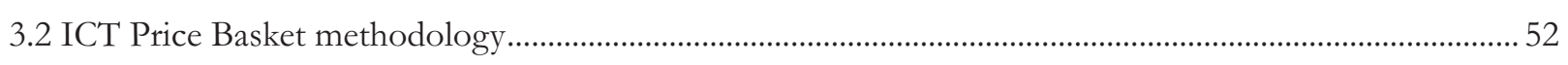

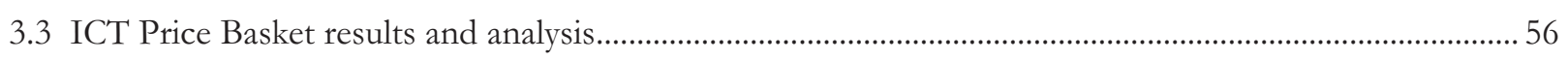

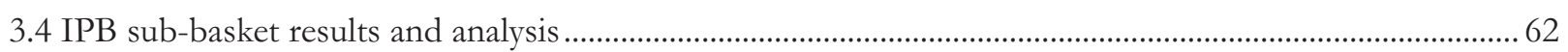

3.5 Comparing mobile-broadband prices - high speed, limited volume ……………………………………….... 77

Chapter 4. Understanding broadband: addressing issues of capacity, speed and quality of service ....... 85

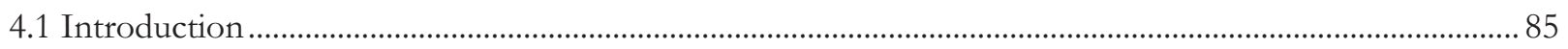

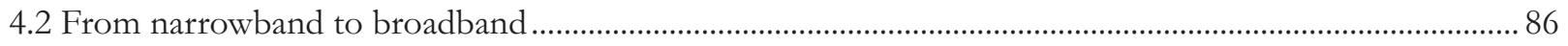

4.3 Broadband revisited: the importance of capacity, speed and quality .............................................................. 89

4.4 Conclusions and recommendations …………………............................................................................. 102

Chapter 5. Increasing Internet use: the role of education, income, gender, age and location .............107

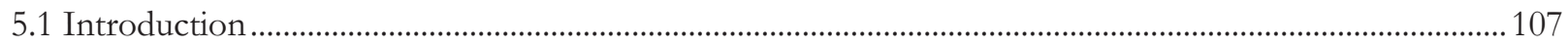

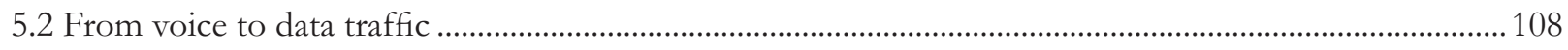

5.3 Education matters................................................................................................................................... 111

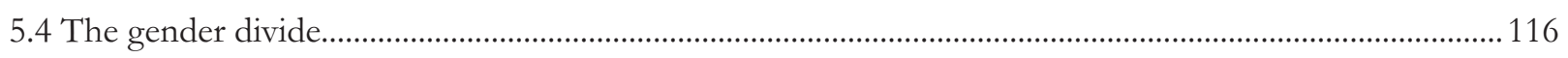

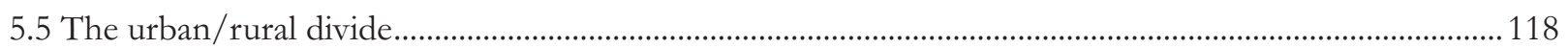

5.6 From e-mail to social networks: drivers of Internet use ........................................................................ 121

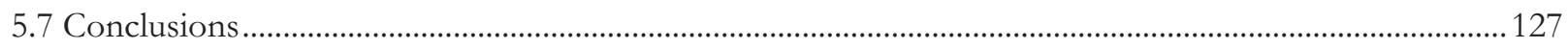

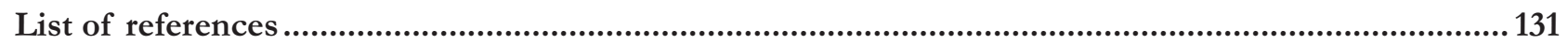

Annex 1. ICT Development Index (IDI) methodology.......................................................................135

Annex 2. ICT Price Basket (IPB) methodology ....................................................................................143

Annex 3. Methodological aspects related to household survey results ...................................................149

Annex 4. Statistical tables of indicators used to compute the IDI ........................................................ 151

Annex 5. Statistical tables of tariffs used to compute the IPB ...............................................................159 


\section{List of charts}

1.1 Global ICT developments, 2000-2010, penetration (left) and annual growth (right) ..................................... 1

1.2 Mobile-cellular subscriptions, 2000-2010, world and by level of development, penetration (left)

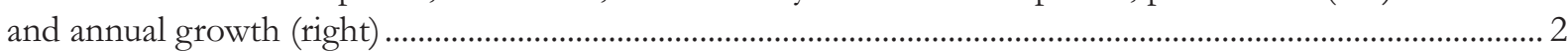

1.3 Fixed-broadband subscriptions, 2000-2010, world and by level of development, penetration (left)

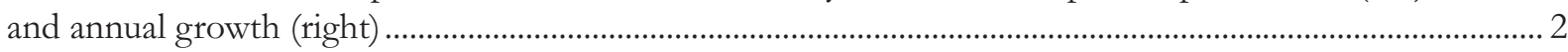

1.4 Mobile-broadband subscriptions, 2007-2010, world and by level of development, penetration (left)

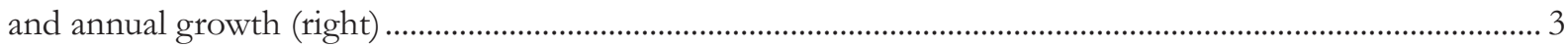

1.5 Internet users, 2000-2010, world and by level of development, penetration (left) and annual growth (right)......... 4

1.6 Households with Internet access, 2002-2010, world and by level of development, penetration (left)

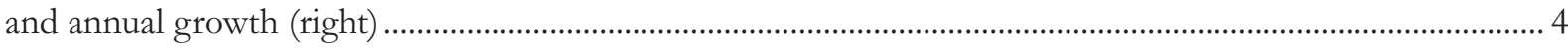

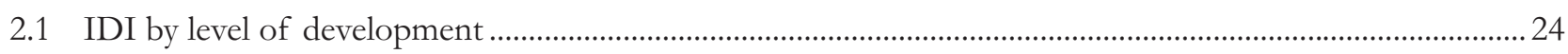

2.2 IDI access sub-index by level of development.........................................................................................24

2.3 IDI use sub-index by level of development..............................................................................................24

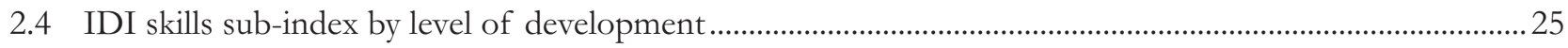

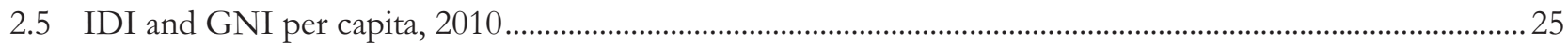

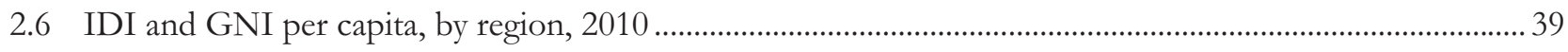

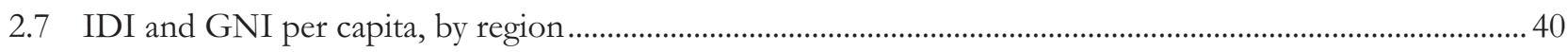

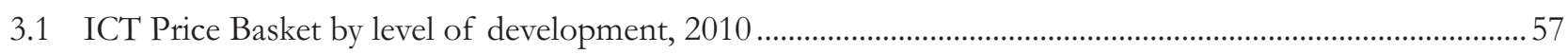

3.2 Relationship between the ICT Development Index and the ICT Price Basket................................................ 61

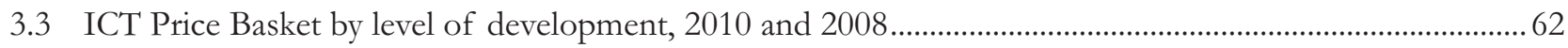

3.4 Fixed-telephone sub-basket by level of development, 2008 and 2010 ............................................................ 66

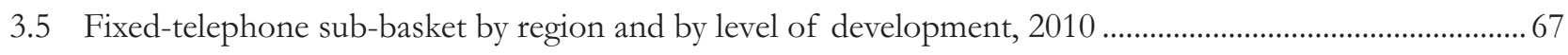

3.6 Mobile-cellular sub-basket by region and by level of development, 2010....................................................... 71

3.7 Mobile-cellular sub-basket by level of development, 2008 and 2010............................................................. 71

3.8 Fixed-broadband sub-basket by level of development, 2008 and 2010........................................................... 74

3.9 Fixed-broadband sub-basket by region and by level of development, 2010 ..................................................... 76

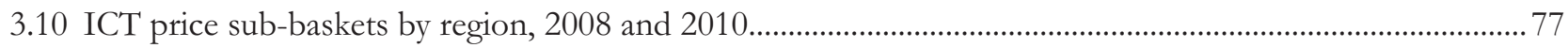

4.1 Broadband subscriptions by technology, United States, June 2010 …………………………....................... 92

4.2 Economies with the highest penetration of fibre-to-the-home/building + LAN........................................ 93

4.3 Broadband subscriptions in the OECD, by technology, December 2010 …………………………………..... 94

4.4 Fixed (wired)-broadband subscriptions by speed, selected economies, 2010 ………....................................... 96

4.5 Fastest broadband speeds advertised by the incumbent telecommunication operator, Mbit/s, all technologies, OECD and selected non-OECD countries, 2010/11 ………………................................ 97

4.6 Average download speed for 2 Mbit/s packages, January-March 2011, Bahrain ........................................... 98

4.7 Total international Internet bandwidth (in TBit/s), by level of development, 2000-2010 …......................100

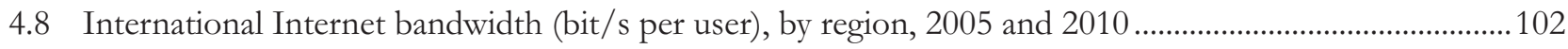


5.1 Percentage of countries collecting data on Internet usage, total and by region............................................. 108

5.2 Percentage of individuals aged 15 to 74 using Internet and computer, latest available year.......................109

5.3 Percentage of individuals aged 15 to 74 using a mobile phone, latest available year ....................................110

5.4 Percentage of individuals aged 16 or older owning a mobile phone and using the Internet, selected African countries, 2007/2008.

5.5 Percentage of individuals using the Internet, by highest educational level attained, latest available year (2008-2010).

5.6 Percentage of individuals aged 16 or older using the Internet, by highest educational level attained, selected African countries, 2007/2008

5.7 Average monthly income of individuals aged 16 or older, by highest educational level attained, selected African countries, 2007/2008, USD.

5.8 Percentage of individuals using the Internet, by highest education attained or currently studying, selected Latin American countries, latest available year..

5.9 Location of Internet use aggregated for 17 African countries, 8 Latin American countries and 35 European countries, latest available year

5.10 Percentage of Internet users, by urban/rural, using the Internet at commercial facility (left) and at home (right), selected countries, latest available year......

5.11 Proportion of individuals using the Internet, by age group, latest available year (2009/2010).

\section{List of figures}

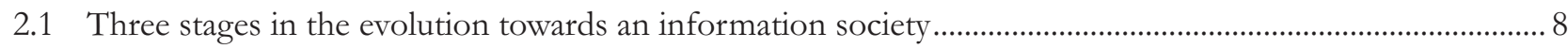

2.2 ICT Development Index: indicators and weights...................................................................................... 10

2.3 Spider charts, selected dynamic countries, 2010 and 2008 ............................................................................21

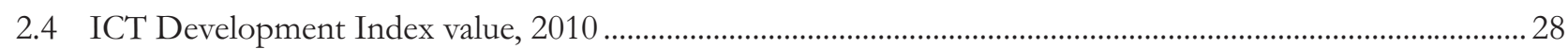

3.1 ICT Price Basket methodology …………………………………………………………………………….... 53

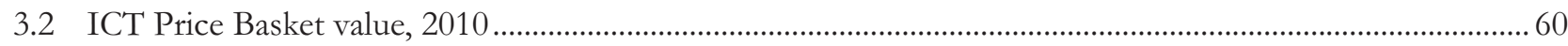

4.1 The rise of 3G: countries that offer 2G/3G services commercially, 2010 ……………………………........ 88

4.2 Fixed (wired)- and wireless-broadband technologies - speed versus mobility …………................................ 90

\section{List of boxes}

2.1 The challenges of measuring mobile broadband 9

2.2 Internet access a legal right in Finland .14

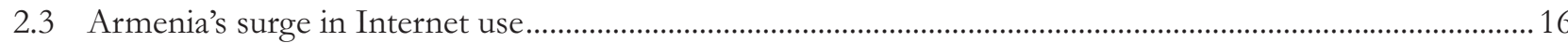

2.4 Kenya - Africa's fastest growing Internet market 17 


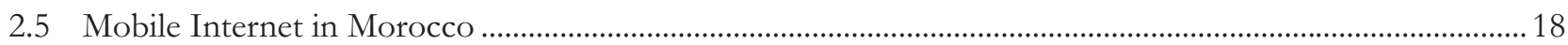

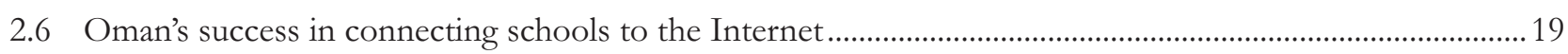

2.7 Mobile-cellular penetration reaching top levels in Saudi Arabia .....................................................................2 20

2.8 The highest ranked IDI country from South America: Uruguay takes the lead............................................. 32

2.9 Government support for ICTs pays off in Viet Nam ................................................................................3

3.1 Competitive pressure and mobile-cellular prices in Africa...............................................................................5

3.2 Prepaid services: not always more expensive than postpaid subscriptions …………………………………....56

3.3 Fast, faster, the fastest: differences in broadband speeds, prices and data caps ............................................. 75

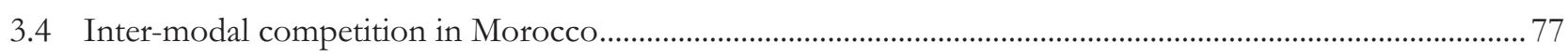

3.5 Both USD and PPP adjusted prices highlight the high cost of fixed-broadband services in

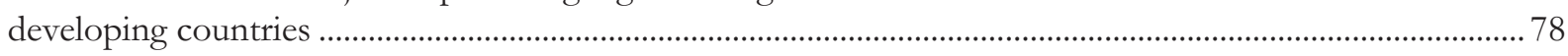

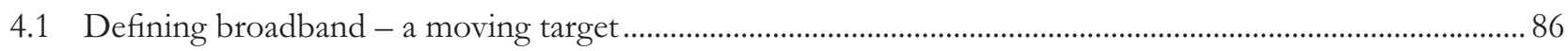

4.2 The spectrum crisis: struggling to keep up the speed, capacity and quality of mobile services.................... 95

4.3 Sri Lanka Telecommunications Regulatory Commission’s (TRCSL) guidelines on advertising mobile-broadband speeds ................................................................................................................... 99

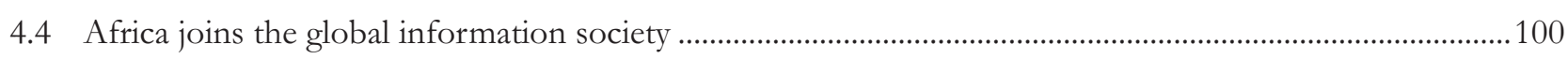

5.1 Social networking as a key driver for bridging the Internet divide in Namibia ........................................... 125

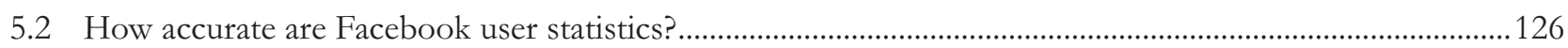

\section{List of tables}

2.1 IDI changes, 2008-2010 ........................................................................................................................

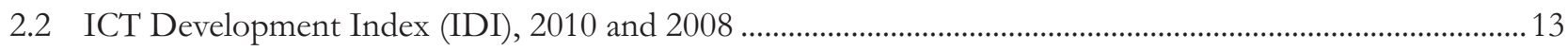

2.3 Most dynamic countries (top ten) - changes between IDI 2010 and 2008....................................................15

2.4 Country groups based on different IDI levels ........................................................................................26

2.5 Advancement of countries between IDI groups (2008-2010) ......................................................................... 27

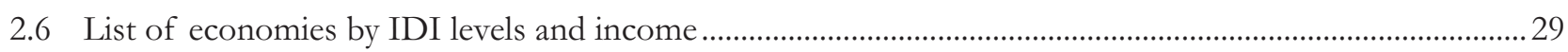

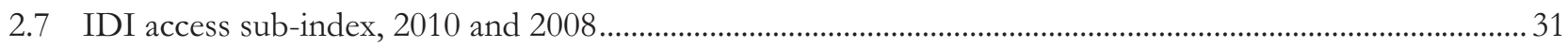

2.8 Top ten economies with the greatest 2008-2010 change in the IDI access sub-index, by absolute value change (left) and rank change (right) ................................................................................................ 32

2.9 IDI use sub-index, 2010 and 2008

2.10 Top ten economies with the greatest 2008-2010 change in the IDI use sub-index, by absolute value change (left) and rank change (right) ....................................................................................................... 35

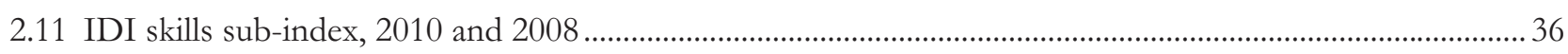

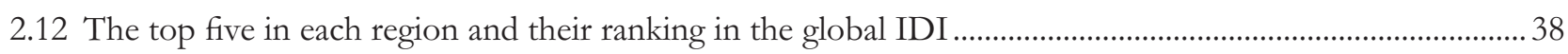

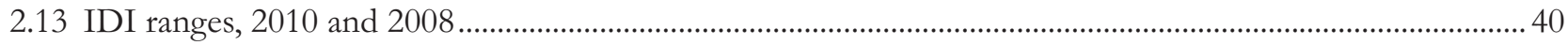




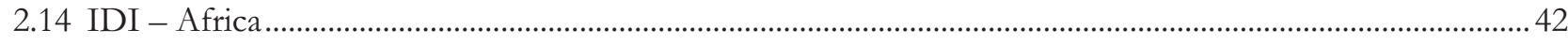

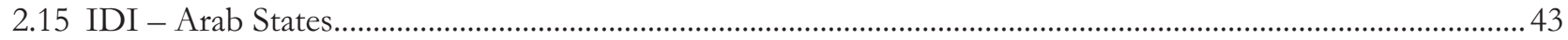

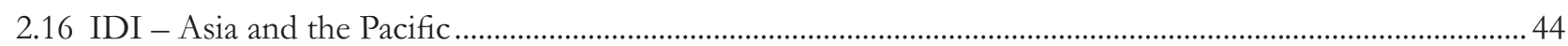

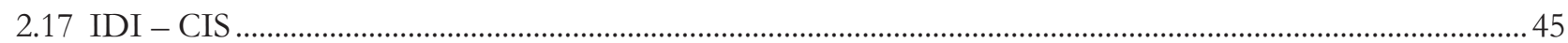

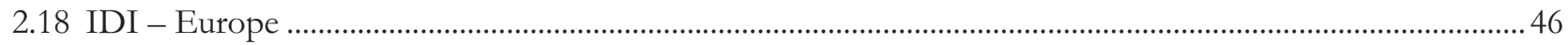

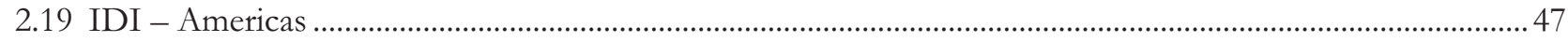

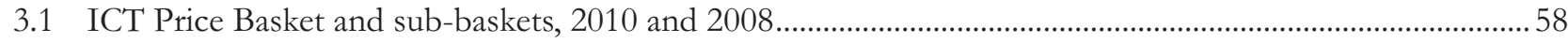

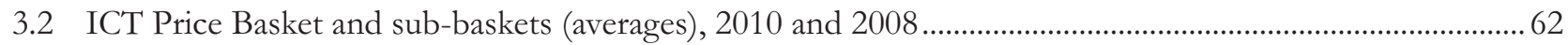

3.3 Ten economies with the greatest 2008-2010 decrease in the ICT Price Basket, by relative change

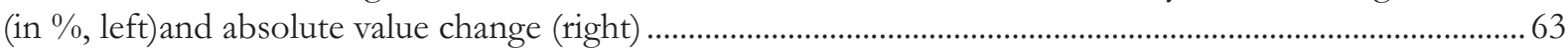

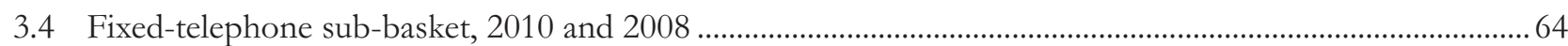

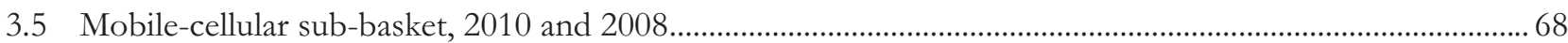

3.6 Ten economies with the greatest 2008-2010 decrease in the mobile-cellular sub-basket, by absolute value change (left) and relative change (in \%, right) .................................................................................... 70

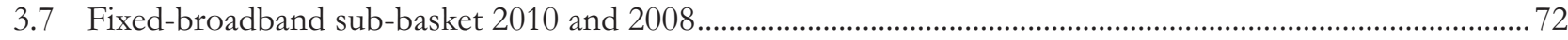

3.8 Ten economies with the greatest 2008-2010 decrease in fixed-broadband prices, by absolute value change (left) and relative change (in \%, right) .................................................................................. 74

3.9 Mobile-broadband and fixed-broadband monthly prices and speeds compared, selected economies, 2011.........81

4.1 Percentage of the population covered by a 2G/3G network, selected countries, 2009 and $2010 \ldots \ldots \ldots \ldots . . . .87$

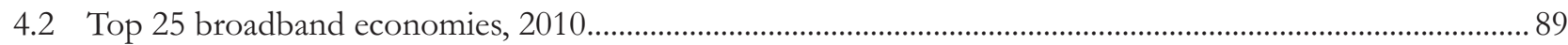

4.3 Time needed to download online content at different connection speeds ................................................. 91

5.1 Percentage of individuals aged 16 and older using the Internet, by income, selected African countries, 2007/2008

5.2 The gender divide: percentage of women and men aged 15 to 74 using the Internet, latest available year.

5.3 Knowing about the Internet and using it: the gender divide, 2007/2008

5.4 Percentage of individuals using the Internet, by urban/rural, latest available year 119

5.5 Internet activities carried out by Internet users, latest available year ( $\%)$ 122

5.6 Facebook penetration (selected countries), August 2011 



\section{Chapter 1. Introduction}

Over the past year, the world has witnessed continuous growth in ICT services and uptake worldwide. As post-2008-crisis data become available, they confirm the sustained growth of the telecommunication and Internet market overall, albeit with some notable variations.

Fixed telephony continues to decline, as it has done since 2005, especially in developed countries, where a saturated fixed-line market has been overtaken by mobile-cellular telephony. Today, in developed countries, mobile-cellular telephony has reached saturation levels, too, recording penetration rates of over 100 per cent and a growth of only one per cent during the past year. In developing countries, by contrast, growth in mobile subscriptions is still buoyant, at 20 per cent, with no sign of a slowdown, thus confirming the continuation of the "mobile miracle"(Charts 1.1 and 1.2).

Policy-makers and investors have been directing considerable attention towards the diffusion of broadband networks. Available data show that fixed-broadband subscriptions have more than doubled over the past five years. The developing countries' share is increasing rapidly, but there is still a huge divide when it comes to fixed-broadband access. While fixed-broadband penetration in developed countries had climbed to almost 24 per cent by end 2010, and growth is slowing, suggesting that saturation levels are being reached, it stands at only 4.2 per cent in developing countries, with major differences among countries and regions (Chart 1.3).

Wireless-broadband Internet access remains the strongest growth sector. Indeed, the single most dynamic ICT development over the past year has been the surge in mobile-broadband subscriptions (Charts 1.1 and 1.4). Wireless-broadband access, including prepaid mobile broadband, is mushrooming in developing countries, and Internet users are shifting more and more from fixed to wireless connections and devices. The potential development impact of bringing people from develop-

\section{Chart 1.1: Global ICT developments, 2000-2010, penetration (left) and annual growth (right)}
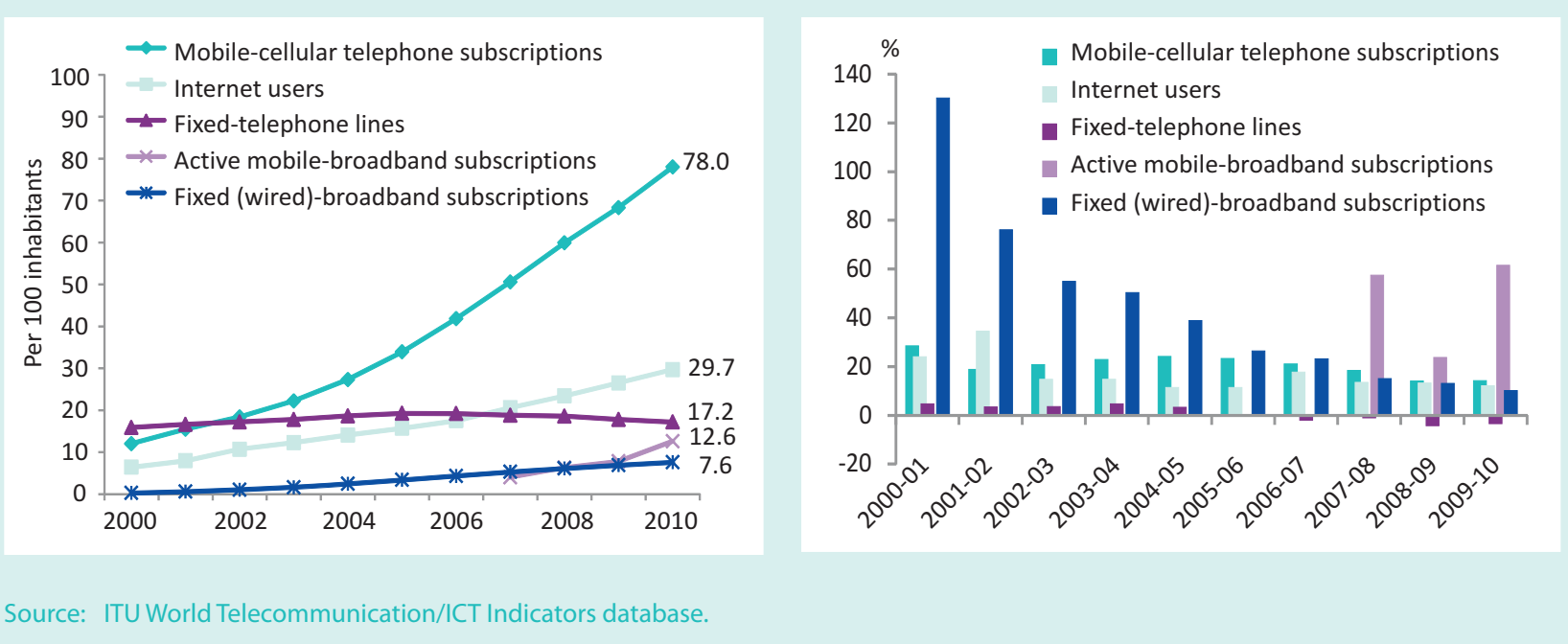

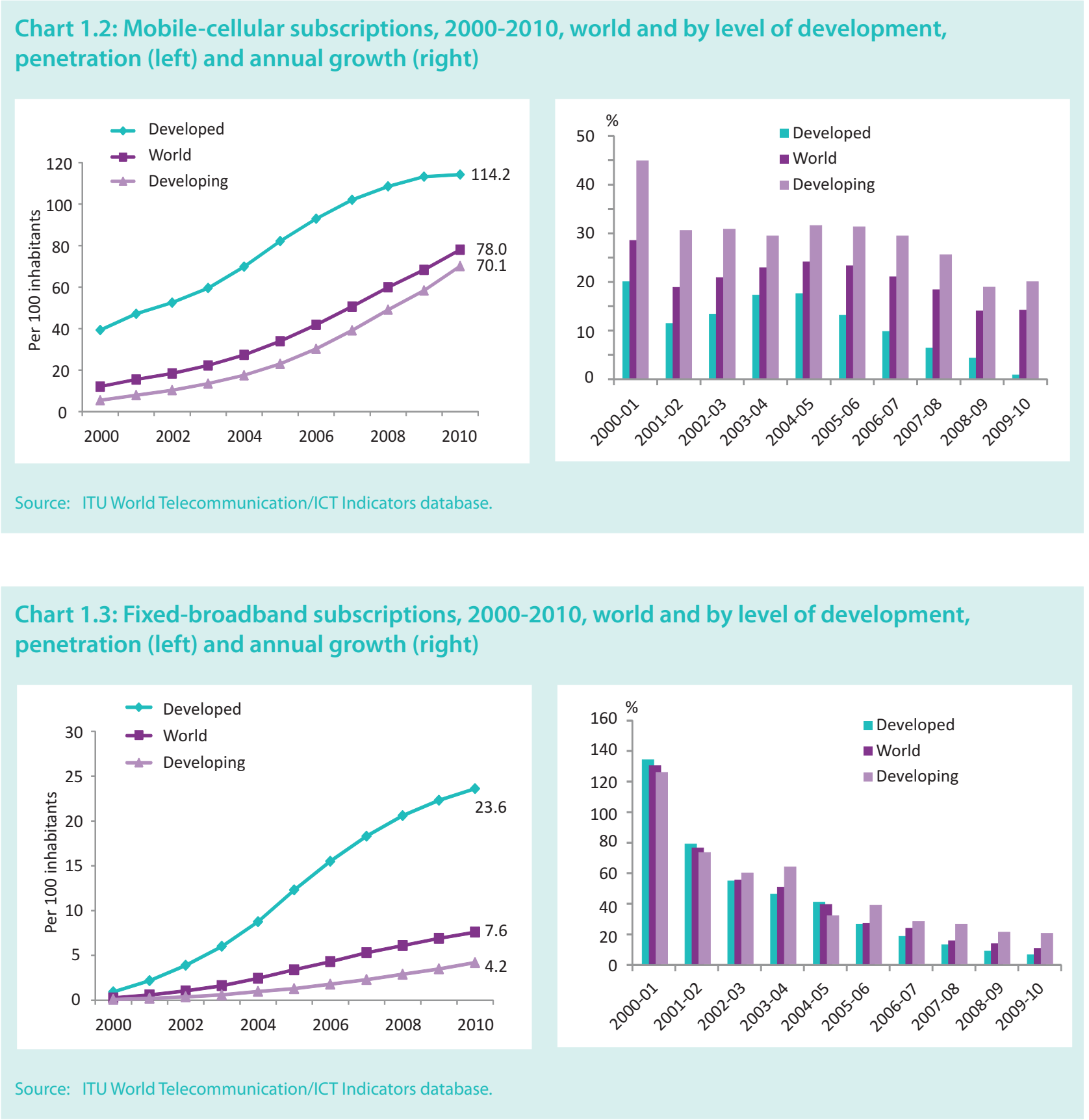

ing countries online via wireless access is enormous, and policy-makers are aware of the need to act swiftly in order to facilitate this process.

Mobile Internet - at broadband speeds - was practically non-existent at the time when the Millennium Development Goals (MDGs) were set in 2000, and was in its infancy when the World Summit on the Information Society (WSIS) concluded in 2005. At the same time, the mobile revolution - including the emerging mobilebroadband Internet - is a key enabler for the achieve- ment of internationally agreed development goals. The recognition of ICTs as a tool to generate income and employment, to provide access to business and health information and to enable e-learning and facilitate egovernment is now well established. This is why the Broadband Commission for Digital Development was launched in 2010, with the mission to promote the adoption of broadband-enabling policies, especially in developing countries. ${ }^{1}$ The Commission thus complements other development processes by advocating the role of broadband in accelerating achievement of the MDGs. 


\section{Chart 1.4: Mobile-broadband subscriptions, 2007-2010, world and by level of development, penetration (left) and annual growth (right)}
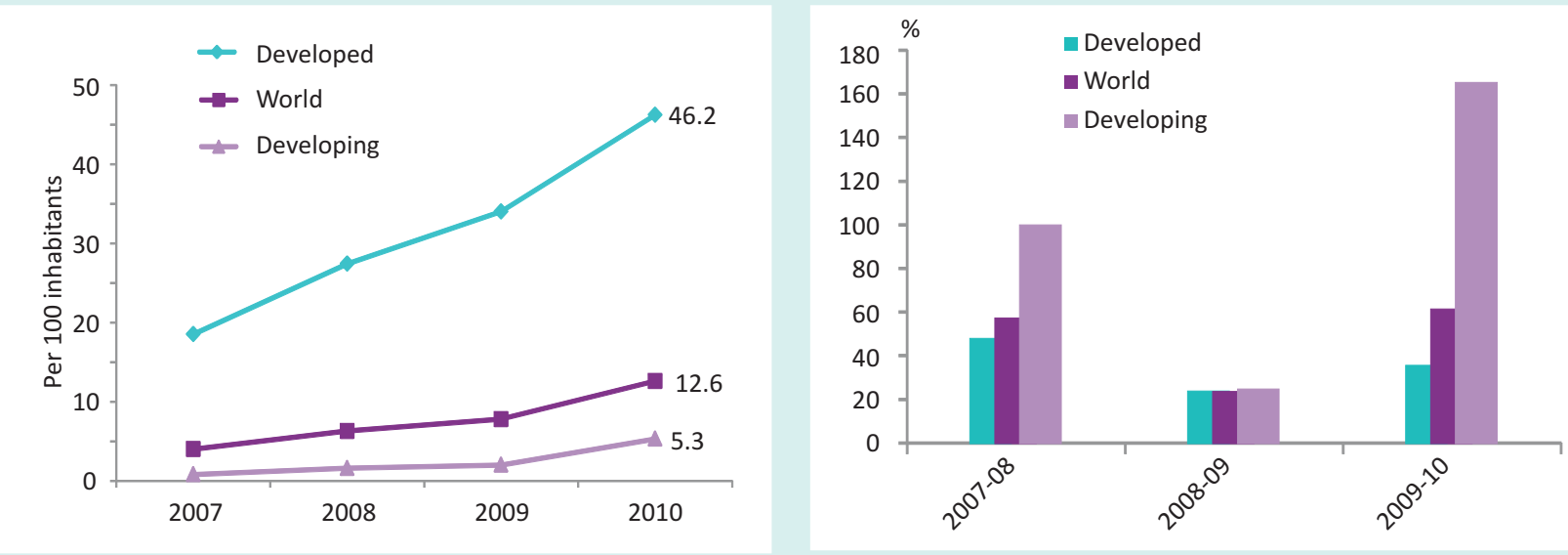

Source: ITU World Telecommunication/ICT Indicators database.

In the run-up to 2015 - which is in less than five years' time - a strong interest, and an urgency to act, can be observed in the international community to work towards the international development goals. ITU's WSIS mid-term review in 2010 has shown that good progress has been made in terms of connecting people via mobile technologies (ITU, 2010a). Mobile-cellular network coverage already stands at nearly 90 per cent of the population, and there is every chance it will rise to almost 100 per cent by 2015 . Similarly, basic radio and TV services are widely available, and could reach the majority of the world's population by 2015, provided that the lack of electricity and broadcast content are properly addressed.

Most remarkably, the number of Internet users has doubled over the past five years and there are now more than two billion Internet users worldwide. Growth rates in developing countries are high, and absolute numbers are driven by large countries such as China, Brazil, India, Nigeria and the Russian Federation. By end 2010, around 30 per cent of the world's population was online - up from around 12 per cent in 2003 and six per cent in 2000 (Chart 1.5). Good progress has also been made in bringing Internet access to central governments, research and scientific institutions and to some extent schools, hospitals, museums, libraries and archives, at least in the major cities of developing countries. The proportion of households with access to the Internet is growing steadily, especially in the developing countries (Chart 1.6), where around 16 per cent of households had access to the Internet at end 2010, as against 66 per cent in developed countries.

Besides the role of ICTs in achieving development goals, recent events such as the Arab spring and the publication of confidential political information on the Internet have demonstrated the power of communication and connectedness and enormously increased political interest in the information society. The spread of ICTs in societies where communication and access to information has hitherto been very limited is making ICTs an even more powerful tool than ever.

Social networking and user-created content are now among the main online activities, in which young people especially (who constitute the majority of the population in developing countries) are actively engaging - yet another manifestation of the continuous transformation towards information and digital societies where, eventually, most of social and working life will have a strong online component.

Despite these encouraging trends, as at end 2010, 70 per cent of the world's population (and nearly 80 per cent of the developing countries' population) were not yet using the Internet, and even fewer via a broadband connection. In most developing countries, households, schools, hospitals and other public institutions located outside the major urban areas are not yet connected to high-speed Internet. 


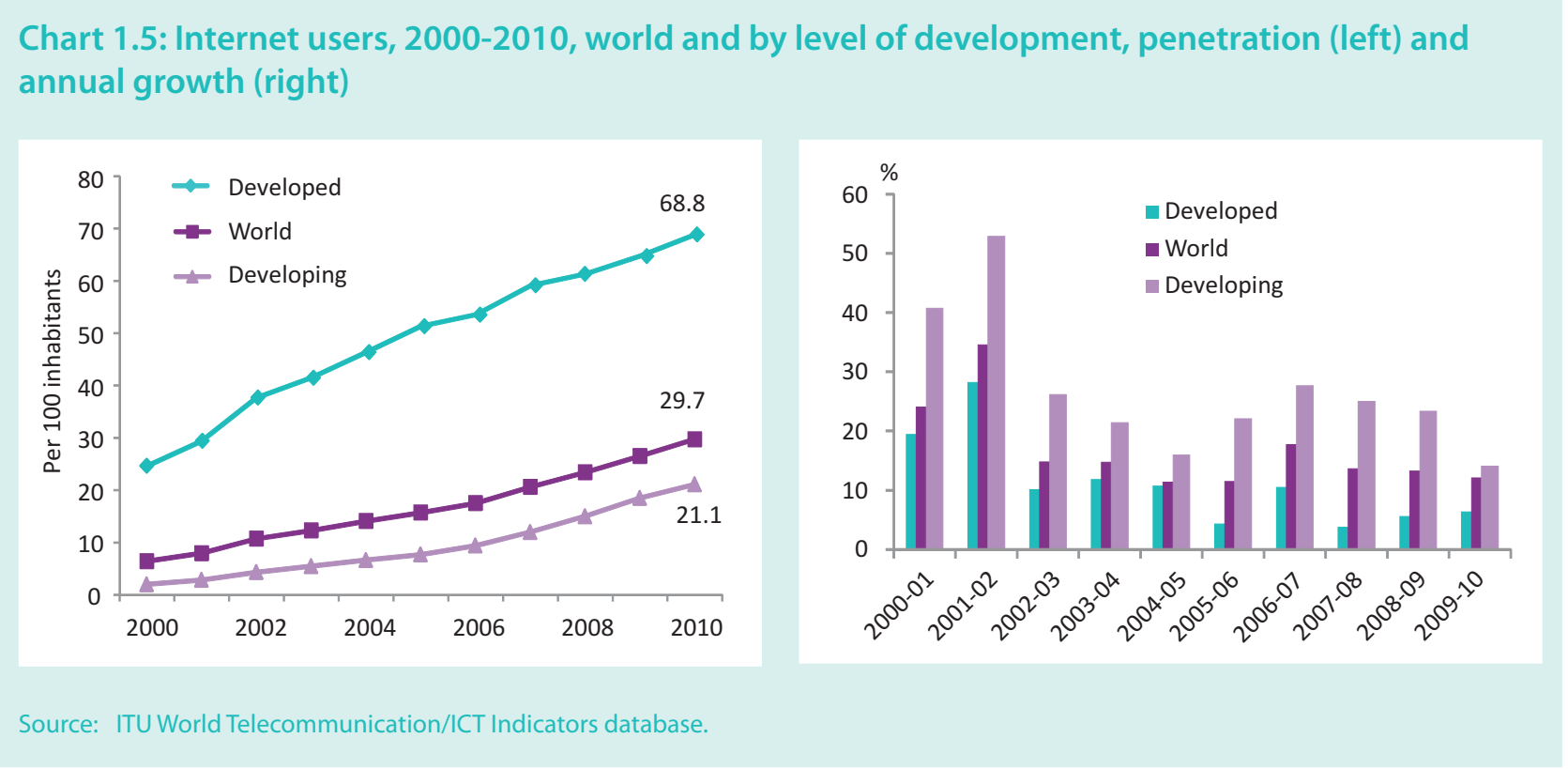

\section{Chart 1.6: Households with Internet access, 2002-2010, world and by level of development, penetration (left) and annual growth (right)}
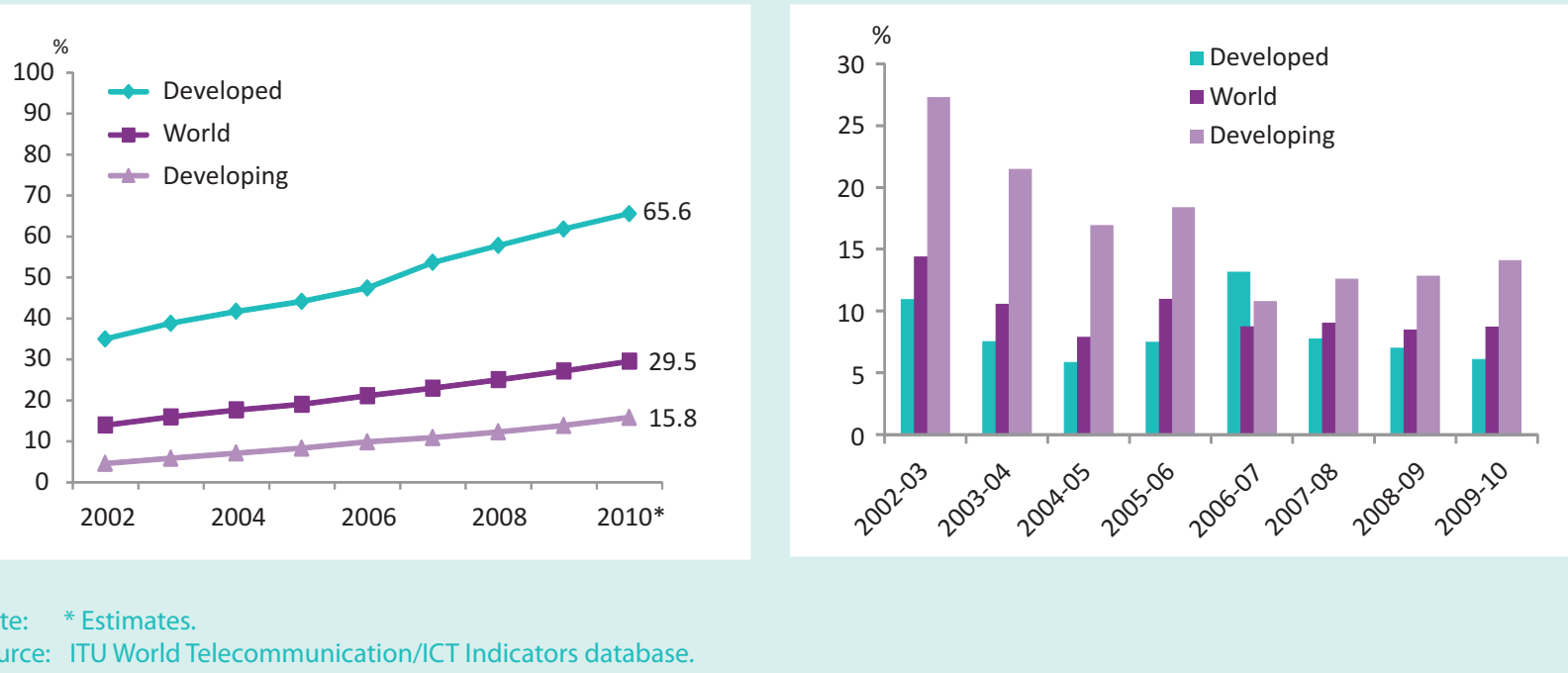

The revolution experienced through the mobile telephone needs to be replicated to bring people online. The emergence of new mobile devices (such as smartphones and tablet computers) is certainly accelerating this process, but they are still too expensive in developing countries and there is a need to develop more affordable models and devices. Furthermore, the use and hence the beneficial impact of ICTs will increasingly be determined by the availability of bandwidth and capacity. A digital divide is unfolding between those with high-speed/capacity/quality access (as is the case is many high-income countries) and those with lower speed/capacity/quality access (as is the case in many low-income countries).

To ensure that the information society will be truly global and inclusive, much remains to be done to bring its benefits to the poorest in our societies. This means that 
future policy action needs to address issues not only of access, but also of price, bandwidth, speed and quality of service, skills, content and language and applications targeting low-end users. To assess progress will require continuous monitoring based on reliable indicators. This publication is a key contribution to this process.

\section{Overview of this publication}

The main objective of this report is to inform policymakers, investors and analysts about the main developments in the diffusion and uptake of ICTs, both globally and at the country level. By providing a comprehensive analysis of key ICT indicators, it constitutes a major input to the policy debate, especially in developing countries.

The report features two ICT benchmarking tools: the ICT Development Index (IDI) and the ICT Price Basket (IPB). The latest results for these two metrics will help policy-makers monitor trends, identify areas for policy action and benchmark their ICT developments against other markets.

This is the third edition of the Measuring the Information Society report. Whereas the 2009 and 2010 editions were released in March, it was decided to change the production schedule as from this edition and to release the report in September. This decision was taken in response to views expressed by the readership, who are keen for the report to feature more recent data (the reference date is December of the previous year). This edition will thus feature the IDI and IPB for the two years 2010 and 2008, as well as detailed end-2010 data for a range of ICT indicators.

The data used in the report are primarily statistics collected by ITU, complemented by data received from the United Nations Population Division (population statistics), the UNESCO Institute for Statistics (UIS) (statistics on literacy and school enrolment), the World Bank (data on GNI per capita and PPP dollars), Wireless Intelligence (data on mobile broadband) and Research ICT Africa (household survey data on Africa).

Chapter 2 features the main results for the latest ICT Development Index (IDI), comparing the years 2010 and 2008. After introducing the main objectives and methodology of the IDI, it goes on to analyse the IDI at the global level, highlighting key performers and most dynamic countries (i.e. those with highest growth rates), especially among the developing countries. It also looks at the relationship between the IDI and
GNI per capita, and presents IDI results by level of development and by groups of countries with different IDI levels and incomes. This is followed by an analysis of the three IDI sub-indices: the access sub-index, the use sub-index and the skills sub-index, also highlighting key performers in each case. Finally, IDI results are presented for six regions, briefly describing the main findings. The entire chapter is supplemented by concrete country examples highlighting best practices and distilling lessons learned.

The results for the second key benchmarking tool, the ICT Price Basket (IPB) are presented in Chapter 3. First, the main purpose of the IPB is explained, along with an overview of the IPB methodology. This is followed by an analysis of the main results for the IPB, comparing 2010 and 2008 tariffs. While the IPB is determined as a percentage of GNI per capita, data are also shown in USD and PPP dollars. The chapter highlights countries recording the highest decrease in prices, especially in developing countries. It also looks at the correlation between the IPB and the IDI, identifying outliers. Thereafter, each IPB sub-basket is analysed in turn: the fixed-telephone sub-basket, the mobile-cellular sub-basket and the fixed-broadband sub-basket. The results are shown at the global level, by level of development, as well as across different regions, in terms of GNI per capita, USD and PPP dollars. The chapter also introduces mobile-broadband tariffs, with examples, notably for prepaid wireless-broadband tariffs in developing countries, as well as a comparison with fixed-broadband tariffs.

In view of the continuous decline of narrowband connections and the shift towards broadband Internet, Chapter 4 takes a closer look at the different broadband speeds, broadband quality and (international) Internet bandwidth available in countries/regions, and how these factors impact on broadband uptake in both developed and developing countries. The chapter highlights recent national broadband policies, and makes suggestions on how policy-makers could further enhance broadband in developing countries.

Finally, Chapter 5 looks beyond access and connectivity and provides a more in-depth analysis of Internet users and usage, based on data available from household individual surveys. It presents the main characteristics of the majority of Internet users today, and identifies the main divides along dimensions such as gender, age, educational background, income and urban/rural location. It also looks at some of the key emerging activities, especially those related to social networking. The chapter 
discusses how, in the light of those divides, more people can be brought online, making the information society more inclusive. A large part of the analysis focuses on African countries, drawing on the results of user surveys carried out by Research ICT Africa.
The publication ends with a list of references, three methodological annexes and country-level statistical tables featuring the data used in the IDI and IPB

1 For more information on the Broadband Commission for Digital Development, see http://www.broadbandcommission.org/. 


\section{Chapter 2. The ICT Development Index (IDI)}

\subsection{Introduction}

The ICT Development Index (IDI) is a composite index combining 11 indicators into one benchmark measure that serves to monitor and compare developments in information and communication technology (ICT) across countries. The IDI was developed by ITU in 2008 and first presented in the 2009 edition of Measuring the Information Society (ITU, 2009). It was established in response to ITU Member States' request to develop a "single index" and publish it regularly. This section briefly describes the main objectives, conceptual framework and methodology of the IDI. ${ }^{1}$

The main objectives of the IDI are to measure:

- The level and evolution over time of ICT developments in countries and relative to other countries.

- Progress in ICT development in both developed and developing countries: the index should be global and reflect changes taking place in countries at different levels of ICT development.

- The digital divide, i.e. differences between countries with different levels of ICT development.

- The development potential of ICTs or the extent to which countries can make use of ICTs to enhance growth and development, based on available capabilities and skills.

\section{Conceptual framework}

The recognition that ICTs can be a development enabler, if applied and used appropriately, is critical to countries that are moving towards information or knowledge- based societies, and is central to the IDI's conceptual framework. The ICT development process, and a country's transformation to becoming an information society, can be depicted using the following three-stage model (Figure 2.1):

- stage 1: ICT readiness (reflecting the level of networked infrastructure and access to ICTs)

- stage 2: ICT intensity (reflecting the level of use of ICTs in the society)

- stage 3: ICT impact(reflecting the result/outcome of efficient and effective ICT use).

Advancing through these stages depends on a combination of three factors: the availability of ICT infrastructure and access, a high level of ICT usage and the capability to use ICTs effectively. Accordingly, the first two stages listed above correspond to two major components of the IDI: ICT access and ICT use.

Reaching the final stage, and maximizing the impact of ICTs, crucially depends on the third component of the IDI: ICT skills. ICT (and other) skills determine the effective use that is made of ICTs, and are critical to leveraging the full potential of ICTs for socio-economic development. Economic growth and development will remain below potential if economies are not capable of exploiting new technologies and reaping their benefits. Therefore, the IDI includes a measure of the capability to use ICTs effectively.

A single indicator cannot track progress in all three components (access, usage and skills) of the ICT development process, thus requiring the construction of a composite index such as the IDI. The IDI aims 


\section{Figure 2.1: Three stages in the evolution towards an information society}

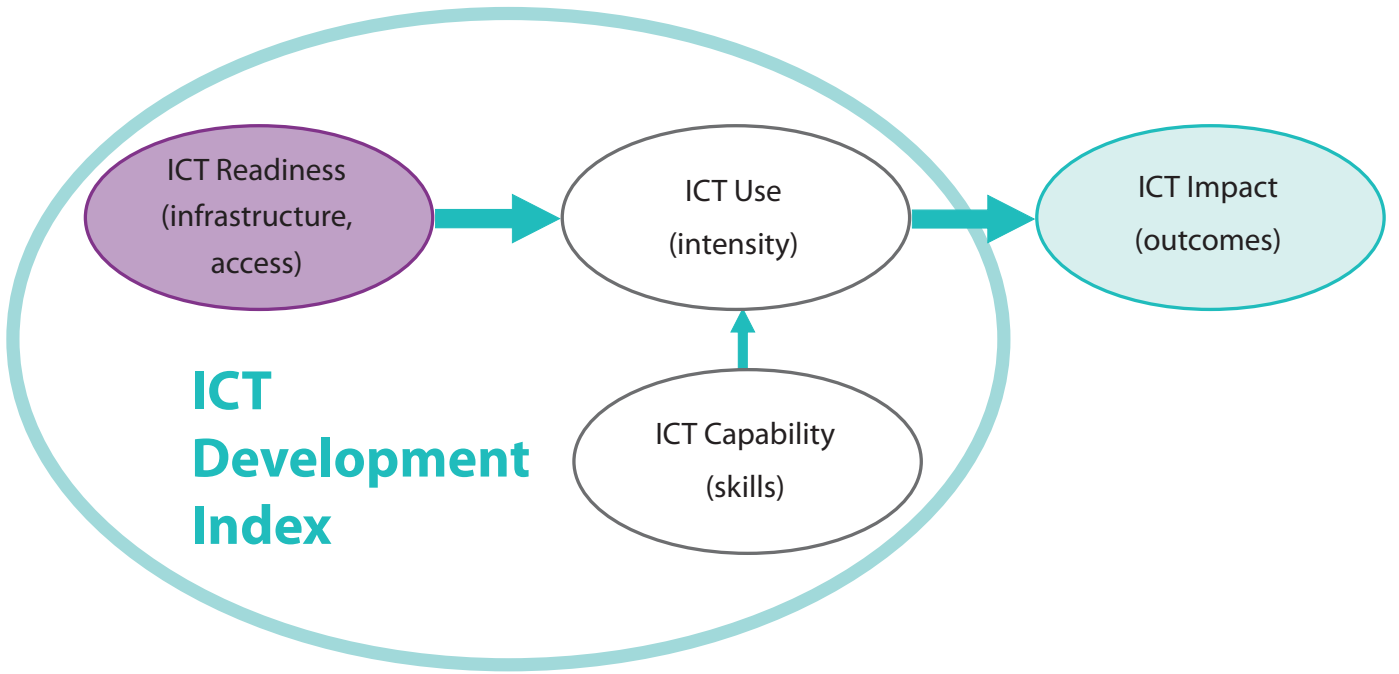

Source: ITU.

to capture the evolution of the information society as it goes through its different stages of development, taking into consideration technology convergence and the emergence of new technologies.

Based on this conceptual framework, the IDI is divided into the following three sub-indices:

- Access sub-index: This sub-index captures ICT readiness, and includes five infrastructure and access indicators (fixed-telephony, mobile telephony, international Internet bandwidth, households with computers, and households with Internet).

- Use sub-index: This sub-index captures ICT intensity, and includes three ICT intensity and usage indicators (Internet users, fixed (wired)-broadband, and mobile broadband).

- Skills sub-index: This sub-index captures ICT capability or skills as indispensable input indicators. It includes three proxy indicators (adult literacy, gross secondary enrolment and gross tertiary enrolment), and therefore is given less weight in the computation of the IDI compared with the other two sub-indices.

The choice of indicators included in each of the three sub-indices reflects the corresponding stage of trans- formation to the information society. Therefore, the indicators in each sub-index may change over time to reflect technological developments related to ICTs, and as more and better data become available. For example, what was considered basic infrastructure in the past such as fixed-telephone lines - is fast becoming less relevant in the light of increasing fixed to mobile substitution. Similarly, broadband is currently considered an advanced technology, characterizing intense Internet use, and is therefore included in stage 2 (as an indicator in the use sub-index). However, in the future it may become essential and be moved to stage 1 (as an indicator in the access sub-index), while another, new technology may appear in stage 2 .

\section{Methodology}

The IDI includes 11 indicators (Figure 2.2). A detailed definition of each indicator is provided in Annex 1.

Selection of the indicators was based on:

- The relevance of a particular indicator for contributing to the main objectives and conceptual framework of the IDI. For example, the selected indicators need to be relevant to both developed and developing countries, and should reflect - as much as possible - the framework's three components described above. In this context, the recommendations made by experts in relation to 
the development of the single index were taken into consideration. ${ }^{2}$

- Data availability and quality. Data are required for a large number of countries, as the IDI is a global index. There is relative paucity of ICT-related data, especially at the household level, in the majority of developing countries. In particular, the three indicators included in the skills sub-index should be considered as proxies until data directly relating to ICT skills become available for more countries.

- The results of various statistical analyses. The statistical associations between various indicators were examined, and principal components analysis (PCA) was used to examine the underlying nature of the data and to explore whether the different dimensions are statistically well-balanced.

While the basic methodology has remained the same since the IDI was first published, minor adjustments are being made each year.
Given the dynamic nature of the ICT sector and related data availability, the types of indicators to be included in the IDI and its sub-indices are under regular discussion in ITU, in consultation with experts. ${ }^{3}$ A major consideration is eventually to replace some of the subscription-based (supply-side) data with more data based on national household surveys (demand-side indicators). For example, in the case of mobile-cellular subscriptions, around half of the countries included in the IDI have surpassed the 100 per cent penetration mark. ${ }^{4}$ Much of this is due to multiple SIM card holders - which can vary significantly across countries - and therefore an indicator reflecting the actual number of individuals using a mobile phone would be preferable. It is expected that within a couple of years such an indicator will become widely available and could replace mobile-cellular subscriptions.

Another key indicator that is in the throes of major changes at the moment is wireless-broadband access. Box 2.1 provides more information on how this year's IDI has been adapted to take those changes on board.

\section{Box 2.1: The challenges of measuring mobile broadband}

As more and more countries launch $3 \mathrm{G}$ networks, and at the same time mobile devices designed to go online at high speed (e.g. smartphones, tablet computers) become increasingly popular, data that accurately reflect such developments are needed. In the past, ITU statistics measured mobile-broadband access primarily through its indicator "mobile-cellular subscriptions with access to data communications at broadband speeds". This indicator measures the potential of mobile-cellular subscriptions to access, for example, $3 \mathrm{G}$ networks (and the Internet), but it does not reveal how many subscriptions have actually been actively used for data transfer. In other words, the indicator only captures "potential" broadband access rather than active usage. During the past couple of years, more and more countries (especially OECD countries) report that all of their mobile subscriptions are by now $3 \mathrm{G}$ enabled. At the same time, many countries no longer report subscriptions with potential access, but rather the number of active broadband subscriptions (i.e. those that have been used for data connections). As a result, data have become incomparable across countries, with some countries reporting potential access, others active usage and yet others none at all.

In anticipation of these developments, ITU revised the definition of wireless-broadband subscriptions in 2010 and started to collect new indicators in the same year. ${ }^{5}$ The new indicators include satellite broadband subscriptions, terrestrial fixed wireless-broadband subscriptions and terrestrial mobile wireless subscriptions. For the purpose of this edition of the IDI, the latter of the three, terrestrial mobile wireless subscriptions, has been used. ${ }^{6}$ Terrestrial mobile wireless subscriptions include (a) standard mobile subscriptions with use of data communications at broadband speeds (i.e. mobile-cellular subscriptions with advertised data speeds of $256 \mathrm{kbit} / \mathrm{s}$ or greater and which have been used to set up an Internet data connection) and (b) dedicated mobile data subscriptions at broadband speeds (i.e. subscriptions to dedicated data services over a mobile network which are purchased separately from voice services, either as a standalone service - e.g. using a data card such as a USB modem/dongle - or as an add-on data package to voice services requiring an additional subscription).

The reporting on those two new indicators is still very patchy. Therefore, ITU has complemented the data using private data sources (from Wireless Intelligence). ${ }^{7}$ While the values of the new indicator are generally lower than those of the previous one, they are consistent across countries and - most importantly are more meaningful since they look at actual data connections to broadband networks rather than potential connections. 
The IDI was computed using the same methodology as in the past, applying the following steps (Figure 2.2 and Annex 1):

- Preparation of the complete data set. This step includes filling in missing values using various statistical techniques.

- Normalization of data. This is necessary in order to transform the values of the IDI indicators into the same unit of measurement. The chosen normalization method was the distance to a reference measure (or goalpost). The reference values were either 100 or obtained through a statistical procedure.

- Rescaling of data. The data were rescaled on a scale from 1 to 10 in order to compare the values of the indicators and the sub-indices.
- Weighting of indicators and sub-indices. The indicator weights were chosen based on the PCA results. The access and use sub-indices were given equal weight (40 per cent each). The skills sub-index was given less weight (20 per cent), since it is based on proxy indicators.

This chapter presents the IDI results for 2010 in comparison with 2008. It should be noted that the 2008 IDI values have changed from those published in the previous edition of this report as a result of:

- Country data revisions. As more accurate data become available, countries provide ITU with revised statistics for previous years, which have been taken into consideration. This also allows ITU to identify inconsistencies and revise previous estimates.

Figure 2.2: ICT Development Index: indicators and weights

\begin{tabular}{|l|c|c|}
\hline ICT access & Ref. value & (\%) \\
\hline 1. Fixed-telephone lines per 100 inhabitants & 60 & 20 \\
\hline 2. Mobile-cellular telephone subscriptions per 100 inhabitants & 180 & 20 \\
3. International Internet bandwidth (bit/s) per Internet user & $280^{\prime} 377^{*}$ & 20 \\
4. Percentage of households with a computer & 100 & 20 \\
5. Percentage of households with Internet access & 100 & 20 \\
\hline
\end{tabular}

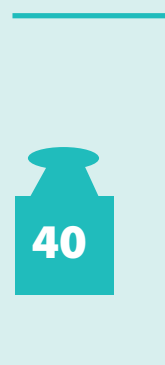

\begin{tabular}{|l|c|c|}
\hline ICT use & 100 & 33 \\
\hline 6. Percentage of individuals using the Internet & 60 & 33 \\
7. Fixed (wired)-broadband Internet subscriptions per 100 inhab. & 100 & 33 \\
8. Active mobile-broadband subscriptions per 100 inhab. & 100 & \\
\hline
\end{tabular}

\begin{tabular}{|l|c|c|}
\hline ICT skills & Ref. value & $(\%)$ \\
\hline 9. Adult literacy rate & 100 & 33 \\
10. Secondary gross enrolment ratio & 100 & 33 \\
11. Tertiary gross enrolment ratio & 100 & 33 \\
\hline
\end{tabular}

Note: * This corresponds to a log value of 5.45 , which was used in the normalization step. Source: ITU. 
- Updates of population data. Population statistics are regularly revised by the United Nations Population Division (UNPD), including for previous years. The data included in this report reflect the latest updates (March 2011).

\section{- Updated data on international Internet bandwidth.}

- Definitional changes to the indicator on mobile-broadband. With the rapid increase of wireless-broadband access and use, the indicator is undergoing constant review. This version of the IDI includes mobile-broadband subscriptions with active use, in contrast to the previous version of the IDI which included mobile-cellular subscriptions with access to broadband networks (i.e. potential use). Box 2.1 provides more insights on the revisions of this indicator.

- Differences among countries included in the IDI. Since the IDI is a relative measure, the calculation of the IDI value depends on the values of the other countries included. In each new edition, some countries are excluded and others added based on data availability. Overall, this version of the IDI includes 152 countries/economies as compared with 159 in last year's edition.

The remainder of the chapter is structured as follows. Section 2.2 presents the IDI results at the global level. It highlights some of the top performers, as well as the most dynamic countries in terms of changes in IDI value and rank. It also looks at the relationship between a country's IDI score and its income level, presents IDI results by level of development (developed/developing countries) and by groups of countries with different IDI levels.
Section 2.3 analyses the three sub-indices (access, use and skills), providing additional insights into areas of high/low ICT growth, in order to identify areas requiring further attention from policy-makers and private stakeholders.

Finally, section 2.4 presents a regional analysis of the IDI. It shows IDI results for six regions (Africa, Americas, Arab States, Asia and the Pacific, Commonwealth of Independent States (CIS) and Europe), as well as a comparative analysis of the six regions.

\subsection{Global IDI analysis}

\section{Overall results}

The IDI is presented on a scale from 1 to 10 in order to compare values and benchmark progress. Between 2008 and 2010, all 152 countries included in the IDI improved their scores, which confirms the continuous spread of ICTs and the growth of the information society worldwide. Overall, the average value of the IDI increased from 3.62 to 4.08 , i.e. by 0.46 points. The subindices values also increased. However, an interesting observation can be made: in the past (2002-2007), the access sub-index used to be the one with the strongest growth; between 2007 and 2008, both the access subindex and the use sub-index grew equally; now, the use sub-index has overtaken the access sub-index as the one that grew most between 2008 and 2010 (Table 2.1). This tallies with the conceptual framework on which the IDI is based: countries are moving through stages as they develop their information societies, from ICT readiness to ICT intensity and on to ICT impact. Most countries have advanced considerably on ICT access -

Table 2.1: IDI changes, 2008-2010

\begin{tabular}{|c|c|c|c|c|c|c|c|}
\hline & \multicolumn{3}{|c|}{$\begin{array}{c}\text { IDI } \\
2008\end{array}$} & \multicolumn{3}{|c|}{$\begin{array}{c}\text { IDI } \\
2010\end{array}$} & \multirow{2}{*}{$\begin{array}{c}\text { Change in } \\
\text { average value } \\
2008-2010\end{array}$} \\
\hline & $\begin{array}{l}\text { Average } \\
\text { value* }\end{array}$ & Min.-Max. & Range & $\begin{array}{l}\text { Average } \\
\text { value* }\end{array}$ & Min.-Max. & Range & \\
\hline IDI & 3.62 & $0.79-7.80$ & 7.01 & 4.08 & $0.83-8.40$ & 7.57 & 0.46 \\
\hline Access sub-index & 4.05 & $0.80-8.77$ & 7.97 & 4.53 & $0.87-9.06$ & 8.19 & 0.48 \\
\hline Use sub-index & 1.75 & $0.01-6.92$ & 6.91 & 2.37 & $0.01-7.85$ & 7.84 & 0.62 \\
\hline Skills sub-index & 6.49 & $1.36-9.80$ & 8.44 & 6.58 & $1.44-9.89$ & 8.45 & 0.09 \\
\hline
\end{tabular}

Note: * Simple averages

Source: ITU. 
the access sub-index has now reached a value of 4.53. At 2.37, the use sub-index is still relatively low, but has increased considerably over the past two years as more and more people are using broadband and the Internet. The skills sub-index changes little, and has the highest average value, given that many countries have already reached rather high literacy and education levels.

There are huge differences between countries when it comes to ICT development, with an IDI value of 0.8 for the country ranking at the bottom and 8.4 for the country ranking at the top of the IDI. Also of concern is the observation that the range has actually increased for both the IDI and two of its sub-indices (access and use). In other words, the difference between the country at the top and the country at the bottom has increased, with relatively more progress being made at the top and almost no progress being made at the very bottom. The range of the skills sub-index has remained stable, but it is also the largest range of all three sub-indices.

\section{Selected top IDI countries}

Table 2.2 presents the IDI results and country rankings for both years (2010 and 2008). Except for the Republic of Korea and Hong Kong (China), all economies in the top ten are from Europe. They include four Nordic countries (Sweden, Iceland, Denmark and Finland), as well as Luxembourg, Switzerland, the Netherlands and the United Kingdom. The Republic of Korea, Sweden and Iceland (the top three) have surpassed the IDI eightpoint mark. While overall the differences between the top countries are rather small, it is noteworthy that both the Republic of Korea and Sweden have very high values not only in absolute but also in relative terms, and the value difference between them and the following top countries is quite high. In other words, the performance of those two countries is indeed outstanding.

Looking at the top thirty, apart from the United States and Canada, all are from Europe (22 countries) or East Asia/Pacific. They largely correspond to the world's high-income economies, given the strong correlation between the level of ICT development and GDP (see below).

The following section highlights the performance of selected top countries.

The Republic of Korea tops the IDI 2010, as it did in 2008. ${ }^{8}$ The Republic of Korea has been a leader in terms of ICT diffusion and uptake for many years. The country has made ICTs an engine of economic growth and implemented policies allowing it to become an "IT powerhouse". By creating a competitive and dynamic regulatory environment, the Republic of Korea has become an inclusive information society, and a number of government-driven initiatives - including the Giga internet pilot project, which includes the construction of $100 \mathrm{Mbit} / \mathrm{s}$ broadband networks in rural areas - are helping it to meet future demands. ${ }^{9}$ The Republic of Korea tops the IDI use sub-index (see section 2.3). It has the highest mobile-broadband penetration worldwide (91 per cent) and very high fixed-broadband penetration (36.6 per cent). It also excels when it comes to households with Internet connections (almost 97 per cent of all households). In addition, it stands out on the skills sub-index, with very high performance on all three indicators (secondary and tertiary school enrolment and adult literacy).

Sweden ranks in second place, also unchanged from 2008. It displays very high performance on all three sub-indices. With 90 per cent of the population using the Internet, Sweden is among the top five countries online, along with Iceland, Norway, the Netherlands and Luxembourg. Moreover, the country is among the world's top ten in commercial fibre-to-the-home (FTTH) penetration. ${ }^{10}$ Such extensive fibre deployments have been achieved through a successful public-private strategy that has involved both private operators and local authorities. ${ }^{11}$ Mobile-broadband penetration is among the highest in the world (after the Republic of Korea and Japan). Recent data show that in Sweden there are now almost as many mobile-broadband subscriptions as fixed-broadband, and that mobile data traffic continues to grow strongly, with an increase of just over 90 per cent in the last year. ${ }^{12}$ This indicates that mobile-broadband uptake and usage is matching that of fixed broadband.

Iceland has moved up four places in the IDI 2010 compared with 2008, to third place. With 95 per cent of the population online, Iceland has the highest Internetuser penetration of all countries and shows clear signs of crisis recovery. Iceland also has the highest fixed-line penetration worldwide, followed by Hong Kong (China), Malta, the Republic of Korea and Switzerland. The proportion of households with computers is highest in Iceland, at 93 per cent, and 92 per cent of households have Internet connections. The strong IDI improvements are due to the uptake of mobile broadband, which did not exist in 2008, but reached a penetration level of 45 per cent in 2010 . The country was among the last to assign $3 \mathrm{G}$ frequencies in Europe, the process having been delayed until 2007. Despite the delay, the issuance 
Table 2.2: ICT Development Index (IDI), 2010 and 2008

\begin{tabular}{|c|c|c|c|c|}
\hline Economy & Rank 2010 & IDI 2010 & Rank 2008 & IDI 2008 \\
\hline Korea (Rep.) & 1 & 8.40 & 1 & 7.80 \\
\hline Sweden & 2 & 8.23 & 2 & 7.53 \\
\hline Iceland & 3 & 8.06 & 7 & 7.12 \\
\hline Denmark & 4 & 7.97 & 3 & 7.46 \\
\hline Finland & 5 & 7.87 & 12 & 6.92 \\
\hline Hong Kong, China & 6 & 7.79 & 6 & 7.14 \\
\hline Luxembourg & 7 & 7.78 & 4 & 7.34 \\
\hline Switzerland & 8 & 7.67 & 9 & 7.06 \\
\hline Netherlands & 9 & 7.61 & 5 & 7.30 \\
\hline United Kingdom & 10 & 7.60 & 10 & 7.03 \\
\hline Norway & 11 & 7.60 & 8 & 7.12 \\
\hline New Zealand & 12 & 7.43 & 16 & 6.65 \\
\hline Japan & 13 & 7.42 & 11 & 7.01 \\
\hline Australia & 14 & 7.36 & 14 & 6.78 \\
\hline Germany & 15 & 7.27 & 13 & 6.87 \\
\hline Austria & 16 & 7.17 & 21 & 6.41 \\
\hline United States & 17 & 7.09 & 17 & 6.55 \\
\hline France & 18 & 7.09 & 18 & 6.48 \\
\hline Singapore & 19 & 7.08 & 15 & 6.71 \\
\hline Israel & 20 & 6.87 & 23 & 6.20 \\
\hline Macao, China & 21 & 6.84 & 27 & 5.84 \\
\hline Belgium & 22 & 6.83 & 22 & 6.31 \\
\hline Ireland & 23 & 6.78 & 19 & 6.43 \\
\hline Slovenia & 24 & 6.75 & 24 & 6.19 \\
\hline Spain & 25 & 6.73 & 25 & 6.18 \\
\hline Canada & 26 & 6.69 & 20 & 6.42 \\
\hline Portugal & 27 & 6.64 & 29 & 5.70 \\
\hline Italy & 28 & 6.57 & 26 & 6.10 \\
\hline Malta & 29 & 6.43 & 31 & 5.68 \\
\hline Greece & 30 & 6.28 & 30 & 5.70 \\
\hline Croatia & 31 & 6.21 & 36 & 5.43 \\
\hline United Arab Emirates & 32 & 6.19 & 32 & 5.63 \\
\hline Estonia & 33 & 6.16 & 28 & 5.81 \\
\hline Hungary & 34 & 6.04 & 34 & 5.47 \\
\hline Lithuania & 35 & 6.04 & 35 & 5.44 \\
\hline Cyprus & 36 & 5.98 & 43 & 5.02 \\
\hline Czech Republic & 37 & 5.97 & 37 & 5.42 \\
\hline Poland & 38 & 5.95 & 41 & 5.29 \\
\hline Slovak Republic & 39 & 5.94 & 40 & 5.30 \\
\hline Latvia & 40 & 5.90 & 39 & 5.31 \\
\hline Barbados & 41 & 5.83 & 33 & 5.47 \\
\hline Antigua \& Barbuda & 42 & 5.63 & 38 & 5.32 \\
\hline Brunei Darussalam & 43 & 5.61 & 44 & 4.97 \\
\hline Qatar & 44 & 5.60 & 48 & 4.50 \\
\hline Bahrain & 45 & 5.57 & 42 & 5.16 \\
\hline Saudi Arabia & 46 & 5.42 & 55 & 4.13 \\
\hline Russia & 47 & 5.38 & 49 & 4.42 \\
\hline Romania & 48 & 5.20 & 46 & 4.67 \\
\hline Bulgaria & 49 & 5.19 & 45 & 4.75 \\
\hline Serbia & 50 & 5.11 & 47 & 4.51 \\
\hline Montenegro & 51 & 5.03 & 50 & 4.29 \\
\hline Belarus & 52 & 5.01 & 58 & 3.93 \\
\hline TFYR Macedonia & 53 & 4.98 & 52 & 4.20 \\
\hline Uruguay & 54 & 4.93 & 51 & 4.21 \\
\hline Chile & 55 & 4.65 & 54 & 4.14 \\
\hline Argentina & 56 & 4.64 & 53 & 4.16 \\
\hline Moldova & 57 & 4.47 & 64 & 3.57 \\
\hline Malaysia & 58 & 4.45 & 57 & 3.96 \\
\hline Turkey & 59 & 4.42 & 60 & 3.81 \\
\hline Oman & 60 & 4.38 & 68 & 3.45 \\
\hline Trinidad \& Tobago & 61 & 4.36 & 56 & 3.99 \\
\hline Ukraine & 62 & 4.34 & 59 & 3.83 \\
\hline Bosnia and Herzegovina & 63 & 4.31 & 63 & 3.58 \\
\hline Brazil & 64 & 4.22 & 62 & 3.72 \\
\hline Venezuela & 65 & 4.11 & 61 & 3.73 \\
\hline Panama & 66 & 4.09 & 67 & 3.52 \\
\hline Maldives & 67 & 4.05 & 66 & 3.54 \\
\hline Kazakhstan & 68 & 4.02 & 72 & 3.39 \\
\hline Mauritius & 69 & 4.00 & 70 & 3.43 \\
\hline Costa Rica & 70 & 3.99 & 69 & 3.45 \\
\hline Seychelles & 71 & 3.94 & 65 & 3.56 \\
\hline Armenia & 72 & 3.87 & 86 & 2.94 \\
\hline Jordan & 73 & 3.83 & 73 & 3.29 \\
\hline Azerbaijan & 74 & 3.78 & 83 & 2.97 \\
\hline Mexico & 75 & 3.75 & 74 & 3.26 \\
\hline Colombia & 76 & 3.75 & 71 & 3.39 \\
\hline
\end{tabular}

\begin{tabular}{|c|c|c|c|c|}
\hline Economy & Rank 2010 & IDI 2010 & Rank 2008 & IDI 2008 \\
\hline Georgia & 77 & 3.65 & 85 & 2.96 \\
\hline Albania & 78 & 3.61 & 81 & 2.99 \\
\hline Lebanon & 79 & 3.57 & 77 & 3.12 \\
\hline China & 80 & 3.55 & 75 & 3.17 \\
\hline Viet Nam & 81 & 3.53 & 91 & 2.76 \\
\hline Suriname & 82 & 3.52 & 78 & 3.09 \\
\hline Peru & 83 & 3.52 & 76 & 3.12 \\
\hline Tunisia & 84 & 3.43 & 82 & 2.98 \\
\hline Jamaica & 85 & 3.41 & 79 & 3.06 \\
\hline Mongolia & 86 & 3.41 & 87 & 2.90 \\
\hline Iran (I.R.) & 87 & 3.39 & 84 & 2.96 \\
\hline Ecuador & 88 & 3.37 & 88 & 2.87 \\
\hline Thailand & 89 & 3.30 & 80 & 3.03 \\
\hline Morocco & 90 & 3.29 & 100 & 2.60 \\
\hline Egypt & 91 & 3.28 & 92 & 2.73 \\
\hline Philippines & 92 & 3.22 & 95 & 2.69 \\
\hline Dominican Rep. & 93 & 3.21 & 89 & 2.84 \\
\hline Fiji & 94 & 3.16 & 90 & 2.82 \\
\hline Guyana & 95 & 3.08 & 93 & 2.73 \\
\hline Syria & 96 & 3.05 & 96 & 2.66 \\
\hline South Africa & 97 & 3.00 & 94 & 2.71 \\
\hline El Salvador & 98 & 2.89 & 101 & 2.57 \\
\hline Paraguay & 99 & 2.87 & 97 & 2.66 \\
\hline Kyrgyzstan & 100 & 2.84 & 99 & 2.62 \\
\hline Indonesia & 101 & 2.83 & 107 & 2.39 \\
\hline Bolivia & 102 & 2.83 & 102 & 2.54 \\
\hline Algeria & 103 & 2.82 & 105 & 2.41 \\
\hline Cape Verde & 104 & 2.81 & 103 & 2.50 \\
\hline Sri Lanka & 105 & 2.79 & 106 & 2.41 \\
\hline Honduras & 106 & 2.72 & 104 & 2.42 \\
\hline Cuba & 107 & 2.69 & 98 & 2.62 \\
\hline Guatemala & 108 & 2.65 & 108 & 2.39 \\
\hline Botswana & 109 & 2.59 & 109 & 2.25 \\
\hline Uzbekistan & 110 & 2.55 & 110 & 2.22 \\
\hline Turkmenistan & 111 & 2.50 & 111 & 2.15 \\
\hline Gabon & 112 & 2.42 & 112 & 2.10 \\
\hline Namibia & 113 & 2.36 & 114 & 2.06 \\
\hline Nicaragua & 114 & 2.31 & 113 & 2.09 \\
\hline Kenya & 115 & 2.29 & 116 & 1.74 \\
\hline India & 116 & 2.01 & 117 & 1.72 \\
\hline Cambodia & 117 & 1.99 & 120 & 1.63 \\
\hline Swaziland & 118 & 1.93 & 115 & 1.80 \\
\hline Bhutan & 119 & 1.93 & 123 & 1.58 \\
\hline Ghana & 120 & 1.90 & 118 & 1.68 \\
\hline Lao P.D.R. & 121 & 1.90 & 119 & 1.64 \\
\hline Nigeria & 122 & 1.85 & 125 & 1.54 \\
\hline Pakistan & 123 & 1.83 & 121 & 1.59 \\
\hline Zimbabwe & 124 & 1.81 & 128 & 1.49 \\
\hline Senegal & 125 & 1.78 & 129 & 1.46 \\
\hline Gambia & 126 & 1.74 & 122 & 1.59 \\
\hline Yemen & 127 & 1.72 & 127 & 1.49 \\
\hline Comoros & 128 & 1.67 & 130 & 1.44 \\
\hline Djibouti & 129 & 1.66 & 124 & 1.56 \\
\hline Côte d'Ivoire & 130 & 1.61 & 132 & 1.43 \\
\hline Mauritania & 131 & 1.58 & 126 & 1.50 \\
\hline Angola & 132 & 1.58 & 136 & 1.31 \\
\hline Togo & 133 & 1.57 & 134 & 1.36 \\
\hline Nepal & 134 & 1.56 & 137 & 1.28 \\
\hline Benin & 135 & 1.54 & 138 & 1.27 \\
\hline Cameroon & 136 & 1.53 & 133 & 1.40 \\
\hline Bangladesh & 137 & 1.52 & 135 & 1.31 \\
\hline Tanzania & 138 & 1.51 & 141 & 1.23 \\
\hline Zambia & 139 & 1.50 & 131 & 1.44 \\
\hline Uganda & 140 & 1.49 & 140 & 1.24 \\
\hline Madagascar & 141 & 1.45 & 142 & 1.20 \\
\hline Rwanda & 142 & 1.44 & 143 & 1.18 \\
\hline Papua New Guinea & 143 & 1.38 & 139 & 1.24 \\
\hline Guinea & 144 & 1.31 & 144 & 1.16 \\
\hline Mozambique & 145 & 1.30 & 146 & 1.10 \\
\hline Mali & 146 & 1.26 & 145 & 1.11 \\
\hline Congo (Dem. Rep.) & 147 & 1.17 & 147 & 1.04 \\
\hline Eritrea & 148 & 1.09 & 148 & 1.03 \\
\hline Burkina Faso & 149 & 1.08 & 149 & 0.98 \\
\hline Ethiopia & 150 & 1.08 & 150 & 0.94 \\
\hline Niger & 151 & 0.92 & 152 & 0.79 \\
\hline Chad & 152 & 0.83 & 151 & 0.80 \\
\hline
\end{tabular}

Source: ITU. 


\section{Box 2.2: Internet access a legal right in Finland}

Finland continues to be an impressive top ICT country. It ranks fifth in the IDI (gaining seven places over the past two years) and shows dynamic changes of seven per cent and 35 per cent in the access and use sub-indices, respectively. The country has a history of being an early adopter of new technologies and forward-looking policies. It was the first country in the world to launch a commercial GSM network, and one of the first countries to trial mobile payments and license $3 \mathrm{G}$ services. In 2009, it became the first country in the world to make highspeed Internet access a legal right. ${ }^{14}$

The improvement in the IDI access sub-index results from the substantial increase in international Internet bandwidth of 150 per cent - from $200000 \mathrm{Mbit} / \mathrm{s}$ to $500000 \mathrm{Mbit} / \mathrm{s}$. In addition, Finland features as one of the top five countries in the use sub-index (ranked fourth) thanks to efforts undertaken to improve high-end user access. Finland's regulator FICORA has mandated a law assigning 26 operators to provide a broadband connection to customers in their coverage areas, making Finland the first country to take this measure. This is part of Finland's updated universal service obligation (USO). ISPs are obliged to provide subscribers with at least a $1 \mathrm{Mbit} / \mathrm{s}$ connection as of July 2010 and committed to providing $2 \mathrm{Mbit} / \mathrm{s}$ and $100 \mathrm{Mbit} / \mathrm{s}$ services by 2012 and 2015, respectively. ${ }^{15}$ For those zones to be covered by USO, FICORA envisages a fixed-broadband monthly charge ranging from USD 42 to USD $57,{ }^{16}$ which compares with a USD 35 monthly charge in commercially available offers measured by the fixed-broadband sub-basket in the 2010 ICT Price Basket. Finland comes ninth out of the top ten countries with the lowest mobile-cellular sub-basket in the 2010 ICT Price Basket.

Growth in mobile-broadband Internet subscriptions (where penetration increased from 24 to 78 per cent between 2008 and 2010) is the main contributor to the increase in the use sub-index. Mobile operators continue to develop new mobile-broadband networks and solutions to support FICORA's regulation. In 2010, new 4G technology (LTE) was launched in some of Finland's major cities (Turku and Espoo, by TeliaSonera and Elisa, respectively), gaining new subscribers with early delivery in UHF bands. More recently, Finnish telco DNA acquired Welho's business operations, deploying an improved network and new service plans attracting mobile-broadband Internet subscribers. DNA fully upgraded its broadband network to a maximum bandwidth of $200 \mathrm{Mbit} / \mathrm{s}$ and also modified the terms of service to offer non-fixed commitments. DNA will follow in 2011 and roll out its LTE network while simultaneously extending HSPA+ technology to serve Finland's rural areas. Finland and the other high-income Nordic countries are leaders in Europe when it comes to mobile-broadband deployment. of $3 \mathrm{G}$ licences and the refarming of other bands to allow $3 \mathrm{G}$ services have facilitated the entrance of the new player, Nova. The new entrant has brought competition into the mobile market, traditionally dominated by the incumbent Siminn and Vodafone. This has been the case especially in the mobile-broadband segment, where by the end of 2010 Nova had secured the biggest market share. ${ }^{13}$ Such an increase in mobile-broadband competition together with its late launch may explain the rapid growth of the service in the country.

Among the top thirty countries, the one whose performance improved most over the two year-period is Finland, which moved up seven places in the IDI, to rank fifth in 2010. Despite the continuous decrease in its fixed-line network over the past two years (from 31 to 23 per cent penetration), the country significantly increased international bandwidth as well as mobilebroadband uptake (from 24 to 78 percent penetration) (see Box 2.2).
Switzerland moved up one place to eighth in the IDI 2010. The country has one of the highest fixed-broadband penetration rate worldwide (38 per cent) and a very high proportion of households with computers and Internet access (86 per cent each). According to the Swiss Federal Communications Commission, the number of homes and businesses served by fibre had reached 250 000 by the end of 2010, representing approximately eight per cent of households. ${ }^{17}$ Mobile broadband, on the other hand, is still emerging and, with 44 per cent penetration, Switzerland lags behind many of the top performers (rank 25th globally).

New Zealand moved up four places to 12th. International Internet bandwidth per Internet user increased significantly during the past two years (from 9700 to $19300 \mathrm{Mbit} / \mathrm{s} /$ user), but other key indicators such as mobile broadband, Internet access at home and Internet usage, as well as skills, all increased, too. New Zealand's 
government has made broadband "a vital component of New Zealand's economic growth, productivity improvements and the government's wider strategy to increase New Zealand's global competitiveness". To upgrade the country's broadband infrastructure, it has earmarked a total of NZD 1.5 billion, including 300 million to improve rural broadband connectivity. ${ }^{18}$

Another country among the top performers that improved significantly is Austria, which moved up from 21 st to 16 th place. This is mainly due to sharp increases in the numbers of mobile-telephone and mobile-broadband subscriptions, as well as international Internet bandwidth. Indeed, regulation and uptake of mobile broadband in Austria is a very unique case. According to customer surveys, some 76 per cent of residential mobile-broadband customers use it on a standalone basis, and in most cases from a fixed location. ${ }^{19}$ Together with the wide coverage of HSDPA networks and the high penetration of mobile broadband in the country, this has led the regulator to conclude that it is a substitute for rather than a complement to fixed broadband. So far, Austria is the only EU country where fixed-mobile broadband substitution has been proven, which highlights the importance of detailed ICT data for adapting regulation to technological changes and customers' usage of technology.

The United States kept the same position (17th place) over the two-year period. The relatively low mobile- cellular and household Internet access penetration rates (85 per cent as against more than 100 per cent for most European countries, and 71 per cent compared with between 85 and 90 per cent in Europe, respectively) have already been discussed in last year's edition of this report (ITU, 2010b). Indeed, the United States went down three places on the IDI access sub-index (from 20 th to $23 \mathrm{rd}$ ). On the other hand, mobile broadband is increasing rapidly in the country, and penetration rates rose to 54 per cent at the end of 2010, compared with 26 per cent at the end of 2008 .

\section{Most dynamic countries}

The previous section has shown that the top IDI performers (both for 2008 and 2010) are largely dominated by developed countries. Over the same time period, however, a number of developing countries have made significant progress in terms of ICT diffusion and uptake. It is therefore useful to identify the most "dynamic" IDI countries - or countries with the largest change in IDI ranking and IDI value in both absolute and relative terms (see Table 2.3). This section takes a closer look at those countries, highlights their key performance indicators and identifies selected best practices that resulted in the outstanding/above-average IDI results achieved. The "spider" charts (Figure 2.3) illustrate the normalized values, and changes between 2008 and 2010, in each of the 11 indicators included in the IDI for those countries.

Table 2.3: Most dynamic countries (top ten) - changes between IDI 2010 and 2008

\begin{tabular}{|c|c|c|c|c|c|c|c|c|}
\hline \multicolumn{3}{|c|}{ Change in IDI ranking } & \multicolumn{3}{|c|}{ Change in IDI value (absolute) } & \multicolumn{3}{|c|}{ Change in IDI value (\%) } \\
\hline $\begin{array}{l}\text { IDI } \\
2010 \\
\text { rank }\end{array}$ & Country & $\begin{array}{c}\text { IDI rank } \\
\text { change } \\
2008-2010\end{array}$ & $\begin{array}{l}\text { IDI } \\
2010 \\
\text { rank }\end{array}$ & Country & $\begin{array}{l}\text { IDI value } \\
\text { change } \\
2008-2010\end{array}$ & $\begin{array}{c}\text { IDI } \\
2010 \\
\text { rank }\end{array}$ & Country & $\begin{array}{c}\text { IDI \% } \\
\text { change } \\
2008-2010\end{array}$ \\
\hline 72 & Armenia & 14 & 46 & Saudi Arabia & 1.29 & 72 & Armenia & 31 \\
\hline 90 & Morocco & 10 & 44 & Qatar & 1.11 & 46 & Saudi Arabia & 31 \\
\hline 81 & Viet Nam & 10 & 52 & Belarus & 1.08 & 115 & Kenya & 28 \\
\hline 74 & Azerbaijan & 9 & 21 & Macao, China & 1.01 & 81 & Viet Nam & 28 \\
\hline 46 & Saudi Arabia & 9 & 47 & Russia & 0.96 & 52 & Belarus & 28 \\
\hline 77 & Georgia & 8 & 36 & Cyprus & 0.96 & 74 & Azerbaijan & 27 \\
\hline 60 & Oman & 8 & 5 & Finland & 0.94 & 60 & Oman & 27 \\
\hline 36 & Cyprus & 7 & 27 & Portugal & 0.94 & 90 & Morocco & 26 \\
\hline 5 & Finland & 7 & 3 & Iceland & 0.94 & 57 & Moldova & 25 \\
\hline 57 & Moldova & 7 & 60 & Oman & 0.93 & 44 & Qatar & 25 \\
\hline
\end{tabular}




\section{Box 2.3: Armenia's surge in Internet use}

Since 2008, Armenia has increased its IDI unit value by 31 per cent and moved up from rank 86 to 72 . Armenia progressed in the access sub-index, by 26 per cent, and in the use sub-index, moving up 44 places to 82 in this category. International Internet bandwidth and mobile-cellular subscriptions contribute to this year's higher access sub-index, Internet bandwidth in Armenia having increased tenfold from $1083 \mathrm{Mbit} / \mathrm{s}$ to $10547 \mathrm{Mbit} / \mathrm{s}$. This is reflected in the higher use of Internet in the country compared with neighbouring countries' Internet penetration rates: Armenia (37 per cent), Azerbaijan (36 per cent), Georgia (27 per cent), the Islamic Republic of Iran (13 per cent) and the CIS average (29 per cent) (Chart Box 2.3). The country is almost on a par with Turkey's Internet penetration rate of 40 per cent. Furthermore, mobile broad- band increased from no subscriptions in 2008 to about five per cent penetration rate in 2010.

Fixed-broadband penetration is around three per cent but there are positive signs for growth in Armenia's broadband sector. The Ministry of Economy of Armenia plans to build and expand a mixture of fibre-optic, WiMAX and satellite technologies working to develop the country's high-speed broadband network at a cost of approximately USD 24 million. ${ }^{20}$ The country's main operator ArmenTel has extended its $3 \mathrm{G}$ footprint, deploying additional $3 \mathrm{G}$ base stations in new regions so as to improve coverage, and will introduce VDSL technology to deliver higher capacity. As a result, next year could see a further growth in mobile-broadband subscriptions in Armenia.

\section{Chart Box 2.3: Internet users per 100 inhabitants, 2000-2010}

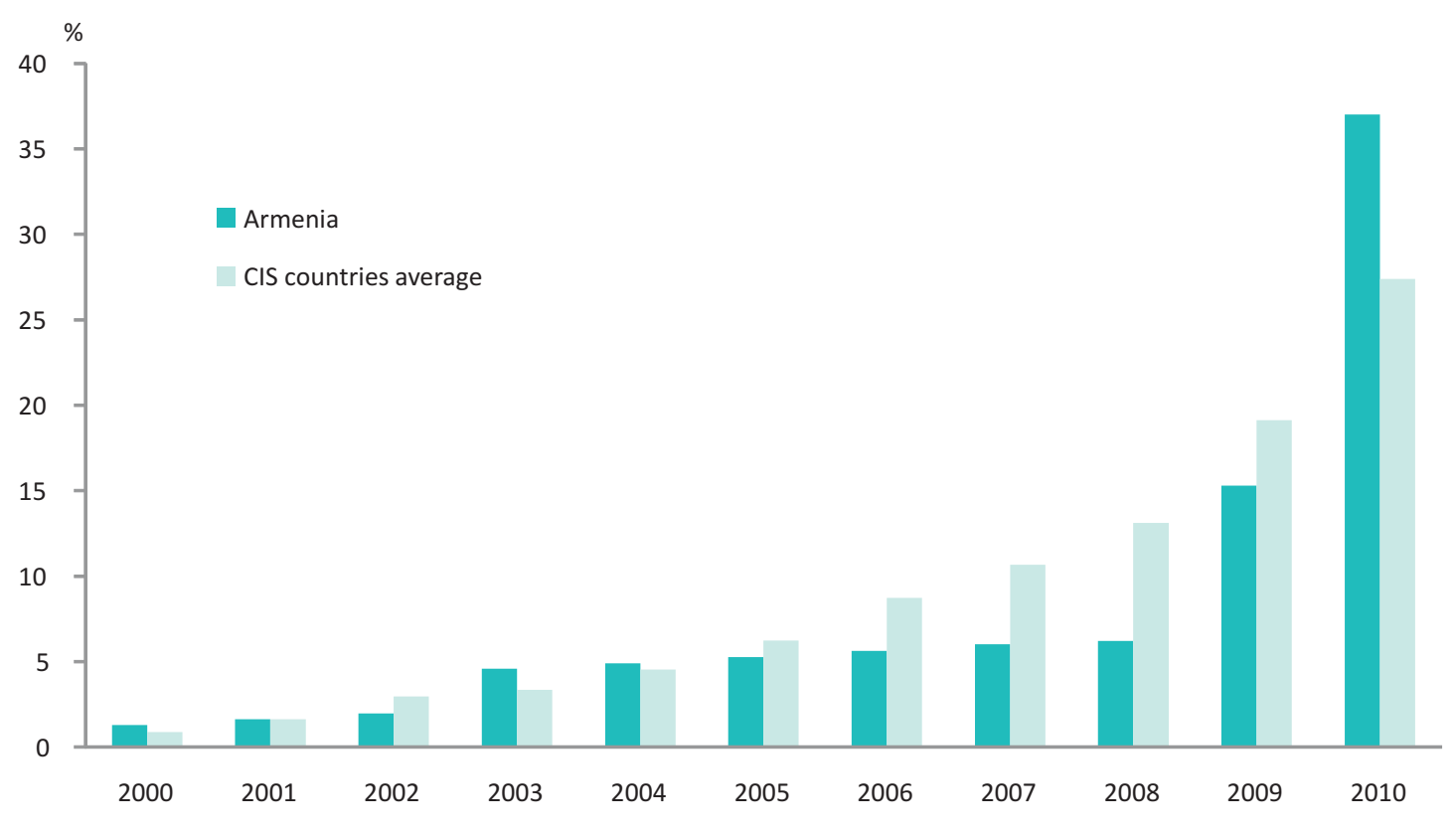

Source: ITU World Telecommunication/ICT Indicators database.

The country that improved most in terms of rankings is Armenia, which moved up 14 places between 2008 and 2010, reaching 72nd place and increasing its IDI value by 31 per cent. This impressive growth is based on improvements in both the access and use sub-indices. For example, mobile penetration increased from 75 to 125 per cent (reaching levels above the developedcountry average), and household access to computers and Internet rose significantly, also leading to an increase in Internet usage. In addition, both fixed- and mobilebroadband services - almost non-existent in 2008 - are now available and growing in usage (see Box 2.3).

Azerbaijan has made similar improvements to Armenia, leading to a jump of nine places in the rankings, to 74 th place in the IDI 2010, and increasing its IDI value by 


\section{Box 2.4: Kenya - Africa's fastest growing Internet market}

Kenya is one of Africa's fastest growing Internet markets, showing a $0.55 \mathrm{IDI}$ value increase as compared with the world average of 0.46 and the African average of 0.23 . This improvement is a result of the 37 per cent increase in the access sub-index due to the large growth in mobile-cellular subscriptions and a high increase in the country's Internet bandwidth capacity. The use sub-index jumped 19 places to a value of 1.05 , and compares very favourably with the African countries' average of 0.44 .

Mobile-cellular tariffs have come down considerably due to increasing competition between providers in Kenya. The 2010 ICT Price Basket results show a substantial decrease in the mobile sub-basket, in both absolute (-14 per cent) and relative (-46 per cent) terms. New entrant Airtel sparked a price war and initiated fierce competition in the Kenyan market last year by reducing voice-call rates by half and cutting prices of sms charges (in local currency) from KES 3 to KES 1 (USD 0.03 to USD 0.01). Other operators, such as Safaricom and Telkom Kenya, expectedly followed suit, making further cuts to their mobile rates. The cheaper calling rates captured new subscribers in under-penetrated market segments and made cellphone services more affordable. A recent halt to any further tariff reductions was announced in May 2011 by the Communications Commission of Kenya (CCK) and President Kibaki in order to evaluate the impacts and economic profitability of the price wars. ${ }^{21}$ The presence of Airtel will still exert an effect as it continues to roll out its $3 G$ network this year and double the amount of $2 \mathrm{G}$ stations already deployed. CCK also confirmed authorization of mobile-number portability, which will add user flexibility to change between service providers.

In addition, several initiatives were taken to increase Internet bandwidth. Last year, Verizon Business, a unit of US Verizon Communications, expanded its IP network coverage in Kenya to serve Verizon's business customers. This was in alliance with Gateway Business Africa, in an effort to provide better connectivity in the eastern parts of Africa and other developing regions. ${ }^{22}$ Another network extension in Kenya is the Lower Indian Ocean Network (LION) project. In consortium with Africa Coast to Europe (ACE), this project involves the construction of undersea cables in the Indian Ocean providing broadband Internet service between Europe and South Africa. The entire network project is expected to be completed by 2012. The second phase of the project has started and will increase bandwidth capacity up to $1.28 \mathrm{Tbit} / \mathrm{s}^{23}$

The efforts to enhance networks and mobile-market competition have already started to produce an effect by increasing the number of Internet users, including those connecting to the Internet via mobile networks. In December 2010, Kenya reached 10.2 million Internet users, a penetration rate of about 26 per cent.
27 per cent. While mobile broadband was still almost zero at the end of 2010, fixed-broadband penetration had increased from close to zero to more than five per cent, most likely as a result of big price drops (of almost 90 per cent) in the fixed-broadband sub-basket during that time period (see Chapter 3).

Among the CIS countries, Belarus ranks second after the Russian Federation, reaching 52nd place worldwide and improving its IDI value by 28 per cent. This is primarily due to improvements in the use sub-index thanks to very high growth in Internet users and in fixed and mobile-broadband subscriptions.

Georgia moved up eight places to 77th place in 2010. It improved on both ICT access and use. Indeed, apart from fixed-line penetration, the country made significant advances on all the indicators included in the two sub-indices, as well as on the skills sub-index. Mobilebroadband penetration has climbed to 18.8 per cent by the end of 2010 (up from nine per cent in 2008), the highest among CIS countries.

Kenya stands out in terms of relative IDI change, with an increase in value of 29 per cent (compared with an average of 14 per cent for all countries included in the IDI). Kenya has significantly increased its international Internet bandwidth, mobile-cellular and mobile-broadband penetration and number of Internet users (see Box 2.4). It is one of the top ten countries with the highest relative drop in ICT prices (see Chapter 3), which is likely to have led to an increase in mobile subscriptions and Internet usage.

Moldova moved up seven places to 57 th in the IDI 2010 and increased its IDI value by 25 per cent. The country doubled its international bandwidth per Internet user, and household access to Internet grew from 16 to 34 per cent. Similarly, fixed- and mobile-broadband and Internet usage increased substantially during the two-year period. 


\section{Box 2.5: Mobile Internet in Morocco}

Morocco improved its ranking by ten places, attaining an IDI value of 3.29 as compared with the average IDI in developing countries of 3.19. This improvement is a result of increases of 62 per cent in the use sub-index and 27 per cent in the access sub-index during the past two years. The significant progress in the access sub-index - moving the country up seven places - was due to the almost threefold increase of international Internet bandwidth, from $25130 \mathrm{Mbit} / \mathrm{s}$ to $75000 \mathrm{Mbit} / \mathrm{s}$. Internet user penetration increased by almost 50 per cent, mainly due to mobile broadband. Within two years of $3 \mathrm{G}$ mobile-broadband services being introduced in Morocco, mobile-broadband penetration jumped from 2.3 per cent in 2008 to ten per cent in 2010 (Chart Box 2.5). This trend is expected to continue, with mobile broadband to grow faster than fixed broadband. Fixed-broadband penetration remains flat, recording one per cent growth from 2008 to 2010, whereas mobile-broadband penetration, which represents 76 per cent of total broadband subscriptions, grew from two to ten per cent. Morocco has three operators sharing the mobile-broadband Internet market, thus creating a more competitive sector, and mobile-broadband prices have come down substantially and are today competitive with fixed-broadband prices (see Table 3.8 in Chapter 3). The fixed-broadband ADSL market is dominated by incumbent operator Maroc Telecom, which holds a monopoly.

Moroccan incumbent Maroc Telecom continues to develop the fibre-optic backbone network, which will link Morocco with West African countries. In 2010, Maroc Telecom reached 60 per cent completion in the first phase of plans to roll out the fibre-optic backbone network. Maroc Telecom plans to also deliver mCommerce solutions to the growing mobile-broadband market and in view of the growing demand for mobile financial transactions. ${ }^{24}$

Moroccan telecommunication regulator ANRT has set a 65-70 per cent reduction target for voice-termination interconnection tariffs on fixed and mobile calls between 2010-2013 for Morocco's mobile operators. ANRT has also set a 24-40 per cent end reduction target for asymmetric interconnection tariffs for 2013. The measure is intended to further stimulate competition in the fixed and mobile markets in the interests of end users. ${ }^{25}$

Chart Box 2.5: Mobile-broadband subscriptions per 100 inhabitants, 2008, 2010

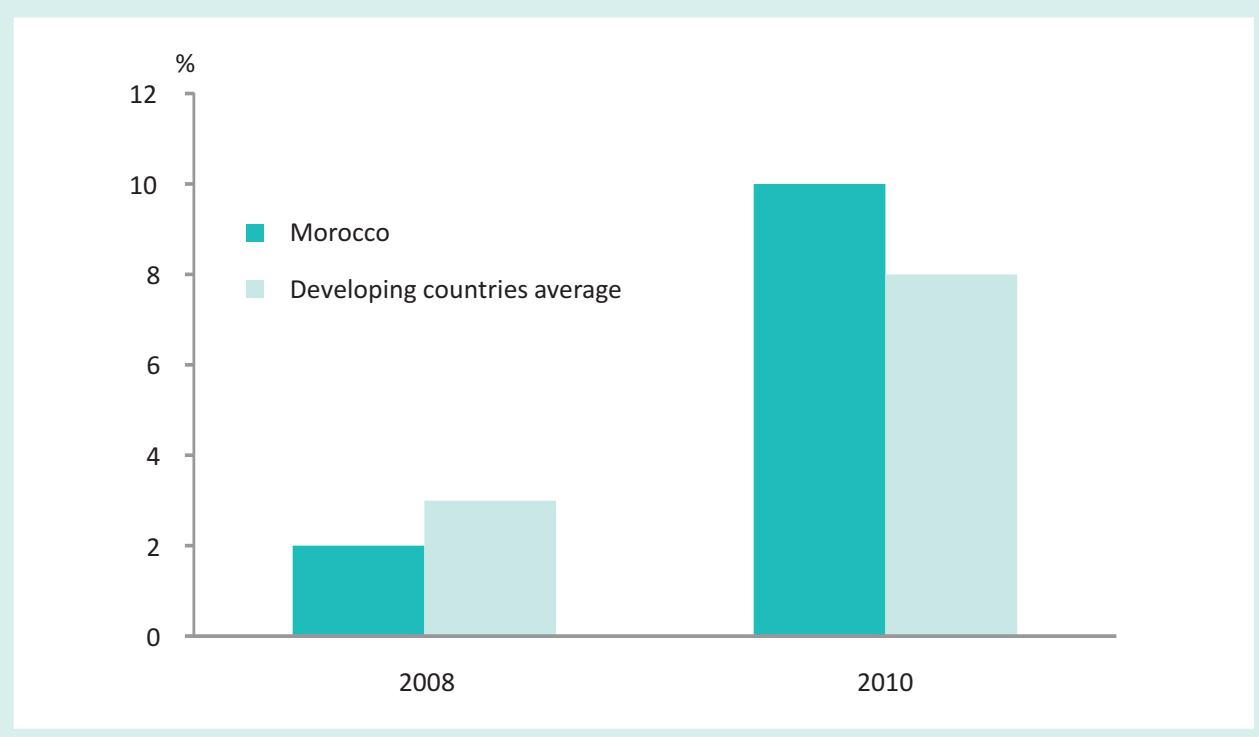

Source: ITU World Telecommunication/ICT Indicators database.

Another country that made impressive strides is Morocco, moving up ten places to 90th in the latest IDI. Internet access at home increased significantly, as did broadband penetration, contributing to an overall growth in the number of Internet users. Fixedbroadband prices in Morocco fell by 40 per cent over the two-year time period (see Box 2.5 and Box 3.4 in Chapter 3). 
Oman moved up eight places (to 60th) and increased its IDI value by 0.93 or 27 per cent. While the country improved on almost all of the indicators, Internet user penetration increased significantly over the past two years, mainly due to mobile broadband coupled with an increase in public Internet access (see Box 2.6).

Qatar also recorded above-average improvements in ICT access and use, moving up four places and increasing its IDI value by 1.11. Ranking 44th, Qatar now comes second among the Arab countries, after the United Arab Emirates (ranked 32nd). Internetuser penetration has grown from 38 to 69 per cent, which is close to the developed-country average (of 71 per cent) and way above the Arab States' average of 25 per cent. Similarly, household access to comput- ers and Internet has increased substantially over the two-year period.

The Russian Federation has improved its IDI value by 0.93 (around twice the global average improvement of 0.46 ) and moved up two places to 47 th. The country has improved its performance on both ICT access and use. In particular, international Internet bandwidth has increased significantly over this period on account of several submarine and transnational network infrastructure projects. For example, the operator Rostelecom doubled its Internet link capacity with Far East Telecom, up to 7.3 Gbit/s. ${ }^{32}$ The Russia-Japan Cable Network project was also launched, linking the two countries through an undersea cable system. ${ }^{33}$ Recently, Rostelecom and China Telecom announced an agree-

\section{Box 2.6: Oman's success in connecting schools to the Internet}

Oman moved up eight places in the global IDI country ranking. The growth in the number of Internet users and mobile-broadband subscriptions contributed to a jump of 24 places in the use sub-index. The number of Internet users per 100 inhabitants increased impressively from 20 to 63 in the space of only two years. Popular use of Internet cafes and the younger generation participating in social media activities and blogging contributed to driving the growth in Internet users. ${ }^{26}$ The Sultanate has decided to invest in ICTs for education, and the Ministry of Education has implemented a number of policies to connect the country's schools with ICTs, to improve ICT skills and to integrate ICTs in the curriculum. ${ }^{27}$ The government's telecommunication regulatory authority ITA plans to connect all schools to the Internet and to provide all students and teachers with laptops. ${ }^{28}$ These initiatives are part of the government's eOman project, which aims at creating a knowledge-based economy and society. ${ }^{29}$

Fixed-broadband Internet subscriptions in Oman are still fairly low, at two per cent, but more growth is evident in mobile broadband with a penetration rate of 11 per cent (up from six per cent in 2008).

Oman's mobile sector is now highly competitive, with five resellers entering the market in 2010. Omantel is the main operator along with new provider Nawras. The introduction of resellers is the result of the government's efforts to create a more competitive telecom sector for the saturated market (166 per cent mobile-penetration rate). The mobile-cellular sector reached 4.6 million subscriptions in 2010, a 43 per cent increase from 2008. The new entrants'tariff rates vary, but in general they are relying on low costs and discount plans as their business model. ${ }^{30}$ This may prompt future adjustments in price plans from the two main Omani providers next year. With the already high penetration rate, we may also expect a slower rate of growth in the following years for Oman's mature market.

Unlike in the mobile market, Oman's fixed-line sector is a duopoly of Omantel and Nawras, which recently acquired licences for fixed lines and international gateway. Although there has been a 12 per cent decrease in fixed lines since 2008, Nawras' launch of commercial fixed-line services last year may mitigate a future decline in the fixed-line sector.

For 2011, the Europe to India (EIG) and Gulf Bridge International (GBI) submarine cable projects are important to note. Omantel, which is part of the EIG consortium, announced partial activation of the undersea cable early this year, and this will enhance capacity between the Middle East and Asia and Europe with a full cable system up to 3.84 Tbit/s. ${ }^{31}$ Omantel has also concluded an agreement to launch this year the GBI cable system, connecting the Gulf countries to Europe and Asia using a submarine fibre cable ring. On account of its geographic location, the country remains a global hub for these projects and will benefit in terms of international broadband traffic capacity when the full networks are completed. 


\section{Box 2.7: Mobile-cellular penetration reaching top levels in Saudi Arabia}

Among developing countries, Saudi Arabia experienced the highest IDI percentage value increase (31 per cent, as compared with the developing country average of 15 per cent). Saudi Arabia moved up eight places in the access sub-index and ten places in the use sub-index. Underlying the access sub-index increase was the important progress in international Internet bandwidth, which grew from $20000 \mathrm{Mbit} / \mathrm{s}$ to 317940 $\mathrm{Mbit} / \mathrm{s}$, and in mobile-cellular subscriptions, which grew from 138 to 188 per 100 inhabitants (Chart Box 2.7). Internet user penetration stands at 41 users per 100 inhabitants, and fixedbroadband subscriptions showed a 36 per cent increase, along with a large increase in mobile-broadband subscriptions. It is no surprise that the jump in mobile-broadband subscriptions is the main reason behind the increase in the use sub-index. Saudi Arabia's mobile-broadband penetration grew from nine per cent in 2008 to 58 per cent in 2010 (Chart Box 2.7). The expat customers and younger age groups are an influential part of this subscription base. This shows that there is still much room for potential growth in the Saudi Arabian broadband market.

The Saudi Arabian mobile sector is one of the more competitive markets in the region, with the three largest Middle Eastern regional players having a presence in the country (STC, Etisalat and Zain). Mobily is pushing an extensive mobile-broadband network after winning the GSM/3G licence in 2004, and has future plans to provide WiMAX service to the 20 cities it covers. Fixed-telephone line penetration remains steady, with 4165750 lines in 2010 and a penetration rate of 15 per cent (one per cent year-on-year growth).

Under the National Communications and Information Technology Plan (NCITP) initiatives, the Government of Saudi Arabia has launched several projects, especially in the e-business segment, with the aim of facilitating access to the Internet and improving its performance..$^{35}$

\section{Chart Box 2.7: Mobile-cellular subscriptions per 100 inhabitants, 2000-2010 (left) and active mobile-broadband subscriptions per 100 inhabitants, 2008 and 2010 (right)}
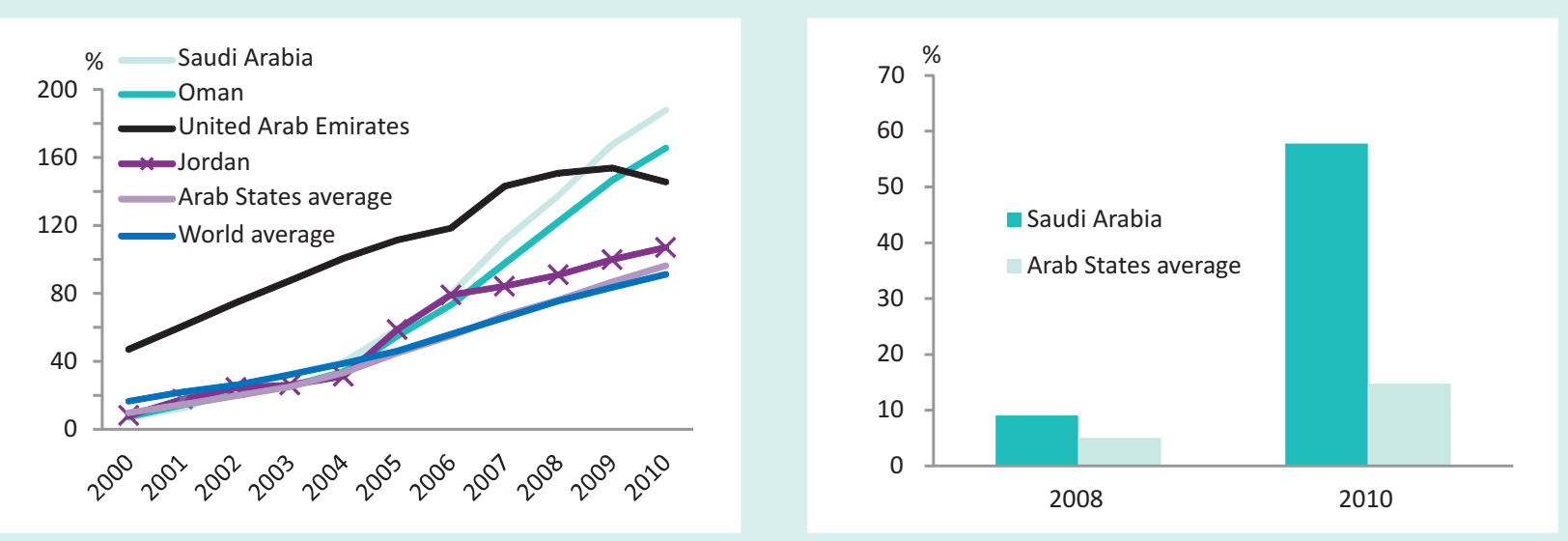

Source: ITU World Telecommunication/ICT Indicators database.

ment to further expand Europe-Asia traffic, with the first phase planned to increase total capacity by 200 Gbit/s. ${ }^{34}$ This will serve to increase transit bandwidth in the Russian Federation for traffic between Europe and Asia through the Transit Europe-Asia (TEA) project. At the same time, Internet access at home, broadband penetration and Internet usage have all increased substantially.
Saudi Arabia jumped nine places to 46th place. The country now has the third highest mobile-cellular penetration worldwide (almost 186 per cent), after Macao (China) and Hong Kong (China). Saudi Arabia is the country that has improved most of all countries in terms of its IDI value (an increase of 1.29, or 31 per cent). Box 2.7 provides more insights into the country's remarkable progress in ICTs. 
Figure 2.3: Spider charts, selected dynamic countries, 2010 and 2008*
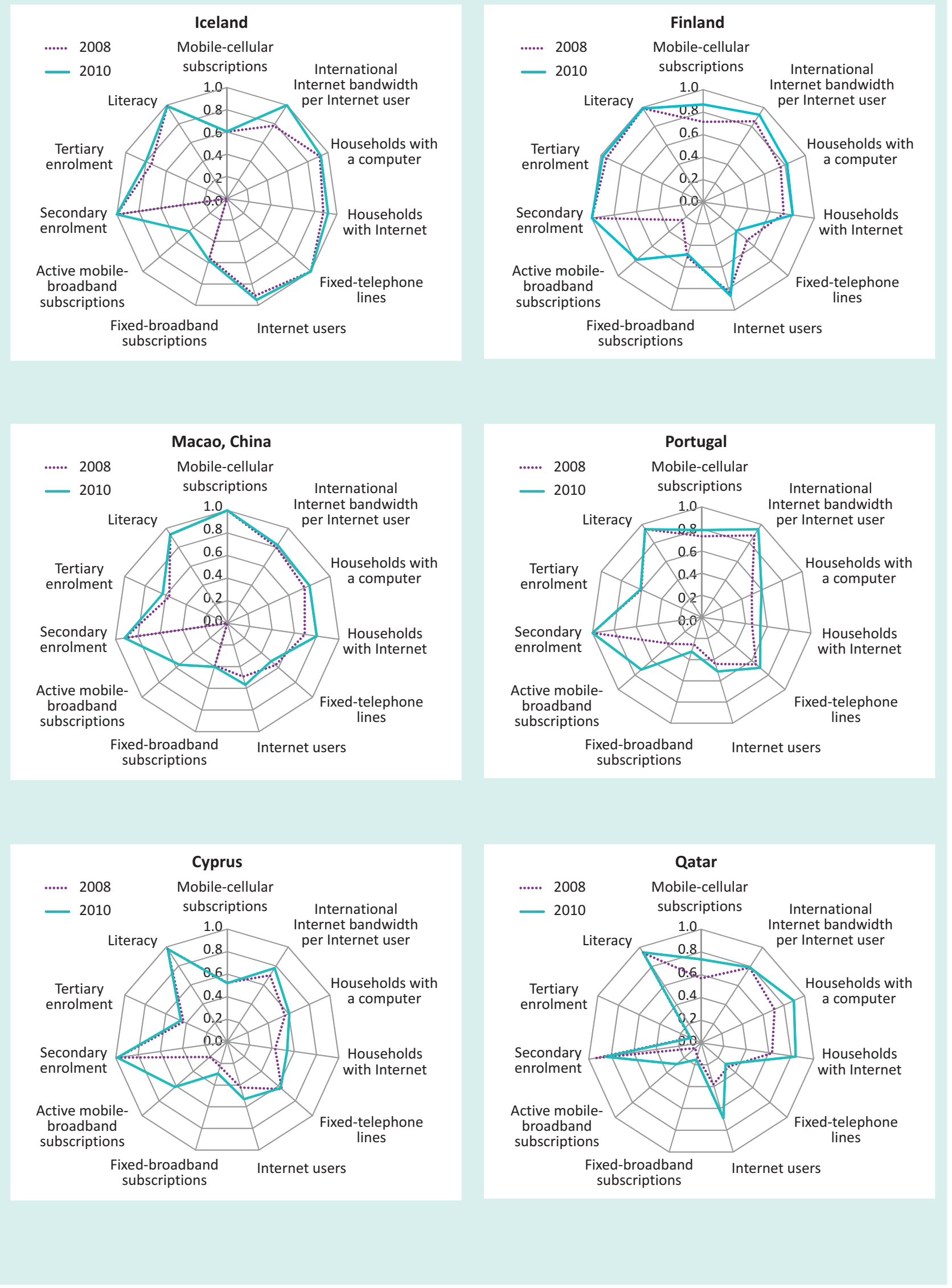
Figure 2.3: Spider charts, selected dynamic countries, 2010 and 2008* (continued)

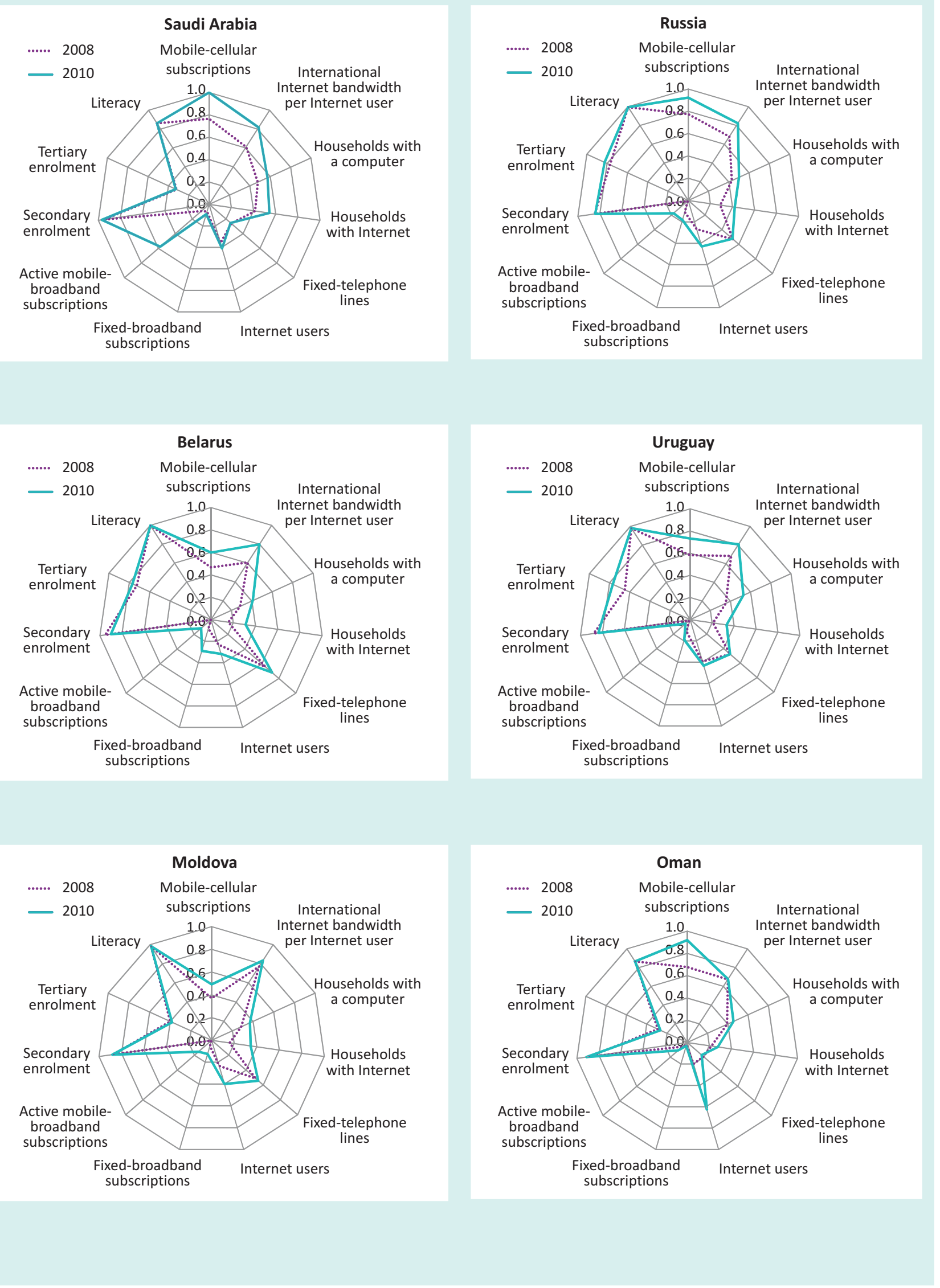


Figure 2.3: Spider charts, selected dynamic countries, 2010 and 2008* (continued)

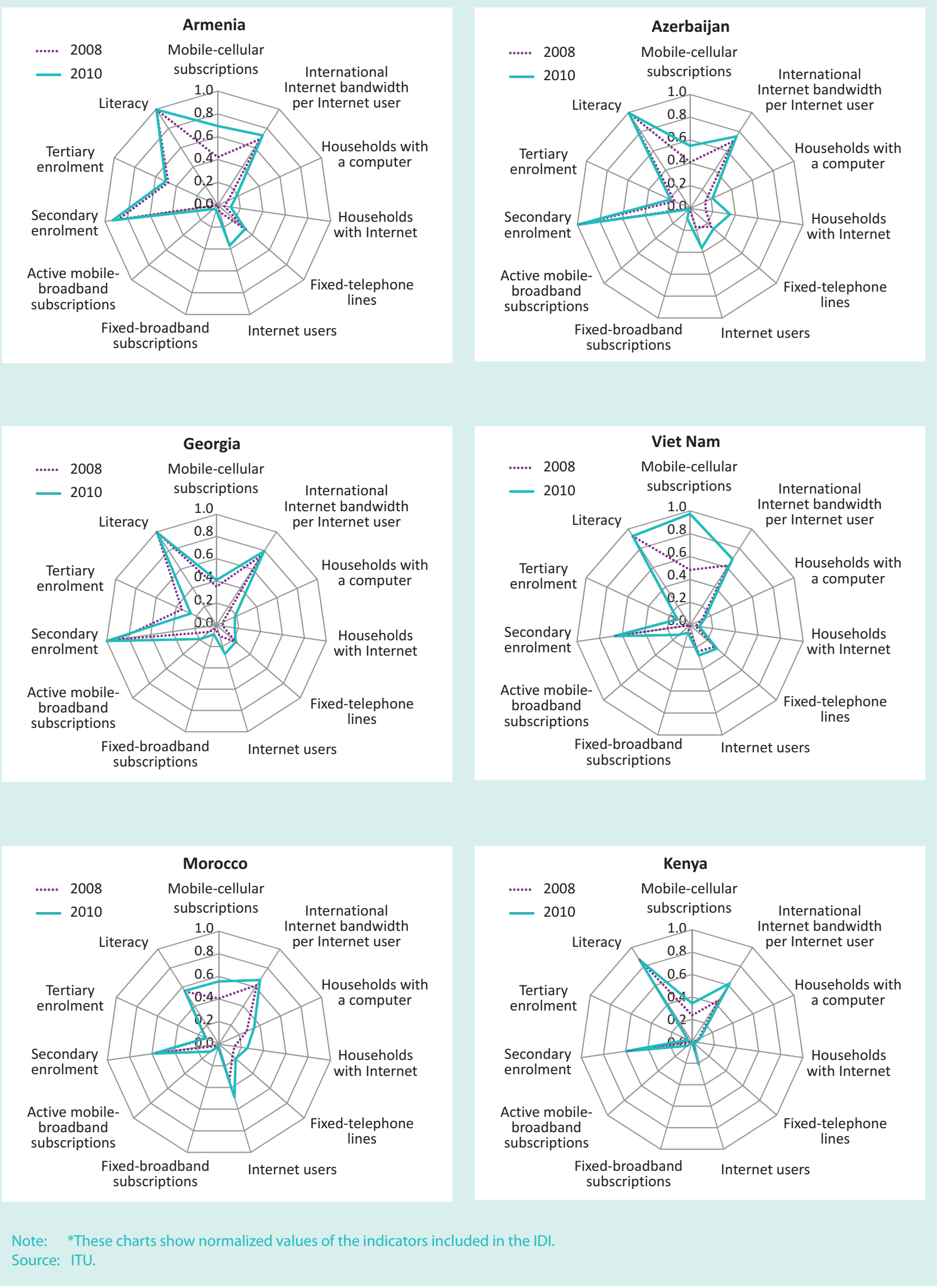


Viet Nam (ranked 81st) increased its IDI value by 28 per cent, rising ten places. Its already relatively high mobile-phone penetration in 2008 (87 per cent) climbed to 175 per cent by the end of 2010 . This puts the country in eighth place worldwide in terms of mobile-cellular penetration. Household access to computers and the Internet, on the other hand, is still relatively low. Mobile broadband was practically non-existent in 2008, and has reached 13 per cent in 2010. This is likely to increase Internet usage in the near future (see Box 2.9 in section 2.3).

\section{IDI by level of development}

A key objective of the IDI is to monitor progress in countries at different levels of development and to identify the differences between those countries - i.e. the digital divide. The nature of the digital divide has changed significantly over the past ten years. Developing countries have made enormous progress in telecommunications, and access to mobile networks is almost ubiquitous today in terms of population coverage. There is still a huge divide when it comes to Internet access, however, and even more in terms of broadband Internet. The gap has been growing during the past few years, but mobile-broadband access is expected to narrow the gap in the near future. The focus of the digital divide will increasingly shift towards the bandwidth, speed and quality of Internet (or broadband) connections and major differences among countries can be observed in this regard (see Chapter 4).

Charts 2.1 to 2.4 compare the IDI and its sub-indices between developed and developing countries. ${ }^{36}$ Overall, IDI values in developing countries are about half those of developed countries in 2010, but relative growth in developing countries is stronger. The access sub-index has continued to grow at higher levels than the use sub-index in developing countries, whereas growth in the access subindex in developed countries is relatively low, indicating that most developed countries have reached saturation levels and have moved from stage 1 (ICT readiness) to stage 2 (ICT use) within the IDI conceptual framework (Figure 2.1). Developing countries, on the other hand, are still building their ICT access levels, at least partly, although some of them have moved to stage 2 and have become intense ICT users. Accordingly, the use sub-index shows stronger growth, in relation to the previous period, although it still registers rather low absolute levels for developing countries on average.

The skills sub-index shows relatively little movement, which reflects the high level of achievement in de-

\section{Chart 2.1: IDI by level of development*}

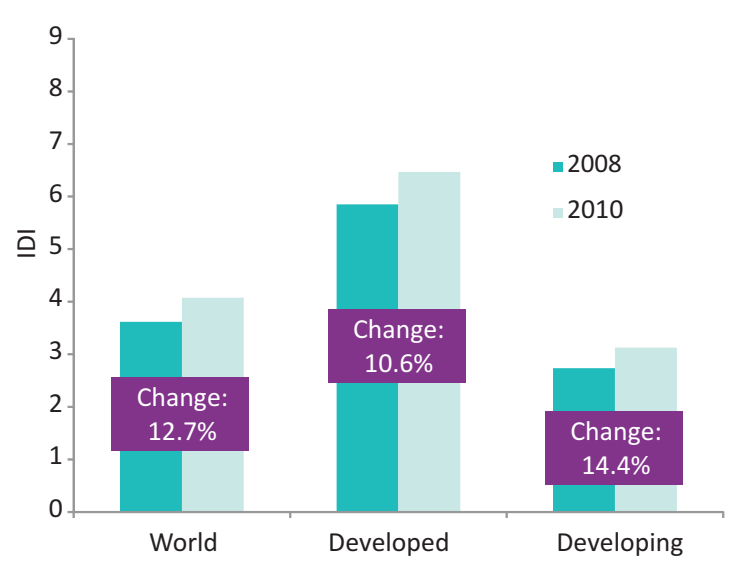

Chart 2.2: IDI access sub-index by level of development*

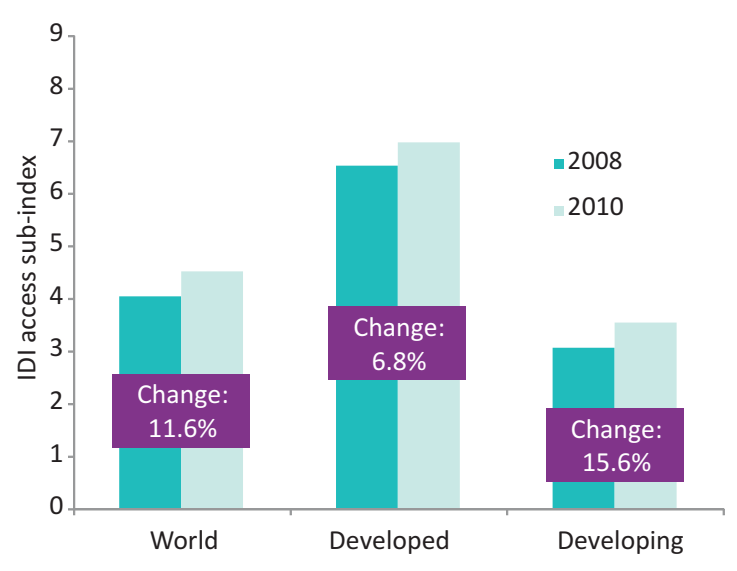

Chart 2.3: IDI use sub-index by level of development*

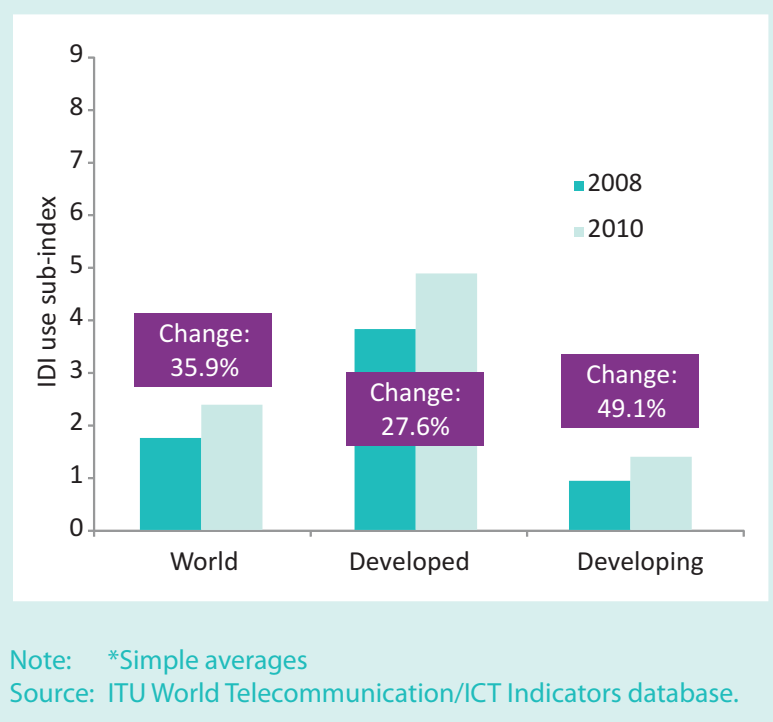




\section{Chart 2.4: IDI skills sub-index by level of development*}

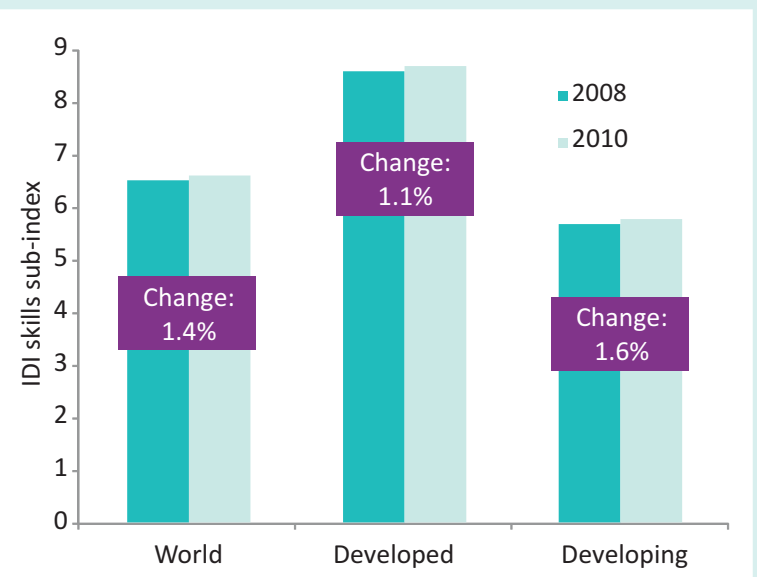

Note: $\quad *$ Simple averages

Source: ITU World Telecommunication/ICT Indicators database.

veloped countries as well as the nature of the proxy indicators employed. Since the sub-index is composed of school enrolment and literacy indicators, change and growth is much less dynamic than for ICT infrastruc- ture market developments and ICT uptake in society, in particular in developing countries.

\section{Comparing income and IDI levels}

As is the case with many indicators related to socioeconomic development, ICT indicators have a strong relationship with countries' national income levels. Chart 2.5 plots the IDI against gross national income (GNI) per capita (PPP\$), which results in an R-squared value of 0.8 , indicating a very strong relationship between the two variables. Accordingly, lower income levels correspond to lower IDI levels and vice versa, following a logarithmic curve. There are a number of countries that are relatively far away from the curve fitting the data. As in the past, IDI levels in the Republic of Korea (the top-ranked country) are much higher relative to its GNI per capita level. Other cases above the curve featuring a high IDI include Sweden, Iceland, Denmark and Finland. In those countries, factors other than income play an important role in driving ICT developments. These include strong ICTtargeted policies (including widely available broadband infrastructure) and a strong ICT sector. Towards the lower end of the curve, there are more countries that lie far below the curve. These are thus countries where

Chart 2.5: IDI and GNI per capita, 2010

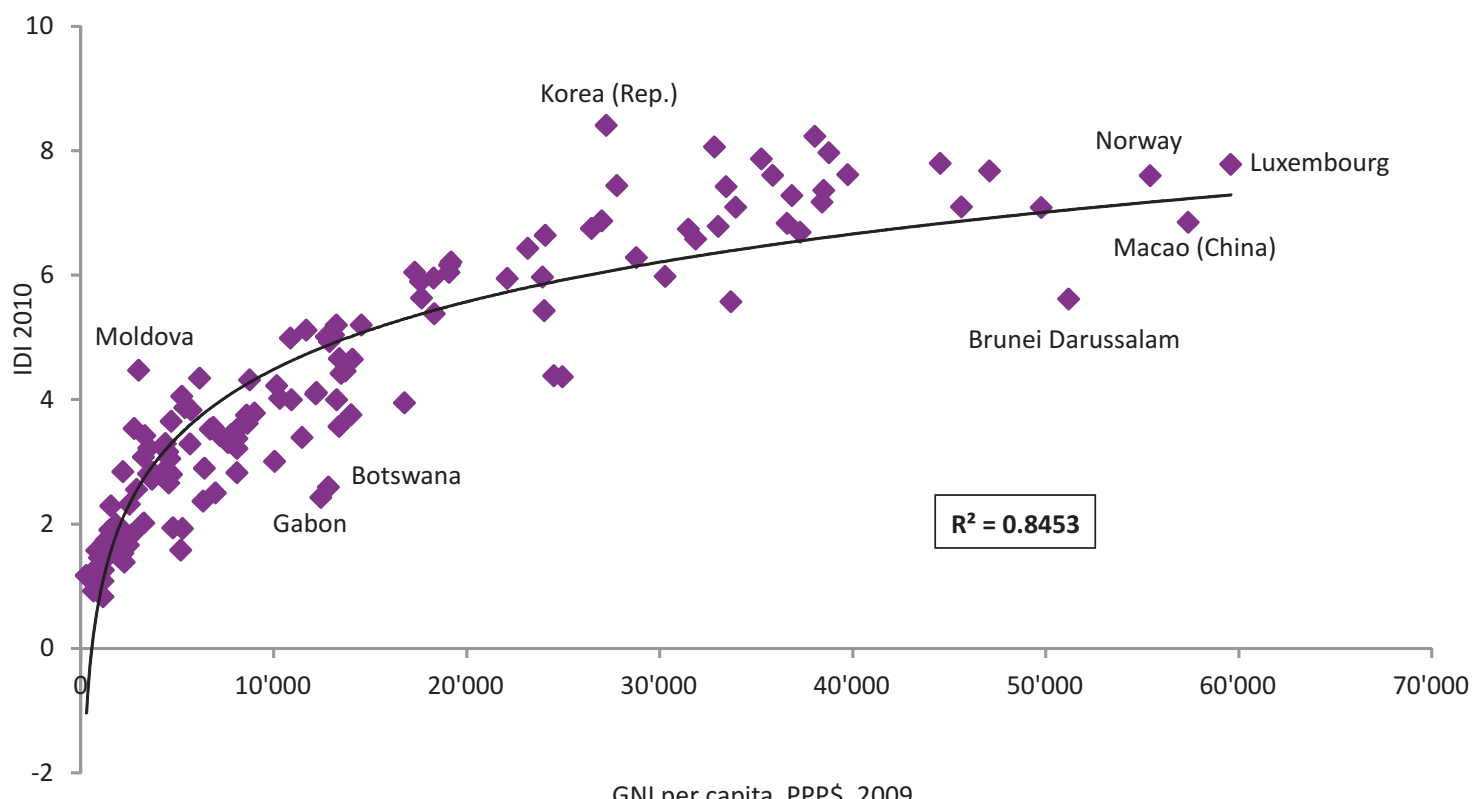

GNI per capita, PPP\$, 2009 
Table 2.4: Country groups based on different IDI levels

\begin{tabular}{|l|c|c|c|c|}
\hline \multirow{2}{*}{ Group } & \multirow{2}{*}{$\begin{array}{c}\text { Number of } \\
\text { countries }\end{array}$} & $\begin{array}{c}\text { Population } \\
\%\end{array}$ & \multicolumn{2}{|c|}{ IDI 2010} \\
\cline { 4 - 6 } & 33 & 15.0 & 6.16 & 8.40 \\
\hline High & 33 & 11.2 & 4.09 & 6.04 \\
\hline Upper & 43 & 37.8 & 2.59 & 4.05 \\
\hline Medium & 43 & 35.9 & 0.83 & 2.55 \\
\hline Low & $\mathbf{1 5 2}$ & $\mathbf{1 0 0 . 0}$ & $\mathbf{0 . 8 3}$ & $\mathbf{8 . 4 0}$ \\
\hline Total & & & & \\
\hline
\end{tabular}

Source: ITU.

ICT development would be expected to be higher given their levels of income. They include Botswana, Brunei Darussalam, Gabon, Oman and Trinidad and Tobago. In those countries, ICT has not been a key driver for development, and a shift in policies could have a significant positive impact on their ICT advancement.

One of the main advantages of producing a composite index such as the IDI is that countries can be grouped according to their levels of ICT advancement. Although the above illustrated the strong correlation between the IDI and national income, the relationship is not perfect and there are a number of countries lying above or below the trend line. The real digital divide between countries should be measured based on their different levels of ICT.

For this purpose, countries have been distributed among four groups based on their IDI levels (high, upper, medium and low). ${ }^{37}$ Table 2.4 shows the distribution of the number of countries across the groups, their share in total population and their IDI ranges. Table 2.6 provides a full list of countries included in each group, and Figure 2.4 shows their geographic distribution. It is noteworthy, that some countries have succeeded in moving (up) from one group to another (Table 2.5). These countries have managed to increase their IDI values more than countries with previously similar IDI values.

The groups are composed as follows:

High (IDI values above 6.16): This group is composed of 33 economies, mainly from OECD member states as well as Croatia, Hong Kong (China), Malta, Ma- cao (China), Singapore and United Arab Emirates. Economies in this group account for 15 per cent of the population covered by the IDI, and have high ICT access, use and skills values. Croatia and the United Arab Emirates advanced from the "upper" group (in 2008) to the "high" group in 2010.

Upper (IDI values between 4.09 and 6.04): This group is composed of 33 economies from Latin America, the Arab region and Eastern Europe. It also includes the Russian Federation and some Caribbean island states. Malaysia is the only South-East Asian country in this group. Countries in this group comprise 11 per cent of the population covered by the IDI, and have achieved an elevated level of ICT access, use and skills. Four countries (Bosnia and Herzegovina, Moldova, Oman and Panama) advanced from the "medium" (2008) to this "upper" group in 2010 by succeeding in improving their ICT levels more than countries with previously similar IDI values.

Medium (IDI values between 2.59 and 4.05): This group is composed of 43 economies from Latin America, the CIS region and the Arab States, accounting for 38 per cent of the population covered by the IDI. The group includes some large Asian countries (including China and Indonesia) and some African countries (Botswana, Cape Verde, Mauritius, Seychelles, South Africa), as well as the Islamic Republic of Iran. Countries in this group have on average achieved reasonable levels of ICT access, but are still relatively low in ICT usage. Botswana and Guatemala improved their IDI values sufficiently to advance from the "low" group in 2008 to the "medium" group in 2010. 
Table 2.5: Advancement of countries between IDI groups (2008-2010)

\begin{tabular}{|l|c|c|}
\hline Country & From IDI 2008 group & To IDI 2010 group \\
\hline Bosnia and Herzegovina & Medium & Upper \\
\hline Botswana & Low & Medium \\
\hline Croatia & Upper & High \\
\hline Guatemala & Low & Medium \\
\hline Moldova & Medium & Upper \\
\hline Oman & Medium & Upper \\
\hline Panama & Medium & Upper \\
\hline United Arab Emirates & Upper & High \\
\hline
\end{tabular}

Source: ITU.

Low (IDI values below 2.55): This group is composed of 43 countries, mainly from Africa and South Asia (including India), including all of the least developed countries (LDCs) covered in the IDI. The group also includes non-LDCs such as Cote d'Ivoire, Ghana, Kenya, Namibia, Nicaragua, Nigeria, Turkmenistan, Uzbekistan and Zimbabwe. Countries included in this group account for 36 per cent of the population covered by the IDI and have on average very low levels of ICT access, use and skills, with some exceptions described earlier in this chapter. They are the countries that need the most attention from policy-makers and ICT investors.

Comparing the economies according to their IDI groups and income groups provides an additional perspective for some countries. The income groups were derived by grouping the economies using the same methodology applied to the IDI groupings, but using the 2009 GNI per capita (PPP\$) values. ${ }^{38}$ The income groups are: low (economies with GNI per capita (PPP\$) of 4570 or less), medium (4 571 to 14 090), upper (14 091 to 31870 ), and high (31 871 or more).
Sixty-six per cent of economies are classified in the same group for both the IDI and income. Fourtytwo economies (28 per cent) were in the IDI group above their income group (see Table 2.6). Some of these countries were mentioned in previous sections (such as the Republic of Korea, New Zealand, Moldova). Moldova, notably, which is classified as a country with low GNI per capita (PPP\$), performed better in the IDI compared with other countries with similar income levels, and is classified in the IDI upper group. For nine countries (six per cent), including Bahrain, Brunei Darussalam, Gabon, Namibia and Turkmenistan, the reverse is true, i.e. they display lower IDI levels than their incomes would predict. In these countries, there are other barriers to ICT adoption and use that policy-makers need to address. These may include skills, awareness of the important benefits that ICTs can bring, improving ICT infrastructure in underserved areas and creating local content (including in local languages where people do not speak the more widely available Internet languages). 


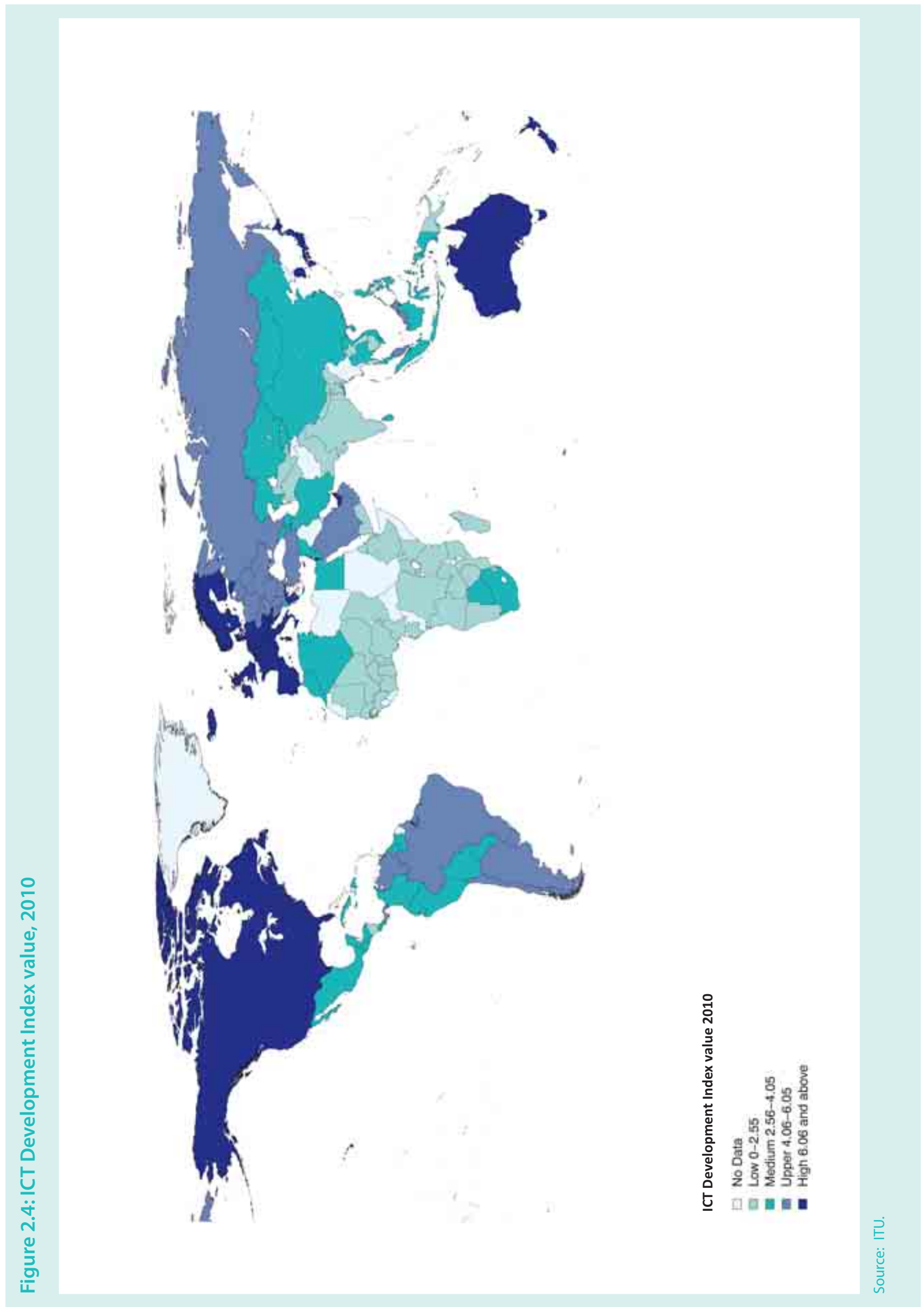


Table 2.6: List of economies by IDI levels and income

\begin{tabular}{|c|c|c|c|c|c|c|c|}
\hline High IDI (6.16-8.40) & Income & Upper IDI (4.09-6.04) & Income & Medium IDI (2.59-4.05) & Income & Low IDI $(0.83-2.55)$ & Income \\
\hline Australia & High & Antigua \& Barbuda & Upper & Albania & Medium & Angola & Medium \\
\hline Austria & High & Argentina & Medium & Algeria & Medium & Bangladesh & Low \\
\hline Belgium & High & Bahrain & High & Armenia & Medium & Benin & Low \\
\hline Canada & High & Barbados & Medium & Azerbaijan & Medium & Bhutan & Medium \\
\hline Croatia & Upper & Belarus & Medium & Bolivia & Low & Burkina Faso & Low \\
\hline Denmark & High & Bosnia and Herzegovina & Medium & Botswana & Medium & Cambodia & Low \\
\hline Estonia & Upper & Brazil & Medium & Cape Verde & Low & Cameroon & Low \\
\hline Finland & High & Brunei Darussalam & High & China & Medium & Chad & Low \\
\hline France & High & Bulgaria & Medium & Colombia & Medium & Comoros & Low \\
\hline Germany & High & Chile & Medium & Costa Rica & Medium & Congo (Dem. Rep.) & Low \\
\hline Greece & Upper & Cyprus & Upper & Cuba & Medium & Côte d'Ivoire & Low \\
\hline Hong Kong, China & High & Czech Republic & Upper & Dominican Rep. & Medium & Djibouti & Low \\
\hline Iceland & High & Hungary & Upper & Ecuador & Medium & Eritrea & Low \\
\hline Ireland & High & Latvia & Upper & Egypt & Medium & Ethiopia & Low \\
\hline Israel & Upper & Lithuania & Upper & El Salvador & Medium & Gabon & Medium \\
\hline Italy & Upper & Malaysia & Medium & Fiji & Low & Gambia & Low \\
\hline Japan & High & Moldova & Low & Georgia & Medium & Ghana & Low \\
\hline Korea (Rep.) & Upper & Montenegro & Medium & Guatemala & Low & Guinea & Low \\
\hline Luxembourg & High & Oman & Upper & Guyana & Low & India & Low \\
\hline Macao, China & High & Panama & Medium & Honduras & Low & Kenya & Low \\
\hline Malta & Upper & Poland & Upper & Indonesia & Low & Lao P.D.R. & Low \\
\hline Netherlands & High & Qatar & High & Iran (I.R.) & Medium & Madagascar & Low \\
\hline New Zealand & Upper & Romania & Upper & Jamaica & Medium & Mali & Low \\
\hline Norway & High & Russia & Upper & Jordan & Medium & Mauritania & Low \\
\hline Portugal & Upper & Saudi Arabia & Upper & Kazakhstan & Medium & Mozambique & Low \\
\hline Singapore & High & Serbia & Medium & Kyrgyzstan & Low & Namibia & Medium \\
\hline Slovenia & Upper & Slovak Republic & Upper & Lebanon & Medium & Nepal & Low \\
\hline Spain & Upper & TFYR Macedonia & Medium & Maldives & Medium & Nicaragua & Low \\
\hline Sweden & High & Trinidad \& Tobago & Upper & Mauritius & Medium & Niger & Low \\
\hline Switzerland & High & Turkey & Medium & Mexico & Medium & Nigeria & Low \\
\hline United Arab Emirates & High & Ukraine & Medium & Mongolia & Low & Pakistan & Low \\
\hline United Kingdom & High & Uruguay & Medium & Morocco & Low & Papua New Guinea & Low \\
\hline United States & High & Venezuela & Medium & Paraguay & Low & Rwanda & Low \\
\hline & & & & Peru & Medium & Senegal & Low \\
\hline & & & & Philippines & Low & Swaziland & Medium \\
\hline & & & & Seychelles & Upper & Tanzania & Low \\
\hline & & & & South Africa & Medium & Togo & Low \\
\hline & & & & Sri Lanka & Medium & Turkmenistan & Medium \\
\hline & & & & Suriname & Medium & Uganda & Low \\
\hline & & & & Syria & Medium & Uzbekistan & Low \\
\hline & & & & Thailand & Medium & Yemen & Low \\
\hline & & & & Tunisia & Medium & Zambia & Low \\
\hline & & & & Viet Nam & Low & Zimbabwe & Low \\
\hline
\end{tabular}

Source: ITU. 


\subsection{IDI breakdown by sub-indices}

As described earlier, the overall ICT Development Index (IDI) is composed of the three sub-indices - covering ICT access, use and skills. Each of these sub-indices includes a certain number of indicators that help evaluate a country's development stage: five indicators to measure access and infrastructure developments, three indicators to gauge uptake and use of ICTs, and finally three indicators to understand the ability of people to make efficient use of ICTs. By looking at each one of the sub-indices separately, it is not only possible to assess a country's development status, but also to identify strengths and weaknesses in any of the three areas, and to adopt policies accordingly.

Among the IDI sub-indices, the greatest change took place in the use sub-index, which recorded a value change of 0.62 between 2008 and 2010, as against a value change of 0.48 in the access sub-index. This reflects the fact that many countries have reached saturation levels in terms of ICT readiness and are moving towards the ICT intensity and usage stage. The skills sub-index value changed by only 0.09 over the same period (see Table 2.1), reflecting the fact that school enrolment and literacy rates only change very gradually over time, particularly in comparison with ICT developments.

\section{Access sub-index}

The five indicators included in the access sub-index are: fixed-telephone subscriptions per 100 inhabitants, mobile-cellular telephone subscriptions per 100 inhabitants, international Internet bandwidth per Internet user, proportion of households with a computer, and proportion of households with Internet access at home. Together, these indicators measure the basic level of access and infrastructure development within a country, a key prerequisite for countries to join the information society. Not surprisingly, the top performers in the access sub-index, including Hong Kong (China), Iceland, Sweden and Denmark, also rank high on the overall IDI (Table 2.7).

Between 2008 and 2010, the greatest changes within the access sub-index have taken place in terms of the international Internet bandwidth per Internet user. Overall, international Internet bandwidth, which is a crucial building block in an increasingly data-intensive and high-speed information society, has increased from $29000 \mathrm{Tbit} / \mathrm{s}$ to $59000 \mathrm{Tbit} / \mathrm{s}$ globally, and op- erators worldwide have sought extra capacity to cater for an increasing number of Internet users. International Internet bandwidth has grown rapidly in all regions of the world, bringing down both wholesale and retail broadband prices. A number of new fibreoptic submarine cables in Africa, in particular, have made the headlines and substantially increased bandwidth capacity in that part of the world. Comoros, for example, was connected to a submarine cable for the first time in 2010, increasing bandwidth tenfold within the space of a few months. Madagascar received extra connectivity in early $2010^{39}$ and has been able to increase international Internet bandwidth from 155 Mbit/s in 2008 to close to $2 \mathrm{Gbit} / \mathrm{s}$ by the end of 2010. Other countries that have invested substantially in international connectivity include Saudi Arabia, Viet Nam and Belarus, where BelTelecom's national broadband development strategy focused on investments in a high-speed broadband network including international connectivity. ${ }^{40}$ All three countries rank in the list of top ten economies recording the greatest 2008-2010 change in the IDI access sub-index, both in terms of value and ranking (Table 2.8). Albania, the Russian Federation and Uruguay (see Box 2.8) also made considerable gains in international Internet bandwidth, which led to important changes in their access sub-index value and ranking.

A number of countries have also made impressive gains in terms of the number of mobile-cellular subscriptions, and by end 2010 a total of 79 countries (52 per cent of all those included in the IDI) have surpassed the 100 per cent penetration mark. A total of 128 countries have passed the 50 per cent mark. While many developed countries have reached saturation levels, in several developing countries, including India, Turkmenistan, Viet Nam and Zimbabwe, the number of mobile-cellular subscriptions more than doubled between 2008 and 2010. All of these countries now have mobile-cellular penetration rates well above 50 per cent, and Viet Nam stands out for having reached a penetration of close to 180 per cent by end 2010 (Box 2.9).

The level of ICT access by households remains very low in many developing countries and penetration rates tend to increase more gradually over time than for some of the other indicators, such as the bandwidth and mobile-cellular indicators. However, a number of countries have made important strides in connecting homes, thus helping them to achieve higher access sub-index levels. In Mongolia, data from the National Statistical Office show that the 
Table 2.7: IDI access sub-index, 2010 and 2008

\begin{tabular}{|c|c|c|c|c|}
\hline Economy & $\begin{array}{l}\text { Rank } \\
2010\end{array}$ & $\begin{array}{c}\text { Access } \\
2010\end{array}$ & $\begin{array}{l}\text { Rank } \\
2008\end{array}$ & $\begin{array}{c}\text { Access } \\
2008\end{array}$ \\
\hline Hong Kong, China & 1 & 9.06 & 1 & 8.77 \\
\hline Iceland & 2 & 8.91 & 4 & 8.36 \\
\hline Luxembourg & 3 & 8.80 & 2 & 8.42 \\
\hline Switzerland & 4 & 8.70 & 6 & 8.28 \\
\hline Sweden & 5 & 8.57 & 3 & 8.41 \\
\hline Germany & 6 & 8.41 & 7 & 8.27 \\
\hline United Kingdom & 7 & 8.36 & 9 & 8.02 \\
\hline Denmark & 8 & 8.33 & 5 & 8.29 \\
\hline Netherlands & 9 & 8.29 & 8 & 8.23 \\
\hline Korea (Rep.) & 10 & 8.21 & 11 & 7.67 \\
\hline Singapore & 11 & 8.14 & 12 & 7.65 \\
\hline Norway & 12 & 7.88 & 10 & 7.71 \\
\hline Macao, China & 13 & 7.88 & 13 & 7.63 \\
\hline France & 14 & 7.75 & 17 & 7.25 \\
\hline Austria & 15 & 7.68 & 15 & 7.34 \\
\hline Malta & 16 & 7.64 & 21 & 7.03 \\
\hline Finland & 17 & 7.61 & 18 & 7.13 \\
\hline Belgium & 18 & 7.54 & 19 & 7.08 \\
\hline New Zealand & 19 & 7.53 & 24 & 6.92 \\
\hline Ireland & 20 & 7.45 & 14 & 7.39 \\
\hline Canada & 21 & 7.43 & 16 & 7.29 \\
\hline Israel & 22 & 7.30 & 23 & 6.93 \\
\hline United States & 23 & 7.24 & 20 & 7.05 \\
\hline Australia & 24 & 7.22 & 25 & 6.89 \\
\hline Slovenia & 25 & 7.21 & 26 & 6.79 \\
\hline Portugal & 26 & 7.14 & 33 & 6.45 \\
\hline Japan & 27 & 7.14 & 22 & 6.98 \\
\hline Qatar & 28 & 7.09 & 37 & 6.03 \\
\hline Croatia & 29 & 7.05 & 31 & 6.51 \\
\hline Spain & 30 & 6.98 & 28 & 6.67 \\
\hline Barbados & 31 & 6.93 & 35 & 6.31 \\
\hline Italy & 32 & 6.93 & 29 & 6.60 \\
\hline Estonia & 33 & 6.91 & 32 & 6.50 \\
\hline Antigua \& Barbuda & 34 & 6.90 & 34 & 6.43 \\
\hline United Arab Emirates & 35 & 6.76 & 27 & 6.78 \\
\hline Bahrain & 36 & 6.73 & 30 & 6.55 \\
\hline Brunei Darussalam & 37 & 6.51 & 40 & 5.91 \\
\hline Poland & 38 & 6.49 & 43 & 5.79 \\
\hline Czech Republic & 39 & 6.48 & 41 & 5.88 \\
\hline Lithuania & 40 & 6.48 & 36 & 6.06 \\
\hline Russia & 41 & 6.38 & 47 & 5.41 \\
\hline Greece & 42 & 6.37 & 39 & 5.94 \\
\hline Saudi Arabia & 43 & 6.37 & 51 & 5.06 \\
\hline Hungary & 44 & 6.34 & 38 & 6.01 \\
\hline Serbia & 45 & 6.32 & 45 & 5.59 \\
\hline Slovak Republic & 46 & 6.16 & 42 & 5.79 \\
\hline Cyprus & 47 & 6.13 & 44 & 5.71 \\
\hline Latvia & 48 & 6.03 & 46 & 5.54 \\
\hline Bulgaria & 49 & 5.77 & 48 & 5.40 \\
\hline Uruguay & 50 & 5.75 & 56 & 4.61 \\
\hline Belarus & 51 & 5.67 & 61 & 4.31 \\
\hline TFYR Macedonia & 52 & 5.57 & 53 & 4.80 \\
\hline Montenegro & 53 & 5.55 & 49 & 5.20 \\
\hline Romania & 54 & 5.50 & 52 & 5.00 \\
\hline Maldives & 55 & 5.45 & 55 & 4.61 \\
\hline Trinidad \& Tobago & 56 & 5.32 & 50 & 5.12 \\
\hline Argentina & 57 & 5.26 & 54 & 4.79 \\
\hline Chile & 58 & 5.17 & 57 & 4.49 \\
\hline Moldova & 59 & 5.17 & 62 & 4.20 \\
\hline Oman & 60 & 5.00 & 60 & 4.31 \\
\hline Turkey & 61 & 4.97 & 58 & 4.44 \\
\hline Ukraine & 62 & 4.79 & 59 & 4.40 \\
\hline Panama & 63 & 4.75 & 70 & 3.85 \\
\hline Seychelles & 64 & 4.71 & 65 & 4.07 \\
\hline Malaysia & 65 & 4.70 & 63 & 4.19 \\
\hline Mauritius & 66 & 4.65 & 66 & 4.02 \\
\hline Brazil & 67 & 4.62 & 64 & 4.08 \\
\hline Kazakhstan & 68 & 4.61 & 68 & 3.90 \\
\hline Costa Rica & 69 & 4.60 & 69 & 3.88 \\
\hline Iran (I.R.) & 70 & 4.60 & 73 & 3.69 \\
\hline Suriname & 71 & 4.54 & 67 & 3.93 \\
\hline Viet Nam & 72 & 4.39 & 88 & 3.11 \\
\hline Bosnia and Herzegovina & 73 & 4.35 & 71 & 3.83 \\
\hline Jordan & 74 & 4.32 & 75 & 3.65 \\
\hline Azerbaijan & 75 & 4.28 & 81 & 3.28 \\
\hline Fiji & 76 & 4.09 & 79 & 3.38 \\
\hline
\end{tabular}

\begin{tabular}{|c|c|c|c|c|}
\hline Economy & $\begin{array}{l}\text { Rank } \\
2010\end{array}$ & $\begin{array}{c}\text { Access } \\
2010\end{array}$ & $\begin{array}{l}\text { Rank } \\
2008\end{array}$ & $\begin{array}{c}\text { Access } \\
2008\end{array}$ \\
\hline Armenia & 77 & 4.07 & 84 & 3.22 \\
\hline Egypt & 78 & 4.07 & 83 & 3.23 \\
\hline Morocco & 79 & 4.05 & 86 & 3.19 \\
\hline Syria & 80 & 3.96 & 77 & 3.54 \\
\hline Mexico & 81 & 3.94 & 78 & 3.50 \\
\hline Albania & 82 & 3.93 & 92 & 3.05 \\
\hline Colombia & 83 & 3.91 & 72 & 3.77 \\
\hline Lebanon & 84 & 3.89 & 89 & 3.08 \\
\hline China & 85 & 3.86 & 76 & 3.61 \\
\hline Venezuela & 86 & 3.83 & 74 & 3.66 \\
\hline Ecuador & 87 & 3.80 & 85 & 3.20 \\
\hline Jamaica & 88 & 3.80 & 80 & 3.29 \\
\hline Thailand & 89 & 3.62 & 82 & 3.27 \\
\hline Peru & 90 & 3.62 & 91 & 3.06 \\
\hline Mongolia & 91 & 3.60 & 99 & 2.84 \\
\hline Tunisia & 92 & 3.60 & 93 & 3.02 \\
\hline Georgia & 93 & 3.56 & 98 & 2.89 \\
\hline El Salvador & 94 & 3.53 & 90 & 3.08 \\
\hline Honduras & 95 & 3.45 & 96 & 2.93 \\
\hline Guatemala & 96 & 3.44 & 87 & 3.16 \\
\hline Algeria & 97 & 3.34 & 103 & 2.57 \\
\hline Gabon & 98 & 3.26 & 104 & 2.54 \\
\hline South Africa & 99 & 3.15 & 94 & 3.00 \\
\hline Sri Lanka & 100 & 3.15 & 102 & 2.66 \\
\hline Philippines & 101 & 3.14 & 100 & 2.77 \\
\hline Indonesia & 102 & 3.13 & 107 & 2.45 \\
\hline Botswana & 103 & 3.12 & 106 & 2.50 \\
\hline Dominican Rep. & 104 & 3.12 & 95 & 2.98 \\
\hline Guyana & 105 & 3.11 & 101 & 2.66 \\
\hline Paraguay & 106 & 3.03 & 97 & 2.92 \\
\hline Bolivia & 107 & 2.84 & 108 & 2.44 \\
\hline Cape Verde & 108 & 2.83 & 105 & 2.51 \\
\hline Turkmenistan & 109 & 2.73 & 120 & 1.89 \\
\hline Namibia & 110 & 2.69 & 109 & 2.26 \\
\hline Nicaragua & 111 & 2.53 & 110 & 2.25 \\
\hline Cambodia & 112 & 2.45 & 116 & 1.94 \\
\hline Pakistan & 113 & 2.40 & 119 & 1.90 \\
\hline Kyrgyzstan & 114 & 2.38 & 112 & 2.07 \\
\hline India & 115 & 2.37 & 122 & 1.85 \\
\hline Côte d'Ivoire & 116 & 2.36 & 115 & 1.97 \\
\hline Gambia & 117 & 2.33 & 114 & 2.04 \\
\hline Mauritania & 118 & 2.30 & 111 & 2.17 \\
\hline Senegal & 119 & 2.28 & 117 & 1.94 \\
\hline Bhutan & 120 & 2.24 & 124 & 1.78 \\
\hline Ghana & 121 & 2.23 & 118 & 1.92 \\
\hline Benin & 122 & 2.22 & 126 & 1.67 \\
\hline Lao P.D.R. & 123 & 2.21 & 123 & 1.81 \\
\hline Kenya & 124 & 2.17 & 130 & 1.58 \\
\hline Swaziland & 125 & 2.11 & 121 & 1.87 \\
\hline Djibouti & 126 & 2.10 & 113 & 2.05 \\
\hline Uzbekistan & 127 & 2.08 & 125 & 1.75 \\
\hline Togo & 128 & 2.00 & 132 & 1.52 \\
\hline Yemen & 129 & 1.93 & 131 & 1.52 \\
\hline Bangladesh & 130 & 1.91 & 135 & 1.45 \\
\hline Madagascar & 131 & 1.89 & 141 & 1.32 \\
\hline Nigeria & 132 & 1.87 & 133 & 1.51 \\
\hline Zimbabwe & 133 & 1.86 & 149 & 1.08 \\
\hline Angola & 134 & 1.86 & 127 & 1.64 \\
\hline Comoros & 135 & 1.85 & 140 & 1.37 \\
\hline Mali & 136 & 1.84 & 128 & 1.62 \\
\hline Papua New Guinea & 137 & 1.78 & 137 & 1.43 \\
\hline Burkina Faso & 138 & 1.76 & 129 & 1.59 \\
\hline Nepal & 139 & 1.75 & 144 & 1.26 \\
\hline Guinea & 140 & 1.67 & 134 & 1.46 \\
\hline Mozambique & 141 & 1.67 & 139 & 1.40 \\
\hline Tanzania & 142 & 1.64 & 148 & 1.11 \\
\hline Cameroon & 143 & 1.64 & 136 & 1.44 \\
\hline Rwanda & 144 & 1.61 & 145 & 1.24 \\
\hline Uganda & 145 & 1.58 & 147 & 1.16 \\
\hline Niger & 146 & 1.55 & 143 & 1.27 \\
\hline Zambia & 147 & 1.54 & 138 & 1.43 \\
\hline Ethiopia & 148 & 1.53 & 146 & 1.23 \\
\hline Cuba & 149 & 1.39 & 142 & 1.28 \\
\hline Congo (Dem. Rep.) & 150 & 1.07 & 152 & 0.80 \\
\hline Chad & 151 & 1.03 & 150 & 1.01 \\
\hline Eritrea & 152 & 0.87 & 151 & 0.82 \\
\hline
\end{tabular}

Source: ITU. 
Table 2.8: Top ten economies with the greatest 2008-2010 change in the IDI access sub-index, by absolute value change (left) and rank change (right)

\begin{tabular}{|c|c|c|c|}
\hline $\begin{array}{l}\text { IDI } \\
\text { rank } \\
2010\end{array}$ & $\begin{array}{l}\text { Access } \\
\text { rank } \\
2010\end{array}$ & Country & $\begin{array}{c}\text { Access value } \\
\text { change } \\
2008-2010\end{array}$ \\
\hline 52 & 51 & Belarus & 1.36 \\
\hline 46 & 43 & Saudi Arabia & 1.32 \\
\hline 81 & 72 & Viet Nam & 1.28 \\
\hline 54 & 50 & Uruguay & 1.14 \\
\hline 44 & 28 & Qatar & 1.06 \\
\hline 74 & 75 & Azerbaijan & 1.01 \\
\hline 47 & 41 & Russia & 0.97 \\
\hline 57 & 59 & Moldova & 0.97 \\
\hline 87 & 70 & Iran (I.R.) & 0.90 \\
\hline 66 & 63 & Panama & 0.90 \\
\hline
\end{tabular}

\begin{tabular}{|c|llc|}
\hline $\begin{array}{c}\text { IDI } \\
\text { rank } \\
\mathbf{2 0 1 0}\end{array}$ & $\begin{array}{c}\text { Access } \\
\text { rank } \\
\mathbf{2 0 1 0}\end{array}$ & Country & $\begin{array}{c}\text { Access rank } \\
\text { change } \\
\text { 2008-2010 }\end{array}$ \\
\hline 81 & 72 & Viet Nam & 16 \\
\hline 124 & 133 & Zimbabwe & 16 \\
\hline 111 & 109 & Turkmenistan & 11 \\
\hline 78 & 82 & Albania & 10 \\
\hline 52 & 51 & Belarus & 10 \\
\hline 141 & 131 & Madagascar & 10 \\
\hline 44 & 28 & Qatar & 9 \\
\hline 86 & 91 & Mongolia & 8 \\
\hline 46 & 43 & Saudi Arabia & 8 \\
\hline 72 & 77 & Armenia & 7 \\
\hline
\end{tabular}

Source: ITU.

\section{Box 2.8: The highest ranked IDI country from South America: Uruguay takes the lead}

Uruguay is the top South American country in the IDI ranking (ranked 54th) in 2010. Uruguay achieved a 0.72 IDI value change from 2008, significantly above the world average value increase of 0.46 and higher than South America's average value increase of 0.39. This progress was attributable to achievements in both the access and use sub-indices. Uruguay's fixed-telephone line penetration rate stands at 29 per cent at end of 2010, and yet the country's mobile-penetration rate has climbed to a staggering 131 per cent (up from 105 per cent two years ago). The mobile market has made great strides, led by Ancel, the mobile arm of state-owned incumbent Administración Nacional de Telecomunicaciones (Antel). As the Uruguayan telecom market grows, newcomers are beginning to enter into Antel's space, and this could exert an influence in respect of tariff adjustments and competition in new areas for next year.

Uruguay has improved its access and use sub-index values by large magnitudes (by 1.14 and 0.53 as compared with the world averages of 0.47 and 0.63 , respectively). Of the countries of the Americas, Uruguay showed the highest access sub-index increase in 2010, thanks to a large increase in its international Internet bandwidth. In a consortium with marine service provider IT Telecom and Alcatel-Lucent, Antel began deployment of the $250 \mathrm{~km}$ submarine cable network last year. This undersea project is part of efforts to provide greater capacity to countries served by Antel and Telcom Argentina. ${ }^{41}$

Internet use in Uruguay has also increased substantially over the last ten years and, in 2010, more than four out of ten people in Uruguay were using the Internet. ${ }^{42}$ This is above the level in developing countries, where at present only 20 per cent of people are online, and also above the world average of 37 per cent. Future advances in technology will hopefully see an even larger Internet usage rate next year. Uruguay improved most on the household computers and Internet access indicators (from 35 to 53 per cent and from 21 to 33 per cent, respectively). Under its fibre-to-thehome (FTTH) roll-out plans, Antel is aiming to deploy connections to around 80000 households by end 2011 and reach 200000 households by end $2012 .^{43}$ It has also upgraded its HSDPA+ technology and is planning for the next future LTE technology. 


\section{Box 2.9: Government support for ICTs pays off in Viet Nam}

Viet Nam moved up ten places to 81st position with an IDI increase from 2.76 in 2008 to 3.53 in 2010. This 28 per cent improvement in IDI value is mainly due to an increase in the IDI use sub-index, with 13 mobile-broadband subscriptions per 100 inhabitants, up from no subscriptions in 2008 (Chart Box 2.9). Viet Nam jumped 16 places in the access sub-index ratings in relation to 2008, with significant gains in mobile penetration and international Internet bandwidth per user. The official launch of $3 \mathrm{G}$ services at the end of 2009 has contributed to more than doubling mobile subscriptions in the last two years, from 87 to 175 per 100 inhabitants. According to telecom operator Vinaphone, the high-speed $3 \mathrm{G}$ availability of services such as mobile Internet games, multimedia, mobile-TV and online newspapers together with product introductions of iPhone and HTC products have all contributed to the country's mobile-broadband success. International Internet bandwidth rates rose from $50064 \mathrm{Mbit} / \mathrm{s}$ to 134420 Mbit/s. Viet Nam is now connected with three international gateways. The third Asia-America Gateway (AAG) opened in November 2009, connecting southern Asia to America by way of an undersea cable system network with an international transmission capacity of $500 \mathrm{Gbit} / \mathrm{s}^{44}$

Government support has boosted the country's positive ICT direction and status. The National Assembly issued a Law on Telecommunications and a Law on Wireless Radio Frequency, which took effect in July 2010. The two laws aim to encourage all economic and private sectors to develop their telecommunication services, investments and infrastructure. ${ }^{45}$

\section{Chart Box 2.9: Active mobile-broadband subscriptions per 100 inhabitants, 2008-2010}

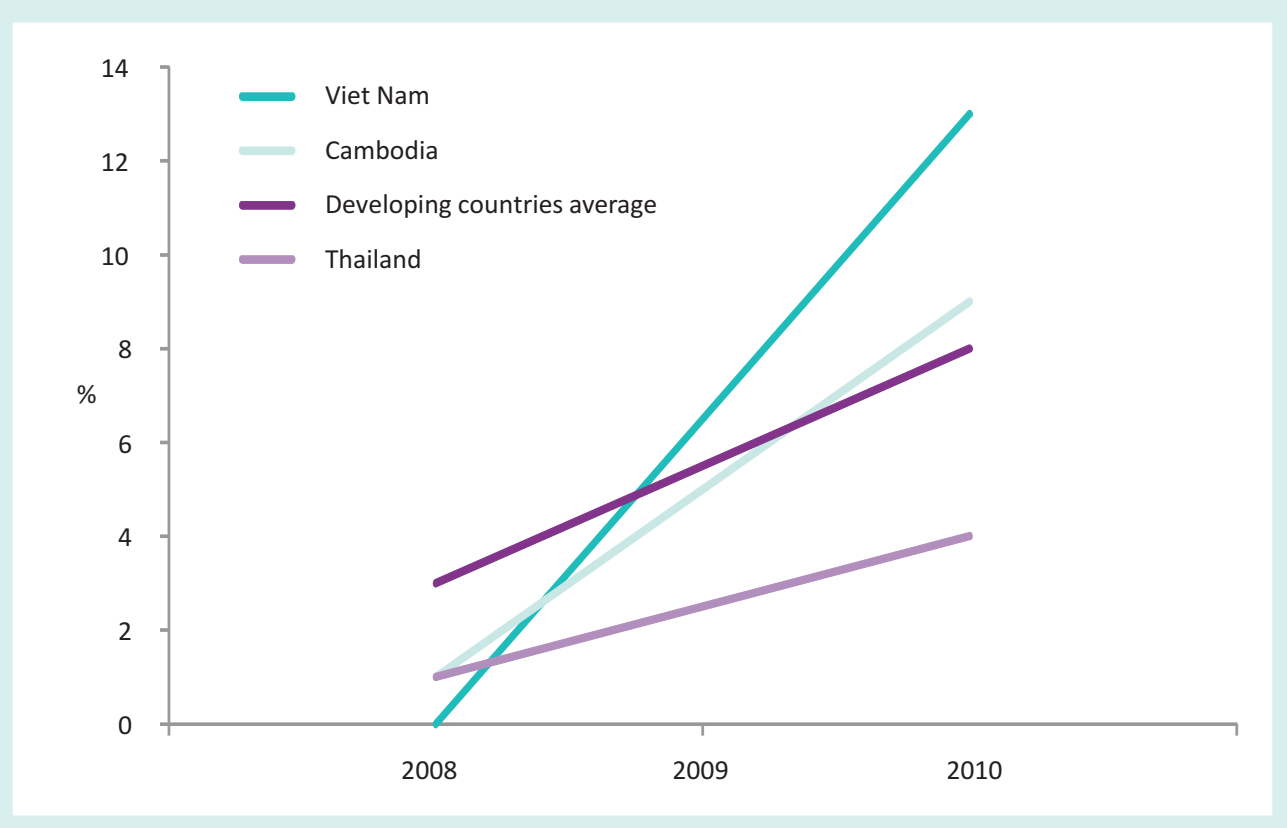

Source: ITU World Telecommunication/ICT Indicators database.

country has increased the proportion of households with Internet access at home from three per cent in 2008 to eight per cent by 2010 . In 2010 , more than 22 per cent of households had a computer, suggesting that there is scope to bring more people online at home. In Armenia, the proportion of households with Internet access has increased substantially over the last few years, mainly due to increased mobilebroadband access and, by the end of 2010, over one-third of homes were connecting to the Internet. At the same time, Armenia showed strong growth in terms of international Internet bandwidth. In Moldova, the number of households with Internet access at home more than doubled between 2008 and 2010 , by when close to 35 per cent of households had an Internet connection. Increasing household ICT access was one of the targets set under the country's National Strategy on Information Society 
Table 2.9: IDI use sub-index, 2010 and 2008

\begin{tabular}{|c|c|c|c|c|}
\hline Economy & $\begin{array}{l}\text { Rank } \\
2010\end{array}$ & $\begin{array}{l}\text { Use } \\
2010\end{array}$ & $\begin{array}{l}\text { Rank } \\
2008\end{array}$ & $\begin{array}{c}\text { Use } \\
2008\end{array}$ \\
\hline Korea (Rep.) & 1 & 7.85 & 1 & 6.92 \\
\hline Sweden & 2 & 7.55 & 4 & 5.92 \\
\hline Luxembourg & 3 & 7.24 & 2 & 6.53 \\
\hline Finland & 4 & 7.11 & 11 & 5.28 \\
\hline Japan & 5 & 7.08 & 3 & 6.27 \\
\hline Denmark & 6 & 6.85 & 5 & 5.76 \\
\hline Norway & 7 & 6.60 & 8 & 5.55 \\
\hline Iceland & 8 & 6.58 & 15 & 4.88 \\
\hline Australia & 9 & 6.57 & 9 & 5.47 \\
\hline Hong Kong, China & 10 & 6.46 & 13 & 5.14 \\
\hline United Kingdom & 11 & 6.44 & 10 & 5.30 \\
\hline Netherlands & 12 & 6.38 & 6 & 5.70 \\
\hline Switzerland & 13 & 6.37 & 12 & 5.28 \\
\hline New Zealand & 14 & 6.35 & 14 & 5.08 \\
\hline Singapore & 15 & 6.03 & 7 & 5.59 \\
\hline Austria & 16 & 5.99 & 19 & 4.45 \\
\hline United States & 17 & 5.89 & 17 & 4.74 \\
\hline France & 18 & 5.74 & 18 & 4.73 \\
\hline Israel & 19 & 5.71 & 20 & 4.44 \\
\hline Germany & 20 & 5.69 & 16 & 4.83 \\
\hline Spain & 21 & 5.35 & 24 & 4.30 \\
\hline Portugal & 22 & 5.19 & 29 & 3.55 \\
\hline Ireland & 23 & 5.17 & 21 & 4.40 \\
\hline Belgium & 24 & 5.16 & 23 & 4.32 \\
\hline United Arab Emirates & 25 & 5.12 & 27 & 3.87 \\
\hline Macao, China & 26 & 5.10 & 42 & 2.94 \\
\hline Italy & 27 & 4.99 & 25 & 4.21 \\
\hline Canada & 28 & 4.87 & 22 & 4.34 \\
\hline Cyprus & 29 & 4.78 & 43 & 2.85 \\
\hline Slovenia & 30 & 4.78 & 26 & 3.97 \\
\hline Malta & 31 & 4.66 & 32 & 3.42 \\
\hline Greece & 32 & 4.52 & 30 & 3.51 \\
\hline Slovak Republic & 33 & 4.44 & 33 & 3.38 \\
\hline Croatia & 34 & 4.33 & 39 & 3.03 \\
\hline Latvia & 35 & 4.26 & 36 & 3.29 \\
\hline Hungary & 36 & 4.26 & 34 & 3.31 \\
\hline Estonia & 37 & 4.09 & 28 & 3.65 \\
\hline Czech Republic & 38 & 4.03 & 31 & 3.47 \\
\hline Brunei Darussalam & 39 & 4.01 & 38 & 3.05 \\
\hline Lithuania & 40 & 3.97 & 41 & 2.95 \\
\hline Poland & 41 & 3.84 & 40 & 2.98 \\
\hline Qatar & 42 & 3.75 & 50 & 1.91 \\
\hline Antigua \& Barbuda & 43 & 3.62 & 35 & 3.30 \\
\hline Saudi Arabia & 44 & 3.59 & 54 & 1.72 \\
\hline Barbados & 45 & 3.48 & 37 & 3.22 \\
\hline Montenegro & 46 & 3.46 & 49 & 1.94 \\
\hline Bahrain & 47 & 3.22 & 44 & 2.75 \\
\hline Romania & 48 & 3.20 & 46 & 2.43 \\
\hline Bulgaria & 49 & 3.17 & 45 & 2.50 \\
\hline Malaysia & 50 & 3.15 & 47 & 2.42 \\
\hline TFYR Macedonia & 51 & 3.11 & 48 & 2.02 \\
\hline Bosnia and Herzegovina & 52 & 2.67 & 61 & 1.43 \\
\hline Russia & 53 & 2.62 & 63 & 1.27 \\
\hline Oman & 54 & 2.55 & 78 & 0.92 \\
\hline Serbia & 55 & 2.47 & 52 & 1.74 \\
\hline Turkey & 56 & 2.46 & 56 & 1.59 \\
\hline Belarus & 57 & 2.41 & 72 & 1.05 \\
\hline Chile & 58 & 2.31 & 51 & 1.79 \\
\hline Uruguay & 59 & 2.26 & 53 & 1.73 \\
\hline Moldova & 60 & 2.26 & 76 & 0.96 \\
\hline Trinidad \& Tobago & 61 & 2.22 & 57 & 1.52 \\
\hline Venezuela & 62 & 2.18 & 62 & 1.41 \\
\hline Argentina & 63 & 2.16 & 60 & 1.44 \\
\hline Brazil & 64 & 2.11 & 58 & 1.49 \\
\hline Morocco & 65 & 2.05 & 64 & 1.27 \\
\hline Panama & 66 & 1.97 & 59 & 1.45 \\
\hline Seychelles & 67 & 1.92 & 55 & 1.60 \\
\hline Mauritius & 68 & 1.91 & 66 & 1.19 \\
\hline Mexico & 69 & 1.86 & 68 & 1.15 \\
\hline Georgia & 70 & 1.81 & 83 & 0.76 \\
\hline Costa Rica & 71 & 1.74 & 65 & 1.21 \\
\hline China & 72 & 1.73 & 70 & 1.10 \\
\hline Colombia & 73 & 1.71 & 71 & 1.07 \\
\hline Albania & 74 & 1.69 & 79 & 0.91 \\
\hline Dominican Rep. & 75 & 1.59 & 81 & 0.84 \\
\hline Viet Nam & 76 & 1.57 & 77 & 0.93 \\
\hline
\end{tabular}

\begin{tabular}{|c|c|c|c|c|}
\hline Economy & $\begin{array}{l}\text { Rank } \\
2010\end{array}$ & $\begin{array}{c}\text { Use } \\
2010\end{array}$ & $\begin{array}{l}\text { Rank } \\
2008\end{array}$ & $\begin{array}{c}\text { Use } \\
2008\end{array}$ \\
\hline Peru & 77 & 1.56 & 67 & 1.17 \\
\hline Armenia & 78 & 1.55 & 122 & 0.22 \\
\hline Azerbaijan & 79 & 1.53 & 90 & 0.61 \\
\hline Jordan & 80 & 1.52 & 80 & 0.90 \\
\hline Tunisia & 81 & 1.52 & 73 & 1.04 \\
\hline Maldives & 82 & 1.51 & 69 & 1.14 \\
\hline Philippines & 83 & 1.49 & 96 & 0.51 \\
\hline Kazakhstan & 84 & 1.44 & 92 & 0.60 \\
\hline Jamaica & 85 & 1.37 & 74 & 1.02 \\
\hline Ukraine & 86 & 1.35 & 91 & 0.61 \\
\hline Lebanon & 87 & 1.29 & 75 & 1.01 \\
\hline Suriname & 88 & 1.22 & 84 & 0.76 \\
\hline Egypt & 89 & 1.20 & 87 & 0.68 \\
\hline Cape Verde & 90 & 1.17 & 85 & 0.75 \\
\hline Ecuador & 91 & 1.16 & 86 & 0.70 \\
\hline Guyana & 92 & 1.08 & 88 & 0.64 \\
\hline Thailand & 93 & 1.05 & 82 & 0.77 \\
\hline Nigeria & 95 & 1.05 & 89 & 0.63 \\
\hline South Africa & 96 & 1.04 & 97 & 0.50 \\
\hline Paraguay & 97 & 0.95 & 93 & 0.56 \\
\hline Kenya & 94 & 1.05 & 113 & 0.29 \\
\hline Mongolia & 98 & 0.86 & 103 & 0.40 \\
\hline El Salvador & 99 & 0.82 & 99 & 0.47 \\
\hline Kyrgyzstan & 100 & 0.82 & 94 & 0.54 \\
\hline Uzbekistan & 101 & 0.81 & 110 & 0.32 \\
\hline Sri Lanka & 102 & 0.77 & 112 & 0.30 \\
\hline Bolivia & 103 & 0.77 & 102 & 0.41 \\
\hline Syria & 104 & 0.75 & 121 & 0.22 \\
\hline Indonesia & 105 & 0.69 & 104 & 0.40 \\
\hline Senegal & 106 & 0.65 & 106 & 0.38 \\
\hline Fiji & 107 & 0.64 & 98 & 0.49 \\
\hline Pakistan & 108 & 0.60 & 95 & 0.53 \\
\hline Guatemala & 109 & 0.57 & 109 & 0.34 \\
\hline Honduras & 110 & 0.56 & 108 & 0.34 \\
\hline Algeria & 111 & 0.56 & 101 & 0.42 \\
\hline Bhutan & 112 & 0.53 & 115 & 0.25 \\
\hline Angola & 113 & 0.53 & 131 & 0.13 \\
\hline Cuba & 114 & 0.51 & 100 & 0.43 \\
\hline Namibia & 115 & 0.49 & 125 & 0.18 \\
\hline Nicaragua & 116 & 0.48 & 120 & 0.23 \\
\hline Iran (I.R.) & 117 & 0.47 & 107 & 0.36 \\
\hline Botswana & 118 & 0.44 & 117 & 0.23 \\
\hline Uganda & 119 & 0.44 & 114 & 0.27 \\
\hline Tanzania & 120 & 0.44 & 111 & 0.31 \\
\hline Zimbabwe & 121 & 0.42 & 105 & 0.39 \\
\hline Yemen & 122 & 0.38 & 116 & 0.24 \\
\hline Cambodia & 123 & 0.35 & 140 & 0.06 \\
\hline India & 124 & 0.33 & 126 & 0.17 \\
\hline Gambia & 125 & 0.32 & 119 & 0.23 \\
\hline Ghana & 126 & 0.32 & 128 & 0.15 \\
\hline Rwanda & 127 & 0.30 & 135 & 0.10 \\
\hline Swaziland & 128 & 0.27 & 118 & 0.23 \\
\hline Djibouti & 129 & 0.27 & 136 & 0.09 \\
\hline Lao P.D.R. & 130 & 0.26 & 132 & 0.12 \\
\hline Gabon & 131 & 0.25 & 123 & 0.22 \\
\hline Nepal & 132 & 0.25 & 141 & 0.06 \\
\hline Zambia & 133 & 0.23 & 124 & 0.19 \\
\hline Mauritania & 134 & 0.21 & 129 & 0.15 \\
\hline Mozambique & 135 & 0.19 & 144 & 0.05 \\
\hline Togo & 136 & 0.18 & 127 & 0.16 \\
\hline Eritrea & 137 & 0.18 & 130 & 0.14 \\
\hline Comoros & 138 & 0.17 & 134 & 0.12 \\
\hline Cameroon & 139 & 0.16 & 133 & 0.12 \\
\hline Bangladesh & 140 & 0.13 & 137 & 0.09 \\
\hline Mali & 141 & 0.13 & 145 & 0.05 \\
\hline Benin & 142 & 0.12 & 139 & 0.06 \\
\hline Côte d'Ivoire & 143 & 0.09 & 138 & 0.07 \\
\hline Madagascar & 144 & 0.09 & 143 & 0.06 \\
\hline Turkmenistan & 145 & 0.07 & 142 & 0.06 \\
\hline Chad & 146 & 0.06 & 147 & 0.04 \\
\hline Burkina Faso & 147 & 0.05 & 148 & 0.03 \\
\hline Papua New Guinea & 148 & 0.05 & 146 & 0.04 \\
\hline Ethiopia & 149 & 0.03 & 151 & 0.02 \\
\hline Guinea & 150 & 0.03 & 149 & 0.03 \\
\hline Niger & 151 & 0.03 & 150 & 0.02 \\
\hline Congo (Dem. Rep.) & 152 & 0.02 & 152 & 0.01 \\
\hline
\end{tabular}

Source: ITU. 
Development (e-Moldova), which was launched in March 2005. ${ }^{46}$

\section{Use sub-index}

The three indicators included in the use sub-index are: Internet users per 100 inhabitants, fixed-broadband Internet subscriptions per 100 inhabitants, and active mobile-broadband subscriptions per 100 inhabitants. These indicators reflect ICT uptake and use, as well as intensity of use. The choice of these indicators highlights the importance attributed to high-speed access to the Internet. All of the top performers in the use sub-index (Table 2.10) rank in the top 15 in the overall IDI, suggesting that ICT use is closely correlated with ICT access and ICT skills and that high ICT usage levels cannot be achieved without the necessary infrastructure or human capacity.

The use sub-index was the IDI component showing the greatest changes between 2008 and 2010, reflecting the developments that have taken place in fixedbroadband but particularly mobile-broadband technologies, services and Internet uptake. The number of mobile-broadband subscriptions worldwide more than doubled between 2008 (when it overtook the number of fixed-broadband subscriptions) and 2010, and by the end of 2010 more than 150 economies had launched $3 \mathrm{G}$ mobile-broadband networks.
An analysis of the most dynamic economies in terms of the change in their use sub-index values and rankings between 2008 and 2010 (see Table 2.10) reveals that the countries that have registered substantial gains in the use sub-index are mostly those that have shown a sizeable increase in terms of mobile-broadband subscriptions. On the other hand, countries that have not yet commercially launched $3 \mathrm{G}$ or have very low mobile-broadband penetration rates - including Algeria, Bolivia, Eritrea, Gabon, the Islamic Republic of Iran, Kyrgyzstan, Togo, Yemen and Zimbabwe have seen their use sub-index ranking fall.

Several economies which had not yet launched $3 \mathrm{G}$ commercially in 2008, such as, for example Iceland and Macao (China), or which had very low penetration levels at that time, including Kenya, Belarus and Moldova, have shown impressive growth in terms of active subscriptions. While Iceland and Macao (China) reached penetration levels of 45 and 56 per cent, respectively, mobile-broadband penetration levels in Kenya, Belarus and Moldova stood at 6,12 and 15 per cent, respectively, by end 2010 .

A group of European countries - Sweden Austria, Cyprus and Portugal - can also be highlighted for their achievements in terms of mobile-broadband penetration in 2010, by when penetration levels stood at between 67 and 84 per cent. At 84 per cent, Sweden has the third-highest mobile-broadband penetration in the

Table 2.10: Top ten economies with the greatest 2008-2010 change in the IDI use sub-index, by absolute value change (left) and rank change (right)

\begin{tabular}{|cclc|}
\hline $\begin{array}{c}\text { IDI } \\
\text { rank } \\
\mathbf{2 0 1 0}\end{array}$ & $\begin{array}{c}\text { Use } \\
\text { rank } \\
\mathbf{2 0 1 0}\end{array}$ & Country & $\begin{array}{c}\text { Use value } \\
\text { change } \\
\text { 2008-2010 }\end{array}$ \\
\hline 21 & 26 & Macao, China & 2.16 \\
\hline 36 & 29 & Cyprus & 1.93 \\
\hline 46 & 44 & Saudi Arabia & 1.87 \\
\hline 44 & 42 & Qatar & 1.84 \\
\hline 5 & 4 & Finland & 1.82 \\
\hline 3 & 8 & Iceland & 1.70 \\
\hline 27 & 22 & Portugal & 1.65 \\
\hline 2 & 2 & Sweden & 1.63 \\
\hline 60 & 54 & Oman & 1.63 \\
\hline 16 & 16 & Austria & 1.54 \\
\hline
\end{tabular}

\begin{tabular}{|cclc|}
$\begin{array}{c}\text { IDI } \\
\text { rank } \\
\mathbf{2 0 1 0}\end{array}$ & $\begin{array}{c}\text { Use } \\
\text { rank } \\
\mathbf{2 0 1 0}\end{array}$ & Country & $\begin{array}{c}\text { Use rank } \\
\text { change } \\
\text { 2008-2010 }\end{array}$ \\
\hline 72 & 78 & Armenia & 44 \\
\hline 60 & 54 & Oman & 24 \\
\hline 115 & 94 & Kenya & 19 \\
\hline 132 & 113 & Angola & 18 \\
\hline 96 & 104 & Syria & 17 \\
\hline 117 & 123 & Cambodia & 17 \\
\hline 21 & 26 & Macao, China & 16 \\
\hline 57 & 60 & Moldova & 16 \\
\hline 52 & 57 & Belarus & 15 \\
\hline 36 & 29 & Cyprus & 14 \\
\hline
\end{tabular}


Table 2.11: IDI skills sub-index, 2010 and 2008

\begin{tabular}{|c|c|c|c|c|}
\hline Economy & $\begin{array}{l}\text { Rank } \\
2010\end{array}$ & $\begin{array}{l}\text { Skills } \\
2010\end{array}$ & $\begin{array}{l}\text { Rank } \\
2008\end{array}$ & $\begin{array}{l}\text { Skills } \\
2008\end{array}$ \\
\hline Finland & 1 & 9.89 & 2 & 9.77 \\
\hline Korea (Rep.) & 2 & 9.89 & 1 & 9.80 \\
\hline Slovenia & 3 & 9.76 & 5 & 9.43 \\
\hline Cuba & 4 & 9.64 & 3 & 9.70 \\
\hline Greece & 5 & 9.59 & 4 & 9.59 \\
\hline Denmark & 6 & 9.47 & 7 & 9.23 \\
\hline Ukraine & 7 & 9.43 & 12 & 9.11 \\
\hline New Zealand & 8 & 9.40 & 6 & 9.24 \\
\hline Lithuania & 9 & 9.32 & 10 & 9.19 \\
\hline Iceland & 10 & 9.30 & 11 & 9.11 \\
\hline Australia & 11 & 9.21 & 9 & 9.19 \\
\hline United States & 12 & 9.21 & 8 & 9.19 \\
\hline Poland & 13 & 9.08 & 15 & 8.94 \\
\hline Hungary & 14 & 9.03 & 23 & 8.72 \\
\hline Italy & 15 & 9.02 & 19 & 8.86 \\
\hline Spain & 16 & 9.01 & 16 & 8.93 \\
\hline Norway & 17 & 9.01 & 13 & 9.06 \\
\hline Latvia & 18 & 8.90 & 18 & 8.89 \\
\hline Sweden & 19 & 8.89 & 14 & 8.99 \\
\hline Belarus & 20 & 8.88 & 17 & 8.92 \\
\hline Russia & 21 & 8.87 & 24 & 8.71 \\
\hline Canada & 22 & 8.85 & 20 & 8.85 \\
\hline Czech Republic & 23 & 8.80 & 34 & 8.40 \\
\hline Estonia & 24 & 8.78 & 21 & 8.75 \\
\hline Belgium & 25 & 8.75 & 22 & 8.72 \\
\hline Netherlands & 26 & 8.71 & 25 & 8.64 \\
\hline Ireland & 27 & 8.66 & 26 & 8.57 \\
\hline Japan & 28 & 8.66 & 27 & 8.56 \\
\hline Uruguay & 29 & 8.62 & 35 & 8.36 \\
\hline Romania & 30 & 8.58 & 31 & 8.48 \\
\hline Slovak Republic & 31 & 8.53 & 40 & 8.15 \\
\hline Venezuela & 32 & 8.52 & 30 & 8.49 \\
\hline Portugal & 33 & 8.52 & 29 & 8.49 \\
\hline Austria & 34 & 8.50 & 32 & 8.45 \\
\hline France & 35 & 8.43 & 33 & 8.44 \\
\hline United Kingdom & 36 & 8.40 & 28 & 8.50 \\
\hline Argentina & 37 & 8.38 & 36 & 8.34 \\
\hline Barbados & 38 & 8.35 & 37 & 8.30 \\
\hline Israel & 39 & 8.32 & 38 & 8.28 \\
\hline Chile & 40 & 8.30 & 42 & 8.12 \\
\hline Croatia & 41 & 8.27 & 43 & 8.07 \\
\hline Macao, China & 42 & 8.27 & 44 & 8.05 \\
\hline Switzerland & 43 & 8.22 & 41 & 8.14 \\
\hline Germany & 44 & 8.17 & 39 & 8.17 \\
\hline Mongolia & 45 & 8.14 & 45 & 8.02 \\
\hline Bulgaria & 46 & 8.09 & 48 & 7.92 \\
\hline Armenia & 47 & 8.08 & 52 & 7.84 \\
\hline Cyprus & 48 & 8.05 & 46 & 7.95 \\
\hline Kazakhstan & 49 & 7.98 & 47 & 7.95 \\
\hline Serbia & 50 & 7.96 & 50 & 7.89 \\
\hline Bahrain & 51 & 7.96 & 62 & 7.22 \\
\hline Hong Kong, China & 52 & 7.92 & 49 & 7.91 \\
\hline Kyrgyzstan & 53 & 7.80 & 51 & 7.87 \\
\hline Brazil & 54 & 7.65 & 55 & 7.48 \\
\hline TFYR Macedonia & 55 & 7.55 & 59 & 7.37 \\
\hline Malta & 56 & 7.53 & 54 & 7.48 \\
\hline Bosnia and Herzegovina & 57 & 7.53 & 58 & 7.38 \\
\hline Georgia & 58 & 7.50 & 56 & 7.46 \\
\hline Moldova & 59 & 7.49 & 53 & 7.53 \\
\hline Colombia & 60 & 7.49 & 61 & 7.30 \\
\hline Jordan & 61 & 7.47 & 60 & 7.36 \\
\hline Lebanon & 62 & 7.47 & 57 & 7.42 \\
\hline Costa Rica & 63 & 7.29 & 70 & 7.06 \\
\hline Peru & 64 & 7.26 & 64 & 7.16 \\
\hline Azerbaijan & 65 & 7.26 & 66 & 7.10 \\
\hline Turkey & 66 & 7.21 & 77 & 6.96 \\
\hline Saudi Arabia & 67 & 7.18 & 67 & 7.09 \\
\hline United Arab Emirates & 68 & 7.18 & 79 & 6.88 \\
\hline Thailand & 69 & 7.18 & 69 & 7.08 \\
\hline Montenegro & 70 & 7.16 & 63 & 7.16 \\
\hline Mexico & 71 & 7.14 & 74 & 6.99 \\
\hline Antigua \& Barbuda & 72 & 7.12 & 65 & 7.12 \\
\hline Singapore & 73 & 7.08 & 68 & 7.08 \\
\hline Panama & 74 & 7.02 & 75 & 6.99 \\
\hline Brunei Darussalam & 75 & 7.01 & 78 & 6.93 \\
\hline Guyana & 76 & 7.00 & 72 & 7.01 \\
\hline
\end{tabular}

\begin{tabular}{|c|c|c|c|c|}
\hline Economy & $\begin{array}{l}\text { Rank } \\
2010\end{array}$ & $\begin{array}{l}\text { Skills } \\
2010\end{array}$ & $\begin{array}{l}\text { Rank } \\
2008\end{array}$ & $\begin{array}{l}\text { Skills } \\
2008\end{array}$ \\
\hline Uzbekistan & 77 & 6.96 & 76 & 6.97 \\
\hline Tunisia & 78 & 6.94 & 84 & 6.76 \\
\hline Ecuador & 79 & 6.92 & 93 & 6.53 \\
\hline Bolivia & 80 & 6.91 & 73 & 7.00 \\
\hline Turkmenistan & 81 & 6.87 & 81 & 6.85 \\
\hline Mauritius & 82 & 6.85 & 86 & 6.71 \\
\hline Philippines & 83 & 6.83 & 80 & 6.88 \\
\hline Albania & 84 & 6.83 & 71 & 7.04 \\
\hline $\operatorname{Iran}(I . R)$. & 85 & 6.81 & 87 & 6.69 \\
\hline Oman & 86 & 6.81 & 83 & 6.79 \\
\hline Luxembourg & 87 & 6.79 & 82 & 6.80 \\
\hline Trinidad \& Tobago & 88 & 6.75 & 88 & 6.67 \\
\hline Jamaica & 89 & 6.74 & 85 & 6.72 \\
\hline Dominican Rep. & 90 & 6.63 & 91 & 6.57 \\
\hline South Africa & 91 & 6.61 & 92 & 6.57 \\
\hline Malaysia & 92 & 6.57 & 90 & 6.58 \\
\hline China & 93 & 6.55 & 95 & 6.42 \\
\hline Indonesia & 94 & 6.50 & 98 & 6.25 \\
\hline Seychelles & 95 & 6.45 & 94 & 6.45 \\
\hline Paraguay & 96 & 6.39 & 97 & 6.32 \\
\hline Maldives & 97 & 6.34 & 99 & 6.20 \\
\hline Qatar & 98 & 6.33 & 89 & 6.60 \\
\hline Fiji & 99 & 6.33 & 96 & 6.37 \\
\hline Algeria & 100 & 6.32 & 102 & 6.06 \\
\hline Sri Lanka & 101 & 6.12 & 100 & 6.11 \\
\hline Suriname & 102 & 6.08 & 101 & 6.07 \\
\hline Cape Verde & 103 & 6.03 & 103 & 5.98 \\
\hline Egypt & 104 & 5.88 & 104 & 5.83 \\
\hline Botswana & 105 & 5.83 & 106 & 5.79 \\
\hline Syria & 106 & 5.82 & 105 & 5.79 \\
\hline El Salvador & 107 & 5.74 & 107 & 5.73 \\
\hline Viet Nam & 108 & 5.72 & 108 & 5.72 \\
\hline Honduras & 109 & 5.58 & 109 & 5.55 \\
\hline Nicaragua & 110 & 5.54 & 110 & 5.51 \\
\hline Namibia & 111 & 5.46 & 111 & 5.44 \\
\hline Guatemala & 112 & 5.24 & 114 & 4.95 \\
\hline Gabon & 113 & 5.08 & 112 & 4.99 \\
\hline Kenya & 114 & 5.01 & 113 & 4.96 \\
\hline Swaziland & 115 & 4.90 & 115 & 4.81 \\
\hline India & 116 & 4.66 & 116 & 4.54 \\
\hline Lao P.D.R. & 117 & 4.56 & 118 & 4.33 \\
\hline Zimbabwe & 118 & 4.50 & 117 & 4.50 \\
\hline Ghana & 119 & 4.41 & 119 & 4.26 \\
\hline Cambodia & 120 & 4.34 & 121 & 4.16 \\
\hline Comoros & 121 & 4.31 & 120 & 4.23 \\
\hline Morocco & 122 & 4.24 & 122 & 4.11 \\
\hline Bhutan & 123 & 4.08 & 126 & 3.85 \\
\hline Cameroon & 124 & 4.03 & 125 & 3.86 \\
\hline Yemen & 125 & 3.97 & 124 & 3.95 \\
\hline Zambia & 126 & 3.96 & 123 & 3.97 \\
\hline Nepal & 127 & 3.78 & 127 & 3.77 \\
\hline Congo (Dem. Rep.) & 128 & 3.65 & 128 & 3.55 \\
\hline Djibouti & 129 & 3.56 & 130 & 3.50 \\
\hline Bangladesh & 130 & 3.52 & 129 & 3.50 \\
\hline Togo & 131 & 3.48 & 131 & 3.44 \\
\hline Uganda & 132 & 3.42 & 134 & 3.34 \\
\hline Rwanda & 133 & 3.40 & 139 & 3.22 \\
\hline Tanzania & 134 & 3.40 & 135 & 3.32 \\
\hline Nigeria & 135 & 3.39 & 132 & 3.43 \\
\hline Gambia & 136 & 3.38 & 133 & 3.39 \\
\hline Eritrea & 137 & 3.34 & 138 & 3.25 \\
\hline Madagascar & 138 & 3.32 & 137 & 3.26 \\
\hline Papua New Guinea & 139 & 3.27 & 136 & 3.27 \\
\hline Pakistan & 140 & 3.16 & 140 & 3.12 \\
\hline Guinea & 141 & 3.14 & 145 & 2.81 \\
\hline Côte d'Ivoire & 142 & 3.13 & 141 & 3.05 \\
\hline Angola & 143 & 3.12 & 142 & 2.99 \\
\hline Senegal & 144 & 3.02 & 146 & 2.66 \\
\hline Benin & 145 & 3.00 & 143 & 2.90 \\
\hline Mauritania & 146 & 2.87 & 144 & 2.85 \\
\hline Mozambique & 147 & 2.77 & 147 & 2.61 \\
\hline Mali & 148 & 2.35 & 149 & 2.21 \\
\hline Ethiopia & 149 & 2.29 & 148 & 2.23 \\
\hline Chad & 150 & 1.99 & 150 & 1.91 \\
\hline Burkina Faso & 151 & 1.78 & 151 & 1.67 \\
\hline Niger & 152 & 1.44 & 152 & 1.36 \\
\hline
\end{tabular}

Source: ITU. 
world, just behind the Republic of Korea and Japan, which launched 3G services as far back as 2001-2002.

3G mobile-broadband networks and services have also made an important impact in a number of developing countries, including Angola, Armenia, Belarus, Cambodia, Ecuador, Kenya, Paraguay, Peru and Saudi Arabia, all of which have substantially increased mobile-broadband penetration rates over the 2008-2010 time period.

While fixed-broadband penetration rates remain very low in many developing countries, some economies have made good progress between 2008 and 2010. These include Armenia and Belarus, where fixedbroadband penetration rates increased from 0.2 and 5 per cent to 3 and 17 per cent, respectively. Both countries, which were also highlighted earlier for their achievements in terms of international Internet bandwidth growth, have seen a rapid rise in the number of Internet users over the same time period. Moldova has also managed to improve its use sub-index rank by no less than 16 places by not only making considerable progress in mobile broadband but also more than doubling the number of fixed-broadband subscriptions. These improvements are reflected in a large increase in the number of Internet users, and by end 2010 two out of five people in Moldova were online.

A number of developing countries highlight the impact that mobile-broadband services can have in bringing more people online. Morocco and Oman, for example, have substantially increased Internet user penetration - from 33 to 49 per cent in Morocco and from 20 to over 60 per cent in Oman - partly through the success of mobile broadband. While Oman more than doubled mobile-broadband subscriptions between 2008 and 2010, Morocco's even tripled. In Kenya, the number of fixed-broadband subscriptions grew only slightly between 2008 and 2010 (and actually decreased from 2009 to 2010), but mobile broadband grew at a very high rate, allowing many more Kenyans to go online. According to the country's regulatory authority, more than 25 per cent of the population in Kenya use the Internet, almost three times as many as in 2008.

Some of the countries that have effectively shown important value or ranking changes between 2008 and 2010 continue to lag behind in terms of their ICT use levels. In Cambodia, for example, despite an increase in the access sub-index above the world's average gain between 2008 and 2010, fixed-broadband penetration levels remain negligible and only just over one per cent of the population use the Internet.

\section{Skills sub-index}

The three indicators included in the skills sub-index are: adult literacy rate, gross secondary school enrolment, and gross tertiary school enrolment. These indicators are proxy indicators used to gauge a country's level of human capacity and its ability to absorb and take advantage of ICTs. More targeted indicators would be ones that measured countries' ICT literacy, but these are not (yet) available. For this reason, the skills sub-index is given less weight in the calculation of the overall IDI ( 20 per cent compared with 40 per cent for the other two sub-indices).

Changes in the skills sub-index are relatively small, particularly in comparison with the other two sub-indices, reflecting the fact that educational levels evolve only very gradually over time. A country's position in terms of the skills sub-index (Table 2.11) can nonetheless provide useful policy guidance, since the ability to use ICTs efficiently and effectively is crucial for countries to become globally competitive information societies. In particular, the importance and effect of human capital for the overall impact that ICTs have on social and economic development have been highlighted, and the World Summit on the Information Society (WSIS) recognized the need for countries to take active steps in investing in people and their skills. Two of the ten WSIS targets refer to connecting educational institutions and expanding ICT skills, and Action Line C4 is devoted to capacity building. ${ }^{47}$

\subsection{Regional IDI analysis}

A regional analysis of the IDI, ${ }^{48}$ shows that the countries with the highest IDI rankings are from Europe and Asia. Apart from the United States (which ranks 17 th on the IDI), all of the top 25 IDI economies are either European or from Asia-Pacific. This is illustrated in Table 2.12, which shows the top five countries within each region, as well as their position in the global ranking. The highest ranked countries from the Arab States and the CIS are the United Arab Emirates and the Russian Federation, ranked 32nd and 47th, respectively. Africa lags behind, with Mauritius being the highest ranked country in the region, but occupying only 69 th place globally. 
Table 2.12: The top five in each region and their ranking in the global IDI

\begin{tabular}{|c|c|c|c|c|c|c|c|c|c|c|c|c|}
\hline $\begin{array}{l}\text { Regional } \\
\text { IDI rank }\end{array}$ & Europe & $\begin{array}{c}\text { Global } \\
\text { IDI } \\
\text { rank }\end{array}$ & $\begin{array}{l}\text { Asia \& } \\
\text { Pacific }\end{array}$ & $\begin{array}{c}\text { Global } \\
\text { IDI } \\
\text { rank }\end{array}$ & Americas & $\begin{array}{c}\text { Global } \\
\text { IDI } \\
\text { rank }\end{array}$ & Arab States & $\begin{array}{c}\text { Global } \\
\text { IDI } \\
\text { rank }\end{array}$ & CIS & $\begin{array}{c}\text { Global } \\
\text { IDI } \\
\text { rank }\end{array}$ & Africa & $\begin{array}{c}\text { Global } \\
\text { IDI } \\
\text { rank }\end{array}$ \\
\hline 1 & Sweden & 2 & Korea (Rep.) & 1 & United States & 17 & UAE & 32 & Russia & 47 & Mauritius & 69 \\
\hline 2 & Iceland & 3 & HK, China & 6 & Canada & 26 & Qatar & 44 & Belarus & 52 & Seychelles & 71 \\
\hline 3 & Denmark & 4 & New Zealand & 12 & Barbados & 41 & Bahrain & 45 & Moldova & 57 & South Africa & 97 \\
\hline 4 & Finland & 5 & Japan & 13 & Uruguay & 54 & Saudi Arabia & 46 & Ukraine & 62 & Cape Verde & 104 \\
\hline 5 & Luxembourg & 7 & Australia & 14 & Chile & 55 & Oman & 60 & Kazakhstan & 68 & Botswana & 109 \\
\hline
\end{tabular}

Source: ITU.

To highlight differences in ICT levels within each region, it is also interesting to look at the difference in the global rankings separating the top five countries of the region. Again, Europe and Asia-Pacific stand out because there is relatively little difference between the global rankings of their top five. In both the Arab States and the CIS, some 20 places separate the top-ranked and fifth-ranked countries. A much larger gap (of 38 places) is visible in the Americas, where the regional top five range from a global rank of 17 (United States) to 55 (Chile). Africa, where 40 places separate Mauritius from Botswana, is the region with the greatest global ranking difference between the top five countries.

A comparison of regional ranges that includes all IDI countries (see Table 2.13) highlights that by far the largest regional IDI value ranges in both 2008 and 2010 - calculated by deducting the lowest value from the highest value - are found in Asia and the Pacific. The Americas has the second highest 2010 range in countries' IDI values, followed by Europe and the Arab States, which share the same range figure. Africa and the CIS have relatively smaller range values. While these findings do not refer to the level of ICT development of the regions, they point to the variations in ICT development within each region, which are often linked to differences in income levels, but can also be the result of national policies and other factors (such as skills or geographic and population characteristics).

It is also interesting to analyse the change in ranges over time, since these help to understand whether countries within the regions are developing in the same direction, and at similar speeds (see Table 2.13). A 2008 and 2010 comparison of range differences shows that ranges increased somewhat in all regions, suggesting that regional differences are increasing. However, in Europe, for example, the difference is negligible, suggesting that European countries are moving at similar speeds, which is certainly also the result of a common set of policies and directives set by the European Union, for example through the Digital Agenda. ${ }^{49}$ The largest increase in IDI ranges between 2008 and 2010 can be observed in the CIS, followed by Africa, where countries with relatively lower ICT levels are not catching up as fast as their counterparts in other regions.

There is a strong link between regional ICT developments, on the one hand, and income levels - as measured by GNI per capita - on the other, as shown in Chart 2.6, which plots IDI and GNI per capita values against each other. The CIS is the region with the lowest R-squared value - indicating a relatively weaker linkage between income levels and ICT development. This is mainly because the region only includes a total of 11 countries and because it has two main outliers: Moldova and Turkmenistan. While Moldova is doing relatively better in terms of ICT development than its income level would suggest, Turkmenistan lies well below the trend line, suggesting that, given its income level, it should have a much higher IDI value. The distribution of countries is relatively homogeneous along the trend line for Africa (except for Mauritius and Seychelles) and for Europe. The Americas, the Arab States and Asia and the Pacific show a different pattern, with a cluster of relatively low-income countries at one end and some few(er) high-income economies at the other end. In the Arab States region, the United Arab Emirates, Bahrain and Saudi Arabia stand out for their high income and ICT development levels, while in the Americas region the United States and Canada are well 


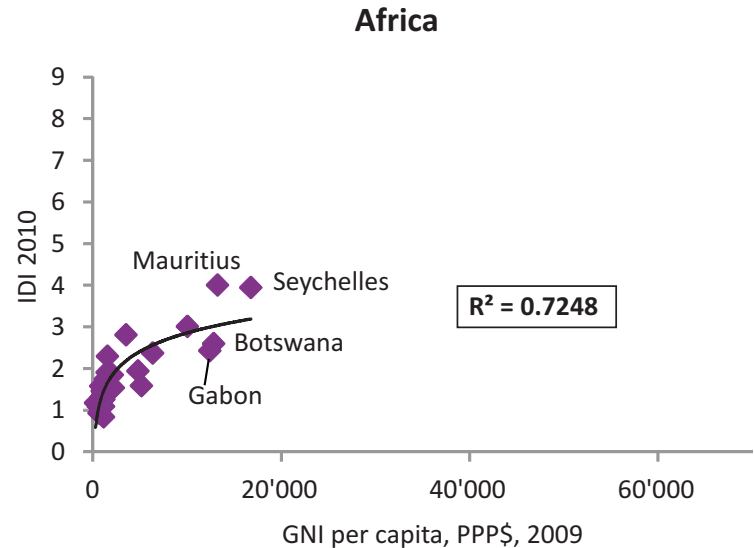

Asia \& Pacific

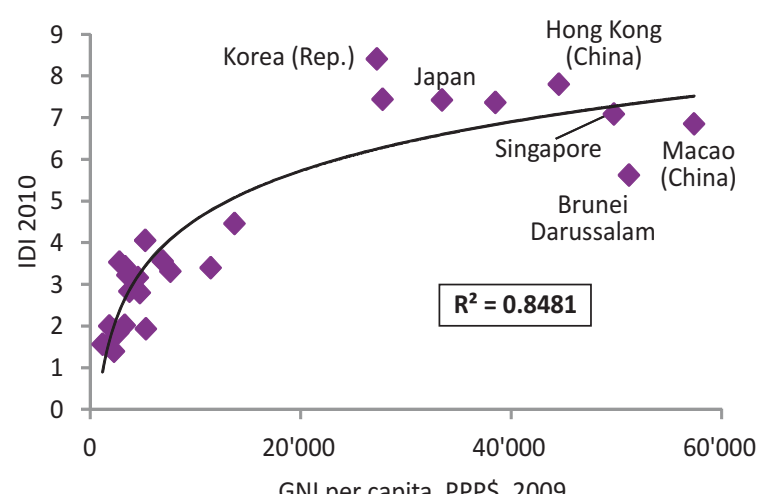

GNI per capita, PPP\$, 2009

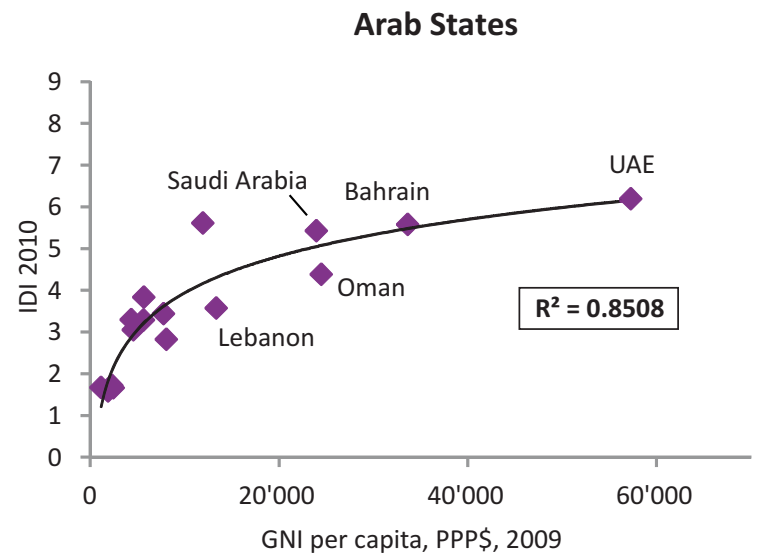

CIS

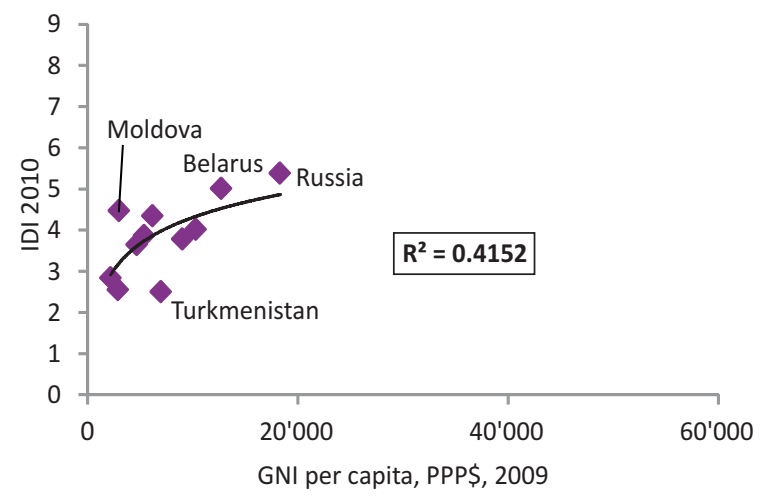

The Americas

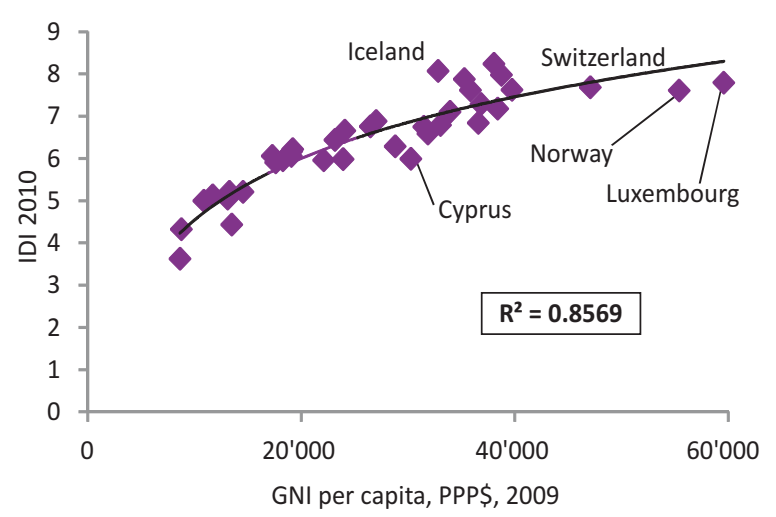

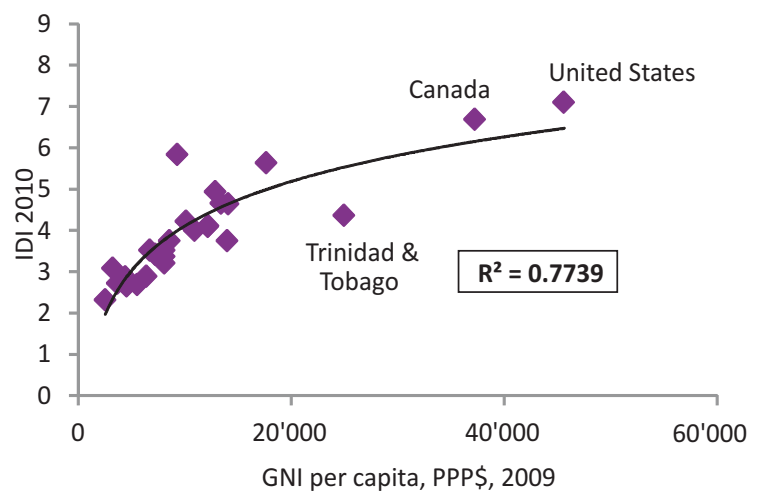

Note: The R-squared value of a logarithmic regression provides a measure of how well the trendline approximates the real data points. It varies from 0 to 1, the latter being the value obtained by a perfect fit of the data points. In the case of a regression between IDI and GNI per capita, the higher the R-squared value, the stronger the link between IDI and GNI per capita, as expressed by a logarithmic curve. Source: Regions in these charts are based on the ITU/BDT Regions, see: http://www.itu.int/ITU-D/ict/definitions/regions/index.html. 
Table 2.13: IDI ranges, 2010 and 2008

\begin{tabular}{|l|c|c|c|c|c|c|c|}
\hline & \multicolumn{3}{|c|}{$\mathbf{2 0 1 0}$} & \multicolumn{2}{c|}{$\mathbf{2 0 0 8}$} & $\begin{array}{c}\text { Difference range } \\
\text { 2008-2010 }\end{array}$ \\
\cline { 2 - 9 } & Max. & Min. & Range & Max. & Min. & Range & 0.46 \\
\hline Asia \& Pacific & 8.40 & 1.38 & 7.02 & 7.80 & 1.24 & 6.56 & 0.32 \\
\hline The Americas & 7.09 & 2.31 & 4.78 & 6.55 & 2.09 & 4.46 & 0.07 \\
\hline Europe & 8.23 & 3.61 & 4.61 & 7.53 & 2.99 & 4.54 & 0.47 \\
\hline Arab States & 6.19 & 1.58 & 4.61 & 5.63 & 1.50 & 4.14 & 0.54 \\
\hline Africa & 4.00 & 0.83 & 3.16 & 3.43 & 0.80 & 2.62 & 0.61 \\
\hline CIS & 5.38 & 2.50 & 2.88 & 4.42 & 2.15 & 2.27 & \\
\hline
\end{tabular}

Source: ITU.

ahead in terms of both their IDI and GNI per capita values. In Asia and the Pacific, a number of economies, including Hong Kong (China) and Singapore, display both high income and high IDI levels, but a few other economies, including the Republic of Korea, Japan, New Zealand and Australia, have higher IDI levels than their income level would predict.

Chart 2.7 plots on a single chart the relation between IDI and GNI per capita in each region. The CIS and Africa have the weakest relation between the two vari- ables, being especially weak in Africa. This is seen in the chart where the curves of both regions are below the rest. For instance, a country with GNI per capita of PPP\$ 10000 in Africa will tend to have a lower IDI than a country with the same income from any other region. To a lesser extent, this also applies to CIS countries. This finding highlights the importance of effective ICT policies and efficient investment, which may make the difference in terms of achieving increased ICT development with the same (or similar) economic resources.

Chart 2.7: IDI and GNI per capita, by region

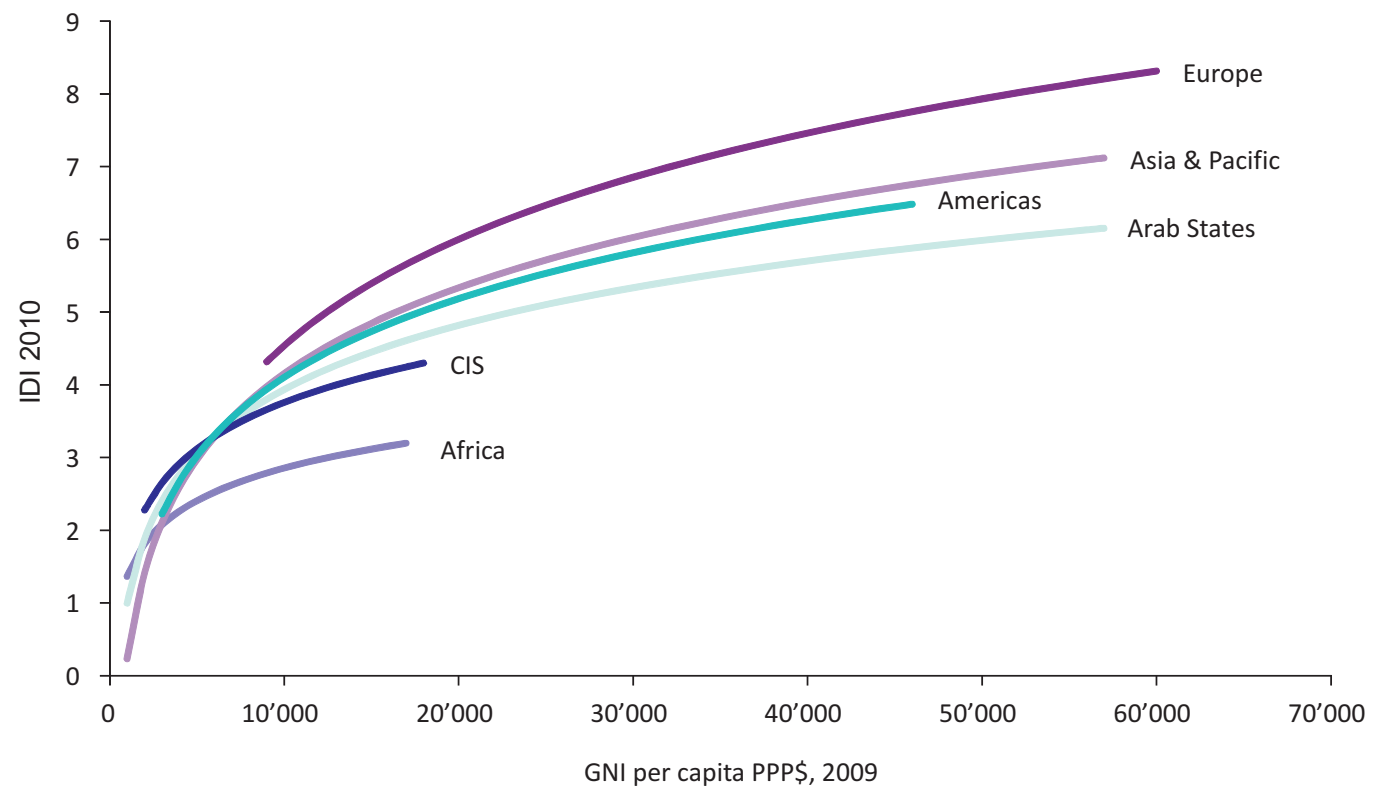

Source: ITU. 
The countries with high income and high IDI appear at the other end of the chart. Of all regions which are home to countries with high GNI per capita, the Arab States has the weakest relation between income and IDI. Indeed, the Arab States' curve lies below those for the Americas, Asia and the Pacific and Europe. This means that, for instance, a country with a GNI per capita of PPP\$ 40000 in the Arab States will tend to have a lower IDI than a country with the same income in the Americas, Asia and the Pacific or Europe. This suggests that, given their economic resources, the Arab States possess a high potential for further ICT development, at least to reach the ICT performance of countries with similar incomes in other regions. To achieve this objective, effective ICT policies will play a crucial role.

\section{Africa}

In 2010, Africa remains the region with the lowest IDI values, with countries ranking between 69th (Mauritius), and 152nd (Chad) in the overall IDI (see Table 2.14). Mauritius, the Seychelles and South Africa have the highest IDI values in the region, of between 3 and 4 (as compared with a maximum of 8.4 achieved by the Republic of Korea). These are also the only three African countries that rank within the top 100 in the 2010 IDI.

At the same time, IDI values for all African countries increased between 2008 and 2010. Mauritius and Kenya recorded the highest value increase over this period, and Angola, Senegal and Zimbabwe managed to move four places up the IDI rankings. Zambia, which has not yet launched $3 \mathrm{G}$ commercially, and which continues to have a relatively low mobilecellular penetration rate (below 38 per cent at end 2010), fell eight places in the overall IDI rankings in relation to 2008 .

As highlighted in section 2.3 (as well as in Chapter 4), Africa has made great progress in international Internet connectivity over the 2008-2010 time period. Many African countries have doubled or tripled their international bandwidth capacity; some have witnessed a tenfold increase. If accompanied by effective policy measures that ensure competitive access to the newly available bandwidth, this increase may have a positive impact on broadband affordability - one of the major issues in the region.

Additionally, a number of African countries, including Rwanda, Senegal, Tanzania and Zimbabwe, have increased their mobile penetration rate by over 30 per cent. While all countries saw an increase in the number of households with a computer and with Internet access at home, penetration rates remain very low. Except for Angola, Gabon, Mauritius, Nigeria, Seychelles and South Africa, all countries have less than five per cent of their households connected to the Internet.

Value changes in the different sub-indices show that Africa continues to make more progress in the access sub-index than in the use sub-index, suggesting that the region is still at an early stage of ICT development, with infrastructure developments the key drivers of ICT growth. Most African countries still have very low fixed-broadband penetration rates, and only four countries (Cape Verde, Mauritius, Seychelles and South Africa) have a broadband penetration rate of above one per cent. Fixed-broadband growth is hampered by a very limited number of fixed-telephone lines and by the absence of cable networks. Unless these issues are addressed, the region's broadband development will largely depend on its ability to leverage the potential of mobile-broadband technologies and services and therefore on the policy decisions taken on some key issues such as spectrum, planning, licensing and investment promotion.

Some African countries displayed relatively strong growth in the use sub-index. Progress in Mauritius and South Africa was driven by strong increases in the number of active mobile-broadband subscriptions, and both countries have achieved mobile-broadband penetration rates of above 15 per cent. Angola and Nigeria were able to improve in the area of ICT use through a significant rise in the number of Internet users.

\section{Arab States}

The differences in income levels of the countries of the Arab States are reflected in differences in IDI values and rankings. The high-income economies of the Gulf Cooperation Council (GCC), including the United Arab Emirates, Bahrain, Qatar and Saudi Arabia which all figure in the top 50 of the global IDI, have achieved relatively high ICT levels and rank at the top of the regional IDI (see Table 2.15).

It is noteworthy that while fixed (wired) infrastructure and access remain relatively limited in the region, many countries have taken advantage of mobile technology and leveraged mobile-broadband services to bring more 
Table 2.14: IDI - Africa

\begin{tabular}{|c|c|c|c|c|c|c|}
\hline Economy & $\begin{array}{c}\text { Regional rank } \\
2010\end{array}$ & $\begin{array}{l}\text { Global rank } \\
2010\end{array}$ & IDI 2010 & $\begin{array}{c}\text { Global rank } \\
2008\end{array}$ & IDI 2008 & $\begin{array}{c}\text { Global rank } \\
\text { change } \\
2008-2010\end{array}$ \\
\hline Mauritius & 1 & 69 & 4.00 & 70 & 3.43 & 1 \\
\hline Seychelles & 2 & 71 & 3.94 & 65 & 3.56 & -6 \\
\hline South Africa & 3 & 97 & 3.00 & 94 & 2.71 & -3 \\
\hline Cape Verde & 4 & 104 & 2.81 & 103 & 2.50 & -1 \\
\hline Botswana & 5 & 109 & 2.59 & 109 & 2.25 & 0 \\
\hline Gabon & 6 & 112 & 2.42 & 112 & 2.10 & 0 \\
\hline Namibia & 7 & 113 & 2.36 & 114 & 2.06 & 1 \\
\hline Kenya & 8 & 115 & 2.29 & 116 & 1.74 & 1 \\
\hline Swaziland & 9 & 118 & 1.93 & 115 & 1.80 & -3 \\
\hline Ghana & 10 & 120 & 1.90 & 118 & 1.68 & -2 \\
\hline Nigeria & 11 & 122 & 1.85 & 125 & 1.54 & 3 \\
\hline Zimbabwe & 12 & 124 & 1.81 & 128 & 1.49 & 4 \\
\hline Senegal & 13 & 125 & 1.78 & 129 & 1.46 & 4 \\
\hline Gambia & 14 & 126 & 1.74 & 122 & 1.59 & -4 \\
\hline Côte d'Ivoire & 15 & 130 & 1.61 & 132 & 1.43 & 2 \\
\hline Angola & 16 & 132 & 1.58 & 136 & 1.31 & 4 \\
\hline Togo & 17 & 133 & 1.57 & 134 & 1.36 & 1 \\
\hline Benin & 18 & 135 & 1.54 & 138 & 1.27 & 3 \\
\hline Cameroon & 19 & 136 & 1.53 & 133 & 1.40 & -3 \\
\hline Tanzania & 20 & 138 & 1.51 & 141 & 1.23 & 3 \\
\hline Zambia & 21 & 139 & 1.50 & 131 & 1.44 & -8 \\
\hline Uganda & 22 & 140 & 1.49 & 140 & 1.24 & 0 \\
\hline Madagascar & 23 & 141 & 1.45 & 142 & 1.20 & 1 \\
\hline Rwanda & 24 & 142 & 1.44 & 143 & 1.18 & 1 \\
\hline Guinea & 25 & 144 & 1.31 & 144 & 1.16 & 0 \\
\hline Mozambique & 26 & 145 & 1.30 & 146 & 1.10 & 1 \\
\hline Mali & 27 & 146 & 1.26 & 145 & 1.11 & -1 \\
\hline Congo (Dem. Rep.) & 28 & 147 & 1.17 & 147 & 1.04 & 0 \\
\hline Eritrea & 29 & 148 & 1.09 & 148 & 1.03 & 0 \\
\hline Burkina Faso & 30 & 149 & 1.08 & 149 & 0.98 & 0 \\
\hline Ethiopia & 31 & 150 & 1.08 & 150 & 0.94 & 0 \\
\hline Niger & 32 & 151 & 0.92 & 152 & 0.79 & 1 \\
\hline Chad & 33 & 152 & 0.83 & 151 & 0.80 & -1 \\
\hline Average (simple) & & & 1.81 & & 1.57 & \\
\hline
\end{tabular}

Source: ITU.

people online. Most of the countries in the region saw a decline in the number of fixed-telephone lines, and penetration levels remain low, even in the GCC countries. As a consequence, fixed-broadband penetration levels also remain relatively low, at 2.5 per cent, compared with eight per cent globally and over four per cent for developing countries worldwide. By the end of 2010, half of the countries in the region had achieved a mobile-cellular penetration of above 100 per cent and both the United Arab Emirates and Saudi Arabia had achieved mobile-broadband penetration levels of 58 per cent. However, a number of countries, including Yemen, Comoros and Djibouti, but also Algeria and Lebanon, had not yet launched commercial $3 \mathrm{G}$ services, effectively falling behind in an area where most other countries in the region, but also globally, have made great progress over the last few years.
The United Arab Emirates tops the regional list and is ranked 32nd, globally. It has attained a high level of mobile-cellular penetration (over 145 per cent by end 2010) and mobile-broadband penetration (over 58 per cent) and a relatively high proportion of households connected to the Internet (65 per cent). At 78 per cent, it has by far the highest percentage of the population using the Internet in the region. On the other hand, both fixed-telephone penetration and fixed-broadband penetration levels remain low (at around ten per cent) compared with other high-income economies, which effectively limits the country's ability to bring high-speed Internet access to larger parts of the population, as well as to businesses and homes. Although the country has a relatively high fibre-to-the-home/business penetration rate, ${ }^{50}$ these subscriptions provide speeds that are below what operators in some other high-income economies are 
Table 2.15: IDI - Arab States

\begin{tabular}{|c|c|c|c|c|c|c|}
\hline Economy & $\begin{array}{c}\text { Regional rank } \\
2010\end{array}$ & $\begin{array}{c}\text { Global rank } \\
2010\end{array}$ & IDI 2010 & $\begin{array}{c}\text { Global rank } \\
2008\end{array}$ & IDI 2008 & $\begin{array}{c}\text { Global rank } \\
\text { change } \\
2008-2010\end{array}$ \\
\hline United Arab Emirates & 1 & 32 & 6.19 & 32 & 5.63 & 0 \\
\hline Qatar & 2 & 44 & 5.60 & 48 & 4.50 & 4 \\
\hline Bahrain & 3 & 45 & 5.57 & 42 & 5.16 & -3 \\
\hline Saudi Arabia & 4 & 46 & 5.42 & 55 & 4.13 & 9 \\
\hline Oman & 5 & 60 & 4.38 & 68 & 3.45 & 8 \\
\hline Jordan & 6 & 73 & 3.83 & 73 & 3.29 & 0 \\
\hline Lebanon & 7 & 79 & 3.57 & 77 & 3.12 & -2 \\
\hline Tunisia & 8 & 84 & 3.43 & 82 & 2.98 & -2 \\
\hline Morocco & 9 & 90 & 3.29 & 100 & 2.60 & 10 \\
\hline Egypt & 10 & 91 & 3.28 & 92 & 2.73 & 1 \\
\hline Syria & 11 & 96 & 3.05 & 96 & 2.66 & 0 \\
\hline Algeria & 12 & 103 & 2.82 & 105 & 2.41 & 2 \\
\hline Yemen & 13 & 127 & 1.72 & 127 & 1.49 & 0 \\
\hline Comoros & 14 & 128 & 1.67 & 130 & 1.44 & 2 \\
\hline Djibouti & 15 & 129 & 1.66 & 124 & 1.56 & -5 \\
\hline Mauritania & 16 & 131 & 1.58 & 126 & 1.50 & -5 \\
\hline Average (simple) & & & 3.57 & & 3.04 & \\
\hline
\end{tabular}

now offering. In 2010, some 65 per cent of the United Arab Emirates broadband subscriptions provided speeds of between $256 \mathrm{kbit} / \mathrm{s}$ and $2 \mathrm{Mbit} / \mathrm{s}$, and 35 per cent speeds between 2 and $10 \mathrm{Mbit} / \mathrm{s}$. Higher-speed subscriptions were not available.

The Arab States region also contains a number of lowincome economies, including Comoros, Djibouti, Mauritania and Yemen, all of which occupy low positions in the regional as well as in the global IDI rankings. These disparities are reflected in a large variation in IDI values in the region, which ranged from 6.19 in the United Arab Emirates to 1.58 in Mauritania. Both Mauritania and Djibouti fell five places in the 2010 IDI rankings in relation to 2008, with relatively little progress in most areas, including international Internet bandwidth and fixed telephony. Dibouti is one of the few countries in the world that has a mobile-cellular penetration of below 20 per cent.

During the period 2008 to 2010, Morocco, Oman and Saudi Arabia, on the other hand, registered the highest rank increase. These three countries are also among the most dynamic countries in the global IDI (see section 2.2). Morocco and Oman substantially increased the number of Internet users, together with the number of active mobile-broadband subscriptions, while Saudi Arabia made important progress in international Internet bandwidth, and in terms of the number of mobile- broadband subscriptions, which increased from 2 million to almost 16 million between 2008 and 2010. By 2010, Qatar was leading the region in terms of the proportion of households with a computer and Internet, allowing the country to gain four places in the global rankings.

\section{Asia and the Pacific}

The Asia and the Pacific region stands out for featuring some of the world's leaders in ICT development. These include the Republic of Korea and Hong Kong (China), which came first and second in the regional IDI rankings, as well as a number of other economies, including New Zealand, Japan, Australia, Singapore and Macao (China) (see Table 2.16). In contrast to these ICT champions, this highly diverse region is also home to a number of low-income economies with low ICT levels, including Papua New Guinea, Bangladesh and Nepal. IDI values in the region range from a low 1.4 to a high 8.4.

In terms of the access sub-index, Viet Nam and the Islamic Republic of Iran showed the highest increase between 2008 and 2010. Viet Nam more than doubled both its number of mobile-cellular subscriptions and its international Internet bandwidth. The percentage of households with Internet access increased from below five to over eight, and the country gained ten places in the sub-index rankings in relation to 2008. Despite strong progress in terms of international Internet bandwidth 
and household ICT access, the number of Internet users in the Islamic Republic of Iran grew less than in other countries, and by 2010 fixed-broadband penetration remained below one per cent. Mobile-broadband services had not been launched, and the country dropped three places in the rankings overall.

A number of economies with high ICT levels, such as Japan and Hong Kong (China), showed the lowest increases in the access sub-index, suggesting that saturation levels have been reached. Other high-income economies, including Macao (China) and New Zealand, made strong progress in household ICT access, and by end 2010 around four out of five of their households had a computer and Internet access. Both economies also made substantial improvements in terms of mobilebroadband subscriptions and were able to improve their overall IDI rankings.

While many of the countries with the highest fixedbroadband penetration rates also had the highest mobile-broadband penetration rates, there are some ex- ceptions. In Indonesia and the Philippines, for example, mobile-broadband access is becoming a substitute for fixed-broadband access, which remains very limited due to the limited fixed-telephone infrastructure. While the growth in mobile-broadband subscriptions is a positive development that testifies to the demand for high-speed Internet access, mobile-broadband technologies do not have the same capacity as fixed-broadband networks and therefore are not generally able to provide the same type of speed as fixed networks, especially fibre, but also xDSL and cable. Governments must therefore pay special attention to monitoring and boosting fixedbroadband networks.

In developed countries, too, mobile-broadband services are increasingly popular, particularly when fixed access is not available. In New Zealand, for example, mobilebroadband penetration increased from 44 to 66 per cent by end 2010, and a Statistics New Zealand survey showed that "a quarter of Internet users in 2009 used mobile phones or wireless hotspots to access the Internet while they were away from home". 51

Table 2.16: IDI - Asia and the Pacific

\begin{tabular}{|c|c|c|c|c|c|c|}
\hline Economy & $\begin{array}{c}\text { Regional rank } \\
2010\end{array}$ & $\begin{array}{c}\text { Global rank } \\
2010\end{array}$ & IDI 2010 & $\begin{array}{c}\text { Global rank } \\
2008\end{array}$ & IDI 2008 & $\begin{array}{c}\text { Global rank } \\
\text { change } \\
2008-2010\end{array}$ \\
\hline Korea (Rep.) & 1 & 1 & 8.40 & 1 & 7.80 & 0 \\
\hline Hong Kong, China & 2 & 6 & 7.79 & 6 & 7.14 & 0 \\
\hline New Zealand & 3 & 12 & 7.43 & 16 & 6.65 & 4 \\
\hline Japan & 4 & 13 & 7.42 & 11 & 7.01 & -2 \\
\hline Australia & 5 & 14 & 7.36 & 14 & 6.78 & 0 \\
\hline Singapore & 6 & 19 & 7.08 & 15 & 6.71 & -4 \\
\hline Macao, China & 7 & 21 & 6.84 & 27 & 5.84 & 6 \\
\hline Brunei Darussalam & 8 & 43 & 5.61 & 44 & 4.97 & 1 \\
\hline Malaysia & 9 & 58 & 4.45 & 57 & 3.96 & -1 \\
\hline Maldives & 10 & 67 & 4.05 & 66 & 3.54 & -1 \\
\hline China & 11 & 80 & 3.55 & 75 & 3.17 & -5 \\
\hline Viet Nam & 12 & 81 & 3.53 & 91 & 2.76 & 10 \\
\hline Mongolia & 13 & 86 & 3.41 & 87 & 2.90 & 1 \\
\hline Iran (I.R.) & 14 & 87 & 3.39 & 84 & 2.96 & -3 \\
\hline Thailand & 15 & 89 & 3.30 & 80 & 3.03 & -9 \\
\hline Philippines & 16 & 92 & 3.22 & 95 & 2.69 & 3 \\
\hline Fiji & 17 & 94 & 3.16 & 90 & 2.82 & -4 \\
\hline Indonesia & 18 & 101 & 2.83 & 107 & 2.39 & 6 \\
\hline Sri Lanka & 19 & 105 & 2.79 & 106 & 2.41 & 1 \\
\hline India & 20 & 116 & 2.01 & 117 & 1.72 & 1 \\
\hline Cambodia & 21 & 117 & 1.99 & 120 & 1.63 & 3 \\
\hline Bhutan & 22 & 119 & 1.93 & 123 & 1.58 & 4 \\
\hline Lao P.D.R. & 23 & 121 & 1.90 & 119 & 1.64 & -2 \\
\hline Pakistan & 24 & 123 & 1.83 & 121 & 1.59 & -2 \\
\hline Nepal & 25 & 134 & 1.56 & 137 & 1.28 & 3 \\
\hline Bangladesh & 26 & 137 & 1.52 & 135 & 1.31 & -2 \\
\hline Papua New Guinea & 27 & 143 & 1.38 & 139 & 1.24 & -4 \\
\hline Average (simple) & & & 4.06 & & 3.61 & \\
\hline
\end{tabular}

Source: ITU. 
By end 2010, only Papua New Guinea and the Islamic Republic of Iran had not commercially launched $3 \mathrm{G}$ networks, but Bangladesh, Bhutan, Lao P.D.R. and Nepal all had penetration rates of below 0.5 per cent. Although both India and China launched 3G services in 2009, their mobile-broadband penetration rates remain very low (below one and two per cent, respectively). In comparison with India, however, China has been able to grow its fixed-broadband network, which reached a penetration rate of 9.4 per cent by end 2010, as against less than one per cent in India. China also ranks comparatively high in terms of fibre-to-the-home/business connections, and by February 2011 it had a higher percentage of homes connected to fibre than France or Italy. ${ }^{52}$ This has helped China to make great progress in terms of bringing more people online, and between 2008 and 2010 the country recorded one of the highest growth rates in the region in terms of the number of Internet users. At end 2010, more than one in three Chinese were online, as against one in ten Indians. Another country that has made great strides in terms of Internet users is the Philippines, where an estimated one quarter of the population was using the Internet by end 2010. Both China and the Philippines have made headlines for their active use of social media, and according to one survey the Philippines had the highest social networking usage in the region in $2010 . .^{53}$

\section{Commonwealth of Independent States}

Most of the CIS countries fall in the medium group of the global IDI and only the Russian Federation is in the top 50, or upper level IDI group (see section 2.2). Kyrgyzstan, Uzbekistan and Turkmenistan have the lowest
IDI values in the region and they made relatively little progress between 2008 and 2010, particularly compared with the Russian Federation, Belarus, Moldova, Armenia, Azerbaijan and Georgia. Based on these diverging developments, the CIS witnessed the largest increase in IDI ranges over the period from 2008 to 2010.

Azerbaijan, Belarus, Moldova and the Russian Federation made the greatest progress in terms of the IDI access sub-index, and all four countries substantially increased household ICT access. Azerbaijan, Belarus and Moldova more than doubled their international Internet bandwidth, and the Russian Federation increased its Internet bandwidth from $300000 \mathrm{Mbit} / \mathrm{s}$ to over 1.8 Tbit/s. During the same time period, Armenia increased its mobile-cellular penetration from 75 to 125 per cent.

Armenia, Belarus, Moldova and the Russian Federation registered strong growth in both fixed- and mobilebroadband subscriptions, and by end 2010 Internet penetration in these countries reached between 32 and 43 per cent. In Georgia, which more than doubled fixed- and mobile-broadband subscriptions, 27 per cent of the population were online. Turkmenistan remained the only country in the region without commercial $3 \mathrm{G}$ services. It also displayed a negligible fixed-broadband penetration level and only 2.2 per cent Internet user penetration. Although Ukraine launched 3G services commercially as early as 2007, the market has not shown much growth, and by end 2010 mobile-broadband penetration had only reached four per cent. While the country has a competitive mobile market and several mobile operators, only one operator holds a $3 \mathrm{G}$ licence.

Table 2.17: IDI - CIS

\begin{tabular}{|c|c|c|c|c|c|c|}
\hline Economy & $\begin{array}{c}\text { Regional rank } \\
2010\end{array}$ & $\begin{array}{c}\text { Global rank } \\
2010\end{array}$ & IDI 2010 & $\begin{array}{c}\text { Global rank } \\
2008\end{array}$ & IDI 2008 & $\begin{array}{c}\text { Global rank } \\
\text { change } \\
2008-2010\end{array}$ \\
\hline Russia & 1 & 47 & 5.38 & 49 & 4.42 & 2 \\
\hline Belarus & 2 & 52 & 5.01 & 58 & 3.93 & 6 \\
\hline Moldova & 3 & 57 & 4.47 & 64 & 3.57 & 7 \\
\hline Ukraine & 4 & 62 & 4.34 & 59 & 3.83 & -3 \\
\hline Kazakhstan & 5 & 68 & 4.02 & 72 & 3.39 & 4 \\
\hline Armenia & 6 & 72 & 3.87 & 86 & 2.94 & 14 \\
\hline Azerbaijan & 7 & 74 & 3.78 & 83 & 2.97 & 9 \\
\hline Georgia & 8 & 77 & 3.65 & 85 & 2.96 & 8 \\
\hline Kyrgyzstan & 9 & 100 & 2.84 & 99 & 2.62 & -1 \\
\hline Uzbekistan & 10 & 110 & 2.55 & 110 & 2.22 & 0 \\
\hline Turkmenistan & 11 & 111 & 2.50 & 111 & 2.15 & 0 \\
\hline Average (simple) & & & 3.85 & & 3.18 & \\
\hline
\end{tabular}

Source: ITU. 


\section{Europe}

Countries from Europe rank high on the IDI, and eight out of the top ten countries on the global IDI are European. Over 85 per cent of the European countries figure in the top third of the global IDI, and the lowest ranked country in the region (Albania) occupies 78th place on the global IDI. Europe is also the region with the lowest range difference in IDI values, so countries are improving their ICT levels at similar speeds. As discussed in (ITU, 2010b), this is largely due to the adoption of a harmonized legal and regulatory framework and common technological platforms among EU member states. "As early as 2002, all Member States agreed on the implementation of a harmonized regulatory framework, addressing key regulatory bottlenecks, such as network interconnections, open access, unbundling, spectrum policy and universal service". ${ }^{54}$

There is a clear shift from access/infrastructure improvements to progress in the use and uptake of ICTs. Only three European countries (Albania, Serbia and the Czech Republic) showed a greater value increase in the access sub-index. By end 2010 all European countries, with the exception of Bosnia and Herzegovina, Cyprus and Turkey, had reached more than 100 per cent mobile-cellular penetration. The largest differences continue to exist in household ICT penetration levels. While in the vast majority of European countries more

Table 2.18: IDI - Europe

\begin{tabular}{|c|c|c|c|c|c|c|}
\hline Economy & $\begin{array}{c}\text { Regional rank } \\
2010\end{array}$ & $\begin{array}{c}\text { Global rank } \\
2010\end{array}$ & IDI 2010 & $\begin{array}{c}\text { Global rank } \\
2008\end{array}$ & IDI 2008 & $\begin{array}{c}\text { Global rank } \\
\text { change } \\
2008-2010\end{array}$ \\
\hline Sweden & 1 & 2 & 8.23 & 2 & 7.53 & 0 \\
\hline Iceland & 2 & 3 & 8.06 & 7 & 7.12 & 4 \\
\hline Denmark & 3 & 4 & 7.97 & 3 & 7.46 & -1 \\
\hline Finland & 4 & 5 & 7.87 & 12 & 6.92 & 7 \\
\hline Luxembourg & 5 & 7 & 7.78 & 4 & 7.34 & -3 \\
\hline Switzerland & 6 & 8 & 7.67 & 9 & 7.06 & 1 \\
\hline Netherlands & 7 & 9 & 7.61 & 5 & 7.30 & -4 \\
\hline United Kingdom & 8 & 10 & 7.60 & 10 & 7.03 & 0 \\
\hline Norway & 9 & 11 & 7.60 & 8 & 7.12 & -3 \\
\hline Germany & 10 & 15 & 7.27 & 13 & 6.87 & -2 \\
\hline Austria & 11 & 16 & 7.17 & 21 & 6.41 & 5 \\
\hline France & 12 & 18 & 7.09 & 18 & 6.48 & 0 \\
\hline |srael & 13 & 20 & 6.87 & 23 & 6.20 & 3 \\
\hline Belgium & 14 & 22 & 6.83 & 22 & 6.31 & 0 \\
\hline Ireland & 15 & 23 & 6.78 & 19 & 6.43 & -4 \\
\hline Slovenia & 16 & 24 & 6.75 & 24 & 6.19 & 0 \\
\hline Spain & 17 & 25 & 6.73 & 25 & 6.18 & 0 \\
\hline Portugal & 18 & 27 & 6.64 & 29 & 5.70 & 2 \\
\hline Italy & 19 & 28 & 6.57 & 26 & 6.10 & -2 \\
\hline Malta & 20 & 29 & 6.43 & 31 & 5.68 & 2 \\
\hline Greece & 21 & 30 & 6.28 & 30 & 5.70 & 0 \\
\hline Croatia & 22 & 31 & 6.21 & 36 & 5.43 & 5 \\
\hline Estonia & 23 & 33 & 6.16 & 28 & 5.81 & -5 \\
\hline Hungary & 24 & 34 & 6.04 & 34 & 5.47 & 0 \\
\hline Lithuania & 25 & 35 & 6.04 & 35 & 5.44 & 0 \\
\hline Cyprus & 26 & 36 & 5.98 & 43 & 5.02 & 7 \\
\hline Czech Republic & 27 & 37 & 5.97 & 37 & 5.42 & 0 \\
\hline Poland & 28 & 38 & 5.95 & 41 & 5.29 & 3 \\
\hline Slovak Republic & 29 & 39 & 5.94 & 40 & 5.30 & 1 \\
\hline Latvia & 30 & 40 & 5.90 & 39 & 5.31 & -1 \\
\hline Romania & 31 & 48 & 5.20 & 46 & 4.67 & -2 \\
\hline Bulgaria & 32 & 49 & 5.19 & 45 & 4.75 & -4 \\
\hline Serbia & 33 & 50 & 5.11 & 47 & 4.51 & -3 \\
\hline Montenegro & 34 & 51 & 5.03 & 50 & 4.29 & -1 \\
\hline TFYR Macedonia & 35 & 53 & 4.98 & 52 & 4.20 & -1 \\
\hline Turkey & 36 & 59 & 4.42 & 60 & 3.81 & 1 \\
\hline Bosnia and Herzegovina & 37 & 63 & 4.31 & 63 & 3.58 & 0 \\
\hline Albania & 38 & 78 & 3.61 & 81 & 2.99 & 3 \\
\hline Average (simple) & & & 6.42 & & 5.80 & \\
\hline
\end{tabular}

Source: ITU. 
than 50 per cent (and often more than 80 per cent) of households have a computer and Internet access at home, some countries in the region register relatively low levels, including Albania, Bosnia and Herzegovina and Montenegro, where only 12, 18 and 22 per cent of households have Internet access, respectively. Bringing ICTs to homes is an important step for countries to become information societies and to leverage the full benefits of ICTs.

With the exception of Albania, all European countries have launched $3 \mathrm{G}$ mobile-broadband services, and the number of subscriptions is growing rapidly, particularly in Austria, Cyprus, Finland, Portugal and Sweden, where penetration levels have attained 60 per cent or more. Fixed-broadband penetration levels have reached 38 per cent in Switzerland and the Netherlands - among the highest in the world - but still lie below 20 per cent in about one-third of the European countries.

As fixed-and mobile-broadband subscriptions increase, Internet user penetration in Europe continues to grow in most countries, and by end 2010 more than two in three people were online. While Internet user penetration is growing only slowly in those countries which already have high penetration rates (around 80 per cent), other countries are catching up. Both Croatia and France, for example, pushed up their Internet user penetration rates from around 70 to 80 per cent and from 50 to 60 per cent, respectively. In Cyprus, Internet penetration increased from 42 to 53 per cent.

\section{The Americas}

The only country from the Americas region that figures in the top 25 of the overall IDI is the United States, ranked 17th. Together, the United States and Canada - both high-income economies - stand out for their relatively high ranking compared with their regional counterparts. The Unites States position as a relative outlier also increases the regional IDI range, which extends from 7.09 in the United States to 2.31 in Nicaragua, i.e. a range of 4.78 .

While all countries in the region increased their IDI values between 2008 and 2010, a total of 21 countries (77.8 per

Table 2.19: IDI - Americas

\begin{tabular}{|c|c|c|c|c|c|c|}
\hline Economy & $\begin{array}{c}\text { Regional rank } \\
2010\end{array}$ & $\begin{array}{c}\text { Global rank } \\
2010\end{array}$ & IDI 2010 & $\begin{array}{c}\text { Global rank } \\
2008\end{array}$ & IDI 2008 & $\begin{array}{c}\text { Global rank } \\
\text { change } \\
2008-2010\end{array}$ \\
\hline United States & 1 & 17 & 7.09 & 17 & 6.55 & 0 \\
\hline Canada & 2 & 26 & 6.69 & 20 & 6.42 & -6 \\
\hline Barbados & 3 & 41 & 5.83 & 33 & 5.47 & -8 \\
\hline Uruguay & 4 & 54 & 4.93 & 51 & 4.21 & -3 \\
\hline Chile & 5 & 55 & 4.65 & 54 & 4.14 & -1 \\
\hline Argentina & 6 & 56 & 4.64 & 53 & 4.16 & -3 \\
\hline Trinidad \& Tobago & 7 & 61 & 4.36 & 56 & 3.99 & -5 \\
\hline Brazil & 8 & 64 & 4.22 & 62 & 3.72 & -2 \\
\hline Venezuela & 9 & 65 & 4.11 & 61 & 3.73 & -4 \\
\hline Panama & 10 & 66 & 4.09 & 67 & 3.52 & 1 \\
\hline Costa Rica & 11 & 70 & 3.99 & 69 & 3.45 & -1 \\
\hline Mexico & 12 & 75 & 3.75 & 74 & 3.26 & -1 \\
\hline Colombia & 13 & 76 & 3.75 & 71 & 3.39 & -5 \\
\hline Suriname & 14 & 82 & 3.52 & 78 & 3.09 & -4 \\
\hline Peru & 15 & 83 & 3.52 & 76 & 3.12 & -7 \\
\hline Jamaica & 16 & 85 & 3.41 & 79 & 3.06 & -6 \\
\hline Ecuador & 17 & 88 & 3.37 & 88 & 2.87 & 0 \\
\hline Dominican Rep. & 18 & 93 & 3.21 & 89 & 2.84 & -4 \\
\hline Guyana & 19 & 95 & 3.08 & 93 & 2.73 & -2 \\
\hline El Salvador & 20 & 98 & 2.89 & 101 & 2.57 & 3 \\
\hline Paraguay & 21 & 99 & 2.87 & 97 & 2.66 & -2 \\
\hline Bolivia & 22 & 102 & 2.83 & 102 & 2.54 & 0 \\
\hline Honduras & 23 & 106 & 2.72 & 104 & 2.42 & -2 \\
\hline Cuba & 24 & 107 & 2.69 & 98 & 2.62 & -9 \\
\hline Guatemala & 25 & 108 & 2.65 & 108 & 2.39 & 0 \\
\hline Nicaragua & 26 & 114 & 2.31 & 113 & 2.09 & -1 \\
\hline Average (simple) & & & 3.89 & & 3.50 & \\
\hline
\end{tabular}


cent) in the Americas region dropped in the IDI rankings. This makes the region the least dynamic region over the 2008-2010 period, with the largest number of countries with a negative rank change. For a number of countries this decline can be attributed to relatively slow progress in the use sub-index, and in particular in terms of mobilebroadband subscriptions. By 2010, Canada, for example, had a much lower mobile-broadband penetration rate (15 per cent) than the United States (54 per cent) and many other high-income economies. Barbados, which ranked third on the regional IDI but fell eight places in the overall IDI rankings, had not yet launched $3 \mathrm{G}$ mobilebroadband services commercially. Four other countries (Antigua and Barbuda, Trinidad and Tobago and Cuba) did not offer mobile-broadband services, and in general countries' mobile-broadband penetration levels remained low, with only two countries exceeding a penetration of 15 per cent. Fixed broadband, too, is still very low in the region. There are four countries where at end 2010 penetration remains below one per cent, namely Bolivia, Cuba, Nicaragua and Paraguay; and only three countries, namely Barbados, Canada and United States, have penetration levels of between 20 and 30 per cent. Antigua and Barbuda, Chile, Trinidad and Tobago and Uruguay have surpassed the ten per cent mark.

Especially in the Dominican Republic and Trinidad and Tobago, but also in Paraguay, there was a high increase in the number of Internet users but not in the international Internet bandwidth. Increasing the Internet bandwidth capacity is necessary if countries want to bring more people online, at high speed and with a suitable quality of service.
Between 2008 and 2010, Chile and Brazil registered the greatest improvements in their IDI values, mainly due to changes in the access sub-index. Both countries showed strong growth in the number of mobile-cellular subscriptions (surpassing the 100 per cent penetration rate), doubled their international Internet bandwidth, and connected more households with ICTs. In Chile, the number of households with Internet access climbed from 27 to 35 per cent.

Other countries that witnessed strong progress in terms of ICT access and infrastructure were Costa Rica and Ecuador. Costa Rica increased its mobilecellular penetration from 42 to 65 , more than doubled international Internet bandwidth and increased the percentage of households with Internet access from 15 to 24 per cent. Ecuador tripled international Internet bandwidth and by end 2010 had connected 12 per cent of homes, compared with seven per cent two years earlier.

In respect of the use sub-index, Argentina, the Dominican Republic and Mexico achieved the highest value increases, due mainly to an increase in mobilebroadband subscriptions and Internet users. While the number of fixed-broadband subscriptions in Argentina and Mexico increased only slightly, mobile-broadband services grew rapidly. Argentina and Mexico increased their mobile-broadband penetration rates from 2 per cent to 13 and 8 per cent, respectively. Between 2008 and 2010, Mexico increased its number of Internet users from 22 to 31 per cent. 


\section{Endnotes}

1 The reader is also advised to consult the 2009 edition of Measuring the Information Society, which provides more information on the development of the IDI concept and methodology. Annex 1 to this report describes the methodology in more detail.

2 Between 2007 and 2008, ITU maintained an online discussion forum with more than 100 participants on the preparation of the "single index".

3 In 2011, the ITU Expert Group on Telecommunication/ICT Indicators (EGTI) has opened a discussion item on the IDI on its online forum.

4 ITU (2010b), Chapter 2, Box 2.1, provides more insight on the need to improve data quality through household ICT statistics.

5 The revision was part of the overall review of the ITU's infrastructure indicators, and was carried out through its Expert Group on Telecommunication/ICT Indicators (EGTI). The revised definition is harmonized with the OECD definitions of wireless broadband. For more information, see http://www.itu.int/ITU-D/ict/handbook.html.

6 So far, very few data are available for satellite broadband subscriptions and for terrestrial fixed wireless-broadband subscriptions. It is hoped that they can be added in the future.

7 Wireless Intelligence is part of GSM Media LLC, a wholly owned subsidiary of GSMC Limited, the organization behind the GSMA Mobile World Congress and GSMA Mobile Asia Congress, see https://www.wirelessintelligence.com/about/.

8 Note that, due to some changes in the data used for the IDI (see section 2.1), the top rankings are not the same as those published in previous editions of the MIS report.

9 See Korea Communications Commission (2010).

10 See latest data from FTTH Council: http://www.ftthcouncil.org/node/1425.

11 By the end of 2011 Sweden had roughly 150 independent fibre networks, the most notable being Stokab, owned by the city of Stockholm. For more information, see BEREC (2011), and Stokab's website (http://www.stokab.se/).

12 See the press release from the Swedish Post and Telecom Agency: http://www.pts.se/en-gb/News/Press-releases/2011/For-the-firsttime-we-are-spending-more-money-on-mobile-services-than-on-fixed-services/.

13 See Post and Telecom Administration in Iceland (2011).

14 See the document from the Ministry of Transport and Communications of Finland available at: http://www.lvm.fi/c/document library $/$ get file? folderId=913424\&name $=$ DLFE- 10509 .pdf\&title $=$ Questions $\% 20$ and $\% 20$ Answers. $\% 20$ Access $\% 20$ to $\% 20 \mathrm{a} \% 20 \mathrm{mini}$ mum $\% 20$ of $\% 201 \% 20$ Mbit $\% 20$ Internet $\% 20(16.10 .2009)$.

15 See the press release from FICORA available at: http://www.ficora.fi/en/index/viestintavirasto/lehdistotiedotteet/2010/P 27.html. Under its USO, Finland will be the only country in the world that legally requires Internet access as a basic right.

16 See http://www.ficora.fi/en/index/viestintavirasto/lehdistotiedotteet/2010/P 27.html.

17 See Swiss Federal Communication Commission (2011).

18 See http://www.med.govt.nz/templates/StandardSummary_ 40551.aspx.

19 See pages 5 and 6 of the European Commission's letter of withdrawal of serious doubts and comments in response to the proposal of wholesale broadband access regulation in Austria (Case AT/2009/0970). Available at Circa: http://circa.europa.eu/Public/irc/infso/ ecctf/library?l=/sterreich/registeredsnotifications/at20090970/at-2009-0970 acte-withdr/ EN 1.0 \&a=d.

20 See http://www.itu.int/ITU-D/ict/newslog/Ministry+Reveals+High+Speed+Broadband+Network+Plan+Armenia.aspx.

${ }^{21}$ See http://www.businessdailyafrica.com/Corporate+News/-/539550/1176762/-/rp4s11/-/index.html.

22 See http://www.itnewsafrica.com/2010/10/verizon-to-extend-african-footprint-with-gateway-business/. Verizon Business has agreement with Gateway Business to leverage their network presence and extend coverage of the Verizon MPLS network to 14 African countries by using interconnection points between the companies' networks.

23 See http://www.itnewsafrica.com/2010/03/mauritius-completes-first-phase-of-lion-cable-project/.

24 See http://wirelessfederation.com/news/24359-maroc-telecom-launches-mobile-service-mobi-cash-morocco/.

5 See http://www.itu.int/ITU-D/ict/newslog/Morocco+To+Cut+Call+Termination+Rates+By+6570+Over+3+Years.aspx.

See Gulvady (2009).

7 See Ministry of Eduction, Sultanate of Oman (2008).

28 See http://www.ita.gov.om/ITAPortal/MediaCenter/NewsDetail.aspx?NID=341.

29 Information Technology Authority, Sultanate of Oman (2008).

30 See http://maxwellsci.com/print/ajbm/v2-94-109.pdf.

31 See http://main.omanobserver.om/node/42153.

32 See http://www.telegeography.com/products/commsupdate/articles/2010/07/20/rostelecom-doubles-internet-capacity-for-far-easttelecom/.

33 See http://www.submarinenetworks.com/systems/asia-europe-africa/ricn/ricn-ready-for-service.

34 See http://www.itar-tass.com/en/c154/159007_print.html. 
35 See Que et al. (2010).

36 The developed/developing country classifications are based on the UN M49, see: http://www.itu.int/ITU-D/ict/definitions/regions/index.html.

37 The 152 economies included in the IDI were grouped into four categories (high, upper, medium, and low) based on the 2010 IDI values. The countries were grouped by locating the position of the average IDI value (of 4.08) among all IDI values. The average value was thus placed after the 86th country, which resulted in 66 countries above the average and 86 below. The 66 countries above the average were then classified into two equal groups (high and upper). The 86 countries below the average were also divided into two equal groups (medium and low).

38 The 152 economies were grouped into four categories (high, upper, medium and low) based on their 2009 GNI per capita, PPP\$ values. The countries were grouped by locating the position of the average GNI per capita (PPP\$) value (of 14 401) among all GNI per capita (PPP\$) values. The average value was thus placed after the 103rd country, giving 49 countries above the average and 103 below. The 49 countries above the average were then classified into two equal groups (high and upper). The 103 countries below the average were also divided into two equal groups (medium and low).

39 See http://www.gov.mu/portal/site/Mainhomepage/menuitem.a42b24128104d9845dabddd154508a0c/?content id=b15f3e8d304972 10VgnVCM1000000a04a8c0RCRD and http://www.pcworld.com/businesscenter/article/193025/lion cable links madagascar mauritius reunion.html.

40 See http://www.e-belarus.org/news/201101271.html.

41 See http://www.alcatel-lucent.com/wps/portal/!ut/p/kcxml/04 Sj9SPykssy0xPLMnMz0vM0Y QjzKLd4w3MfQFSYGYRq6mpEoYgbxjgiRIH1vfV-P_NxU_QD9gtzQiHJHR0UAAD_zXg!!/delta/base64xml/L0lJayEvUUd3QndJQSEvNEIVRkNBISEvNl9B X0U4QS9lb193dw!!?LMSG CABINET=Docs and Resource Ctr\&LMSG CONTENT FILE=News Releases 2009/News Article 001776.xml.

42 This is in part due to Plan Ceibal, a plan aiming at connecting schools, pupils and teachers around the country. See also Chapter 5, Section 5.3 and www.ceibal.org.uy.

43 See http://www.telecoms.com/28953/uruguays-antel-hoping-to-connect-80k-homes-with-fibre-by-year-end/.

44 See http://www.vnpt.com.vn/en/News/NewsEvents/View/tabid/219/newsid/11007/seo/10-outstanding-events-of-VNPTin-2009/Default.aspx.

45 See http://www.vnpt.com.vn/en/News/NewsEvents/View/tabid/219/newsid/10938/seo/3G-appearance-tops-ICT-events-of-theyear/Default.aspx.

46 See Government of Republic of Moldova (2005).

47 See ITU (2003).

48 The regional analysis is based on the ITU/BDT regional classification. For a complete overview of the ITU/BDT regions, see: http://www.itu.int/ITU-D/ict/definitions/regions/index.html.

49 See http://ec.europa.eu/information society/digital-agenda/index en.htm.

50 See the last graph at: http://www.ftthcouncil.org/node/1425, according to which the UAE has over 30 per cent of homes connected to a fibre connection.

51 See http://www.techday.co.nz/netguide/news/kiwis-go-unplugged/17158/.

52 See http://www.ftthcouncil.org/en/newsroom/2011/02/10/global-ftth-councils-latest-country-ranking-shows-further-momentumon-all-fiber-.

53 See press release from ABS-CBNnews available at: http://www.abs-cbnnews.com/lifestyle/04/08/10/filipino-internet-users-most-engaged-social-media-survey.

54 See ITU (2010b), page 33. 


\section{Chapter 3. The ICT Price Basket (IPB)}

\subsection{Introduction}

ICT services have to be affordable if people are going to use them. As with other goods or services, the price of a phone call, an sms or an Internet connection influences how many people will use information and communication technologies (ICTs), and how often. It is therefore important that any analysis of the information society should not only consider and understand such factors as ICT infrastructure, awareness or skills, but also take into account the cost and affordability of services.

ITU's ICT Price Basket (IPB) is a composite basket based on the price for fixed-telephony, mobile-cellular telephony and fixed-broadband Internet services, and computed as a percentage of average income levels. As a comprehensive benchmarking tool, the IPB monitors the cost of ICT services and provides a useful indication of how affordable services are across countries, and over time. It also provides information on global and regional trends in ICT tariffs, and points to the difference in prices between developed and developing regions. The IPB, which covers a total of 165 economies, remains the only price basket to track and benchmark the affordability of ICT services worldwide. ${ }^{1}$

The ICT Price Basket is published together with the ICT Development Index (IDI), thereby highlighting the link between ICT prices, on the one hand, and ICT diffusion/ access and use, on the other. Since the affordability of telecommunication and ICT services is expected to have a major influence on ICT uptake, the IPB is an explanatory variable in the IDI. Conversely, over time higher levels of ICT access and use may bring down prices, with operators leveraging economies of scale. Additionally, lower prices are often the result of increased liberalization and competition, leading to higher levels of ICT uptake.

The price of ICT services in a given country depends on a number of factors, including the level and degree of competition, different measures of regulatory intervention, market size, operators' costs for providing services, and profit margins. While this chapter addresses some of these factors when analysing or explaining price developments, it does not provide a detailed analysis of price trends at the country level. Rather, it focuses on global and regional trends, and on the differences between developed and developing countries, highlighting selected economies that have made progress in making ICT services more affordable.

The mobile-cellular market remains the fastest growing telecommunication service market in history (see Chapter 1). While growth in the developed countries, where saturation levels of well above 100 per cent penetration in mobilecellular subscriptions have been achieved, is modest, the developing countries continue to register double-digit growth in the number of subscriptions. By the end of 2010, there were 5.3 billion mobile-cellular subscriptions worldwide, compared to 4 billion at the end of 2008. Over the same period, the mobile-cellular market has witnessed major price reductions, and between 2008 and 2010 the mobile component of the ICT Price Basket dropped by 21.8 per cent. Most mobile-handset manufacturers are eager to enter smartphone markets in order to capture high-end users, and operators are investing in high-speed mobile networks to increase their data-revenue shares. At the same time, there is a parallel trend, particularly in the developing markets, to seize low-end market segments. In 'price-sensitive' India, for example, a large number of mobile operators are competing for low-income customers by decreasing mobile-cellular tariffs, and offering cheaper, more affordable, handsets. ${ }^{2}$ Chinese manufacturers are increasingly betting on low-cost smartphones, for people with average incomes, at home as well as abroad. ${ }^{3}$

As access to mobile-cellular services is becoming more affordable, prices for fixed-broadband Internet access are also falling. ${ }^{4}$ Between 2008 and 2010, the fixed-broadband component of the ICT Price Basket dropped by no less 
than 52.2 per cent, driven mainly by significant price reductions in developing countries, where broadband services were, and in some cases remain, very expensive. The spread and popularity of mobile-broadband services has stimulated (inter-modal) competition and put pressure on operators to lower prices.

Research carried out on the IPB also suggests that more and more broadband subscribers are getting greater speeds, often for the same price. In comparison with 2008, several of the 2010 entry-level broadband plans provide several times the required minimum speed of $256 \mathrm{kbit} / \mathrm{s}$, not only in developed countries but also, increasingly, in many developing countries. ${ }^{5}$ While this trend cannot be taken into consideration for the calculation of the ICT Price Basket - which is based on entry-level broadband plans - it means that customers actually get faster and better services for their money.

\section{Objectives of the ICT Price Basket}

The main objective of the ICT Price Basket is to provide information on the cost and affordability of ICT services across countries and regions. As a price benchmarking tool, it will help policy-makers take informed policy decisions. Prices are presented in absolute terms, both in USD and purchasing power parity (PPP) adjusted. However, the IPB value and ranking is based on the relative cost (or affordability) of ICT services within a country, as it is computed as the percentage of average income. ${ }^{6}$ As the IPB is calculated annually, it serves as a tool allowing policy-makers to evaluate the evolving cost and affordability of ICT services in their country and to benchmark them against those in other countries. This information will put national prices into perspective, and provide a starting point for looking into ways of lowering prices - for example, by introducing or strengthening competition, or by reviewing specific tariff policies. ${ }^{7}$ It will further allow policy-makers to evaluate the impact that specific projects and policies, such as the licensing of additional operators, the introduction of mobile number portability (MNP) or the liberalization of international gateway services, will have on prices.

This chapter will first provide an overview of the methodology of the ICT Price Basket, and present some of its strengths and weaknesses. Next, it will present the overall IPB, which combines relative fixed-telephone, mobile-cellular and fixedbroadband prices into one single value and ranks countries accordingly. The latest (2010) IPB, which is based on 2010 tariffs, will then be compared with the 2008 IPB.

The results of the IPB are linked to countries' broader ICT development and trends, as captured by the ICT
Development Index (IDI). This chapter will therefore examine the link between ICT prices, on the one hand, and ICT uptake, on the other, and discuss the significance of the IPB as an explanatory variable. While both the IPB and IDI data refer to 2010, it is important to recognize that the link between a given change in price and ICT uptake will depend on the country and the magnitude of the price change. In the majority of cases, a given change in prices is likely to have a gradual and often delayed impact on the uptake of services.

In a next step, the IPB is broken down into its three sub-baskets, thus recognizing the importance of each of the services and access methods. ${ }^{8}$ The presentation of absolute and relative (USD and PPP\$) values for each sub-basket independently will allow policy-makers to identify the relative cost of each ICT service. The subbasket results will also be presented by region and by level of development, and highlight some of the differences in the cost of ICT services that exist across the world.

Finally, and in view of the expansion of the mobile broadband market, the chapter will present a comparison of mobile-broadband prices with fixed-broadband prices.

\subsection{ICT Price Basket methodology}

The ICT Price Basket is a composite basket that includes three tariff sets, referred to as sub-baskets: fixed-telephony, mobile-cellular telephony and fixed-broadband Internet services. The IPB is the value derived from the sum of the price of each sub-basket (in USD) as a percentage of a country's monthly GNI per capita ${ }^{9}$ divided by three (Figure 3.1). For this exercise, the cost of each sub-basket as a percentage of the monthly GNI per capita is capped at a maximum value of 100 , so the final price basket value may vary between a theoretical 'zero' (tariffs represent 'zero per cent of average monthly GNI per capita', and all three services are for free) and 100 (the price of all three sub-baskets is equal to, or exceeds, the monthly GNI per capita). This means that the IPB gives equal weight to each of the three ICT service components. Based on the IPB value, countries are ranked from 1 to 165 (the total number of countries included in the 2010 ICT Price Basket).

Data for the three ICT services are collected through the ITU Tariff Indicators Questionnaire, which is sent out to all ITU Member States/national statistical contacts. ${ }^{10}$ For all countries that did not reply to the questionnaire, prices are gathered directly from national operators' websites, 


\section{Figure 3.1: ICT Price Basket methodology}

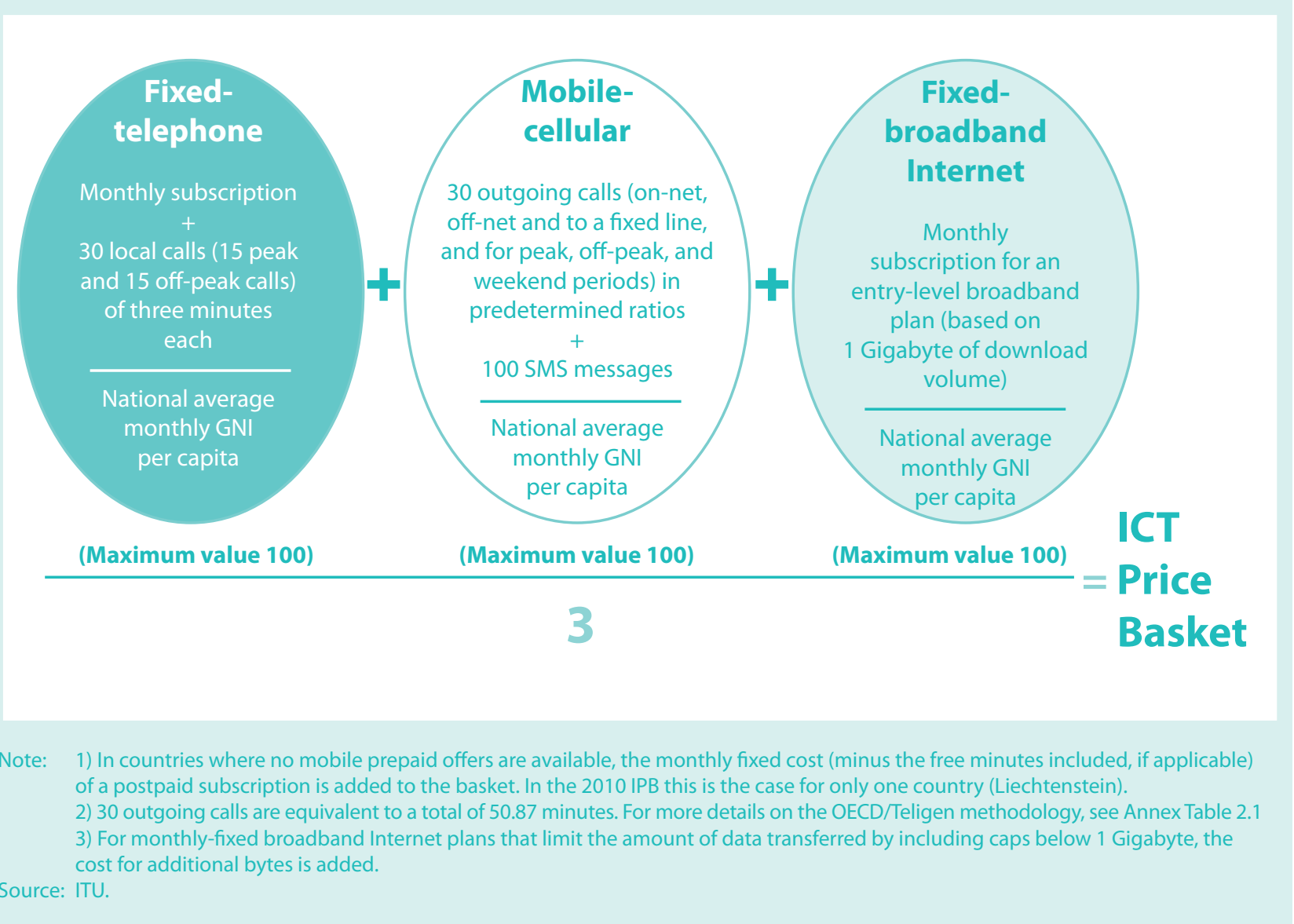

in local currencies, and converted into United States dollars. ${ }^{11}$ The only reason for any of ITU's $192 \mathrm{Mem}-$ ber States not being included in the ICT Price Basket is the unavailability of one or more of the tariffs used to compute the IPB.

It is important to note that there has been a methodological change in the computation of the ICT Price Basket's mobile-cellular sub-basket, so the values in this report are not strictly comparable with those published in the previous IPB (ITU, 2010b). This change in methodology is due to an update in the OECD low-user basket, which ITU has adopted. In particular, the new (2009) OECD low-user basket includes more calls and more sms, so the overall value of the latest IPB will be higher.

Given the increasing number of countries launching $3 \mathrm{G}$ networks and the growing number of people that access the Internet over a mobile-cellular network, it is expected that mobile-broadband prices will eventually be included in the IPB. While national and international efforts to track mobile-broadband uptake and usage are on the rise, the harmonization of indicators to track mobilebroadband uptake is still in its early stages. Comparing mobile-broadband prices remains challenging, for a number of reasons (see Section 3.5).

\section{Fixed-telephone prices}

The fixed-telephone sub-basket represents the cost of local fixed residential telephone services. It refers to the traditional fixed-telephone line and does not refer, for example, to prices for managed VoIP. The sub-basket includes the monthly subscription fee charged for subscribing to the public switched telephone network (PSTN), plus the cost of 30 local calls of three minutes each to the same (fixed) network (15 peak and 15 offpeak calls). See Annex 2 for more information on the fixed-telephone sub-basket methodology.

\section{Mobile-cellular prices}

The mobile-cellular telephony sub-basket is largely based on, but does not entirely follow, the 2009 methodology 
of the OECD low-user basket. ${ }^{12}$ This basket gives the price of a standard basket of monthly mobile usage in USD determined by the OECD for 30 outgoing calls per month (on-net, off-net, to a fixed line and for peak and off-peak times) in predetermined ratios, plus 100 sms messages.

As stated above, the current IPB's mobile-cellular subbasket methodology has changed from the previous IPB - published in ITU (2010b) - insofar as OECD has revised, and ITU has adopted, its methodology. While the previous (2001) OECD low-user basket methodology included only 25 calls and 30 sms, the revised (2009) OECD methodology includes 30 calls and 100 sms. Since the updated mobile sub-basket methodology includes more calls and more sms, it will be relatively more expensive than the previous mobile sub-basket and, consequently, increase the IPB value. For this reason, the latest IPB is not strictly comparable with the previous IPB.

The mobile-cellular sub-basket used in the IPB is based on prepaid tariffs. Prepaid tariffs (as opposed to postpaid tariffs) were used since they represent the dominant payment method in the majority of countries and because they are often the only payment method available to low-income users, who may not qualify for a postpaid subscription. By end 2010, 71 per cent of all mobile subscriptions worldwide were prepaid. See Annex 2 for more information on the mobile-cellular sub-basket methodology.

\section{Fixed-broadband Internet prices}

The fixed-broadband Internet sub-basket is calculated on the basis of the price of the monthly subscription to an entry-level fixed-broadband plan. For comparability reasons, the fixed-broadband sub-basket is based on a monthly usage of (a minimum of) 1 Gigabyte (GB). For plans that limit the monthly amount of data transferred by including caps below $1 \mathrm{~GB}$, the cost of additional bytes is added to the sub-basket. Refer to Annex 2 for more details on the fixed-broadband Internet sub-basket methodology.

\section{Calculating the three price sub-baskets}

The sub-baskets for fixed-telephony, mobile-cellular telephony and fixed-broadband Internet tariffs are presented as follows: ${ }^{13}$

- In USD, using the average annual UN operational rate of exchange.
- In international dollars (PPP\$), using purchasing power parity (PPP) conversion factors instead of market exchange rates. The use of PPP exchange factors helps to screen out price and exchangerate distortions, thus providing a measure of the cost of a given service taking into account the purchasing power equivalences between countries. ${ }^{14}$

- As a percentage of countries' monthly GNI per capita (Atlas method ${ }^{15}$ ), latest available data, capped at 100 per cent. This implies that the lower the percentage, the lower the relative cost of the service. The value of the sub-baskets is only capped at 100 per cent for the purpose of calculating the overall ICT Price Basket so that a very high relative price of, for example, fixedbroadband services does not distort the overall IPB. In reality, a sub-basket value could exceed 100 per cent, meaning that the price of the service in question would exceed the average monthly GNI per capita. This is the case in some countries for the fixed-broadband service.

\section{Strengths and weaknesses of the IPB}

The main strength of the ICT Price Basket is that it provides a fair international comparison of absolute and relative prices for ICT services over time. As a benchmarking tool, it further raises awareness of the important influence that ICT prices have on ICT development, and allows governments to identify and evaluate policies.

Like any benchmarking tool that covers a large number of countries and reduces a complex reality into one single value, the IPB has its shortcomings. Detailed research on ICT prices has shown that pricing policies and plans across countries and even operators vary as much as prices themselves. Therefore, the need to harmonize prices and make them comparable across countries leads to some distortions, and tariffs may not always reflect what the majority of people are actually paying. Since the IPB includes a very large number of countries (165), including the large majority of the world's developing nations, it is based on entrylevel offers and packages, as this is what low-income subscribers are most likely to use. It should be noted, however, that entry-level services tend to be more expensive, since operators can leverage economies of scale and will offer relatively cheaper tariffs for a guaranteed amount of consumption and revenues. 


\section{Box 3.1: Competitive pressure and mobile-cellular prices in Africa}

A recent price comparison between mobile prepaid cellular services in 18 African countries showed that, even in a liberalized and competitive market environment, prices for mobile-cellular services can vary noticeably between operators. The study, carried out by Research ICT Africa, found that, in six countries, the dominant operator was also the cheapest operator. In eight countries, the dominant operator was actually the most expensive operator, although in most cases the difference in price was less than 30 per cent (Figure Box 3.1).

Two exceptions are Tanzania and Nigeria, where the cheapest operators are over 50 per cent cheaper than the dominant operator. Both countries have very dynamic and competitive mobile markets and are home to more than five operators each, with several smaller operators trying to gain market shares. In Tanzania, one of these relatively new and small operators, Benson Informatics, is also the cheapest operator. The company, which started out as a technology consultancy and Internet service provider, launched its mobile services at the end of 2008, but despite low prices, by end 2010, held only
0.01 per cent of the country's market share. Nigeria's cheapest mobile operator, Starcomms, provides CDMA services but is limited to around 30 major cities and 175 towns across the country. By end 2010, it had around 1.8 million mobile-cellular subscriptions, representing about 1.4 per cent in Nigeria's 90 million subscription market. One of the reasons that smaller/ new operators may find it difficult to gain market share is because their off-net prices have to be competitive with the large operator's on-net prices. Since most of the calls of smaller operators are likely to terminate on another operator's network, off-net tariffs must be kept low; otherwise it is in the customers' interest to stay with the (or a) dominant operator, particularly in a market where mobile-termination rates, which tend to favour dominant operators, are high.

While the relatively lower prices of these two operators could further increase competition and force other operators to adjust (i.e. lower) their own prices, their very limited market shares suggest that currently only few people benefit from their low tariffs.

Figure Box 3.1: Cheapest prepaid mobile-cellular prices, in USD, selected African countries

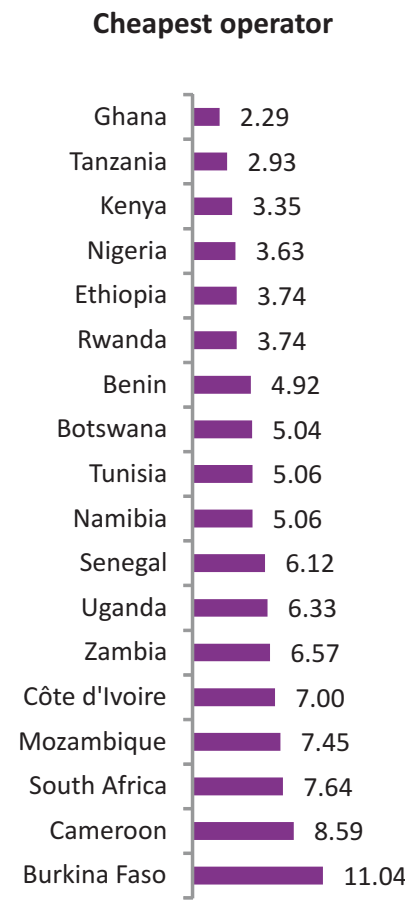

Note: Prices in this graph are based on the 2006 OECD methodology and on the cheapest mobile prepaid product available, presented in USD. They may differ from the tariffs presented in the IPB, which is based on the 2009 OECD methodology.

Source: Stork and Lumingu, 2010. See also http://www.tcra.go.tz/publications/telecomStatsDec10.pdf, and http://allafrica.com/stories/201008061127.html. 
Therefore, the IPB does not necessarily show the cheapest offers and options available, for example for high-end users. More sophisticated packages and offers, which include more minutes/bytes/sms, or bundled packages that combine several services, are also not taken into consideration.

The IPB is based on the dominant market player in terms of the number of subscriptions within each ICT service. It does not represent an average of several operators or packages. Since one of the assumptions in an increasingly competitive ICT market is that operators are adjusting their prices to competitors, tariffs should not in theory differ substantially between operators. Reality, however, shows that, in some countries, there are relatively important price disparities, which the IPB does not take into account ${ }^{16}$ (Box 3.1).

Nor does the IPB take into account special offers that are limited to a certain time-period, since they are not likely to be representative over time. In some cases, special offers are advertised all year round, although the operator reserves the right to cancel the offer at any time. Furthermore, the IPB does not necessarily consider the main type of service or plan to which most users are subscribing. For example, the mobile-cellular sub-basket is based on pre- paid tariffs, even in countries such as, for example, Japan and the Republic of Korea, where the large majority of subscriptions are postpaid. In other countries, most subscribers may chose a subscription package that includes a large number of call minutes or sms, which reduces the price of the call or sms, but for comparability reasons these cannot be considered (Box 3.2).

While these shortcomings need to be taken into consideration, most of them only apply to a limited number of countries, ${ }^{19}$ and so the overall potential of the IPB as a powerful benchmarking tool is not jeopardized.

\subsection{ICT Price Basket results and analysis}

The results of the 2010 and 2008 ICT Price Baskets are presented in Table 3.1. Countries are ranked according to their 2010 IPB value, which is based on the relative prices for fixed-telephony, mobile-cellular telephony and fixed-broadband Internet services. ${ }^{20}$

A number of findings can be highlighted. First, there are important differences in relative ICT prices among

\section{Box 3.2: Prepaid services: not always more expensive than postpaid subscriptions}

Prepaid is the subscription service of choice for the majority of today's mobile-cellular subscribers: by the end of 2010, around 70 per cent of the world's mobile-cellular subscriptions were prepaid. Prepaid services usually do not tie customers to a contract or a monthly subscription fee and therefore often promise greater freedom of use and choice of operators. They protect mobile operators from unpaid bills, since services are paid for in advance. On the other hand, prepaid services do not necessarily cost the same (price per minute, or per sms), since they do not provide operators with a fixed revenue stream, and flexibility and freedom are usually sold at a higher price - at least, per minute. Using the example of the Republic of Korea, a comparison was carried out to show how prepaid and postpaid tariffs compare in terms of the IPB's mobile-cellular sub-basket:

The Republic of Korea, like a number of other countries, has very few prepaid subscriptions - less than 1.5 per cent. Although the price per minute and per sms for prepaid services is more expensive (KRW 288 instead of KRW 108 for calls, and KRW 22 instead of KRW 20 per sms), a comparison that takes into account the monthly subscription charge (KRW 12000 for postpaid customers only) reveals that the prepaid basket (at USD 14.4) is actually cheaper than the same basket using the postpaid tariffs (which would amount to USD 16.7).

The example from the Republic of Korea shows that, for lowend users, prepaid services are more interesting than postpaid services, and that the choice of prepaid services for the IPB does not necessarily disadvantage countries. What may penalize countries that display intensive use of ICT services is the fact that the IPB is based on an entry-level or low-user basket. Operators in developed countries, in particular, offer relatively cheap (per minute) prices for high-end users. For example, in the United States, a fixed monthly subscription of USD 39.99 gives subscribers 450 minutes of free calls, which translates into only USD 0.09 per minute, compared to the USD 0.25 that customers pay when they subscribe to the entry-level prepaid plan. ${ }^{17}$ In Austria, a EUR 8.80 monthly subscription comes with 1000 free minutes of calls, which effectively brings down the per-minute price to EUR 0.009, compared to EUR 0.07 for the prepaid tariff. ${ }^{18}$ 
the 165 economies included in the IPB, pointing to an important price divide. The values vary from a low 0.2 in Monaco, to a high 71.6 in Niger. This compares to a similar range (but between different countries than in 2010) of between 0.3 and 77.1 in 2008, suggesting that important differences persist between the countries with the lowest and highest relative ICT prices.

All of the economies ranked at the top of the IPB have high gross national incomes per capita, including many small economies, such as Macao (China), Monaco, Liechtenstein, Hong Kong (China) and Singapore. With the exception of the United Arab Emirates, all economies in the top ten are from Europe and Asia and the Pacific.

It is also important to point out that the countries ranked at the top of the IPB have very similar IPB values. Twenty-eight countries have an IPB value of below one and, as shown in Table 3.1, many share the same value, with only the second decimal place making the difference. This suggests that those countries ranked at the top of the IPB have all achieved relatively low prices that make ICT services generally affordable to their citizens.

On the other hand, all of the countries with the highest relative ICT prices are low-income countries from
Africa. The most expensive relative prices were observed in Niger, Malawi, Zimbabwe, Madagascar, Togo, Burkina Faso, Rwanda, Comoros, Mozambique and Mali. Indeed, there seems to be an almost inverse relationship between the relative price of ICT services and income levels. A regression analysis, comparing income levels and IPB ranks, indicates an R-squared value of 0.86 , confirming that relatively high-income countries pay relatively little for ICT services, while low-income countries pay relatively high prices. Exceptions include the Russian Federation, Costa Rica, Lithuania and Mauritius: contrary to what is observed above, ICT prices in these countries are lower than the income levels would suggest. Kiribati, Swaziland and Lesotho, on the other hand, have ICT prices above what their income levels would suggest.

Not surprisingly, a similar trend can be observed in terms of development status, which is linked to income levels. In 46 out of 47 developed countries, the IPB value does not exceed five per cent of monthly per capita income. In 37 of them, it represents less than two per cent of monthly incomes. Higher values (above eight, indicating that prices are relatively high) for the IPB, on the other hand, are found only in developing countries (Chart 3.1). The map in Figure 3.2 illustrates the global differences in ICT prices.

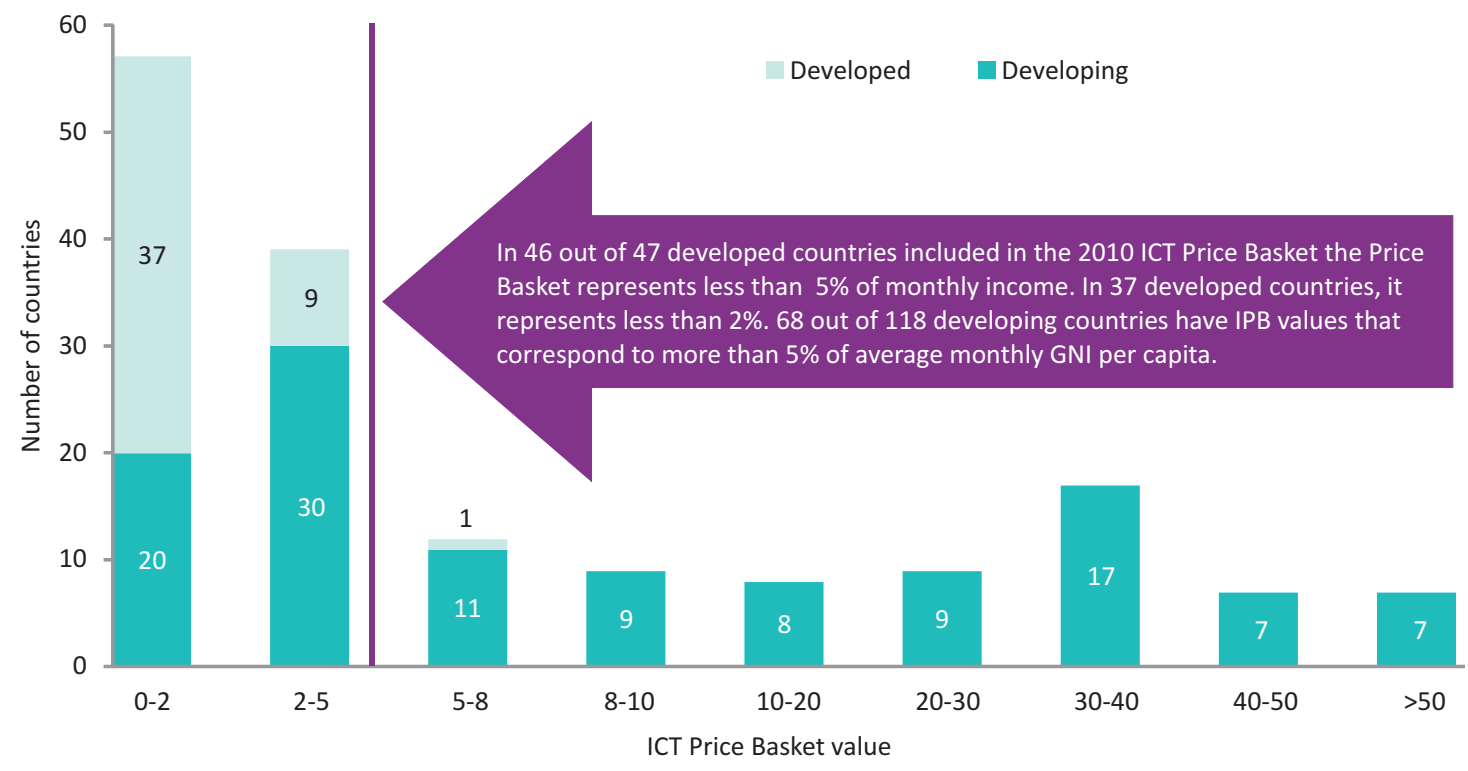


Table 3.1: ICT Price Basket and sub-baskets, 2010 and 2008

\begin{tabular}{|c|c|c|c|c|c|c|c|c|c|c|}
\hline \multirow[t]{2}{*}{ Rank } & Economy & ICT Pr & asket & $\begin{array}{l}\text { Fixed- } \\
\text { sub-ba } \\
\text { of GNI }\end{array}$ & $\begin{array}{l}\text { hone } \\
\text { as a } \% \\
\text { capita }\end{array}$ & $\begin{array}{r}\text { Mobil } \\
\text { sub-ba } \\
\text { of GNI }\end{array}$ & $\begin{array}{l}\text { Ilular } \\
\text { as a } \% \\
\text { capita }\end{array}$ & $\begin{array}{l}\text { Fixed-1 } \\
\text { sub-ba } \\
\text { of GNI }\end{array}$ & $\begin{array}{l}\text { dband } \\
\text { as a } \% \\
\text { capita }\end{array}$ & $\begin{array}{l}\text { GNI per capita, } \\
\text { USD, } 2009 \\
\text { (or latest }\end{array}$ \\
\hline & & 2010 & 2008 & 2010 & 2008 & 2010 & 2008 & 2010 & 2008 & available year) \\
\hline 1 & Monaco & 0.2 & N/A & 0.1 & N/A & 0.3 & N/A & 0.3 & $\mathrm{~N} / \mathrm{A}$ & 203 '900 \\
\hline 2 & Macao, China & 0.3 & 0.3 & 0.3 & 0.3 & 0.2 & 0.2 & 0.3 & 0.3 & $35 ' 360$ \\
\hline 3 & Liechtenstein & 0.4 & N/A & 0.3 & N/A & 0.2 & N/A & 0.5 & N/A & $113^{\prime} 210$ \\
\hline 4 & Hong Kong, China & 0.4 & 0.3 & 0.3 & 0.3 & 0.1 & 0.1 & 0.7 & 0.6 & $31^{\prime} 420$ \\
\hline 5 & United Arab Emirates & 0.4 & 0.4 & 0.1 & 0.1 & 0.2 & 0.2 & 0.8 & 0.8 & $57^{\prime} 340$ \\
\hline 6 & Singapore & 0.5 & 0.4 & 0.3 & 0.2 & 0.3 & 0.2 & 0.9 & 0.7 & $37^{\prime} 220$ \\
\hline 7 & Luxembourg & 0.5 & 0.5 & 0.4 & 0.4 & 0.4 & 0.4 & 0.6 & 0.6 & $76^{\prime} 710$ \\
\hline 8 & Norway & 0.5 & 0.5 & 0.5 & 0.5 & 0.3 & 0.3 & 0.7 & 0.7 & $84^{\prime} 640$ \\
\hline 9 & Iceland & 0.5 & 0.7 & 0.5 & 0.5 & 0.5 & 0.5 & 0.7 & 1.1 & $43^{\prime} 430$ \\
\hline 10 & Denmark & 0.6 & 0.5 & 0.6 & 0.6 & 0.2 & 0.2 & 0.9 & 0.6 & $59^{\prime} 060$ \\
\hline 11 & Austria & 0.6 & 1.1 & 0.7 & 0.7 & 0.4 & 1.2 & 0.7 & 1.5 & $46^{\prime} 450$ \\
\hline 12 & United States & 0.6 & 0.5 & 0.3 & 0.4 & 0.8 & 0.8 & 0.5 & 0.4 & $46^{\prime} 360$ \\
\hline 13 & San Marino & 0.6 & N/A & 0.6 & N/A & 0.6 & N/A & 0.5 & N/A & $50^{\prime} 670$ \\
\hline 14 & Finland & 0.6 & 0.7 & 0.4 & 0.5 & 0.3 & 0.7 & 0.9 & 0.9 & $45^{\prime} 940$ \\
\hline 15 & Sweden & 0.6 & 0.6 & 0.6 & 0.5 & 0.4 & 0.8 & 0.8 & 0.7 & $48^{\prime} 840$ \\
\hline 16 & Switzerland & 0.7 & 0.8 & 0.5 & 0.6 & 1.0 & 1.2 & 0.6 & 0.7 & $65^{\prime} 430$ \\
\hline 17 & Netherlands & 0.7 & 0.9 & 0.6 & 0.7 & 0.8 & 1.0 & 0.8 & 0.9 & $48^{\prime} 460$ \\
\hline 18 & Bahrain & 0.7 & 0.7 & 0.2 & 0.2 & 0.7 & 0.7 & 1.3 & 1.3 & $25^{\prime} 420$ \\
\hline 19 & United Kingdom & 0.7 & 0.8 & 0.6 & 0.7 & 0.9 & 1.0 & 0.7 & 0.7 & $41 ' 370$ \\
\hline 20 & Germany & 0.7 & 0.8 & 0.8 & 0.8 & 0.4 & 0.4 & 1.1 & 1.0 & $42^{\prime} 450$ \\
\hline 21 & Canada & 0.8 & 0.8 & 0.6 & 0.9 & 1.0 & 0.9 & 0.7 & 0.6 & $41 ' 980$ \\
\hline 22 & Cyprus & 0.8 & 0.7 & 1.1 & 1.1 & 0.3 & 0.4 & 0.9 & 0.7 & $26^{\prime} 940$ \\
\hline 23 & Australia & 0.8 & 1.1 & 0.8 & 0.7 & 0.8 & 1.2 & 1.0 & 1.4 & $43^{\prime} 770$ \\
\hline 24 & Belgium & 0.9 & 0.9 & 0.8 & 0.9 & 1.1 & 1.1 & 0.7 & 0.8 & $45^{\prime} 270$ \\
\hline 25 & Ireland & 0.9 & 0.9 & 0.7 & 1.0 & 1.0 & 0.9 & 0.9 & 0.9 & $44^{\prime} 280$ \\
\hline 26 & Korea (Rep.) & 0.9 & 0.8 & 0.3 & 0.3 & 0.9 & 1.1 & 1.5 & 1.0 & $19^{\prime} 830$ \\
\hline 27 & Israel & 0.9 & N/A & 0.7 & N/A & 1.6 & N/A & 0.4 & N/A & $25^{\prime} 790$ \\
\hline 28 & Italy & 0.9 & 1.0 & 0.9 & 0.9 & 1.0 & 1.2 & 0.9 & 0.8 & $35^{\prime} 110$ \\
\hline 29 & France & 1.0 & 1.2 & 0.7 & 0.8 & 1.4 & 1.6 & 0.8 & 1.0 & $42^{\prime} 620$ \\
\hline 30 & Trinidad \& Tobago & 1.1 & 1.2 & 1.4 & 1.5 & 0.9 & 1.1 & 0.9 & 1.0 & $16^{\prime} 700$ \\
\hline 31 & Latvia & 1.1 & 1.7 & 1.0 & 1.1 & 1.0 & 1.4 & 1.2 & 2.5 & $12^{\prime} 390$ \\
\hline 32 & Russia & 1.1 & 1.3 & 0.8 & 0.8 & 1.2 & 1.6 & 1.3 & 1.7 & $9 ' 340$ \\
\hline 33 & Costa Rica & 1.1 & 1.2 & 1.3 & 0.9 & 0.6 & 1.1 & 1.3 & 1.7 & $6^{\prime} 260$ \\
\hline 34 & Japan & 1.1 & 1.1 & 0.8 & 0.6 & 1.8 & 1.5 & 0.7 & 1.0 & $38^{\prime} 080$ \\
\hline 35 & Greece & 1.1 & 1.3 & 1.0 & 1.1 & 1.6 & 1.8 & 0.8 & 1.0 & $29^{\prime} 040$ \\
\hline 36 & Saudi Arabia & 1.1 & 1.5 & 0.6 & 0.6 & 1.0 & 1.1 & 1.8 & 2.7 & $17^{\prime} 700$ \\
\hline 37 & Lithuania & 1.2 & 1.5 & 1.4 & 1.5 & 1.0 & 1.4 & 1.1 & 1.5 & $11^{\prime} 410$ \\
\hline 38 & Brunei Darussalam & 1.2 & N/A & 0.5 & N/A & 0.7 & N/A & 2.3 & N/A & $26^{\prime} 740$ \\
\hline 39 & Oman & 1.2 & 1.1 & 0.9 & 0.7 & 0.6 & 0.7 & 2.1 & 2.1 & $17^{\prime} 890$ \\
\hline 40 & Slovenia & 1.2 & 1.4 & 0.9 & 1.0 & 1.1 & 1.1 & 1.7 & 2.1 & $23^{\prime} 520$ \\
\hline 41 & Malta & 1.3 & 1.6 & 0.9 & 1.0 & 1.6 & 2.2 & 1.3 & 1.5 & $16^{\prime} 680$ \\
\hline 42 & Bahamas & 1.3 & N/A & 0.9 & N/A & 1.0 & N/A & 2.0 & N/A & $21^{\prime} 390$ \\
\hline 43 & Spain & 1.3 & 1.5 & 1.0 & 1.1 & 2.0 & 2.2 & 1.0 & 1.0 & $32^{\prime} 120$ \\
\hline 44 & Portugal & 1.4 & 1.5 & 1.4 & 1.5 & 1.3 & 1.3 & 1.4 & 1.6 & $21 ' 910$ \\
\hline 45 & Croatia & 1.5 & 2.0 & 1.5 & 1.6 & 1.5 & 2.5 & 1.6 & 1.8 & $13^{\prime} 720$ \\
\hline 46 & Estonia & 1.6 & 2.1 & 1.0 & 1.1 & 1.9 & 2.2 & 1.8 & 3.1 & $14^{\prime} 060$ \\
\hline 47 & Mauritius & 1.6 & 2.3 & 0.9 & 1.0 & 1.1 & 1.3 & 2.7 & 4.6 & $7 ' 250$ \\
\hline 48 & Venezuela & 1.6 & 4.3 & 0.2 & 0.9 & 2.7 & 5.6 & 1.9 & 6.2 & $10^{\prime} 090$ \\
\hline 49 & New Zealand & 1.6 & 1.4 & 1.5 & 1.4 & 2.1 & 1.7 & 1.3 & 1.2 & $27^{\prime} 260$ \\
\hline 50 & Kazakhstan & 1.7 & N/A & 0.4 & $\mathrm{~N} / \mathrm{A}$ & 2.5 & N/A & 2.3 & $\mathrm{~N} / \mathrm{A}$ & 6 '920 \\
\hline 51 & Poland & 1.8 & 2.4 & 2.0 & 2.6 & 1.5 & 2.0 & 1.8 & 2.5 & $12^{\prime} 260$ \\
\hline 52 & Malaysia & 1.8 & 1.9 & 0.8 & 0.8 & 1.2 & 1.6 & 3.3 & 3.3 & 7'350 \\
\hline 53 & Azerbaijan & 1.8 & 9.9 & 0.6 & 0.8 & 1.7 & 2.2 & 3.1 & 26.7 & $4^{\prime} 840$ \\
\hline 54 & Maldives & 1.9 & 2.2 & 1.2 & 1.3 & 1.7 & 2.1 & 2.8 & 3.0 & 3'970 \\
\hline 55 & Romania & 1.9 & 2.2 & 1.9 & 2.0 & 3.1 & 3.5 & 0.7 & 1.0 & $8^{\prime} 330$ \\
\hline 56 & Belarus & 2.0 & N/A & 0.3 & N/A & 1.7 & N/A & 3.9 & N/A & $5^{\prime} 560$ \\
\hline 57 & Czech Republic & 2.0 & 2.2 & 1.9 & 2.1 & 1.9 & 2.5 & 2.2 & 2.0 & $17 ' 310$ \\
\hline 58 & Hungary & 2.1 & 2.6 & 2.0 & 2.6 & 2.4 & 3.0 & 1.9 & 2.2 & $12^{\prime} 980$ \\
\hline 59 & Slovak Republic & 2.1 & 2.2 & 1.5 & 1.7 & 2.8 & 2.9 & 1.9 & 2.0 & $16^{\prime} 130$ \\
\hline 60 & Serbia & 2.1 & 3.3 & 1.1 & 1.0 & 2.3 & 2.5 & 3.1 & 6.4 & $6^{\prime} 000$ \\
\hline 61 & Uruguay & 2.2 & 2.8 & 1.8 & 1.9 & 2.4 & 3.1 & 2.6 & 3.5 & 9'010 \\
\hline 62 & Panama & 2.3 & 2.1 & 2.2 & 1.7 & 1.6 & 1.7 & 3.0 & 2.9 & $6^{\prime} 570$ \\
\hline 63 & Sri Lanka & 2.4 & 7.3 & 3.0 & 3.5 & 1.1 & 2.6 & 3.0 & 15.7 & $1^{\prime} 990$ \\
\hline 64 & Mexico & 2.4 & 3.0 & 2.5 & 2.5 & 2.3 & 2.3 & 2.3 & 4.2 & $8^{\prime} 960$ \\
\hline 65 & Tunisia & 2.5 & 3.1 & 0.8 & 1.0 & 3.2 & 4.3 & 3.4 & 4.1 & $3^{\prime} 720$ \\
\hline 66 & St. Kitts and Nevis & 2.5 & N/A & 1.4 & $\mathrm{~N} / \mathrm{A}$ & 1.8 & N/A & 4.3 & N/A & $10^{\prime} 150$ \\
\hline 67 & Antigua \& Barbuda & 2.5 & $\mathrm{~N} / \mathrm{A}$ & 1.4 & N/A & 2.2 & N/A & 4.0 & N/A & $12^{\prime} 130$ \\
\hline 68 & Montenegro & 2.6 & 2.8 & 1.4 & 1.9 & 3.0 & 2.8 & 3.3 & 3.8 & $6^{\prime} 650$ \\
\hline 69 & Ukraine & 2.6 & 4.6 & 1.3 & 1.5 & 3.2 & 5.2 & 3.2 & 7.1 & $2^{\prime} 800$ \\
\hline 70 & Qatar & 2.7 & 2.7 & 0.9 & 0.9 & 1.8 & 1.7 & 5.5 & 5.5 & $12^{\prime} 000$ \\
\hline 71 & Algeria & 3.0 & 3.5 & 1.5 & 1.3 & 3.4 & 4.4 & 4.0 & 4.8 & $4^{\prime} 420$ \\
\hline 72 & Lebanon & 3.0 & 3.8 & 1.5 & 1.8 & 4.1 & 5.7 & 3.4 & 4.0 & $8^{\prime} 060$ \\
\hline 73 & China & 3.1 & 3.7 & 1.5 & 1.5 & 2.0 & 2.3 & 5.9 & 7.4 & $3^{\prime} 650$ \\
\hline 74 & Argentina & 3.2 & 3.5 & 0.6 & 0.8 & 4.9 & 3.4 & 4.1 & 6.3 & 7'550 \\
\hline 75 & Bosnia and Herzegovina & 3.3 & 3.7 & 2.4 & 2.4 & 3.9 & 4.8 & 3.7 & 3.8 & $4^{\prime} 700$ \\
\hline 76 & Barbados & 3.4 & 3.8 & 2.6 & 2.4 & 2.6 & 2.6 & 5.0 & 6.4 & 9'330 \\
\hline 77 & Seychelles & 3.5 & 2.8 & 1.3 & 1.1 & 2.3 & 1.9 & 6.8 & 5.5 & $8^{\prime} 480$ \\
\hline 78 & Egypt & 3.5 & 4.4 & 1.7 & 2.0 & 4.1 & 5.6 & 4.6 & 5.5 & $2^{\prime} 070$ \\
\hline 79 & Bhutan & 3.6 & 14.7 & 2.0 & 2.2 & 2.7 & 3.6 & 6.2 & 38.3 & $2^{\prime} 030$ \\
\hline 80 & Turkey & 3.7 & N/A & 2.3 & $\mathrm{~N} / \mathrm{A}$ & 6.0 & N/A & 2.6 & $\mathrm{~N} / \mathrm{A}$ & $8^{\prime} 720$ \\
\hline 81 & Chile & 3.7 & 4.1 & 3.2 & 3.1 & 3.0 & 3.2 & 5.0 & 6.0 & $9^{\prime} 470$ \\
\hline 82 & Bulgaria & 3.7 & 4.4 & 2.5 & 2.9 & 6.1 & 7.2 & 2.7 & 3.1 & $6^{\prime} 060$ \\
\hline 83 & Thailand & 3.9 & 3.7 & 2.8 & 1.9 & 2.8 & 3.4 & 6.0 & 5.8 & $3^{\prime} 760$ \\
\hline
\end{tabular}


Table 3.1: ICT Price Basket and sub-baskets, 2010 and 2008 (continued)

\begin{tabular}{|c|c|c|c|c|c|c|c|c|c|c|}
\hline \multirow[t]{2}{*}{ Rank } & \multirow[t]{2}{*}{ Economy } & ICT Pr & asket & $\begin{array}{l}\text { Fixed-t } \\
\text { sub-ba: } \\
\text { of GNI }\end{array}$ & $\begin{array}{l}\text { hone } \\
\text { as a } \% \\
\text { capita }\end{array}$ & $\begin{array}{l}\text { Mobil } \\
\text { sub-ba } \\
\text { of GNI }\end{array}$ & $\begin{array}{l}\text { llular } \\
\text { as a } \% \\
\text { capita }\end{array}$ & $\begin{array}{l}\text { Fixed-b } \\
\text { sub-ba } \\
\text { of GNI }\end{array}$ & $\begin{array}{l}\text { adband } \\
t \text { as a \% } \\
\text { capita }\end{array}$ & $\begin{array}{l}\text { GNI per capita, } \\
\text { USD, } 2009 \\
\text { (or latest }\end{array}$ \\
\hline & & 2010 & 2008 & 2010 & 2008 & 2010 & 2008 & 2010 & 2008 & available year) \\
\hline 84 & Jordan & 3.9 & 4.4 & 2.9 & 3.1 & 3.2 & 3.4 & 5.7 & 6.7 & 3'980 \\
\hline 85 & Botswana & 3.9 & 3.5 & 3.6 & 3.2 & 2.5 & 2.4 & 5.7 & 5.0 & $6^{\prime} 260$ \\
\hline 86 & Grenada & 4.0 & 3.8 & 2.6 & 2.4 & 3.1 & 3.2 & 6.3 & 6.0 & $5^{\prime} 580$ \\
\hline 87 & India & 4.1 & 4.6 & 3.3 & 3.7 & 3.4 & 3.9 & 5.6 & 6.4 & $1^{\prime} 180$ \\
\hline 88 & Jamaica & 4.2 & 6.0 & 3.0 & 2.6 & 3.1 & 3.6 & 6.5 & 11.9 & 4'590 \\
\hline 89 & Albania & 4.3 & 7.7 & 1.9 & 1.3 & 7.7 & 12.6 & 3.2 & 9.2 & $4^{\prime} 000$ \\
\hline 90 & TFYR Macedonia & 4.4 & 5.1 & 3.3 & 3.9 & 6.4 & 7.4 & 3.5 & 4.1 & $4^{\prime} 400$ \\
\hline 91 & Dominican Rep. & 4.4 & 5.1 & 4.1 & 3.1 & 4.1 & 4.7 & 5.0 & 7.6 & 4'550 \\
\hline 92 & St. Vincent and the Grenadines & 4.6 & 6.7 & 2.6 & 2.5 & 3.5 & 4.5 & 7.9 & 12.9 & $5^{\prime} 130$ \\
\hline 93 & Colombia & 4.7 & 4.9 & 1.4 & 1.3 & 4.1 & 4.4 & 8.5 & 8.8 & $4^{\prime} 990$ \\
\hline 94 & Fiji & 4.7 & 6.0 & 2.4 & 2.8 & 5.9 & 7.8 & 5.7 & 7.3 & $3^{\prime} 840$ \\
\hline 95 & Suriname & 4.8 & N/A & 0.6 & N/A & 3.3 & N/A & 10.6 & N/A & $4^{\prime} 760$ \\
\hline 96 & Brazil & 4.8 & 6.8 & 3.4 & 4.2 & 8.5 & 9.2 & 2.5 & 6.9 & $8^{\prime} 040$ \\
\hline 97 & Ecuador & 4.8 & N/A & 4.3 & N/A & 4.2 & N/A & 6.1 & N/A & $3^{\prime} 970$ \\
\hline 98 & St. Lucia & 4.9 & 6.5 & 2.7 & 2.6 & 5.1 & 4.7 & 6.8 & 12.2 & $5^{\prime} 190$ \\
\hline 99 & South Africa & 5.3 & 4.5 & 5.2 & 4.2 & 4.8 & 4.5 & 5.7 & 4.9 & $5^{\prime} 760$ \\
\hline 100 & El Salvador & 5.3 & 5.5 & 3.6 & 3.9 & 3.4 & 5.6 & 8.9 & 7.1 & $3^{\prime} 370$ \\
\hline 101 & Moldova & 5.4 & 10.8 & 1.5 & 1.8 & 9.7 & 12.0 & 5.0 & 18.5 & $1^{\prime} 560$ \\
\hline 102 & Armenia & 5.9 & 7.0 & 1.6 & 1.8 & 3.4 & 5.2 & 12.5 & 14.0 & $3^{\prime} 100$ \\
\hline 103 & Dominica & 6.0 & 6.6 & 2.6 & 2.7 & 3.5 & 5.1 & 11.7 & 12.0 & $4^{\prime} 900$ \\
\hline 104 & Paraquay & 6.1 & 10.2 & 3.6 & 4.0 & 4.6 & 5.3 & 10.1 & 21.4 & $2^{\prime} 250$ \\
\hline 105 & Indonesia & 6.7 & 7.2 & 2.9 & 3.0 & 4.6 & 5.4 & 12.6 & 13.2 & $2^{\prime} 050$ \\
\hline 106 & Guatemala & 6.9 & 8.0 & 2.5 & 2.7 & 3.6 & 4.2 & 14.7 & 17.1 & $2^{\prime} 650$ \\
\hline 107 & Syria & 7.1 & N/A & 0.6 & N/A & 9.9 & N/A & 10.8 & N/A & $2^{\prime} 410$ \\
\hline 108 & Viet Nam & 7.9 & 12.2 & 3.2 & 3.2 & 7.0 & 9.9 & 13.5 & 23.5 & 930 \\
\hline 109 & Pakistan & 8.0 & 10.0 & 4.0 & 4.5 & 3.0 & 3.8 & 17.1 & 21.7 & $1 ' 000$ \\
\hline 110 & Honduras & 8.3 & N/A & 4.2 & N/A & 5.9 & N/A & 14.7 & N/A & $1^{\prime} 800$ \\
\hline 111 & Georgia & 8.4 & 10.4 & 1.1 & 1.3 & 5.5 & 6.8 & 18.7 & 23.0 & $2^{\prime} 530$ \\
\hline 112 & Guyana & 8.5 & 17.7 & 2.1 & 2.1 & 7.8 & 10.3 & 15.7 & 40.6 & $1 ' 450$ \\
\hline 113 & Tonga & 8.8 & 14.7 & 2.3 & 2.2 & 4.0 & 3.8 & 19.9 & 38.1 & $3^{\prime} 260$ \\
\hline 114 & Philippines & 9.2 & 9.5 & 9.0 & 8.7 & 5.9 & 5.5 & 12.8 & 14.3 & $2^{\prime} 050$ \\
\hline 115 & Micronesia & 9.3 & 9.3 & 4.5 & 3.9 & 4.4 & 4.4 & 19.2 & 19.5 & $2^{\prime} 500$ \\
\hline 116 & Peru & 9.5 & 9.9 & 4.2 & 4.6 & 12.4 & 14.3 & 12.1 & 10.8 & $4^{\prime} 200$ \\
\hline 117 & Morocco & 9.6 & 12.5 & 9.2 & 11.1 & 14.3 & 17.2 & 5.1 & 9.2 & $2^{\prime} 770$ \\
\hline 118 & Cape Verde & 10.8 & 12.6 & 3.3 & 2.3 & 16.6 & 19.4 & 12.6 & 16.2 & $3^{\prime} 010$ \\
\hline 119 & Namibia & 11.9 & 7.5 & 4.3 & 3.7 & 4.8 & 4.9 & 26.7 & 13.7 & $4^{\prime} 270$ \\
\hline 120 & Bangladesh & 12.6 & 36.4 & 2.8 & 3.1 & 4.2 & 6.0 & 31.0 & 123.8 & 580 \\
\hline 121 & Samoa & 12.7 & N/A & 5.1 & N/A & 7.5 & N/A & 25.7 & N/A & $2^{\prime} 840$ \\
\hline 122 & Ghana & 15.5 & 26.2 & 7.3 & 4.5 & 7.4 & 10.8 & 31.8 & 63.1 & $1^{\prime} 190$ \\
\hline 123 & Belize & 16.3 & 16.6 & 6.3 & 7.5 & 10.0 & 10.0 & 32.8 & 32.3 & $3^{\prime} 740$ \\
\hline 124 & Bolivia & 17.2 & 18.7 & 17.5 & 19.0 & 8.3 & 9.1 & 25.7 & 28.0 & $1 ' 630$ \\
\hline 125 & Angola & 18.0 & 24.7 & 5.3 & 7.3 & 6.2 & 8.1 & 42.7 & 58.8 & $3^{\prime} 750$ \\
\hline 126 & Nicaragua & 20.9 & 24.2 & 5.4 & 5.8 & 15.8 & 27.4 & 41.4 & 39.4 & $1 ' 000$ \\
\hline 127 & Timor-Leste & 21.5 & N/A & 8.4 & N/A & 7.9 & N/A & 48.3 & N/A & $2^{\prime} 460$ \\
\hline 128 & Senegal & 22.7 & 28.7 & 11.8 & 20.4 & 14.6 & 16.4 & 41.6 & 49.2 & $1 ' 040$ \\
\hline 129 & Mauritania & 23.4 & 38.0 & 22.5 & 18.2 & 18.3 & 18.6 & 29.4 & 77.1 & 960 \\
\hline 130 & Djibouti & 24.7 & 40.4 & 7.7 & 8.1 & 14.0 & 13.1 & 52.3 & 111.6 & $1^{\prime} 280$ \\
\hline 131 & Nepal & 26.4 & 28.9 & 8.5 & 9.7 & 7.3 & 12.6 & 63.4 & 64.5 & 440 \\
\hline 132 & Nigeria & 27.2 & 44.1 & 14.1 & 10.3 & 13.9 & 22.0 & 53.5 & 692.1 & 1'190 \\
\hline 133 & Kyrgyzstan & 27.3 & N/A & 1.7 & N/A & 4.9 & $\mathrm{~N} / \mathrm{A}$ & 75.3 & N/A & 870 \\
\hline 134 & Côte d'Ivoire & 27.4 & 37.4 & 22.0 & 26.7 & 15.3 & 30.8 & 45.0 & 54.7 & $1 ' 070$ \\
\hline 135 & Uganda & 30.2 & 61.8 & 22.8 & 34.9 & 31.8 & 50.4 & 35.9 & 374.9 & 460 \\
\hline 136 & Tanzania & 31.4 & 57.0 & 21.1 & 28.1 & 23.2 & 43.1 & 50.0 & 174.4 & 500 \\
\hline 137 & Chad & 32.5 & 43.2 & 37.0 & 41.2 & 34.1 & 59.1 & 26.3 & 29.3 & 540 \\
\hline 138 & Kenya & 33.1 & 49.8 & 22.4 & 18.0 & 17.0 & 31.5 & 59.9 & 261.2 & 760 \\
\hline 139 & Uzbekistan & 34.8 & N/A & 1.2 & N/A & 3.3 & N/A & 218.2 & N/A & $1^{\prime} 100$ \\
\hline 140 & Tajikistan & 34.9 & N/A & 1.5 & N/A & 3.2 & N/A & 621.4 & N/A & 700 \\
\hline 141 & Cuba & 35.8 & 36.5 & 0.1 & 0.1 & 7.3 & 9.3 & 379.0 & 380.6 & $5^{\prime} 550$ \\
\hline 142 & Vanuatu & 35.9 & 41.5 & 18.8 & 11.8 & 10.7 & 12.7 & 78.3 & 209.3 & $2^{\prime} 620$ \\
\hline 143 & Lesotho & 36.0 & 30.7 & 15.9 & 13.6 & 29.6 & 25.2 & 62.4 & 53.2 & 980 \\
\hline 144 & Yemen & 36.8 & 37.4 & 1.2 & 1.0 & 9.2 & 11.0 & 134.9 & 281.6 & $1 ' 060$ \\
\hline 145 & Lao P.D.R. & 38.0 & 38.6 & 5.5 & 6.4 & 8.6 & 9.5 & 190.5 & 435.5 & 880 \\
\hline 146 & Swaziland & 38.1 & 37.3 & 2.4 & 2.1 & 11.7 & 10.0 & 424.9 & 805.7 & $2^{\prime} 470$ \\
\hline 147 & Benin & 38.5 & 50.2 & 14.4 & 17.5 & 20.9 & 33.1 & 80.2 & 172.3 & 750 \\
\hline 148 & Cameroon & 38.8 & 48.7 & 15.2 & 15.0 & 20.2 & 31.1 & 80.8 & 185.7 & 1'190 \\
\hline 149 & Ethiopia & 39.5 & 44.2 & 3.5 & 6.3 & 14.9 & 26.5 & 1070.8 & 2721.4 & 330 \\
\hline 150 & Guinea & 39.5 & 42.2 & 5.2 & 9.6 & 13.4 & 17.1 & 2594.6 & 2823.5 & 370 \\
\hline 151 & Kiribati & 39.6 & N/A & 7.6 & N/A & 11.3 & N/A & 251.2 & N/A & $1 ' 830$ \\
\hline 152 & Cambodia & 40.1 & 44.5 & 14.5 & 15.7 & 13.2 & 17.6 & 92.5 & 177.3 & 610 \\
\hline 153 & S. Tomé \& Principe & 40.7 & 43.3 & 8.7 & 12.2 & 13.4 & 17.8 & 300.4 & 316.2 & $1^{\prime} 140$ \\
\hline 154 & Zambia & 41.3 & 52.9 & 29.8 & 33.0 & 20.8 & 25.8 & 73.3 & 108.8 & 970 \\
\hline 155 & Papua New Guinea & 42.8 & 43.1 & 4.6 & 4.3 & 23.7 & 25.1 & 142.5 & 150.9 & $1^{\prime} 180$ \\
\hline 156 & Mali & 43.0 & 50.1 & 15.0 & 18.7 & 25.5 & 31.7 & 88.4 & 109.8 & 680 \\
\hline 157 & Mozambique & 46.6 & 71.8 & 33.7 & 55.0 & 46.2 & 60.4 & 59.8 & 311.9 & 440 \\
\hline 158 & Comoros & 49.1 & 53.7 & 13.8 & 17.9 & 33.5 & 43.2 & 534.5 & 690.8 & 870 \\
\hline 159 & Rwanda & 56.9 & 58.1 & 34.4 & 21.2 & 36.3 & 53.1 & 224.5 & 267.6 & 460 \\
\hline 160 & Burkina Faso & 58.5 & 62.6 & 25.6 & 24.6 & 49.9 & 63.2 & 194.2 & 4466.2 & 510 \\
\hline 161 & Togo & 61.5 & 72.2 & 30.1 & 35.0 & 54.3 & 81.5 & 451.5 & 539.9 & 440 \\
\hline 162 & Madagascar & 65.4 & 71.6 & 52.1 & 49.9 & 44.1 & 65.0 & 259.0 & 327.8 & 420 \\
\hline 163 & Zimbabwe & 66.2 & N/A & 30.2 & N/A & 68.3 & N/A & 1353.2 & N/A & 360 \\
\hline 164 & Malawi & 69.7 & 66.8 & 18.2 & 15.4 & 91.0 & 85.0 & 2408.0 & 4880.7 & 280 \\
\hline 165 & Niger & 71.6 & 77.1 & 41.3 & 47.4 & 73.4 & 83.9 & 210.5 & 241.6 & 340 \\
\hline
\end{tabular}

Note: N/A: Not available.

Source: ITU. 


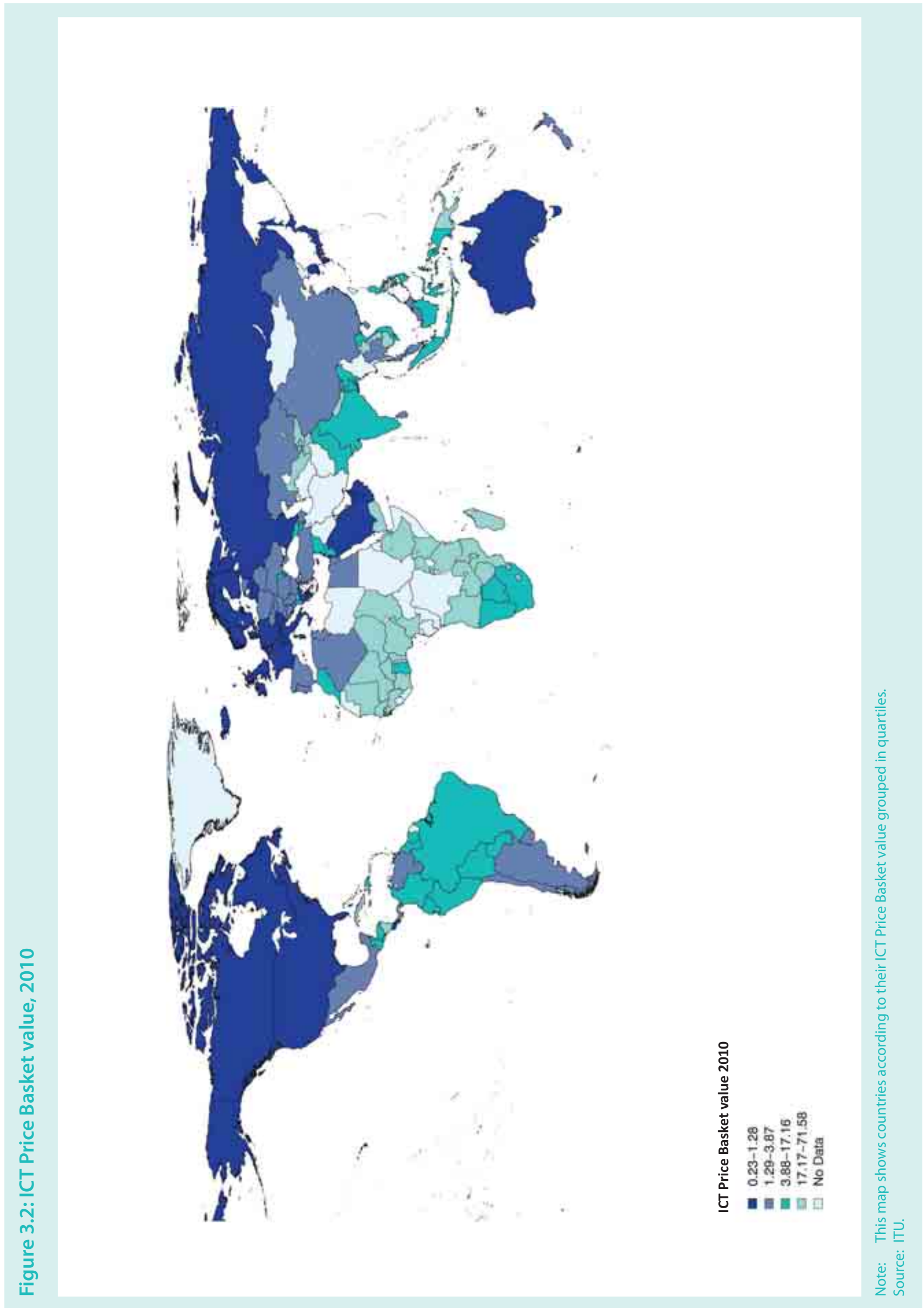


Chart 3.2: Relationship between the ICT Development Index and the ICT Price Basket

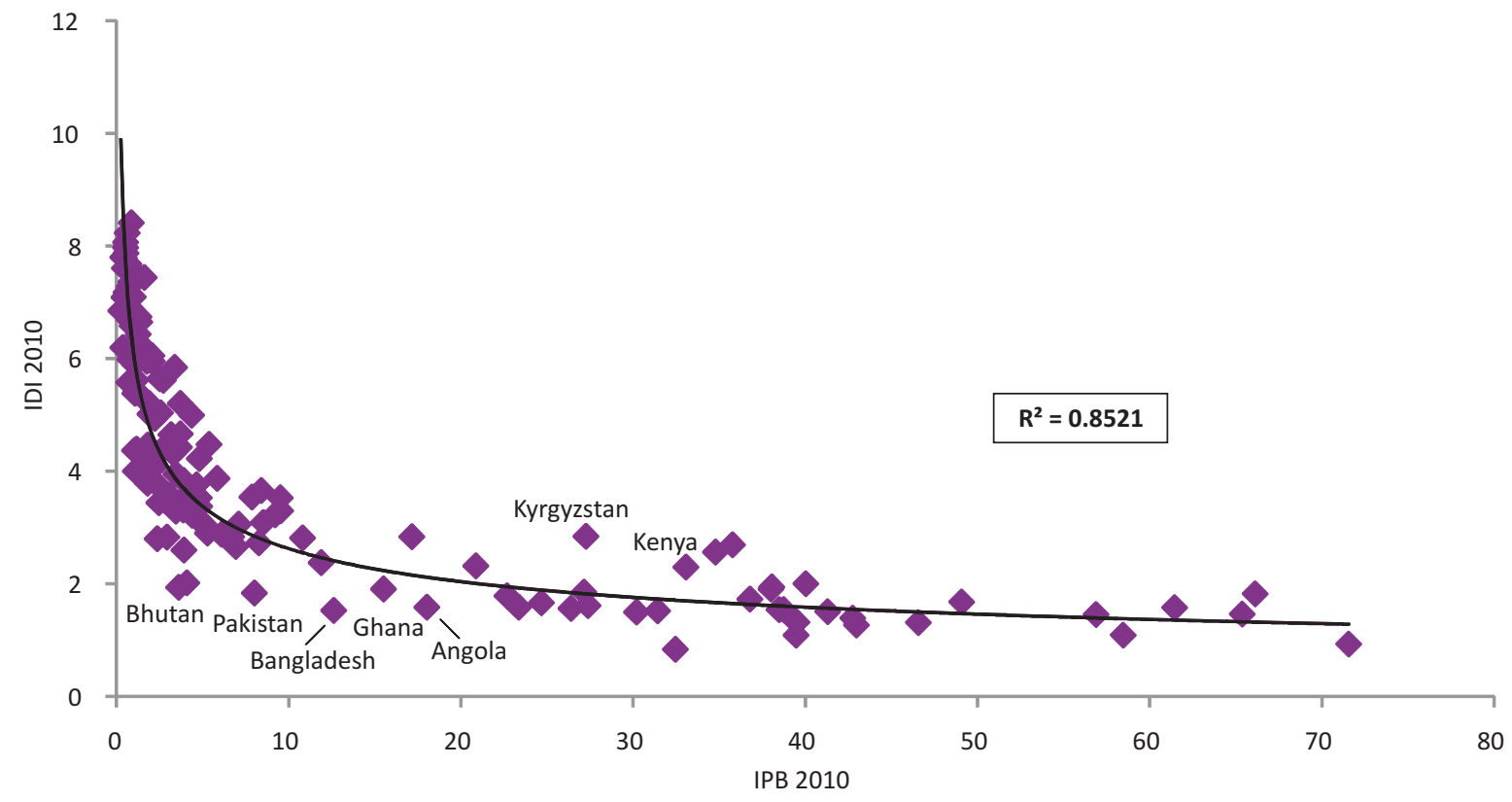

Source: ITU.

Similarly, a comparison of the IPB results with the IDI results (see Chapter 2) shows that countries with relatively high ICT prices have relatively low levels of ICT access and use. Conversely, more people access and use ICTs in countries where ICT services are relatively affordable and almost all of the countries listed in the top 25 of the IDI also rank within the top 25 of the IPB. The close link between ICT prices and uptake is illustrated in Chart 3.2, which plots the results of the IPB against those of the IDI. The comparison also shows that in 69 out of 70 countries where the IDI value is above four (up to a maximum of 8.4, achieved by the Republic of Korea), the IPB value is below five. These findings underline that prices and affordability are an important factor for ICT uptake. Some countries, including Bhutan, Pakistan, Bangladesh, Ghana and Angola, have IDI values that are relatively low in relation to ICT prices, suggesting that in these countries other barriers to higher ICT development levels need to be addressed. These include challenges related to rolling out infrastructure and providing access in more remote and rural areas, making available relevant online content, and increasing educational levels and skills. Some other countries, including Kyrgyzstan and Kenya, lie somewhat above the IDI/IPB trend line, suggesting that despite relatively high prices, they have achieved relatively high ICT development levels.
Comparing the 2010 and 2008 ICT Price Baskets shows that over the last two years there has been an important overall drop in ICT prices for the 143 economies that were included in both years. Prices have come down by an average of 18.3 per cent, with the IPB falling from 15.2 in 2008 to 12.4 in 2010 . The biggest decrease was in fixed-broadband Internet services, where prices have come down by no less than 52.2 per cent. This compares with a decrease of 21.8 per cent in mobile-cellular services and 6.8 per cent in fixed telephony, over the same twoyear period (Table 3.2).

A comparison between developed and developing economies shows that the percentage change (drop) in prices between 2008 and 2010 was somewhat greater in developed countries, where prices have decreased by 23.5 per cent, compared to 18.0 per cent in developing countries (Chart 3.3). While this would suggest that there is a risk of the price divide widening and that developing countries are falling further behind, it must be noted that the percentage change in developing countries would be much higher if the sub-baskets were not capped at a maximum of 100 per cent (i.e. the monthly price for a sub-basket cannot exceed the monthly average GNI per capita). This means that the drop in prices is not fully reflected in the IPB for those countries that actu- 
Table 3.2: ICT Price Basket and sub-baskets (averages), 2010 and 2008*

\begin{tabular}{|l|c|c|c|c|}
\hline & & & \multicolumn{2}{|c|}{ Average 2008/2010 value decrease } \\
\cline { 3 - 5 } & $\mathbf{2 0 0 8}$ & $\mathbf{2 0 1 0}$ & Absolute & Percentage \\
\hline ICT Price Basket & 15.2 & 12.4 & 2.8 & 18.3 \\
\hline Fixed-telephone sub-basket & 6.2 & 5.8 & 0.4 & 6.8 \\
\hline Mobile-cellular sub-basket & 11.0 & 8.6 & 2.4 & 21.8 \\
\hline Fixed-broadband sub-basket & 165.0 & 78.9 & 86.1 & 52.2 \\
\hline
\end{tabular}

Note: *Simple averages. Discrepancies may be due to rounding. Both the 2008 and the 2010 averages are based on the 143 economies for which data are available for both years.

Source: ITU.

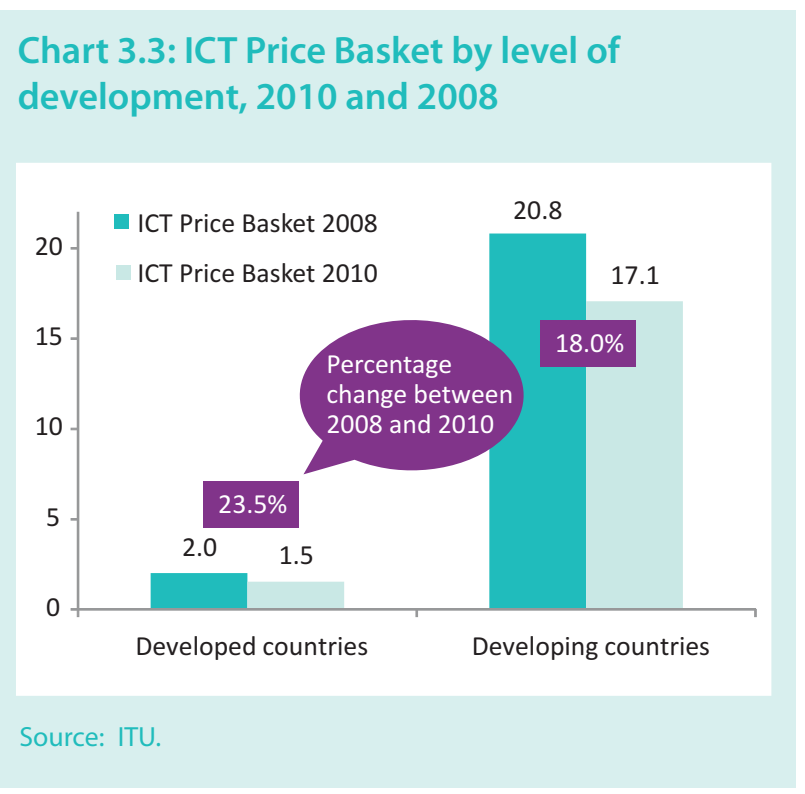

ally exceed the 100 per cent maximum for one of the sub-baskets. This is the case for 19 developing countries, where the fixed-broadband sub-basket exceeds 100. For more information on the sub-baskets and the percentage changes between developed and developing regions, see section 3.4.

Between 2008 and 2010, the steepest fall in the IPB in relative terms was observed in countries from different regions, and with varying income levels. Relative prices decreased by over 50 per cent in Azerbaijan, Bhutan, Sri Lanka, Bangladesh, Venezuela, Guyana, Uganda and Austria (Table 3.3, left). The top ten countries with the greatest IPB value drop are countries with high IPB values and, apart from Bangladesh, all are from Africa
(Table 3.3, right). For countries in both groups, there was a steep drop in the fixed-broadband prices, and for several countries, including Azerbaijan, Bhutan, Benin, Kenya, Sri Lanka, Tanzania and Uganda, mobile tariffs also came down considerably.

\subsection{IPB sub-basket results and analysis}

The ICT Price Basket is calculated on the basis of three distinct price components - fixed telephony, mobilecellular telephony and fixed-broadband Internet services - which each include different subscription and usage charges, such as the monthly subscription and a certain number of calls and text messages (Figure 3.1). The composition of each sub-basket is based on a minimum usage level, intended to reflect first and foremost user patterns of low-income subscribers. The results of the IPB are therefore an indication of relative prices and do not, for example, show what high-end users typically pay. Since the overall IPB value hides differences in the absolute and relative prices of each of the three distinct services, it is useful to look at each component/ sub-basket separately.

Since the three sub-baskets refer to very different services which each have their own pricing structures and particularities, and despite the fact that they are all based on entry-level plans, they are not strictly comparable. Both the fixed and the mobile-cellular telephone subbaskets include 30 voice calls, but the former includes the monthly subscription, whereas the latter, based on prepaid services that do not include a monthly subscription, includes $100 \mathrm{sms}$. The fixed-broadband sub-basket 
Table 3.3: Ten economies with the greatest 2008-2010 decrease in the ICT Price Basket, by relative change (in \%, left) and absolute value change (right)

\begin{tabular}{|c|c|c|c|c|c|}
\hline $\begin{array}{l}2010 \\
\text { Rank }\end{array}$ & Country & $\begin{array}{c}\text { IPB } \\
2010\end{array}$ & $\begin{array}{c}\text { IPB } \\
2008\end{array}$ & $\begin{array}{c}\text { Relative } \\
\text { change } \\
2008- \\
2010 \\
(\%)\end{array}$ & $\begin{array}{c}\text { Value } \\
\text { change } \\
2008- \\
2010\end{array}$ \\
\hline 53 & Azerbaijan & 1.8 & 9.9 & 81.7 & -8.1 \\
\hline 79 & Bhutan & 3.6 & 14.7 & 75.4 & -11.1 \\
\hline 63 & Sri Lanka & 2.4 & 7.3 & 67.4 & -4.9 \\
\hline 120 & Bangladesh & 12.6 & 36.4 & 65.2 & -23.7 \\
\hline 48 & Venezuela & 1.6 & 4.3 & 62.9 & -2.7 \\
\hline 112 & Guyana & 8.5 & 17.7 & 51.6 & -9.1 \\
\hline 135 & Uganda & 30.2 & 61.8 & 51.1 & -31.6 \\
\hline 11 & Austria & 0.6 & 1.1 & 50.4 & -0.6 \\
\hline 101 & Moldova & 5.4 & 10.8 & 49.8 & -5.4 \\
\hline 136 & Tanzania & 31.4 & 57.0 & 44.9 & -25.6 \\
\hline
\end{tabular}

\begin{tabular}{|l|l|c|c|c|c|}
\hline $\begin{array}{l}\mathbf{2 0 1 0} \\
\text { Rank }\end{array}$ & Country & $\begin{array}{c}\text { IPB } \\
\mathbf{2 0 1 0}\end{array}$ & $\begin{array}{c}\text { IPB } \\
\mathbf{2 0 0 8}\end{array}$ & $\begin{array}{c}\text { Value } \\
\text { change } \\
\mathbf{2 0 0 8 -} \\
\mathbf{2 0 1 0}\end{array}$ & $\begin{array}{c}\text { Relative } \\
\text { change } \\
\mathbf{2 0 0 8 -} \\
\mathbf{2 0 1 0} \\
\mathbf{( \% )}\end{array}$ \\
\hline $\mathbf{1 3 5}$ & Uganda & 30.2 & 61.8 & -31.6 & 51.1 \\
\hline 136 & Tanzania & 31.4 & 57.0 & -25.6 & 44.9 \\
\hline 157 & Mozambique & 46.6 & 71.8 & -25.2 & 35.1 \\
\hline 120 & Bangladesh & 12.6 & 36.4 & -23.7 & 65.2 \\
\hline 132 & Nigeria & 27.2 & 44.1 & -17.0 & 38.4 \\
\hline 138 & Kenya & 33.1 & 49.8 & -16.7 & 33.6 \\
\hline 130 & Djibouti & 24.7 & 40.4 & -15.7 & 38.9 \\
\hline 129 & Mauritania & 23.4 & 38.0 & -14.6 & 38.4 \\
\hline 147 & Benin & 38.5 & 50.2 & -11.7 & 23.3 \\
\hline 154 & Zambia & 41.3 & 52.9 & -11.6 & 21.9 \\
\hline
\end{tabular}

Source: ITU.

is very different again, in that it refers to an Internet connection which, although based on a minimum $1 \mathrm{~GB}$ of volume, (often) provides unlimited access to the Internet. Not surprisingly, it is the most expensive sub-basket of the three, at more than nine times the value of the mobile-cellular and 13 times the value of the fixed-telephone sub-basket.

Besides important variations in relative and absolute ICT prices between the different ICT services, absolute prices also vary between countries. For example, prices for the fixed-telephone sub-basket range from as little as USD 0.3 in Cuba to USD 41 in Vanuatu. For the same amount of monthly mobile calls and sms, people in Hong Kong (China) pay USD 1.4, while Brazilians pay USD 57.1. The greatest variations are for a monthly fixed-broadband connection, for which Romanians pay USD 4.8, compared with over USD 1750 that Cubans need to pay.

The following section presents the results of each of the three sub-baskets and highlights the key changes that have taken place between 2008 and 2010. Prices are presented as a percentage of GNI per capita, in absolute USD and in PPP\$. It is important to note that the individual sub-baskets, which were capped at a maximum of 100 (in cases where the sub-basket exceeds the average monthly GNI per capita) in the calculation of the overall IPB, were not capped for this presentation and analysis at the sub-basket level, so that they may exceed 100. This is to show the actual (high) price of ICT services in some countries.

\section{Fixed-telephone sub-basket}

\section{Fixed-telephone prices as a percentage of GNI per capita}

In 2010, the average fixed-telephone sub-basket, which includes the price of the monthly subscription plus 30 local calls - half peak and half off-peak - of three minutes each, corresponded to 5.8 per cent of monthly GNI per capita. This is about two-thirds the price of the mobile-cellular sub-basket, and only seven per cent of the fixed-broadband sub-basket. The fixed-telephone price sub-basket decreased on average by 6.8 per cent in relation to 2008 , which is the smallest percentage change of all three sub-baskets (Table 3.2).

The results for the fixed-telephone sub-basket are presented in Table 3.4. Unlike in the overall IPB, the top ten economies with the lowest relative prices in 2010 are very diverse in terms of income level, development status and region. The list includes Cuba, the United Arab Emirates, Monaco, Venezuela, Bahrain, Singapore, Belarus and the Republic of Korea. For a number of countries, there are substantial differences between their overall IPB rank and their fixed-telephone sub-basket rank, and fixed-telephony prices are relatively cheap, compared to mobile and broadband services. It should be noted that the fixed-telephone sub-basket does not include the price of the (one-time) connection charge, which is relatively high in a number of countries, including in the United Arab Emirates (about USD 49) and Finland (over USD 100). In some countries, citizens 
Table 3.4: Fixed-telephone sub-basket, 2010 and 2008

\begin{tabular}{|c|c|c|c|c|c|c|c|c|}
\hline \multirow[t]{2}{*}{ Rank } & \multirow[t]{2}{*}{ Economy } & $\begin{array}{r}\text { Fixed } \\
\text { su } \\
\text { as \% c } \\
\end{array}$ & $\begin{array}{l}\text { hone } \\
\text { et } \\
\text { capita }\end{array}$ & $\begin{array}{l}\text { Value } \\
\text { change }\end{array}$ & $\begin{array}{c}\text { Relative } \\
\text { change (\%) }\end{array}$ & $\begin{array}{c}\text { Fixed- } \\
\text { telephone } \\
\text { sub-basket, }\end{array}$ & $\begin{array}{l}\text { Fixed- } \\
\text { telephone } \\
\text { sub-basket, }\end{array}$ & $\begin{array}{l}\text { GNI per capita, } \\
\text { USD, } 2009 \\
\text { (or latest }\end{array}$ \\
\hline & & 2010 & 2008 & & 2010 & USD & PPP\$ & available year) \\
\hline 1 & Cuba & 0.1 & 0.1 & 0.0 & -27 & 0.3 & N/A & $5^{\prime} 550$ \\
\hline 2 & United Arab Emirates & 0.1 & 0.1 & 0.0 & -19 & 4.1 & 4.7 & $57 ' 340$ \\
\hline 3 & Monaco & 0.1 & $\mathrm{~N} / \mathrm{A}$ & N/A & N/A & 21.2 & N/A & $203^{\prime} 900$ \\
\hline 4 & Venezuela & 0.2 & 0.9 & -0.7 & -79 & 1.7 & 3.6 & $10^{\prime} 090$ \\
\hline 5 & Bahrain & 0.2 & 0.2 & 0.0 & 2 & 4.8 & 5.9 & $25^{\prime} 420$ \\
\hline 6 & Singapore & 0.3 & 0.2 & 0.0 & 17 & 8.2 & 10.4 & $37^{\prime} 220$ \\
\hline 7 & Belarus & 0.3 & $\mathrm{~N} / \mathrm{A}$ & N/A & N/A & 1.3 & 3.5 & $5^{\prime} 560$ \\
\hline 8 & Macao, China & 0.3 & 0.3 & 0.0 & 0 & 8.4 & 12.3 & $35^{\prime} 360$ \\
\hline 9 & Liechtenstein & 0.3 & $\mathrm{~N} / \mathrm{A}$ & N/A & N/A & 29.0 & $\mathrm{~N} / \mathrm{A}$ & $113^{\prime} 210$ \\
\hline 10 & Korea (Rep.) & 0.3 & 0.3 & 0.0 & 3 & 5.3 & 7.7 & $19^{\prime} 830$ \\
\hline 11 & Hong Kong, China & 0.3 & 0.3 & 0.1 & 20 & 8.5 & 12.2 & $31^{\prime} 420$ \\
\hline 12 & United States & 0.3 & 0.4 & -0.1 & -24 & 12.8 & 12.8 & $46 ' 360$ \\
\hline 13 & Kazakhstan & 0.4 & $\mathrm{~N} / \mathrm{A}$ & N/A & N/A & 2.4 & 3.7 & 6'920 \\
\hline 14 & Luxembourg & 0.4 & 0.4 & 0.0 & -4 & 27.0 & 22.7 & $76^{\prime} 710$ \\
\hline 15 & Finland & 0.4 & 0.5 & 0.0 & -5 & 16.8 & 13.9 & $45^{\prime} 940$ \\
\hline 16 & Iceland & 0.5 & 0.5 & 0.0 & -5 & 16.5 & 16.2 & $43^{\prime} 430$ \\
\hline 17 & Norway & 0.5 & 0.5 & 0.0 & -6 & 32.7 & 22.3 & $84^{\prime} 640$ \\
\hline 18 & Brunei Darussalam & 0.5 & N/A & N/A & N/A & 11.7 & 16.6 & $26^{\prime} 740$ \\
\hline 19 & Switzerland & 0.5 & 0.6 & -0.1 & -16 & 29.4 & 20.0 & $65^{\prime} 430$ \\
\hline 20 & Suriname & 0.6 & N/A & N/A & N/A & 2.2 & 3.0 & $4^{\prime} 760$ \\
\hline 21 & Canada & 0.6 & 0.9 & -0.3 & -35 & 19.4 & 16.7 & $41 ' 980$ \\
\hline 22 & Netherlands & 0.6 & 0.7 & -0.2 & -25 & 22.4 & 20.1 & $48^{\prime} 460$ \\
\hline 23 & Denmark & 0.6 & 0.6 & 0.0 & 1 & 27.8 & 19.3 & $59^{\prime} 060$ \\
\hline 24 & Argentina & 0.6 & 0.8 & -0.2 & -24 & 3.8 & 7.6 & 7'550 \\
\hline 25 & San Marino & 0.6 & $\mathrm{~N} / \mathrm{A}$ & N/A & N/A & 25.6 & N/A & $50^{\prime} 670$ \\
\hline 26 & United Kingdom & 0.6 & 0.7 & -0.1 & -9 & 21.0 & 22.1 & $41^{\prime} 370$ \\
\hline 27 & Azerbaijan & 0.6 & 0.8 & -0.1 & -19 & 2.5 & 4.9 & $4^{\prime} 840$ \\
\hline 28 & Saudi Arabia & 0.6 & 0.6 & 0.0 & 0 & 9.2 & 14.8 & $17^{\prime} 700$ \\
\hline 29 & Syria & 0.6 & $\mathrm{~N} / \mathrm{A}$ & N/A & N/A & 1.3 & 2.4 & $2^{\prime} 410$ \\
\hline 30 & Sweden & 0.6 & 0.5 & 0.1 & 28 & 25.5 & 20.8 & $48^{\prime} 840$ \\
\hline 31 & Austria & 0.7 & 0.7 & -0.1 & -8 & 25.3 & 22.5 & $46^{\prime} 450$ \\
\hline 32 & Ireland & 0.7 & 1.0 & -0.3 & -27 & 26.3 & 22.5 & $44^{\prime} 280$ \\
\hline 33 & Israel & 0.7 & N/A & N/A & N/A & 15.7 & 15.7 & $25^{\prime} 790$ \\
\hline 34 & France & 0.7 & 0.8 & -0.1 & -11 & 26.6 & 23.0 & $42^{\prime} 620$ \\
\hline 35 & Australia & 0.8 & 0.7 & 0.0 & 5 & 27.6 & 20.5 & $43^{\prime} 770$ \\
\hline 36 & Germany & 0.8 & 0.8 & 0.0 & -2 & 27.0 & 25.5 & $42^{\prime} 450$ \\
\hline 37 & Russia & 0.8 & 0.8 & 0.0 & 6 & 6.2 & 12.9 & 9'340 \\
\hline 38 & Tunisia & 0.8 & 1.0 & -0.2 & -18 & 2.5 & 5.8 & $3^{\prime} 720$ \\
\hline 39 & Belgium & 0.8 & 0.9 & -0.1 & -11 & 31.4 & 27.5 & $45^{\prime} 270$ \\
\hline 40 & Japan & 0.8 & 0.6 & 0.2 & 33 & 26.4 & 20.2 & $38^{\prime} 080$ \\
\hline 41 & Malaysia & 0.8 & 0.8 & 0.0 & 2 & 5.1 & 9.4 & 7'350 \\
\hline 42 & Mauritius & 0.9 & 1.0 & -0.1 & -13 & 5.1 & 9.3 & $7^{\prime} 250$ \\
\hline 43 & Italy & 0.9 & 0.9 & 0.0 & -2 & 25.6 & 24.6 & $35^{\prime} 110$ \\
\hline 44 & Oman & 0.9 & 0.7 & 0.2 & 29 & 13.1 & 15.5 & $17^{\prime} 890$ \\
\hline 45 & Qatar & 0.9 & 0.9 & 0.0 & 0 & 9.1 & 11.9 & $12^{\prime} 000$ \\
\hline 46 & Bahamas & 0.9 & N/A & N/A & N/A & 16.3 & N/A & $21 ' 390$ \\
\hline 47 & Slovenia & 0.9 & 1.0 & -0.1 & -7 & 17.9 & 21.6 & $23^{\prime} 520$ \\
\hline 48 & Malta & 0.9 & 1.0 & -0.1 & -10 & 12.8 & 40.0 & $16^{\prime} 680$ \\
\hline 49 & Latvia & 1.0 & 1.1 & -0.2 & -15 & 10.1 & 14.3 & $12^{\prime} 390$ \\
\hline 50 & Greece & 1.0 & 1.1 & -0.1 & -10 & 23.8 & 25.5 & $29^{\prime} 040$ \\
\hline 51 & Estonia & 1.0 & 1.1 & -0.1 & -10 & 11.5 & 17.2 & $14^{\prime} 060$ \\
\hline 52 & Spain & 1.0 & 1.1 & -0.1 & -10 & 27.0 & 29.2 & $32^{\prime} 120$ \\
\hline 53 & Cyprus & 1.1 & 1.1 & -0.1 & -6 & 23.8 & 26.3 & $26^{\prime} 940$ \\
\hline 54 & Georgia & 1.1 & 1.3 & -0.2 & -19 & 2.3 & 4.7 & 2'530 \\
\hline 55 & Serbia & 1.1 & 1.0 & 0.1 & 9 & 5.4 & 12.3 & $6^{\prime} 000$ \\
\hline 56 & Uzbekistan & 1.2 & $N / A$ & $N / A$ & $\mathrm{~N} / \mathrm{A}$ & 1.1 & 2.8 & $1^{\prime} 100$ \\
\hline 57 & Yemen & 1.2 & 1.0 & 0.2 & 15 & 1.1 & 2.6 & $1 ' 060$ \\
\hline 58 & Maldives & 1.2 & 1.3 & -0.1 & -8 & 4.1 & 4.7 & 3'970 \\
\hline 59 & Ukraine & 1.3 & 1.5 & -0.2 & -13 & 3.0 & 7.4 & $2^{\prime} 800$ \\
\hline 60 & Seychelles & 1.3 & 1.1 & 0.1 & 13 & 9.1 & 17.9 & $8^{\prime} 480$ \\
\hline 61 & Costa Rica & 1.3 & 0.9 & 0.4 & 49 & 6.9 & 10.9 & $6^{\prime} 260$ \\
\hline 62 & St. Kitts and Nevis & 1.4 & N/A & N/A & N/A & 11.6 & 15.4 & $10^{\prime} 150$ \\
\hline 63 & Lithuania & 1.4 & 1.5 & -0.1 & -6 & 13.1 & 20.7 & $11^{\prime} 410$ \\
\hline 64 & Portugal & 1.4 & 1.5 & -0.2 & -10 & 25.3 & 29.9 & $21 ' 910$ \\
\hline 65 & Trinidad \& Tobago & 1.4 & 1.5 & -0.1 & -8 & 19.5 & 31.4 & $16^{\prime} 700$ \\
\hline 66 & Antigua \& Barbuda & 1.4 & N/A & N/A & N/A & 14.2 & 20.6 & $12^{\prime} 130$ \\
\hline 67 & Montenegro & 1.4 & 1.9 & -0.5 & -25 & 7.8 & 16.6 & $6^{\prime} 650$ \\
\hline 68 & Colombia & 1.4 & 1.3 & 0.1 & 6 & 5.9 & 9.1 & $4^{\prime} 990$ \\
\hline 69 & Algeria & 1.5 & 1.3 & 0.2 & 15 & 5.4 & 11.2 & $4^{\prime} 420$ \\
\hline 70 & Croatia & 1.5 & 1.6 & -0.2 & -10 & 17.0 & 24.5 & $13^{\prime} 720$ \\
\hline 71 & Moldova & 1.5 & 1.8 & -0.3 & -19 & 1.9 & 4.1 & 1'560 \\
\hline 72 & New Zealand & 1.5 & 1.4 & 0.1 & 8 & 34.1 & 31.6 & $27^{\prime} 260$ \\
\hline 73 & Tajikistan & 1.5 & N/A & N/A & N/A & 0.9 & 2.6 & 700 \\
\hline 74 & Slovak Republic & 1.5 & 1.7 & -0.2 & -12 & 20.4 & 29.8 & $16^{\prime} 130$ \\
\hline 75 & Lebanon & 1.5 & 1.8 & -0.2 & -13 & 10.3 & 16.4 & $8^{\prime} 060$ \\
\hline 76 & China & 1.5 & 1.5 & 0.1 & 5 & 4.7 & 8.4 & $3^{\prime} 650$ \\
\hline 77 & Armenia & 1.6 & 1.8 & -0.2 & -11 & 4.2 & 8.0 & $3^{\prime} 100$ \\
\hline 78 & Kyrgyzstan & 1.7 & N/A & N/A & $\mathrm{N} / \mathrm{A}$ & 1.2 & 3.4 & 870 \\
\hline 79 & Egypt & 1.7 & 2.0 & -0.3 & -16 & 2.9 & 7.3 & $2^{\prime} 070$ \\
\hline 80 & Uruguay & 1.8 & 1.9 & -0.1 & -5 & 13.3 & 16.7 & $9^{\prime} 010$ \\
\hline 81 & Czech Republic & 1.9 & 2.1 & -0.3 & -13 & 26.8 & 37.6 & $17 ' 310$ \\
\hline 82 & Albania & 1.9 & 1.3 & 0.6 & 41 & 6.4 & 15.1 & $4^{\prime} 000$ \\
\hline 83 & Romania & 1.9 & 2.0 & -0.1 & -3 & 13.3 & 26.2 & $8^{\prime} 330$ \\
\hline
\end{tabular}


Measuring the Information Society 2011

Table 3.4: Fixed-telephone sub-basket, 2010 and 2008 (continued)

\begin{tabular}{|c|c|c|c|c|c|c|c|c|}
\hline \multirow[t]{2}{*}{ Rank } & \multirow[t]{2}{*}{ Economy } & \multicolumn{2}{|c|}{$\begin{array}{c}\text { Fixed-telephone } \\
\text { sub-basket } \\
\text { as } \% \text { of GNI capita } \\
\end{array}$} & $\begin{array}{l}\text { Value } \\
\text { change }\end{array}$ & $\begin{array}{c}\text { Relative } \\
\text { change (\%) }\end{array}$ & $\begin{array}{l}\text { Fixed- } \\
\text { telephone } \\
\text { sub-basket, }\end{array}$ & $\begin{array}{l}\text { Fixed- } \\
\text { telephone } \\
\text { sub-basket, }\end{array}$ & $\begin{array}{l}\text { GNI per capita, } \\
\text { USD, } 2009 \\
\text { (or latest }\end{array}$ \\
\hline & & 2010 & 2008 & & 2010 & USD & PPP\$ & available year) \\
\hline 84 & Hungary & 2.0 & 2.6 & -0.7 & -26 & 21.2 & 33.7 & $12^{\prime} 980$ \\
\hline 85 & Poland & 2.0 & 2.6 & -0.6 & -25 & 20.2 & 33.4 & $12^{\prime} 260$ \\
\hline 86 & Bhutan & 2.0 & 2.2 & -0.2 & -10 & 3.4 & 9.4 & $2^{\prime} 030$ \\
\hline 87 & Guyana & 2.1 & 2.1 & 0.0 & 2 & 2.6 & 5.1 & $1 ' 450$ \\
\hline 88 & Panama & 2.2 & 1.7 & 0.5 & 28 & 12.0 & 22.4 & 6'570 \\
\hline 89 & Turkey & 2.3 & N/A & $\mathrm{N} / \mathrm{A}$ & N/A & 16.8 & 27.6 & $8^{\prime} 720$ \\
\hline 90 & Tonga & 2.3 & 2.2 & 0.1 & 6 & 6.4 & 8.3 & $3^{\prime} 260$ \\
\hline 91 & Bosnia and Herzegovina & 2.4 & 2.4 & -0.1 & -2 & 9.3 & 18.4 & $4 ' 700$ \\
\hline 92 & Fiji & 2.4 & 2.8 & -0.3 & -11 & 7.8 & 10.4 & $3^{\prime} 840$ \\
\hline 93 & Swaziland & 2.4 & 2.1 & 0.4 & 18 & 5.0 & 8.7 & $2^{\prime} 470$ \\
\hline 94 & Bulgaria & 2.5 & 2.9 & -0.5 & -15 & 12.5 & 27.4 & $6^{\prime} 060$ \\
\hline 95 & Guatemala & 2.5 & 2.7 & -0.1 & -5 & 5.6 & 9.7 & $2^{\prime} 650$ \\
\hline 96 & Mexico & 2.5 & 2.5 & 0.0 & 2 & 18.9 & 31.2 & $8^{\prime} 960$ \\
\hline 97 & St.Vincent and the Grenadines & 2.6 & 2.5 & 0.0 & 1 & 10.9 & 18.7 & $5^{\prime} 130$ \\
\hline 98 & Barbados & 2.6 & 2.4 & 0.2 & 10 & 20.2 & 33.3 & 9'330 \\
\hline 99 & Dominica & 2.6 & 2.7 & -0.1 & -4 & 10.7 & 18.6 & $4^{\prime} 900$ \\
\hline 100 & Grenada & 2.6 & 2.4 & 0.3 & 11 & 12.3 & 17.0 & $5^{\prime} 580$ \\
\hline 101 & St. Lucia & 2.7 & 2.6 & 0.1 & 5 & 11.6 & 20.3 & $5^{\prime} 190$ \\
\hline 102 & Bangladesh & 2.8 & 3.1 & -0.3 & -10 & 1.3 & 3.4 & 580 \\
\hline 103 & Thailand & 2.8 & 1.9 & 1.0 & 51 & 8.8 & 16.8 & $3^{\prime} 760$ \\
\hline 104 & Jordan & 2.9 & 3.1 & -0.2 & -7 & 9.5 & 12.6 & 3'980 \\
\hline 105 & Indonesia & 2.9 & 3.0 & 0.0 & -1 & 5.0 & 7.8 & $2^{\prime} 050$ \\
\hline 106 & Sri Lanka & 3.0 & 3.5 & -0.6 & -16 & 4.9 & 11.1 & $1^{\prime} 990$ \\
\hline 107 & Jamaica & 3.0 & 2.6 & 0.4 & 15 & 11.6 & 19.4 & 4'590 \\
\hline 108 & Viet Nam & 3.2 & 3.2 & -0.1 & -2 & 2.4 & 7.3 & 930 \\
\hline 109 & Chile & 3.2 & 3.1 & 0.1 & 3 & 25.0 & 33.7 & $9^{\prime} 470$ \\
\hline 110 & TFYR Macedonia & 3.3 & 3.9 & -0.6 & -16 & 11.9 & 30.2 & $4 ' 400$ \\
\hline 111 & Cape Verde & 3.3 & 2.3 & 1.0 & 44 & 8.3 & 10.5 & $3^{\prime} 010$ \\
\hline 112 & India & 3.3 & 3.7 & -0.3 & -9 & 3.3 & 9.1 & '1'180 \\
\hline 113 & Brazil & 3.4 & 4.2 & -0.8 & -19 & 23.0 & 26.0 & $8^{\prime} 040$ \\
\hline 114 & Ethiopia & 3.5 & 6.3 & -2.7 & -44 & 1.0 & 3.2 & 330 \\
\hline 115 & Botswana & 3.6 & 3.2 & 0.4 & 13 & 18.7 & 39.2 & $6^{\prime} 260$ \\
\hline 116 & El Salvador & 3.6 & 3.9 & -0.2 & -6 & 10.2 & 19.8 & $3^{\prime} 370$ \\
\hline 117 & Paraguay & 3.6 & 4.0 & -0.3 & -9 & 6.8 & 13.2 & $2^{\prime} 250$ \\
\hline 118 & Pakistan & 4.0 & 4.5 & -0.4 & -10 & 3.3 & 9.8 & $1^{\prime} 000$ \\
\hline 119 & Dominican Rep. & 4.1 & 3.1 & 1.0 & 31 & 15.5 & 28.9 & 4'550 \\
\hline 120 & Peru & 4.2 & 4.6 & -0.4 & -9 & 14.6 & 26.4 & $4^{\prime} 200$ \\
\hline 121 & Honduras & 4.2 & N/A & N/A & N/A & 6.3 & 12.7 & $1^{\prime} 800$ \\
\hline 122 & Namibia & 4.3 & 3.7 & 0.5 & 14 & 15.1 & 19.6 & $4^{\prime} 270$ \\
\hline 123 & Ecuador & 4.3 & N/A & N/A & N/A & 14.1 & 27.8 & $3^{\prime} 970$ \\
\hline 124 & Micronesia & 4.5 & 3.9 & 0.6 & 15 & 9.4 & 11.7 & $2^{\prime} 500$ \\
\hline 125 & Papua New Guinea & 4.6 & 4.3 & 0.3 & 8 & 4.5 & 8.4 & $1^{\prime} 180$ \\
\hline 126 & Samoa & 5.1 & N/A & $\mathrm{N} / \mathrm{A}$ & N/A & 12.0 & 16.3 & $2^{\prime} 840$ \\
\hline 127 & South Africa & 5.2 & 4.2 & 1.0 & 24 & 25.0 & 38.2 & $5^{\prime} 760$ \\
\hline 128 & Guinea & 5.2 & 9.6 & -4.3 & -45 & 1.6 & 5.0 & 370 \\
\hline 129 & Angola & 5.3 & 7.3 & -2.0 & -27 & 16.5 & 27.2 & $3^{\prime} 750$ \\
\hline 130 & Nicaragua & 5.4 & 5.8 & -0.3 & -6 & 4.5 & 11.8 & $1^{\prime} 000$ \\
\hline 131 & Lao P.D.R. & 5.5 & 6.4 & -0.9 & -14 & 4.0 & 9.3 & 880 \\
\hline 132 & Belize & 6.3 & 7.5 & -1.3 & -17 & 19.6 & 31.7 & $3^{\prime} 740$ \\
\hline 133 & Ghana & 7.3 & 4.5 & 2.8 & 61 & 7.3 & 10.4 & 1'190 \\
\hline 134 & Kiribati & 7.6 & $\mathrm{~N} / \mathrm{A}$ & N/A & N/A & 11.5 & 18.2 & $1^{\prime} 830$ \\
\hline 135 & Djibouti & 7.7 & 8.1 & -0.3 & -4 & 8.3 & 15.9 & $1^{\prime} 280$ \\
\hline 136 & Timor-Leste & 8.4 & N/A & N/A & N/A & 17.3 & 28.3 & $2^{\prime} 460$ \\
\hline 137 & Nepal & 8.5 & 9.7 & -1.2 & -12 & 3.1 & 8.0 & 440 \\
\hline 138 & S. Tomé \& Principe & 8.7 & 12.2 & -3.4 & -28 & 8.3 & 14.5 & 1'140 \\
\hline 139 & Philippines & 9.0 & 8.7 & 0.3 & 3 & 15.3 & 29.3 & $2^{\prime} 050$ \\
\hline 140 & Morocco & 9.2 & 11.1 & -1.8 & -16 & 21.3 & 35.7 & $2^{\prime} 770$ \\
\hline 141 & Senegal & 11.8 & 20.4 & -8.6 & -42 & 10.3 & 19.3 & $1 ' 040$ \\
\hline 142 & Comoros & 13.8 & 17.9 & -4.0 & -23 & 10.0 & 16.6 & 870 \\
\hline 143 & Nigeria & 14.1 & 10.3 & 3.8 & 37 & 14.0 & 27.9 & 1'190 \\
\hline 144 & Benin & 14.4 & 17.5 & -3.1 & -18 & 9.0 & 19.3 & 750 \\
\hline 145 & Cambodia & 14.5 & 15.7 & -1.2 & -8 & 7.4 & 20.1 & 610 \\
\hline 146 & Mali & 15.0 & 18.7 & -3.6 & -19 & 8.5 & 15.4 & 680 \\
\hline 147 & Cameroon & 15.2 & 15.0 & 0.2 & 1 & 15.0 & 30.8 & $1^{\prime} 190$ \\
\hline 148 & Lesotho & 15.9 & 13.6 & 2.4 & 17 & 13.0 & 20.8 & 980 \\
\hline 149 & Bolivia & 17.5 & 19.0 & -1.5 & -8 & 23.7 & 59.5 & $1^{\prime} 630$ \\
\hline 150 & Malawi & 18.2 & 15.4 & 2.8 & 18 & 4.3 & 11.9 & 280 \\
\hline 151 & Vanuatu & 18.8 & 11.8 & 7.0 & 60 & 41.0 & 59.9 & $2^{\prime} 620$ \\
\hline 152 & Tanzania & 21.1 & 28.1 & -7.0 & -25 & 8.8 & 25.5 & 500 \\
\hline 153 & Côte d'Ivoire & 22.0 & 26.7 & -4.8 & -18 & 19.6 & 31.9 & $1^{\prime} 070$ \\
\hline 154 & Kenya & 22.4 & 18.0 & 4.4 & 24 & 14.2 & 30.8 & 760 \\
\hline 155 & Mauritania & 22.5 & 18.2 & 4.3 & 24 & 18.0 & 40.1 & 960 \\
\hline 156 & Uganda & 22.8 & 34.9 & -12.1 & -35 & 8.8 & 24.8 & 460 \\
\hline 157 & Burkina Faso & 25.6 & 24.6 & 0.9 & 4 & 10.9 & 26.4 & 510 \\
\hline 158 & Zambia & 29.8 & 33.0 & 0.9 & 3 & 24.1 & 32.9 & 970 \\
\hline 159 & Togo & 30.1 & 35.0 & -4.9 & -14 & 11.0 & 23.0 & 440 \\
\hline 160 & Zimbabwe & 30.2 & $\mathrm{~N} / \mathrm{A}$ & $\mathrm{N} / \mathrm{A}$ & N/A & 9.1 & $\mathrm{~N} / \mathrm{A}$ & 360 \\
\hline 161 & Mozambique & 33.7 & 55.0 & -21.3 & -39 & 12.4 & 32.6 & 440 \\
\hline 162 & Rwanda & 34.4 & 21.2 & 13.2 & 62 & 13.2 & 28.5 & 460 \\
\hline 163 & Chad & 37.0 & 41.2 & -4.2 & -10 & 16.7 & 37.5 & 540 \\
\hline 164 & Niger & 41.3 & 47.4 & -6.1 & -13 & 11.7 & 23.7 & 340 \\
\hline 165 & Madagascar & 52.1 & 49.9 & 2.2 & 4 & 18.2 & 43.7 & 420 \\
\hline
\end{tabular}

Note: N/A: Not available.

Source: ITU. 
benefit from particularly cheap, or even free, local calls, as is the case in Cuba and Singapore. Usually, very low local prices for calls are compensated by higher prices for long-distance or international calls. In some countries, such as the United States, fixed-telephone services have been subsidized to ensure that all customers, including rural and low-income customers, have basic telephone access. A discussion was launched recently in the United States on the possibility of moving from subsidized fixed telephony to subsidized broadband services. ${ }^{21}$

While fixed-telephone prices have gone down, or remained the same, in about two-thirds of all countries included in the IPB, prices have increased in the others. In some cases, for example Botswana and Mexico, changes to some degree reflect an increase in taxes; in others, the pricing structure has changed. In Senegal, for instance, the one-time installation charge (which is not taken into account in the calculation of the subbasket) has increased substantially, while the monthly subscription price has decreased, thus yielding an overall decrease in the sub-basket. In Mozambique, local prices actually remained the same but a major change in the exchange rate has had a big impact on the USD value of the sub-basket.

\section{Fixed-telephone prices: the regional and development-level perspective}

Between 2008 and 2010, only relatively modest price changes occurred in the fixed-telephone basket overall. Regionally, the Commonwealth of Independent States (CIS) and Europe, where prices dropped by 14 and 12 per cent, respectively, are the only regions with a doubledigit decrease in the fixed-telephone sub-basket. Africa cut fixed-telephone prices by almost ten per cent, which could reflect a reaction to stiff competition from the mobile market. On the other hand, it must be noted that only very few Africans actually use fixed-telephone services, given the extremely low fixed-line penetration in Africa. In developed countries, the fixed-telephone sub-basket decreased by 9.8 per cent, compared to 6.7 per cent in developing countries (Chart 3.4).

A comparison of 2010 prices shows that Europeans and people living in the CIS countries pay the relatively lowest prices, since both regions have a fixed-telephone sub-basket value of 1.1. The sub-baskets in the Americas, Asia and the Pacific and the Arab States are relatively more expensive, but still correspond to less than five per cent of monthly national average incomes. In Africa, the region with the lowest income levels and by far the lowest fixed-line penetration rate (less than two per cent by end 2010), the sub-basket represented 17 per cent of monthly average incomes. This is 15 times the relative price in the developed countries, and more than twice the developing-country average (Chart 3.5).

A large number of developing countries and particularly a lot of countries in Africa have a history of very low fixed-line penetration rates and high prices. In many countries, the number of fixed-telephone lines is either decreasing or stagnating. Both India and China, the two largest developing countries, have seen their number of fixed-telephone lines fall since 2006. For basic voice services, mobile telephony is increasingly complementing or, where fixed-line networks are limited, replacing the fixed-telephone line. While it is true that, currently, the fixed-telephone network continues to be an important access technology for fixed-broadband (DSL) access, the growing availability and popularity of mobile-broadband services is expected to further reduce the necessity for fixed-telephone lines. This assumption is borne out by the fact that in some countries it is increasingly difficult to obtain price information for basic fixed-telephone services on operators' websites. Both Afghanistan and Mongolia, for example, had to be excluded from the 2010 ICT Price Basket since it was not possible to obtain their fixed-telephone tariffs. In both countries, the number of fixed-telephone lines is very small - they both have fewer than 200000 lines, suggesting that these may be primarily for enterprises or organizations. In Nauru, the fixed-telephone line network has been decommissioned, according to the regulatory authority. ${ }^{22}$ Although this trend could suggest that, sooner or later, the fixed-telephone sub-basket

Chart 3.4: Fixed-telephone sub-basket by level of development, 2008 and 2010

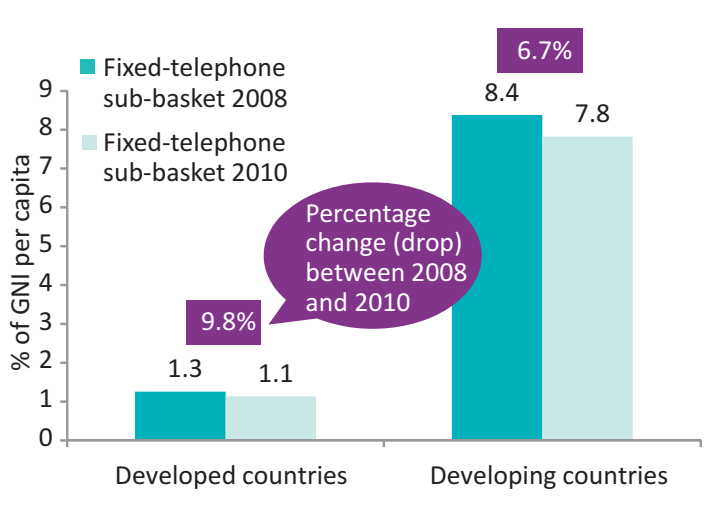

Source: ITU. 


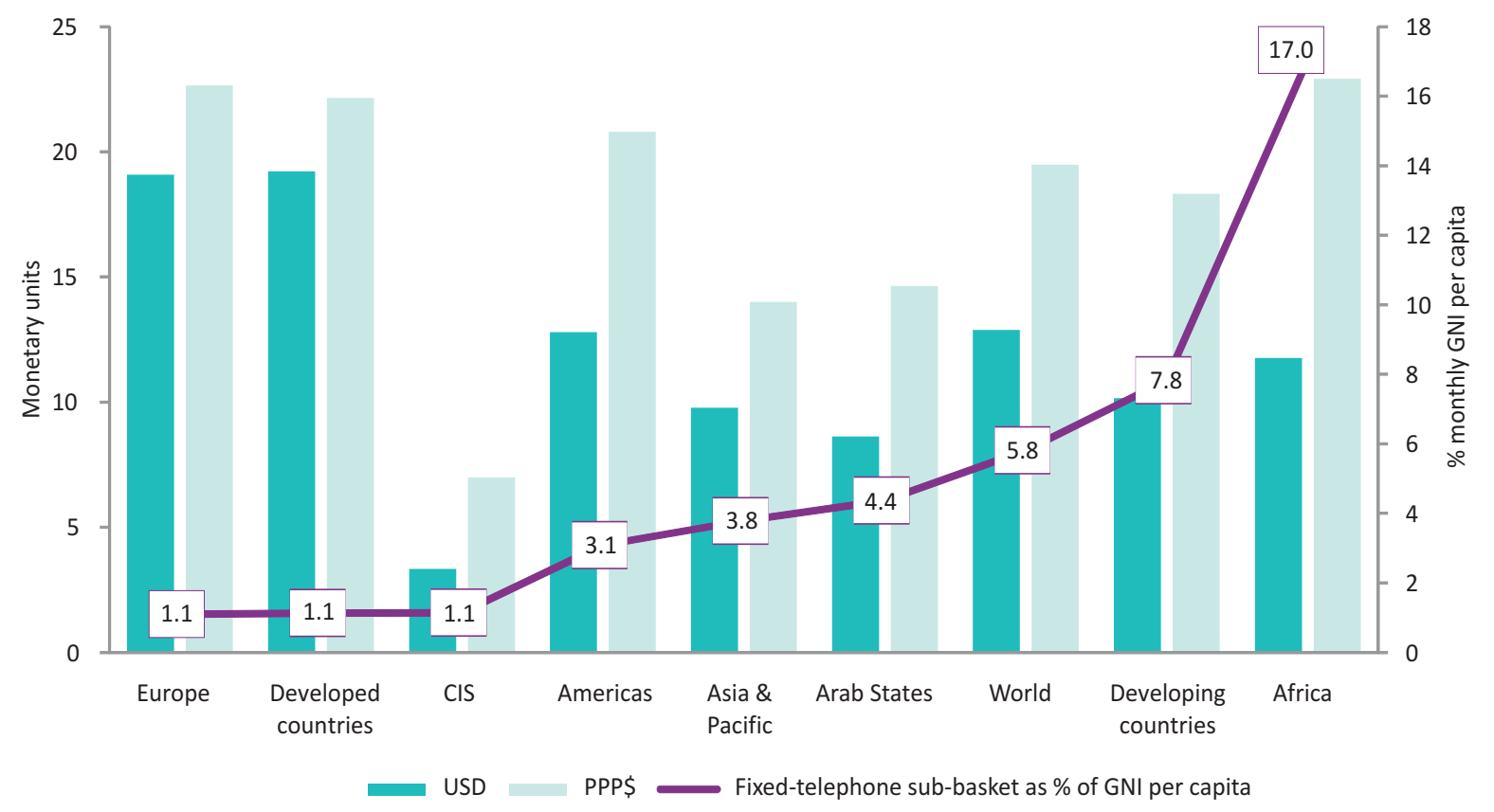

Note: In this chart, Cuba is not included in the USD/PPP\$ values for the Americas region, since the PPP\$ value for Cuba is not available. Source: ITU.

should be removed from the IPB, fixed-telephone services remain important in a number of countries, and also for businesses and organizations.

\section{Mobile-cellular sub-basket}

\section{Mobile-cellular prices as a percentage of GNI per capita}

In 2010, the average mobile-cellular sub-basket, which includes the price of 30 outgoing calls - for peak, offpeak and weekend periods and to the same and other mobile and fixed networks - plus 100 sms, corresponds on average to 8.6 per cent of monthly GNI per capita. ${ }^{23}$ The mobile-cellular sub-basket decreased by 21.8 per cent compared with 2008 (Table 3.2).

All of the top ten countries with the lowest mobilecellular sub-basket are high-income economies, including Hong Kong (China), United Arab Emirates, Macao (China), Denmark, Singapore, Norway and Finland. Costa Rica stands out in that it has a relatively low GNI per capita but ranks 18th on the mobile-cellular subbasket (Table 3.5). While Costa Rica is one of the few countries in the world with only one mobile operator, ${ }^{24}$ the government has subsidized tariffs and prices have been kept low. Another country with relatively low income levels and relatively cheap mobile-cellular tariffs that stands out in the list among generally wealthier economies is Sri Lanka. The country ranks 38th on the mobile-cellular sub-basket (compared to 63rd on the overall IPB) and prices dropped by over 56.7 per cent between 2008 and 2010, one of the highest percentage changes over that period. Sri Lanka has a highly competitive mobile-cellular market, with five operators competing for a total of just over 20 million inhabitants. Other countries where mobile-cellular tariffs have decreased by over 50 per cent include Austria, Hong Kong (China), Venezuela, Finland and Côte d'Ivoire (Table 3.6, right).

The most expensive mobile-cellular tariffs in relative terms are found in low-income developing countries, and the top ten relatively most expensive countries are from Africa. They include Malawi, Niger, Zimbabwe, Togo, Burkina Faso, Mozambique, Madagascar and Chad. Nevertheless, the last five are included in the list of economies registering the greatest decrease in the mobile-telephone sub-basket in absolute value terms (Table 3.6, left), suggesting that mobile services are 
Table 3.5: Mobile-cellular sub-basket, 2010 and 2008

\begin{tabular}{|c|c|c|c|c|c|c|c|c|}
\hline \multirow[t]{2}{*}{ Rank } & \multirow[t]{2}{*}{ Economy } & $\begin{array}{l}\text { Mobi } \\
\text { sub- } \\
\% \text { of }\end{array}$ & $\begin{array}{l}\text { Iular } \\
\text { at as } \\
\text { apita }\end{array}$ & $\begin{array}{l}\text { Value } \\
\text { change }\end{array}$ & $\begin{array}{c}\text { Relative } \\
\text { change (\%) }\end{array}$ & $\begin{array}{l}\text { Mobile- } \\
\text { cellular } \\
\text { sub-basket, }\end{array}$ & $\begin{array}{l}\text { Mobile- } \\
\text { cellular } \\
\text { sub-basket, }\end{array}$ & $\begin{array}{l}\text { GNI per capita, } \\
\text { USD, } 2009 \\
\text { (or latest }\end{array}$ \\
\hline & & 2010 & 2008 & & 2010 & USD & PPP\$ & available year) \\
\hline 1 & Hong Kong, China & 0.1 & 0.1 & -0.1 & -63 & 1.4 & 2.1 & $31 ' 420$ \\
\hline 2 & United Arab Emirates & 0.2 & 0.2 & 0.0 & 0 & 8.6 & 9.9 & $57^{\prime} 340$ \\
\hline 3 & Macao, China & 0.2 & 0.2 & 0.0 & 0 & 5.7 & 8.3 & $35^{\prime} 360$ \\
\hline 4 & Denmark & 0.2 & 0.2 & 0.0 & -11 & 9.8 & 6.8 & $59^{\prime} 060$ \\
\hline 5 & Liechtenstein * & 0.2 & $\mathrm{~N} / \mathrm{A}$ & N/A & N/A & 23.4 & N/A & $113^{\prime} 210$ \\
\hline 6 & Singapore & 0.3 & 0.2 & 0.0 & 6 & 8.1 & 10.4 & $37^{\prime} 220$ \\
\hline 7 & Norway & 0.3 & 0.3 & 0.0 & -7 & 20.5 & 14.0 & $84^{\prime} 640$ \\
\hline 8 & Monaco & 0.3 & N/A & N/A & N/A & 52.6 & N/A & $203^{\prime} 900$ \\
\hline 9 & Finland & 0.3 & 0.7 & -0.4 & -51 & 13.1 & 10.8 & $45^{\prime} 940$ \\
\hline 10 & Cyprus & 0.3 & 0.4 & -0.1 & -13 & 7.7 & 8.5 & $26^{\prime} 940$ \\
\hline 11 & Austria & 0.4 & 1.2 & -0.8 & -69 & 13.9 & 12.4 & $46^{\prime} 450$ \\
\hline 12 & Germany & 0.4 & 0.4 & -0.1 & -18 & 13.1 & 12.3 & $42^{\prime} 450$ \\
\hline 13 & Luxembourg & 0.4 & 0.4 & 0.0 & -3 & 25.8 & 21.7 & $76^{\prime} 710$ \\
\hline 14 & Sweden & 0.4 & 0.8 & -0.3 & -45 & 17.2 & 14.0 & $48^{\prime} 840$ \\
\hline 15 & Iceland & 0.5 & 0.5 & -0.1 & -14 & 16.6 & 16.3 & $43^{\prime} 430$ \\
\hline 16 & San Marino & 0.6 & $\mathrm{~N} / \mathrm{A}$ & N/A & N/A & 23.8 & N/A & $50^{\prime} 670$ \\
\hline 17 & Oman & 0.6 & 0.7 & -0.1 & -8 & 9.1 & 10.7 & $17^{\prime} 890$ \\
\hline 18 & Costa Rica & 0.6 & 1.1 & -0.5 & -44 & 3.4 & 5.3 & 6'260 \\
\hline 19 & Brunei Darussalam & 0.7 & N/A & N/A & N/A & 15.7 & 22.4 & $26^{\prime} 740$ \\
\hline 20 & Bahrain & 0.7 & 0.7 & 0.0 & 7 & 15.0 & 18.7 & $25^{\prime} 420$ \\
\hline 21 & Australia & 0.8 & 1.2 & -0.4 & -36 & 27.7 & 20.5 & $43^{\prime} 770$ \\
\hline 22 & Netherlands & 0.8 & 1.0 & -0.1 & -15 & 33.2 & 29.8 & $48^{\prime} 460$ \\
\hline 23 & United States & 0.8 & 0.8 & 0.0 & 3 & 32.7 & 32.7 & $46^{\prime} 360$ \\
\hline 24 & Trinidad \& Tobago & 0.9 & 1.1 & -0.3 & -22 & 12.1 & 19.6 & $16 ' 700$ \\
\hline 25 & Korea (Rep.) & 0.9 & 1.1 & -0.2 & -18 & 14.4 & 21.0 & $19^{\prime} 830$ \\
\hline 26 & United Kingdom & 0.9 & 1.0 & -0.1 & -8 & 31.0 & 32.6 & $41^{\prime} 370$ \\
\hline 27 & Saudi Arabia & 1.0 & 1.1 & -0.1 & -13 & 14.1 & 22.7 & $17^{\prime} 700$ \\
\hline 28 & Latvia & 1.0 & 1.4 & -0.5 & -32 & 10.1 & 14.2 & $12^{\prime} 390$ \\
\hline 29 & Canada & 1.0 & 0.9 & 0.1 & 7 & 34.3 & 29.6 & $41 ' 980$ \\
\hline 30 & Bahamas & 1.0 & N/A & N/A & N/A & 17.5 & N/A & $21 ' 390$ \\
\hline 31 & Ireland & 1.0 & 0.9 & 0.1 & 16 & 37.3 & 31.9 & $44 ' 280$ \\
\hline 32 & Lithuania & 1.0 & 1.4 & -0.4 & -26 & 9.6 & 15.3 & $11^{\prime} 410$ \\
\hline 33 & Italy & 1.0 & 1.2 & -0.2 & -15 & 29.8 & 28.7 & $35^{\prime} 110$ \\
\hline 34 & Switzerland ** & 1.0 & 1.2 & -0.2 & -15 & 57.0 & 38.7 & $65^{\prime} 430$ \\
\hline 35 & Slovenia & 1.1 & 1.1 & -0.1 & -8 & 20.8 & 25.0 & $23^{\prime} 520$ \\
\hline 36 & Belgium & 1.1 & 1.1 & 0.0 & 1 & 40.2 & 35.3 & $45^{\prime} 270$ \\
\hline 37 & Mauritius & 1.1 & 1.3 & -0.2 & -13 & 6.8 & 12.4 & 7'250 \\
\hline 38 & Sri Lanka & 1.1 & 2.6 & -1.5 & -57 & 1.9 & 4.3 & $1^{\prime} 990$ \\
\hline 39 & Russia & 1.2 & 1.6 & -0.4 & -25 & 9.2 & 19.2 & $9^{\prime} 340$ \\
\hline 40 & Malaysia & 1.2 & 1.6 & -0.4 & -25 & 7.5 & 13.7 & 7'350 \\
\hline 41 & Portugal & 1.3 & 1.3 & 0.0 & -4 & 22.9 & 27.1 & $21 ' 910$ \\
\hline 42 & France & 1.4 & 1.6 & -0.2 & -14 & 48.6 & 42.1 & $42^{\prime} 620$ \\
\hline 43 & Croatia & 1.5 & 2.5 & -1.0 & -40 & 17.1 & 24.6 & $13^{\prime} 720$ \\
\hline 44 & Poland & 1.5 & 2.0 & -0.5 & -25 & 15.8 & 26.0 & $12^{\prime} 260$ \\
\hline 45 & Panama & 1.6 & 1.7 & -0.1 & -6 & 8.5 & 15.8 & 6'570 \\
\hline 46 & Malta & 1.6 & 2.2 & -0.7 & -30 & 21.8 & 67.9 & $16^{\prime} 680$ \\
\hline 47 & Israel & 1.6 & N/A & N/A & N/A & 34.1 & 34.0 & $25^{\prime} 790$ \\
\hline 48 & Greece & 1.6 & 1.8 & -0.2 & -12 & 38.5 & 41.3 & $29^{\prime} 040$ \\
\hline 49 & Azerbaijan & 1.7 & 2.2 & -0.5 & -21 & 6.9 & 13.5 & $4^{\prime} 840$ \\
\hline 50 & Belarus & 1.7 & N/A & N/A & N/A & 7.9 & 21.8 & $5^{\prime} 560$ \\
\hline 51 & Maldives & 1.7 & 2.1 & -0.4 & -18 & 5.7 & 6.6 & $3^{\prime} 970$ \\
\hline 52 & Japan & 1.8 & 1.5 & 0.3 & 18 & 55.9 & 42.7 & $38^{\prime} 080$ \\
\hline 53 & St. Kitts and Nevis & 1.8 & $\mathrm{~N} / \mathrm{A}$ & N/A & N/A & 15.2 & 20.1 & $10^{\prime} 150$ \\
\hline 54 & Qatar & 1.8 & 1.7 & 0.1 & 6 & 18.4 & 24.1 & $12^{\prime} 000$ \\
\hline 55 & Estonia & 1.9 & 2.2 & -0.3 & -13 & 22.3 & 33.4 & $14^{\prime} 060$ \\
\hline 56 & Czech Republic & 1.9 & 2.5 & -0.5 & -22 & 28.1 & 39.4 & $17^{\prime} 310$ \\
\hline 57 & China & 2.0 & 2.3 & -0.3 & -14 & 6.0 & 10.8 & $3^{\prime} 650$ \\
\hline 58 & Spain & 2.0 & 2.2 & -0.3 & -11 & 53.2 & 57.6 & $32^{\prime} 120$ \\
\hline 59 & New Zealand & 2.1 & 1.7 & 0.4 & 24 & 47.2 & 43.6 & $27^{\prime} 260$ \\
\hline 60 & Antigua \& Barbuda & 2.2 & N/A & N/A & N/A & 22.0 & 31.9 & $12^{\prime} 130$ \\
\hline 61 & Seychelles & 2.3 & 1.9 & 0.4 & 21 & 15.9 & 31.2 & $8^{\prime} 480$ \\
\hline 62 & Serbia & 2.3 & 2.5 & -0.2 & -7 & 11.6 & 26.4 & $6^{\prime} 000$ \\
\hline 63 & Mexico & 2.3 & 2.3 & 0.0 & 2 & 17.4 & 28.6 & $8^{\prime} 960$ \\
\hline 64 & Uruguay & 2.4 & 3.1 & -0.8 & -24 & 17.8 & 22.2 & $9^{\prime} 010$ \\
\hline 65 & Hungary & 2.4 & 3.0 & -0.6 & -20 & 25.7 & 40.9 & $12^{\prime} 980$ \\
\hline 66 & Kazakhstan & 2.5 & N/A & N/A & N/A & 14.4 & 22.8 & $6^{\prime} 920$ \\
\hline 67 & Botswana & 2.5 & 2.4 & 0.2 & 6 & 13.2 & 27.7 & $6^{\prime} 260$ \\
\hline 68 & Barbados & 2.6 & 2.6 & 0.0 & -1 & 20.0 & 32.9 & 9'330 \\
\hline 69 & Venezuela & 2.7 & 5.6 & -3.0 & -53 & 22.3 & 47.0 & $10^{\prime} 090$ \\
\hline 70 & Bhutan & 2.7 & 3.6 & -0.9 & -25 & 4.6 & 12.7 & $2^{\prime} 030$ \\
\hline 71 & Thailand & 2.8 & 3.4 & -0.6 & -18 & 8.7 & 16.5 & $3^{\prime} 760$ \\
\hline 72 & Slovak Republic & 2.8 & 2.9 & -0.1 & -3 & 38.2 & 55.8 & $16^{\prime} 130$ \\
\hline 73 & Montenegro & 3.0 & 2.8 & 0.2 & 7 & 16.5 & 35.0 & $6^{\prime} 650$ \\
\hline 74 & Chile & 3.0 & 3.2 & -0.2 & -7 & 23.7 & 31.9 & $9^{\prime} 470$ \\
\hline 75 & Pakistan & 3.0 & 3.8 & -0.8 & -22 & 2.5 & 7.4 & $1^{\prime} 000$ \\
\hline 76 & Grenada & 3.1 & 3.2 & -0.1 & -2 & 14.5 & 20.1 & $5^{\prime} 580$ \\
\hline 77 & Romania & 3.1 & 3.5 & -0.4 & -12 & 21.8 & 43.0 & $8^{\prime} 330$ \\
\hline 78 & Jamaica & 3.1 & 3.6 & -0.4 & -12 & 12.0 & 20.1 & $4^{\prime} 590$ \\
\hline 79 & Tajikistan & 3.2 & $\mathrm{~N} / \mathrm{A}$ & N/A & N/A & 1.8 & 5.4 & 700 \\
\hline 80 & Jordan & 3.2 & 3.4 & -0.3 & -8 & 10.5 & 14.0 & $3^{\prime} 980$ \\
\hline 81 & Ukraine & 3.2 & 5.2 & -2.0 & -38 & 7.5 & 18.8 & $2^{\prime} 800$ \\
\hline 82 & Tunisia & 3.2 & 4.3 & -1.1 & -26 & 10.0 & 23.1 & $3^{\prime} 720$ \\
\hline 83 & Uzbekistan & 3.3 & $\mathrm{~N} / \mathrm{A}$ & N/A & N/A & 3.0 & 7.9 & $1^{\prime} 100$ \\
\hline
\end{tabular}


Measuring the Information Society 2011

Table 3.5: Mobile-cellular sub-basket, 2010 and 2008 (continued)

\begin{tabular}{|c|c|c|c|c|c|c|c|c|}
\hline \multirow[t]{2}{*}{ Rank } & \multirow[t]{2}{*}{ Economy } & \multicolumn{2}{|c|}{$\begin{array}{c}\text { Mobile-cellular } \\
\text { sub-basket as } \\
\% \text { of GNI capita }\end{array}$} & $\begin{array}{l}\text { Value } \\
\text { change }\end{array}$ & $\begin{array}{c}\text { Relative } \\
\text { change (\%) }\end{array}$ & $\begin{array}{l}\text { Mobile- } \\
\text { cellular } \\
\text { sub-basket, }\end{array}$ & $\begin{array}{l}\text { Mobile- } \\
\text { cellular } \\
\text { sub-basket, }\end{array}$ & $\begin{array}{l}\text { GNI per capita, } \\
\text { USD, } 2009 \\
\text { (or latest }\end{array}$ \\
\hline & & 2010 & 2008 & & 2010 & USD & PPP\$ & available year) \\
\hline 84 & Suriname & 3.3 & N/A & N/A & N/A & 13.1 & 18.1 & 4'760 \\
\hline 85 & El Salvador & 3.4 & 5.6 & -2.2 & -40 & 9.5 & 18.4 & 3'370 \\
\hline 86 & Algeria & 3.4 & 4.4 & -1.0 & -23 & 12.5 & 26.0 & $4^{\prime} 420$ \\
\hline 87 & India & 3.4 & 3.9 & -0.4 & -11 & 3.4 & 9.3 & 1'180 \\
\hline 88 & Armenia & 3.4 & 5.2 & -1.8 & -35 & 8.8 & 16.9 & $3^{\prime} 100$ \\
\hline 89 & St. Vincent and the Grenadines & 3.5 & 4.5 & -1.1 & -23 & 14.8 & 25.3 & $5^{\prime} 130$ \\
\hline 90 & Dominica & 3.5 & 5.1 & -1.5 & -30 & 14.5 & 25.1 & $4^{\prime} 900$ \\
\hline 91 & Guatemala & 3.6 & 4.2 & -0.6 & -15 & 7.8 & 13.7 & $2^{\prime} 650$ \\
\hline 92 & Bosnia and Herzegovina & 3.9 & 4.8 & -0.9 & -18 & 15.4 & 30.5 & 4'700 \\
\hline 93 & Tonga & 4.0 & 3.8 & 0.2 & 6 & 11.0 & 14.4 & $3^{\prime} 260$ \\
\hline 94 & Colombia & 4.1 & 4.4 & -0.3 & -8 & 16.9 & 26.0 & 4'990 \\
\hline 95 & Lebanon & 4.1 & 5.7 & -1.6 & -28 & 27.3 & 43.5 & $8^{\prime} 060$ \\
\hline 96 & Egypt & 4.1 & 5.6 & -1.6 & -28 & 7.0 & 17.9 & $2^{\prime} 070$ \\
\hline 97 & Dominican Rep. & 4.1 & 4.7 & -0.6 & -13 & 15.6 & 29.1 & 4'550 \\
\hline 98 & Ecuador & 4.2 & N/A & N/A & N/A & 13.8 & 27.2 & $3^{\prime} 970$ \\
\hline 99 & Bangladesh & 4.2 & 6.0 & -1.8 & -30 & 2.0 & 5.2 & 580 \\
\hline 100 & Micronesia & 4.4 & 4.4 & -0.1 & -2 & 9.1 & 11.3 & $2^{\prime} 500$ \\
\hline 101 & Paraguay & 4.6 & 5.3 & -0.7 & -13 & 8.6 & 16.5 & $2^{\prime} 250$ \\
\hline 102 & Indonesia & 4.6 & 5.4 & -0.8 & -15 & 7.8 & 12.2 & $2^{\prime} 050$ \\
\hline 103 & Namibia & 4.8 & 4.9 & -0.1 & -3 & 17.0 & 22.0 & $4^{\prime} 270$ \\
\hline 104 & South Africa & 4.8 & 4.5 & 0.4 & 8 & 23.3 & 35.5 & $5^{\prime} 760$ \\
\hline 105 & Argentina & 4.9 & 3.4 & 1.5 & 43 & 30.7 & 61.3 & 7'550 \\
\hline 106 & Kyrgyzstan & 4.9 & N/A & $\mathrm{N} / \mathrm{A}$ & N/A & 3.6 & 10.1 & 870 \\
\hline 107 & St. Lucia & 5.1 & 4.7 & 0.4 & 9 & 22.2 & 38.8 & $5^{\prime} 190$ \\
\hline 108 & Georgia & 5.5 & 6.8 & -1.3 & -19 & 11.6 & 24.1 & 2'530 \\
\hline 109 & Fiji & 5.9 & 7.8 & -1.9 & -25 & 18.8 & 24.9 & $3^{\prime} 840$ \\
\hline 110 & Philippines & 5.9 & 5.5 & 0.4 & 7 & 10.1 & 19.3 & $2^{\prime} 050$ \\
\hline 111 & Honduras & 5.9 & N/A & N/A & N/A & 8.9 & 17.8 & $1^{\prime} 800$ \\
\hline 112 & Turkey & 6.0 & N/A & $\mathrm{N} / \mathrm{A}$ & N/A & 43.9 & 72.4 & $8^{\prime} 720$ \\
\hline 113 & Bulgaria & 6.1 & 7.2 & -1.1 & -15 & 30.6 & 67.1 & $6^{\prime} 060$ \\
\hline 114 & Angola & 6.2 & 8.1 & -1.9 & -24 & 19.2 & 31.7 & $3^{\prime} 750$ \\
\hline 115 & TFYR Macedonia & 6.4 & 7.4 & -1.0 & -14 & 23.4 & 59.2 & $4^{\prime} 400$ \\
\hline 116 & Viet Nam & 7.0 & 9.9 & -2.9 & -30 & 5.4 & 16.2 & 930 \\
\hline 117 & Nepal & 7.3 & 12.6 & -5.3 & -42 & 2.7 & 6.9 & 440 \\
\hline 118 & Cuba & 7.3 & 9.3 & -2.0 & -21 & 33.9 & $\mathrm{~N} / \mathrm{A}$ & 5'550 \\
\hline 119 & Ghana & 7.4 & 10.8 & -3.4 & -31 & 7.4 & 10.6 & 1'190 \\
\hline 120 & Samoa & 7.5 & N/A & N/A & N/A & 17.6 & 24.1 & $2^{\prime} 840$ \\
\hline 121 & Albania & 7.7 & 12.6 & -4.8 & -38 & 25.8 & 61.2 & $4^{\prime} 000$ \\
\hline 122 & Guyana & 7.8 & 10.3 & -2.5 & -25 & 9.4 & 18.9 & $1 ' 450$ \\
\hline 123 & Timor-Leste & 7.9 & N/A & N/A & N/A & 16.1 & 26.4 & $2^{\prime} 460$ \\
\hline 124 & Bolivia & 8.3 & 9.1 & -0.8 & -9 & 11.3 & 28.3 & 1'630 \\
\hline 125 & Brazil & 8.5 & 9.2 & -0.7 & -7 & 57.1 & 64.6 & $8^{\prime} 040$ \\
\hline 126 & Lao P.D.R. & 8.6 & 9.5 & -0.9 & -9 & 6.3 & 14.6 & 880 \\
\hline 127 & Yemen & 9.2 & 11.0 & -1.8 & -17 & 8.1 & 19.5 & $1^{\prime} 060$ \\
\hline 128 & Moldova & 9.7 & 12.0 & -2.3 & -19 & 12.6 & 26.3 & 1'560 \\
\hline 129 & Syria & 9.9 & N/A & $\mathrm{N} / \mathrm{A}$ & N/A & 19.9 & 37.7 & $2^{\prime} 410$ \\
\hline 130 & Belize & 10.0 & 10.0 & -0.1 & -1 & 31.0 & 50.3 & $3^{\prime} 740$ \\
\hline 131 & Vanuatu & 10.7 & 12.7 & -2.0 & -16 & 23.3 & 34.0 & $2^{\prime} 620$ \\
\hline 132 & Kiribati & 11.3 & N/A & $\mathrm{N} / \mathrm{A}$ & N/A & 17.3 & 27.2 & $1 ' 830$ \\
\hline 133 & Swaziland & 11.7 & 10.0 & 1.8 & 18 & 24.2 & 41.5 & $2^{\prime} 470$ \\
\hline 134 & Peru & 12.4 & 14.3 & -2.0 & -14 & 43.2 & 78.2 & 4'200 \\
\hline 135 & Cambodia & 13.2 & 17.6 & -4.4 & -25 & 6.7 & 18.3 & 610 \\
\hline 136 & Guinea & 13.4 & 17.1 & -3.7 & -22 & 4.1 & 12.9 & 370 \\
\hline 137 & S. Tomé \& Principe & 13.4 & 17.8 & -4.4 & -25 & 12.7 & 22.2 & $1^{\prime} 140$ \\
\hline 138 & Nigeria & 13.9 & 22.0 & -8.2 & -37 & 13.7 & 27.4 & '190 \\
\hline 139 & Djibouti & 14.0 & 13.1 & 0.9 & 7 & 14.9 & 28.8 & $1^{\prime} 280$ \\
\hline 140 & Morocco & 14.3 & 17.2 & -2.8 & -16 & 33.1 & 55.4 & $2^{\prime} 770$ \\
\hline 141 & Senegal & 14.6 & 16.4 & -1.8 & -11 & 12.7 & 23.8 & $1^{\prime} 040$ \\
\hline 142 & Ethiopia & 14.9 & 26.5 & -11.6 & -44 & 4.1 & 13.6 & 330 \\
\hline 143 & Côte d'Ivoire & 15.3 & 30.8 & -15.6 & -50 & 13.6 & 22.1 & $1^{\prime} 070$ \\
\hline 144 & Nicaragua & 15.8 & 27.4 & -11.6 & -42 & 13.2 & 34.4 & $1 ' 000$ \\
\hline 145 & Cape Verde & 16.6 & 19.4 & -2.8 & -14 & 41.6 & 52.3 & $3^{\prime} 010$ \\
\hline 146 & Kenya & 17.0 & 31.5 & -14.4 & -46 & 10.8 & 23.5 & 760 \\
\hline 147 & Mauritania & 18.3 & 18.6 & -0.4 & -2 & 14.6 & 32.6 & 960 \\
\hline 148 & Cameroon & 20.2 & 31.1 & -10.8 & -35 & 20.1 & 41.2 & $1^{\prime} 190$ \\
\hline 149 & Zambia & 20.8 & 25.8 & -4.9 & -19 & 16.9 & 23.0 & 970 \\
\hline 150 & Benin & 20.9 & 33.1 & -12.2 & -37 & 13.0 & 27.9 & 750 \\
\hline 151 & Tanzania & 23.2 & 43.1 & -19.8 & -46 & 9.7 & 28.1 & 500 \\
\hline 152 & Papua New Guinea & 23.7 & 25.1 & -1.4 & -6 & 23.3 & 43.5 & 1'180 \\
\hline 153 & Mali & 25.5 & 31.7 & -6.2 & -19 & 14.4 & 26.2 & 680 \\
\hline 154 & Lesotho & 29.6 & 25.2 & 4.4 & 17 & 24.1 & 38.6 & 980 \\
\hline 155 & Uganda & 31.8 & 50.4 & -18.5 & -37 & 12.2 & 34.5 & 460 \\
\hline 156 & Comoros & 33.5 & 43.2 & -9.8 & -23 & 24.3 & 40.1 & 870 \\
\hline 157 & Chad & 34.1 & 59.1 & -25.0 & -42 & 15.4 & 34.6 & 540 \\
\hline 158 & Rwanda & 36.3 & 53.1 & -16.8 & -32 & 13.9 & 30.1 & 460 \\
\hline 159 & Madagascar & 44.1 & 65.0 & -20.9 & -32 & 15.4 & 37.0 & 420 \\
\hline 160 & Mozambique & 46.2 & 60.4 & -14.2 & -23 & 17.0 & 44.7 & 440 \\
\hline 161 & Burkina Faso & 49.9 & 63.2 & -13.3 & -21 & 21.2 & 51.5 & 510 \\
\hline 162 & Togo & 54.3 & 81.5 & -27.2 & -33 & 19.9 & 41.4 & 440 \\
\hline 163 & Zimbabwe & 68.3 & N/A & $\mathrm{N} / \mathrm{A}$ & N/A & 20.5 & N/A & 360 \\
\hline 164 & Niger & 73.4 & 83.9 & -10.5 & -12 & 20.8 & 42.1 & 340 \\
\hline 165 & Malawi & 91.0 & 85.0 & 6.0 & 7 & 21.2 & 59.6 & 280 \\
\hline
\end{tabular}

Note: N/A: Not available. *Liechtenstein refers to postpaid plan. It has a monthly charge of CHF 9.90. ** In Switzerland, on-net calls and calls to fixed operators cost CHF 0.80 per hour. This was taken into account when calculating the mobile-cellular sub-basket.

Source: ITU. 
Table 3.6: Ten economies with the greatest 2008-2010 decrease in the mobile-cellular sub-basket, by absolute value change (left) and relative change (in \%, right)

\begin{tabular}{|c|l|c|c|c|c|}
\hline Rank & Economy & $\begin{array}{c}\text { Mobile } \\
\text { sub- } \\
\text { basket } \\
\mathbf{2 0 1 0}\end{array}$ & $\begin{array}{c}\text { Mobile } \\
\text { sub- } \\
\text { basket } \\
\mathbf{2 0 0 8}\end{array}$ & $\begin{array}{c}\text { Value } \\
\text { change } \\
\mathbf{2 0 0 8 -} \\
\mathbf{2 0 1 0}\end{array}$ & $\begin{array}{c}\text { Relative } \\
\text { change } \\
\mathbf{2 0 0 8 -} \\
\mathbf{2 0 1 0} \\
\mathbf{( \% )}\end{array}$ \\
\hline 161 & Togo & 54.3 & 81.5 & -27.2 & -33.4 \\
\hline 137 & Chad & 34.1 & 59.1 & -25.0 & -42.3 \\
\hline 162 & Madagascar & 44.1 & 65.0 & -20.9 & -32.1 \\
\hline 136 & Tanzania & 23.2 & 43.1 & -19.8 & -46.0 \\
\hline 135 & Uganda & 31.8 & 50.4 & -18.5 & -36.8 \\
\hline 159 & Rwanda & 36.3 & 53.1 & -16.8 & -31.6 \\
\hline 134 & Côte d'Ivoire & 15.3 & 30.8 & -15.6 & -50.5 \\
\hline 138 & Kenya & 17.0 & 31.5 & -14.4 & -45.9 \\
\hline 157 & Mozambique & 46.2 & 60.4 & -14.2 & -23.4 \\
\hline 160 & Burkina Faso & 49.9 & 63.2 & -13.3 & -21.0 \\
\hline
\end{tabular}

\begin{tabular}{|c|l|c|c|c|c|}
\hline Rank & Economy & $\begin{array}{c}\text { Mobile } \\
\text { sub- } \\
\text { basket } \\
\mathbf{2 0 1 0}\end{array}$ & $\begin{array}{c}\text { Mobile } \\
\text { sub- } \\
\text { basket } \\
\mathbf{2 0 0 8}\end{array}$ & $\begin{array}{c}\text { Relative } \\
\text { change } \\
\mathbf{2 0 0 8 -} \\
\mathbf{2 0 1 0} \\
\mathbf{( \% )}\end{array}$ & $\begin{array}{c}\text { Value } \\
\text { change } \\
\mathbf{2 0 0 8 -} \\
\mathbf{2 0 1 0}\end{array}$ \\
\hline 11 & Austria & 0.4 & 1.2 & -69.4 & -0.8 \\
\hline 4 & HK, China & 0.1 & 0.1 & -63.2 & -0.1 \\
\hline 63 & Sri Lanka & 1.1 & 2.6 & -56.7 & -1.5 \\
\hline 48 & Venezuela & 2.7 & 5.6 & -52.8 & -3.0 \\
\hline 14 & Finland & 0.3 & 0.7 & -51.1 & -0.4 \\
\hline 134 & Côte d'Ivoire & 15.3 & 30.8 & -50.5 & -15.6 \\
\hline 136 & Tanzania & 23.2 & 43.1 & -46.0 & -19.8 \\
\hline 138 & Kenya & 17.0 & 31.5 & -45.9 & -14.4 \\
\hline 15 & Sweden & 0.4 & 0.8 & -44.9 & -0.3 \\
\hline 149 & Ethiopia & 14.9 & 26.5 & -43.7 & -11.6 \\
\hline
\end{tabular}

Source: ITU.

becoming cheaper and more affordable. In others, for example in Niger, prices decreased relatively little compared to their African neighbours. In Malawi, a comparison of the 2008 and 2010 mobile-cellular sub-baskets actually suggests a slight increase in mobile-cellular tariffs. These are alarming developments, particularly in countries where the mobile-cellular penetration rate is still below 25 per cent, and among the lowest in the world. Other developing countries with relatively low mobile-cellular penetration rates and with a relatively small price decrease (or even a price increase) between 2008 and 2010 include Lesotho, Papua New Guinea, Mauritania and Djibouti.

\section{Mobile-cellular telephone prices: the regional and development-level perspective}

Africa and CIS were the regions recording the greatest decrease in mobile-cellular prices. Here, prices between 2008 and 2010 dropped by 25 per cent, compared with 18 and 15 per cent in Asia and the Pacific and the Arab States, respectively. Prices decreased by around 11 per cent in the Americas and 15 per cent in Europe, such that, by the end of 2010, the mobile-cellular basket corresponded to less than 10 per cent of monthly average incomes in all regions except Africa.

However, absolute and relative price differences in the mobile-cellular sub-basket are substantial between regions. While Europeans pay on average as little as
1.6 per cent of their monthly income for the mobile sub-basket, Africans average as much as 24.6 per cent. Mobile prices are more affordable in the CIS and Asia and the Pacific, where they correspond to 4.1 and 4.6 per cent of incomes, respectively, compared to 5.1 per cent in the Americas and 7.4 per cent in the Arab States.

The difference in relative prices also remains considerable between the developed and the developing countries. While people living in the developed countries pay on average two per cent of their monthly income for mobile-cellular services, those in developing countries average as much as 11.4 per cent (Chart 3.6).

At the same time, a comparison between 2010 and 2008 shows that prices are decreasing faster in the developing world. Prices decreased by 22 per cent in developing countries, as against 19.1 per cent in developed countries (Chart 3.7).

\section{Fixed-broadband Internet sub-basket}

\section{Fixed-broadband prices as a percentage of GNI per capita}

In 2010, the average fixed broadband Internet subbasket, which includes the price of a monthly subscription for an entry-level broadband plan based on 1 Gigabyte of download volume, cost 78.9 per cent of monthly GNI per capita. The fixed-broadband subbasket decreased by 52.2 per cent compared with 2008 


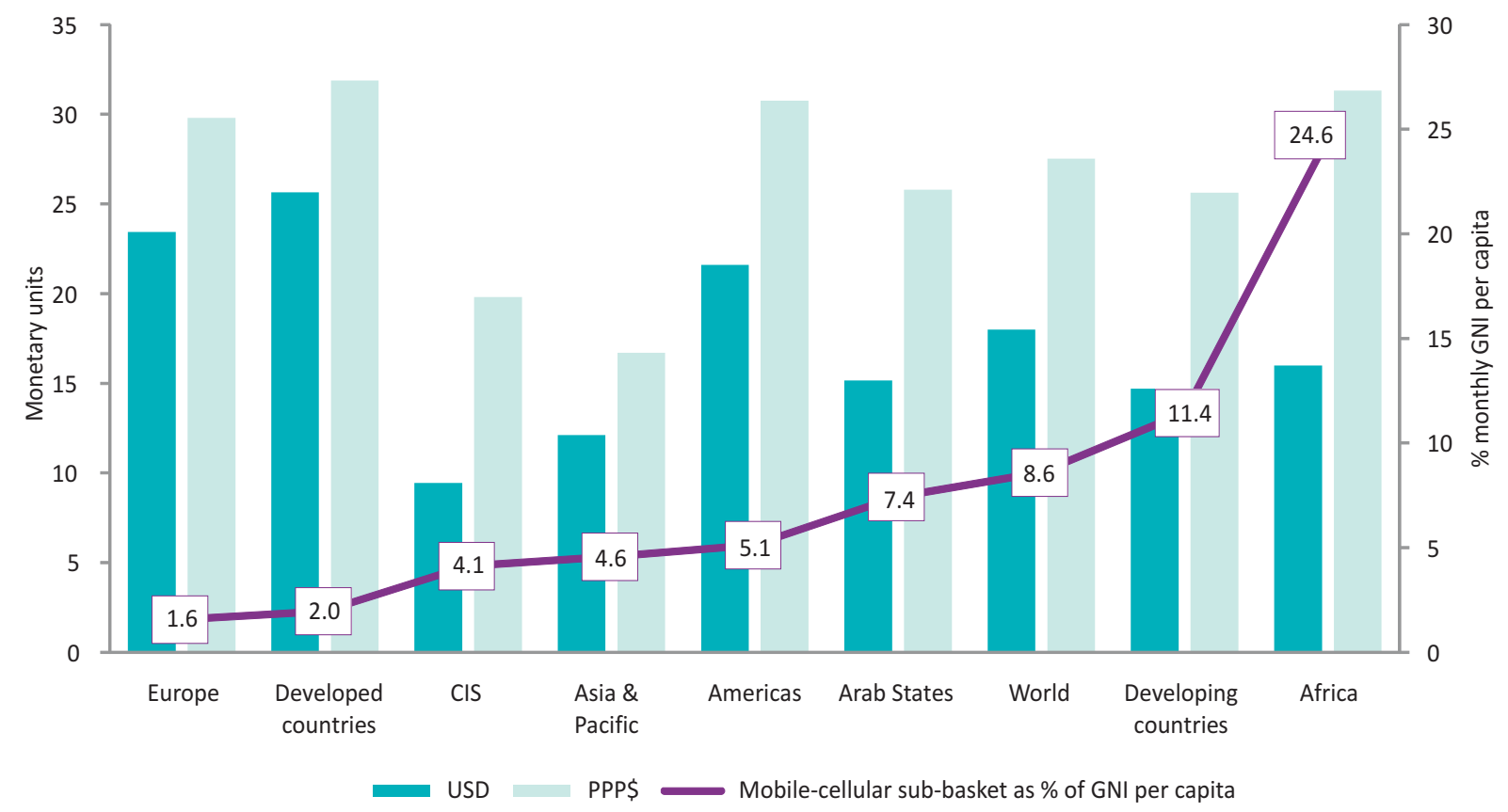

Note: In this chart, Cuba is not included in the USD/PPP\$ values for the Americas region, since the PPP\$ value for Cuba is not available. Source: ITU.

(Table 3.2), the largest decrease of all the sub-baskets. Although this shows that high-speed Internet access is becoming more affordable, it is still beyond the means of most people in the world.

\section{Chart 3.7: Mobile-cellular sub-basket by level of development, 2008 and 2010}

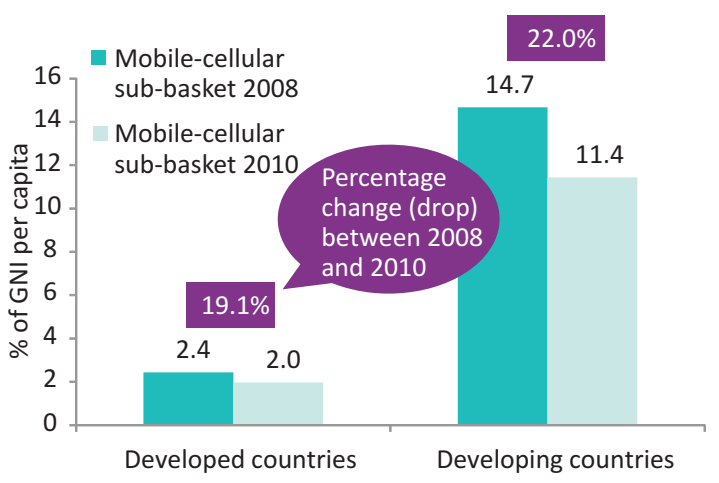

Source: ITU.
Inequalities in broadband prices are reflected in the different prices that people in developed and developing countries pay. While broadband Internet access represents 1.5 per cent of incomes in developed countries, the figure is 112 per cent in the developing countries (Chart 3.8).

The top ten economies with the cheapest relative broadband prices are all high-income economies, and include many of those ranked at the top of the overall IPB: Monaco, Macao (China), Israel, Liechtenstein, the United States and Austria. In a total of 31 countries (or 18 per cent), people pay an equivalent of one per cent - or less - of their average monthly GNI per capita for an entry-level broadband connection (Table 3.7).

On the other hand, the 2010 price data show that, in 19 countries, broadband prices correspond to more than 100 per cent of the monthly average GNI per capita, suggesting that high-speed fixed Internet access remains unaffordable for many citizens. Indeed, in Guinea, Malawi, Zimbabwe and Ethiopia the monthly price for an Internet connection is actually more than ten times the monthly average income, and in a total of 32 countries ( 20 per cent 
Table 3.7: Fixed-broadband sub-basket 2010 and 2008

\begin{tabular}{|c|c|c|c|c|c|c|c|c|}
\hline \multirow[t]{2}{*}{ Rank } & \multirow[t]{2}{*}{ Economy } & $\begin{array}{r}\text { Fixed } \\
\text { su } \\
\text { as } \% \text { c }\end{array}$ & $\begin{array}{l}\text { band } \\
\text { et } \\
\text { eapita }\end{array}$ & $\begin{array}{l}\text { Value } \\
\text { change }\end{array}$ & $\begin{array}{c}\text { Relative } \\
\text { change (\%) }\end{array}$ & $\begin{array}{c}\text { Fixed- } \\
\text { broadband } \\
\text { sub-basket, }\end{array}$ & $\begin{array}{l}\text { Fixed- } \\
\text { broadband } \\
\text { sub-basket, }\end{array}$ & $\begin{array}{l}\text { GNI per capita, } \\
\text { USD, } 2009 \\
\text { (or latest }\end{array}$ \\
\hline & & 2010 & 2008 & & 2010 & USD & PPP\$ & available year) \\
\hline 1 & Monaco & 0.3 & N/A & N/A & $\mathrm{N} / \mathrm{A}$ & 45.9 & N/A & $203^{\prime} 900$ \\
\hline 2 & Macao, China & 0.3 & 0.3 & 0.0 & -10 & 9.0 & 13.2 & $35^{\prime} 360$ \\
\hline 3 & Israel & 0.4 & N/A & N/A & N/A & 8.1 & 8.1 & $25^{\prime} 790$ \\
\hline 4 & Liechtenstein & 0.5 & $\mathrm{~N} / \mathrm{A}$ & N/A & N/A & 47.1 & N/A & $113^{\prime} 210$ \\
\hline 5 & United States & 0.5 & 0.4 & 0.1 & 37 & 20.0 & 20.0 & $46^{\prime} 360$ \\
\hline 6 & San Marino & 0.5 & N/A & N/A & N/A & 22.2 & N/A & $50^{\prime} 670$ \\
\hline 7 & Luxembourg & 0.6 & 0.6 & 0.0 & -4 & 38.1 & 32.1 & $76^{\prime} 710$ \\
\hline 8 & Switzerland & 0.6 & 0.7 & -0.1 & -10 & 32.7 & 22.1 & $65^{\prime} 430$ \\
\hline 9 & Belgium & 0.7 & 0.8 & -0.1 & -16 & 24.8 & 21.8 & $45^{\prime} 270$ \\
\hline 10 & Austria & 0.7 & 1.5 & -0.8 & -55 & 26.2 & 23.3 & $46^{\prime} 450$ \\
\hline 11 & Iceland & 0.7 & 1.1 & -0.4 & -39 & 24.9 & 24.4 & $43^{\prime} 430$ \\
\hline 12 & Norway & 0.7 & 0.7 & -0.1 & -7 & 49.1 & 33.5 & $84^{\prime} 640$ \\
\hline 13 & Romania & 0.7 & 1.0 & -0.3 & -32 & 4.8 & 9.6 & $8^{\prime} 330$ \\
\hline 14 & United Kingdom & 0.7 & 0.7 & 0.0 & -2 & 24.6 & 25.8 & $41 ' 370$ \\
\hline 15 & Japan & 0.7 & 1.0 & -0.3 & -29 & 23.1 & 17.6 & $38^{\prime} 080$ \\
\hline 16 & Hong Kong, China & 0.7 & 0.6 & 0.1 & 23 & 19.1 & 27.3 & $31^{\prime} 420$ \\
\hline 17 & Canada & 0.7 & 0.6 & 0.2 & 28 & 26.2 & 22.6 & $41 ' 980$ \\
\hline 18 & Greece & 0.8 & 1.0 & -0.3 & -25 & 18.9 & 20.2 & $29^{\prime} 040$ \\
\hline 19 & Netherlands & 0.8 & 0.9 & -0.1 & -10 & 32.9 & 29.5 & $48^{\prime} 460$ \\
\hline 20 & France & 0.8 & 1.0 & -0.2 & -18 & 30.1 & 26.1 & $42^{\prime} 620$ \\
\hline 21 & Sweden & 0.8 & 0.7 & 0.2 & 23 & 34.5 & 28.2 & $48^{\prime} 840$ \\
\hline 22 & United Arab Emirates & 0.8 & 0.8 & 0.0 & 0 & 40.6 & 46.8 & $57^{\prime} 340$ \\
\hline 23 & Singapore & 0.9 & 0.7 & 0.2 & 25 & 26.7 & 34.2 & $37^{\prime} 220$ \\
\hline 24 & Ireland & 0.9 & 0.9 & 0.0 & 1 & 32.9 & 28.1 & $44^{\prime} 280$ \\
\hline 25 & Denmark & 0.9 & 0.6 & 0.3 & 49 & 43.9 & 30.5 & $59^{\prime} 060$ \\
\hline 26 & Italy & 0.9 & 0.8 & 0.1 & 7 & 26.2 & 25.2 & $35^{\prime} 110$ \\
\hline 27 & Trinidad \& Tobago & 0.9 & 1.0 & -0.1 & -8 & 12.5 & 20.3 & $16 ' 700$ \\
\hline 28 & Cyprus & 0.9 & 0.7 & 0.2 & 30 & 20.6 & 22.7 & $26^{\prime} 940$ \\
\hline 29 & Finland & 0.9 & 0.9 & 0.0 & 2 & 35.4 & 29.1 & $45^{\prime} 940$ \\
\hline 30 & Spain & 1.0 & 1.0 & -0.1 & -7 & 26.2 & 28.3 & $32^{\prime} 120$ \\
\hline 31 & Australia & 1.0 & 1.4 & -0.4 & -30 & 36.9 & 27.3 & $43^{\prime} 770$ \\
\hline 32 & Lithuania & 1.1 & 1.5 & -0.5 & -30 & 10.3 & 16.3 & $11^{\prime} 410$ \\
\hline 33 & Germany & 1.1 & 1.0 & 0.1 & 8 & 39.4 & 37.1 & $42^{\prime} 450$ \\
\hline 34 & Latvia & 1.2 & 2.5 & -1.2 & -50 & 12.8 & 18.1 & $12^{\prime} 390$ \\
\hline 35 & Bahrain & 1.3 & 1.3 & 0.0 & 0 & 26.6 & 33.1 & $25^{\prime} 420$ \\
\hline 36 & New Zealand & 1.3 & 1.2 & 0.0 & 3 & 28.9 & 26.7 & $27^{\prime} 260$ \\
\hline 37 & Russia & 1.3 & 1.7 & -0.4 & -24 & 9.9 & 20.6 & $9^{\prime} 340$ \\
\hline 38 & Malta & 1.3 & 1.5 & -0.1 & -10 & 18.2 & 56.8 & $16^{\prime} 680$ \\
\hline 39 & Costa Rica & 1.3 & 1.7 & -0.3 & -19 & 7.0 & 11.0 & $6^{\prime} 260$ \\
\hline 40 & Portugal & 1.4 & 1.6 & -0.2 & -11 & 26.3 & 31.1 & $21 ' 910$ \\
\hline 41 & Korea (Rep.) & 1.5 & 1.0 & 0.4 & 44 & 24.0 & 34.9 & $19^{\prime} 830$ \\
\hline 42 & Croatia & 1.6 & 1.8 & -0.2 & -10 & 18.2 & 26.3 & $13^{\prime} 720$ \\
\hline 43 & Slovenia & 1.7 & 2.1 & -0.4 & -17 & 34.2 & 41.1 & $23^{\prime} 520$ \\
\hline 44 & Poland & 1.8 & 2.5 & -0.8 & -30 & 18.0 & 29.7 & $12^{\prime} 260$ \\
\hline 45 & Estonia & 1.8 & 3.1 & -1.3 & -42 & 21.0 & 31.4 & $14^{\prime} 060$ \\
\hline 46 & Saudi Arabia & 1.8 & 2.7 & -0.9 & -33 & 26.6 & 42.9 & $17^{\prime} 700$ \\
\hline 47 & Venezuela & 1.9 & 6.2 & -4.3 & -70 & 15.9 & 33.6 & $10^{\prime} 090$ \\
\hline 48 & Hungary & 1.9 & 2.2 & -0.3 & -12 & 20.7 & 33.0 & $12^{\prime} 980$ \\
\hline 49 & Slovak Republic & 1.9 & 2.0 & -0.1 & -4 & 25.9 & 37.8 & $16^{\prime} 130$ \\
\hline 50 & Bahamas & 2.0 & N/A & N/A & N/A & 35.0 & N/A & $21 ' 390$ \\
\hline 51 & Oman & 2.1 & 2.1 & 0.0 & 0 & 31.0 & 36.7 & $17^{\prime} 890$ \\
\hline 52 & Czech Republic & 2.2 & 2.0 & 0.2 & 8 & 31.2 & 43.8 & $17^{\prime} 310$ \\
\hline 53 & Brunei Darussalam & 2.3 & N/A & N/A & N/A & 50.5 & 71.8 & $26^{\prime} 740$ \\
\hline 54 & Kazakhstan & 2.3 & N/A & N/A & N/A & 13.2 & 20.8 & $6^{\prime} 920$ \\
\hline 55 & Mexico & 2.3 & 4.2 & -1.9 & -45 & 17.3 & 28.5 & $8^{\prime} 960$ \\
\hline 56 & Brazil & 2.5 & 6.9 & -4.4 & -64 & 16.9 & 19.1 & $8^{\prime} 040$ \\
\hline 57 & Uruguay & 2.6 & 3.5 & -0.9 & -26 & 19.3 & 24.2 & $9^{\prime} 010$ \\
\hline 58 & Turkey & 2.6 & N/A & N/A & N/A & 19.2 & 31.6 & $8^{\prime} 720$ \\
\hline 59 & Bulgaria & 2.7 & 3.1 & -0.5 & -15 & 13.4 & 29.5 & $6^{\prime} 060$ \\
\hline 60 & Mauritius & 2.7 & 4.6 & -1.9 & -41 & 16.4 & 29.8 & $7^{\prime} 250$ \\
\hline 61 & Maldives & 2.8 & 3.0 & -0.2 & -8 & 9.3 & 10.8 & $3^{\prime} 970$ \\
\hline 62 & Sri Lanka & 3.0 & 15.7 & -12.7 & -81 & 5.0 & 11.2 & 1'990 \\
\hline 63 & Panama & 3.0 & 2.9 & 0.2 & 6 & 16.6 & 30.9 & $6^{\prime} 570$ \\
\hline 64 & Serbia & 3.1 & 6.4 & -3.4 & -53 & 15.3 & 34.8 & $6^{\prime} 000$ \\
\hline 65 & Azerbaijan & 3.1 & 26.7 & -23.6 & -88 & 12.5 & 24.4 & $4^{\prime} 840$ \\
\hline 66 & Albania & 3.2 & 9.2 & -6.0 & -65 & 10.7 & 25.4 & $4^{\prime} 000$ \\
\hline 67 & Ukraine & 3.2 & 7.1 & -3.8 & -54 & 7.6 & 19.1 & $2^{\prime} 800$ \\
\hline 68 & Montenegro & 3.3 & 3.8 & -0.5 & -13 & 18.4 & 39.0 & $6^{\prime} 650$ \\
\hline 69 & Malaysia & 3.3 & 3.3 & 0.1 & 2 & 20.5 & 37.4 & $7 ' 350$ \\
\hline 70 & Tunisia & 3.4 & 4.1 & -0.7 & -18 & 10.5 & 24.2 & $3^{\prime} 720$ \\
\hline 71 & Lebanon & 3.4 & 4.0 & -0.6 & -14 & 23.0 & 36.6 & $8^{\prime} 060$ \\
\hline 72 & TFYR Macedonia & 3.5 & 4.1 & -0.6 & -15 & 12.8 & 32.6 & $4^{\prime} 400$ \\
\hline 73 & Bosnia and Herzegovina & 3.7 & 3.8 & -0.1 & -3 & 14.4 & 28.6 & $4^{\prime} 700$ \\
\hline 74 & Belarus & 3.9 & $\mathrm{~N} / \mathrm{A}$ & $\mathrm{N} / \mathrm{A}$ & N/A & 18.1 & 49.7 & $5^{\prime} 560$ \\
\hline 75 & Antigua \& Barbuda & 4.0 & $\mathrm{~N} / \mathrm{A}$ & N/A & N/A & 40.5 & 58.8 & $12^{\prime} 130$ \\
\hline 76 & Algeria & 4.0 & 4.8 & -0.8 & -16 & 14.8 & 30.7 & $4^{\prime} 420$ \\
\hline 77 & Argentina & 4.1 & 6.3 & -2.3 & -36 & 25.6 & 51.1 & 7'550 \\
\hline 78 & St. Kitts and Nevis & 4.3 & N/A & N/A & N/A & 36.7 & 48.5 & $10^{\prime} 150$ \\
\hline 79 & Egypt & 4.6 & 5.5 & -0.9 & -16 & 8.0 & 20.4 & $2^{\prime} 070$ \\
\hline 80 & Barbados & 5.0 & 6.4 & -1.4 & -22 & 38.8 & 63.9 & 9'330 \\
\hline 81 & Moldova & 5.0 & 18.5 & -13.5 & -73 & 6.5 & 13.6 & $1^{\prime} 560$ \\
\hline 82 & Chile & 5.0 & 6.0 & -1.0 & -17 & 39.4 & 53.1 & $9^{\prime} 470$ \\
\hline 83 & Dominican Rep. & 5.0 & 7.6 & -2.6 & -34 & 19.0 & 35.4 & $4^{\prime} 550$ \\
\hline
\end{tabular}


Measuring the Information Society 2011

Table 3.7: Fixed-broadband sub-basket 2010 and 2008 (continued)

\begin{tabular}{|c|c|c|c|c|c|c|c|c|}
\hline \multirow[t]{2}{*}{ Rank } & \multirow[t]{2}{*}{ Economy } & \multicolumn{2}{|c|}{$\begin{array}{l}\text { Fixed-broadband } \\
\text { sub-basket } \\
\text { as } \% \text { of GNI capita }\end{array}$} & $\begin{array}{l}\text { Value } \\
\text { change }\end{array}$ & $\begin{array}{c}\text { Relative } \\
\text { change (\%) }\end{array}$ & $\begin{array}{l}\text { Fixed- } \\
\text { broadband } \\
\text { sub-basket, }\end{array}$ & $\begin{array}{l}\text { Fixed- } \\
\text { broadband } \\
\text { sub-basket, }\end{array}$ & $\begin{array}{l}\text { GNI per capita, } \\
\text { USD, } 2009 \\
\text { (or latest }\end{array}$ \\
\hline & & 2010 & 2008 & & 2010 & USD & PPP\$ & available year) \\
\hline 84 & Morocco & 5.1 & 9.2 & -4.1 & -44 & 11.7 & 19.6 & 2'770 \\
\hline 85 & Qatar & 5.5 & 5.5 & 0.0 & 0 & 54.9 & 72.0 & $12^{\prime} 000$ \\
\hline 86 & India & 5.6 & 6.4 & -0.8 & -13 & 5.5 & 15.2 & $1 ' 180$ \\
\hline 87 & Botswana & 5.7 & 5.0 & 0.7 & 13 & 29.7 & 62.4 & $6^{\prime} 260$ \\
\hline 88 & Jordan & 5.7 & 6.7 & -1.0 & -15 & 18.9 & 25.2 & $3^{\prime} 980$ \\
\hline 89 & South Africa & 5.7 & 4.9 & 0.8 & 16 & 27.4 & 41.9 & $5^{\prime} 760$ \\
\hline 90 & Fiji & 5.7 & 7.3 & -1.6 & -22 & 18.3 & 24.3 & $3^{\prime} 840$ \\
\hline 91 & China & 5.9 & 7.4 & -1.5 & -20 & 17.8 & 32.0 & $3^{\prime} 650$ \\
\hline 92 & Thailand & 6.0 & 5.8 & 0.2 & 4 & 18.9 & 35.9 & $3^{\prime} 760$ \\
\hline 93 & Ecuador & 6.1 & N/A & N/A & N/A & 20.2 & 39.7 & $3^{\prime} 970$ \\
\hline 94 & Bhutan & 6.2 & 38.3 & -32.1 & -84 & 10.5 & 29.1 & $2^{\prime} 030$ \\
\hline 95 & Grenada & 6.3 & 6.0 & 0.3 & 5 & 29.3 & 40.6 & $5^{\prime} 580$ \\
\hline 96 & Jamaica & 6.5 & 11.9 & -5.5 & -46 & 24.7 & 41.4 & 4'590 \\
\hline 97 & St. Lucia & 6.8 & 12.2 & -5.4 & -45 & 29.3 & 51.1 & $5^{\prime} 190$ \\
\hline 98 & Seychelles & 6.8 & 5.5 & 1.3 & 23 & 48.1 & 94.3 & $8^{\prime} 480$ \\
\hline 99 & St. Vincent and the Grenadines & 7.9 & 12.9 & -5.0 & -39 & 33.6 & 57.7 & $5^{\prime} 130$ \\
\hline 100 & Colombia & 8.5 & 8.8 & -0.3 & -4 & 35.2 & 54.3 & 4'990 \\
\hline 101 & El Salvador & 8.9 & 7.1 & 1.8 & 25 & 24.9 & 48.2 & 3'370 \\
\hline 102 & Paraguay & 10.1 & 21.4 & -11.3 & -53 & 19.0 & 36.6 & $2^{\prime} 250$ \\
\hline 103 & Suriname & 10.6 & N/A & $\mathrm{N} / \mathrm{A}$ & N/A & 42.1 & 58.2 & $4 ' 760$ \\
\hline 104 & Syria & 10.8 & N/A & N/A & N/A & 21.6 & 40.9 & $2^{\prime} 410$ \\
\hline 105 & Dominica & 11.7 & 12.0 & -0.3 & -2 & 47.8 & 82.7 & $4^{\prime} 900$ \\
\hline 106 & Peru & 12.1 & 10.8 & 1.3 & 12 & 42.2 & 76.3 & 4'200 \\
\hline 107 & Armenia & 12.5 & 14.0 & -1.5 & -11 & 32.4 & 61.7 & $3^{\prime} 100$ \\
\hline 108 & Cape Verde & 12.6 & 16.2 & -3.6 & -22 & 31.5 & 39.6 & $3^{\prime} 010$ \\
\hline 109 & Indonesia & 12.6 & 13.2 & -0.5 & -4 & 21.6 & 33.5 & $2^{\prime} 050$ \\
\hline 110 & Philippines & 12.8 & 14.3 & -1.5 & -10 & 21.9 & 42.0 & $2^{\prime} 050$ \\
\hline 111 & Viet Nam & 13.5 & 23.5 & -10.1 & -43 & 10.5 & 31.1 & 930 \\
\hline 112 & Honduras & 14.7 & $\mathrm{~N} / \mathrm{A}$ & $\mathrm{N} / \mathrm{A}$ & N/A & 22.1 & 44.3 & $1^{\prime} 800$ \\
\hline 113 & Guatemala & 14.7 & 17.1 & -2.4 & -14 & 32.5 & 56.9 & $2^{\prime} 650$ \\
\hline 114 & Guyana & 15.7 & 40.6 & -24.8 & -61 & 19.0 & 38.0 & $1 ' 450$ \\
\hline 115 & Pakistan & 17.1 & 21.7 & -4.7 & -22 & 14.2 & 41.7 & $1^{\prime} 000$ \\
\hline 116 & Georgia & 18.7 & 23.0 & -4.3 & -19 & 39.4 & 81.7 & 2'530 \\
\hline 117 & Micronesia & 19.2 & 19.5 & -0.3 & -2 & 40.0 & 49.8 & $2^{\prime} 500$ \\
\hline 118 & Tonga & 19.9 & 38.1 & -18.2 & -48 & 54.1 & 70.9 & $3^{\prime} 260$ \\
\hline 119 & Samoa & 25.7 & N/A & $\mathrm{N} / \mathrm{A}$ & N/A & 60.8 & 83.1 & $2^{\prime} 840$ \\
\hline 120 & Bolivia & 25.7 & 28.0 & -2.3 & -8 & 35.0 & 87.7 & $1^{\prime} 630$ \\
\hline 121 & Chad & 26.3 & 29.3 & -3.0 & -10 & 11.8 & 26.6 & 540 \\
\hline 122 & Namibia & 26.7 & 13.7 & 13.0 & 95 & 94.9 & 122.6 & $4^{\prime} 270$ \\
\hline 123 & Mauritania & 29.4 & 77.1 & -47.7 & -62 & 23.5 & 52.5 & 960 \\
\hline 124 & Bangladesh & 31.0 & 123.8 & -92.8 & -75 & 15.0 & 38.7 & 580 \\
\hline 125 & Ghana & 31.8 & 63.1 & -31.3 & -50 & 31.5 & 45.2 & $1^{\prime} 190$ \\
\hline 126 & Belize & 32.8 & 32.3 & 0.5 & 2 & 102.2 & 165.9 & $3^{\prime} 740$ \\
\hline 127 & Uganda & 35.9 & 374.9 & -338.9 & -90 & 13.8 & 39.0 & 460 \\
\hline 128 & Nicaragua & 41.4 & 39.4 & 2.0 & 5 & 34.5 & 90.2 & $1^{\prime} 000$ \\
\hline 129 & Senegal & 41.6 & 49.2 & -7.6 & -15 & 36.1 & 67.9 & $1^{\prime} 040$ \\
\hline 130 & Angola & 42.7 & 58.8 & -16.1 & -27 & 133.4 & 219.7 & $3^{\prime} 750$ \\
\hline 131 & Côte d'Ivoire & 45.0 & 54.7 & -9.7 & -18 & 40.1 & 65.2 & $1^{\prime} 070$ \\
\hline 132 & Timor-Leste & 48.3 & $\mathrm{~N} / \mathrm{A}$ & N/A & N/A & 99.0 & 161.8 & $2^{\prime} 460$ \\
\hline 133 & Tanzania & 50.0 & 174.4 & -124.4 & -71 & 20.8 & 60.5 & 500 \\
\hline 134 & Djibouti & 52.3 & 111.6 & -59.3 & -53 & 55.8 & 107.5 & $1^{\prime} 280$ \\
\hline 135 & Nigeria & 53.5 & 692.1 & -638.6 & -92 & 53.1 & 105.9 & 1'190 \\
\hline 136 & Mozambique & 59.8 & 311.9 & -252.1 & -81 & 21.9 & 57.7 & 440 \\
\hline 137 & Kenya & 59.9 & 261.2 & -201.3 & -77 & 37.9 & 82.6 & 760 \\
\hline 138 & Lesotho & 62.4 & 53.2 & 9.2 & 17 & 51.0 & 81.6 & 980 \\
\hline 139 & Nepal & 63.4 & 64.5 & -1.1 & -2 & 23.3 & 59.8 & 440 \\
\hline 140 & Zambia & 73.3 & 108.8 & -35.5 & -33 & 59.3 & 81.0 & 970 \\
\hline 141 & Kyrgyzstan & 75.3 & $\mathrm{~N} / \mathrm{A}$ & N/A & N/A & 54.6 & 154.6 & 870 \\
\hline 142 & Vanuatu & 78.3 & 209.3 & -130.9 & -63 & 171.0 & 249.9 & $2^{\prime} 620$ \\
\hline 143 & Benin & 80.2 & 172.3 & -92.1 & -53 & 50.1 & 107.2 & 750 \\
\hline 144 & Cameroon & 80.8 & 185.7 & -104.9 & -56 & 80.2 & 164.4 & 1'190 \\
\hline 145 & Mali & 88.4 & 109.8 & -21.4 & -19 & 50.1 & 90.8 & 680 \\
\hline 146 & Cambodia & 92.5 & 177.3 & -84.8 & -48 & 47.0 & 128.2 & 610 \\
\hline 147 & Yemen & 134.9 & 281.6 & -146.7 & -52 & 119.2 & 285.8 & $1^{\prime} 060$ \\
\hline 148 & Papua New Guinea & 142.5 & 150.9 & -8.3 & -6 & 140.2 & 260.9 & '1'180 \\
\hline 149 & $\begin{array}{l}\text { Lao P.D.R. } \\
\text {. }\end{array}$ & 190.5 & 435.5 & -245.0 & -56 & 139.7 & 324.1 & 880 \\
\hline 150 & Burkina Faso & 194.2 & 4466.2 & -4272.0 & -96 & 82.5 & 200.4 & 510 \\
\hline 151 & Niger & 210.5 & 241.6 & -31.1 & -13 & 59.6 & 120.7 & 340 \\
\hline 152 & Uzbekistan & 218.2 & $\mathrm{~N} / \mathrm{A}$ & $\mathrm{N} / \mathrm{A}$ & N/A & 200.0 & 529.9 & $1^{\prime} 100$ \\
\hline 153 & Rwanda & 224.5 & 267.6 & -43.1 & -16 & 86.1 & 185.8 & 460 \\
\hline 154 & Kiribati & 251.2 & N/A & $\mathrm{N} / \mathrm{A}$ & N/A & 383.1 & 603.2 & $1 ' 830$ \\
\hline 155 & Madagascar & 259.0 & 327.8 & -68.8 & -21 & 90.6 & 217.3 & 420 \\
\hline 156 & S. Tomé \& Principe & 300.4 & 316.2 & -15.8 & -5 & 285.4 & 499.1 & $1^{\prime} 140$ \\
\hline 157 & Cuba & 379.0 & 380.6 & -1.7 & 0 & 1752.7 & N/A & $5^{\prime} 550$ \\
\hline 158 & Swaziland & 424.9 & 805.7 & -380.8 & -47 & 874.6 & 1502.7 & $2^{\prime} 470$ \\
\hline 159 & Togo & 451.5 & 539.9 & -88.3 & -16 & 165.6 & 344.9 & 440 \\
\hline 160 & Comoros & 534.5 & 690.8 & -156.3 & -23 & 387.5 & 641.4 & 870 \\
\hline 161 & Tajikistan & 621.4 & N/A & N/A & N/A & 362.5 & 1063.8 & 700 \\
\hline 162 & Ethiopia & 1070.8 & 2721.4 & -1650.7 & -61 & 294.5 & 981.2 & 330 \\
\hline 163 & Zimbabwe & 1353.2 & N/A & $\mathrm{N} / \mathrm{A}$ & N/A & 406.0 & N/A & 360 \\
\hline 164 & Malawi & 2408.0 & 4880.7 & -2472.6 & -51 & 561.9 & 1577.9 & 280 \\
\hline 165 & Guinea & 2594.6 & 2823.5 & -228.9 & -8 & 800.0 & 2503.1 & 370 \\
\hline
\end{tabular}

Note: N/A: Not available.

Source: ITU. 


\section{Chart 3.8: Fixed-broadband sub-basket by level of development, 2008 and 2010}

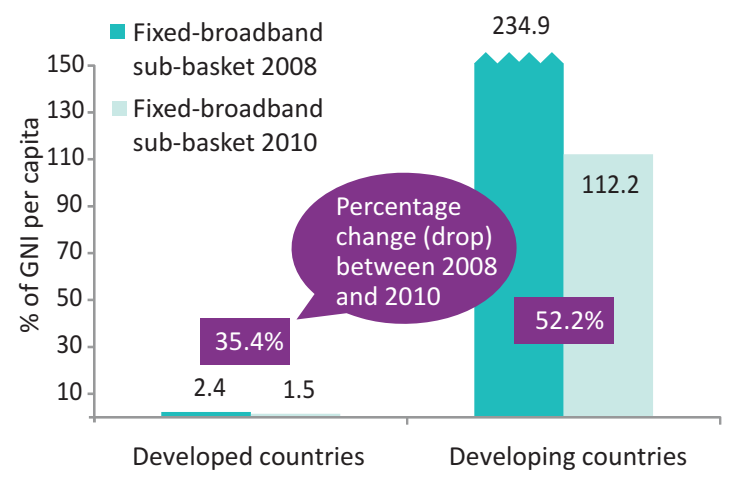

Source: ITU.

of all countries included in the 2010 IPB) a broadband connection costs more than half of the average income. Most of the countries where broadband Internet access remains extremely expensive are low-income economies. Many are African LDCs, but the group also includes Zimbabwe, Tajikistan, Swaziland, Uzbekistan and Papua New Guinea. Not surprisingly, fixed-broadband penetration in these countries remains extremely low, below 0.5 per cent at end 2010.

Despite the fact that broadband prices remain prohibitively high in many developing countries, the IPB indicates that services are becoming more affordable over time, and that the price divide is shrinking. Indeed, the countries with the highest relative broadband prices are also the ones showing the greatest decrease in prices between 2008 and 2010. Impressive price cuts in absolute as well as percentage terms have taken place in a number of developing (and developed) countries. The number of countries where a broadband connection is more expensive than the average income dropped from 28 in 2008 to 19 in 2010.

In Burkina Faso and Nigeria, for example, the broadband sub-basket fell from 4466 to 194 and from 692 to 54 , respectively. All of the top ten countries with the greatest absolute value decrease in the fixed-broadband basket between 2008 and 2010 are low-income countries that had very high fixed-broadband values in 2008; all, with the exception of Lao P.D.R., are from Africa (Table 3.8, left). Burkina Faso leads in both the absolute and the percentage drop, and together with Nigeria and Uganda displays the largest price reductions in percentage values. Prices also dropped by over 70 per cent in Azerbaijan, Bhutan, Mozambique, Sri Lanka, Kenya, Bangladesh and Moldova (Table 3.8, right). Between 2008 and 2010, the broadband sub-basket value decreased by over 50 per cent in no fewer than 30 countries. These include countries from all regions and with varying development status, such as those already mentioned as well as Brazil, Austria, Serbia and Yemen.

In some countries, the average price for the monthly broadband subscription actually rose between 2008 and 2010. However, in almost all cases, this is because the

Table 3.8: Ten economies with the greatest 2008-2010 decrease in fixed-broadband prices, by absolute value change (left) and relative change (in \%, right)

\begin{tabular}{|r|l|r|r|r|r|}
\hline Rank & Economy & $\begin{array}{c}\text { Broad- } \\
\text { band } \\
\text { sub- } \\
\text { basket } \\
\mathbf{2 0 1 0}\end{array}$ & $\begin{array}{c}\text { Broad- } \\
\text { band } \\
\text { sub- } \\
\text { basket } \\
\mathbf{2 0 0 8}\end{array}$ & $\begin{array}{c}\text { Value } \\
\text { change } \\
\mathbf{2 0 0 8 -} \\
\mathbf{2 0 1 0}\end{array}$ & $\begin{array}{c}\text { Relative } \\
\text { change } \\
\mathbf{2 0 0 8 -} \\
\mathbf{2 0 1 0} \\
\mathbf{( \% )}\end{array}$ \\
\hline 160 & Burkina Faso & 194 & $4^{\prime} 466$ & $-4^{\prime} 272$ & -96 \\
\hline 164 & Malawi & $2^{\prime} 408$ & $4^{\prime} 881$ & $-2^{\prime} 473$ & -51 \\
\hline 149 & Ethiopia & $1^{\prime} 071$ & $2^{\prime} 721$ & $-1^{\prime} 651$ & -61 \\
\hline 132 & Nigeria & 54 & 692 & -639 & -92 \\
\hline 146 & Swaziland & 425 & 806 & -381 & -47 \\
\hline 135 & Uganda & 36 & 375 & -339 & -90 \\
\hline 157 & Mozambique & 60 & 312 & -252 & -81 \\
\hline 145 & Lao P.D.R. & 190 & 435 & -245 & -56 \\
\hline 150 & Guinea & $2^{\prime} 595$ & $2^{\prime} 824$ & -229 & -8 \\
\hline 138 & Kenya & 60 & 261 & -201 & -77 \\
\hline
\end{tabular}

\begin{tabular}{|c|l|r|r|r|r|}
\hline Rank & Economy & $\begin{array}{c}\text { Broad- } \\
\text { band } \\
\text { sub- } \\
\text { basket } \\
\mathbf{2 0 1 0}\end{array}$ & $\begin{array}{c}\text { Broad- } \\
\text { band } \\
\text { sub- } \\
\text { basket } \\
\mathbf{2 0 0 8}\end{array}$ & $\begin{array}{c}\text { Relative } \\
\text { change } \\
\mathbf{2 0 0 8 -} \\
\mathbf{2 0 1 0} \\
(\%)\end{array}$ & $\begin{array}{c}\text { Value } \\
\text { change } \\
\mathbf{2 0 0 8 -} \\
\mathbf{2 0 1 0}\end{array}$ \\
\hline 160 & Burkina Faso & 194 & $4{ }^{\prime} 466$ & -96 & $-4 ' 272$ \\
\hline 132 & Nigeria & 54 & 692 & -92 & -639 \\
\hline 135 & Uganda & 36 & 375 & -90 & -339 \\
\hline 53 & Azerbaijan & 3 & 27 & -88 & -24 \\
\hline 79 & Bhutan & 6 & 38 & -84 & -32 \\
\hline 157 & Mozambique & 60 & 312 & -81 & -252 \\
\hline 63 & Sri Lanka & 3 & 16 & -81 & -13 \\
\hline 138 & Kenya & 60 & 261 & -77 & -201 \\
\hline 120 & Bangladesh & 31 & 124 & -75 & -93 \\
\hline 101 & Moldova & 5 & 18 & -73 & -13 \\
\hline
\end{tabular}




\section{Box 3.3: Fast, faster, the fastest: differences in broadband speeds, prices and data caps}

The fixed-broadband sub-basket is based on an entry-level plan that offers a minimum speed of $256 \mathrm{kbit} / \mathrm{s}$. While this standard measure is necessary to be able to compare prices across countries, there are major differences between countries and the advertised speeds in the 165 countries included in the IPB 2010 vary from the minimum of $256 \mathrm{kbit} / \mathrm{s}$ in the majority of countries, to $8 \mathrm{Mbit} / \mathrm{s}$ in Austria and France, $30 \mathrm{Mbit} / \mathrm{s}$ in Monaco and $50 \mathrm{Mbit} / \mathrm{s}$ in the Republic of Korea (see Table Box 3.3). This shows that there are major differences not only in the price for a basic fixed-broadband service, but also in terms of speed and quality. Users in different countries will not share the same online experience, since the speed of the connection will have a major impact on download times, as well as on the quality of the experience.

A comparison of monthly caps that limit the amount of data that can be transferred within one month shows that, while many operators offer unlimited plans, others limit the amount of free data per month, which means that subscribers have to pay for data downloads that exceed this amount.

In addition to the difference in available speeds, the actual speeds at which customers are able to download data vary and can differ substantially from the speeds advertised by operators. A recent study by Ofcom, the UK regulatory authority, showed that "Average download speeds remain less than half of 'up to' speeds advertised by some Internet service providers (ISPS), particularly for current generation copper-based ADSL services". 25 The actual speed that a broadband connection delivers is affected by a number of factors, including how far away customers live from the telephone exchange, how many other people in the same area are using the same service at the same time, internal wiring and even the weather. ${ }^{26}$ This highlights the need for regulators to carry out surveys and set standards in terms of broadband quality of service and speed.

Table Box 3.3: Fixed-broadband Internet prices, caps and speeds, 2010, selected economies

\begin{tabular}{|l|c|c|c|}
\hline Country & $\begin{array}{c}\text { Fixed-broadband } \\
\text { monthly subscriptions (USD) }\end{array}$ & $\begin{array}{c}\text { Fixed-broadband } \\
\text { Internet monthly cap (GB) }\end{array}$ & $\begin{array}{c}\text { Fixed-broadband } \\
\text { Internet speed (Mbit/s) }\end{array}$ \\
\hline India & 5.5 & 1 & 0.256 \\
\hline Syria & 21.6 & 3 & 0.256 \\
\hline South Africa & 27.4 & 2 & 0.384 \\
\hline Pakistan & 14.2 & Unlimited & 1 \\
\hline Australia & 36.9 & 2 & 3 \\
\hline Belgium & 24.8 & 15 & 8 \\
\hline Austria & 26.2 & Unlimited & 8 \\
\hline France & 30.1 & Unlimited & 12 \\
\hline Japan & 23.1 & Unlimited & 12 \\
\hline Portugal & 26.3 & 30 & 30 \\
\hline Monaco & 45.9 & Unlimited & 50 \\
\hline Korea (Rep.) & 24.0 & 40 & \\
\hline
\end{tabular}

Note: These fixed-broadband services refer to the entry-level subscriptions that ITU used in the 2010 IPB.

Source: ITU.

speed of the entry-level broadband package increased, so the higher price provides customers with a higher broadband speed (Box 3.3). In Panama and St Lucia, for example, the entry-level broadband plan in 2010 has an advertised speed of $1 \mathrm{Mbit} / \mathrm{s}$, compared with $256 \mathrm{kbit} / \mathrm{s}$ two years earlier. In Australia, Sweden and Hong Kong (China), broadband speeds were increased to $1.5,6$ and $8 \mathrm{Mbit} / \mathrm{s}$ (from 0.256, 1 and $1.5 \mathrm{Mbit} / \mathrm{s}$ ), respectively. Higher prices are more problematic when they refer to the same transmission speed in countries where prices are already very high and penetration rates low, as is the case in Guinea and Namibia.

\section{Fixed-broadband prices: the regional and development-level perspective}

Although fixed-broadband services are much more expensive in developing countries, it is in these countries that we see the greatest drop in prices. Between 2008 and 2010, fixed-broadband prices fell by 52.2 per cent 
in developing countries, as against 35.4 per cent in developed countries.

Prices for ICT services continue to decrease across the world's regions, but the greatest relative price drop between 2008 and 2010 occurred in Africa's fixedbroadband sub-basket, which fell by 55.2 per cent. The CIS witnessed a similar decrease (of 51.8 per cent) in broadband prices over the same period, followed by Asia and the Pacific (46.7\%), the Arab States (34.7\%) and Europe (18.0\%). The Americas displays the most modest decrease in fixed-broadband prices, and was the only region where the decrease was below 10 per cent. Developing countries benefited from a higher price drop $(52.2 \%)$ than developed countries (35.4\%), suggesting that the broadband price divide is narrowing.

A positive development in terms of broadband prices is the increasing availability of $3 \mathrm{G}$ mobile-broadband networks and services, which creates additional competitive pressure on fixed-broadband operators. In Morocco, for example, two new mobile-broadband operators have exerted competitive pressure, and fixed-broadband prices have decreased by 44 per cent over the last two years (Box 3.4).
Another important factor for the provision and price of broadband services is the availability of sufficient international Internet bandwidth, particularly in countries and regions where most Internet traffic would exit the country/region, such as Africa. Since there are relatively few regional and national gateways, and only a limited amount of national or regional content, Africa, in particular, depends on international Internet bandwidth. ITU data show that a number of African countries have greatly increased international bandwidth capacity over the last few years. They include, for example, Kenya, where international bandwidth capacity has increased from $829 \mathrm{Mbit} / \mathrm{s}$ in 2008, to over $202000 \mathrm{Mbit} / \mathrm{s}$ in 2010. Uganda and Tanzania, too, have considerably increased their international connectivity, and the construction and expansion of a number of submarine-cable systems, including Seacom ${ }^{27}$ and Eassy ${ }^{28}$, have played, and continue to play, an important role in bringing down end-user tariffs. ${ }^{29}$

Although Africa's fixed-broadband basket has dropped by over 50 per cent, the service remains prohibitively expensive, and in 2010 still represented almost three times the monthly average per capita

\section{Chart 3.9: Fixed-broadband sub-basket by region and by level of development, 2010}

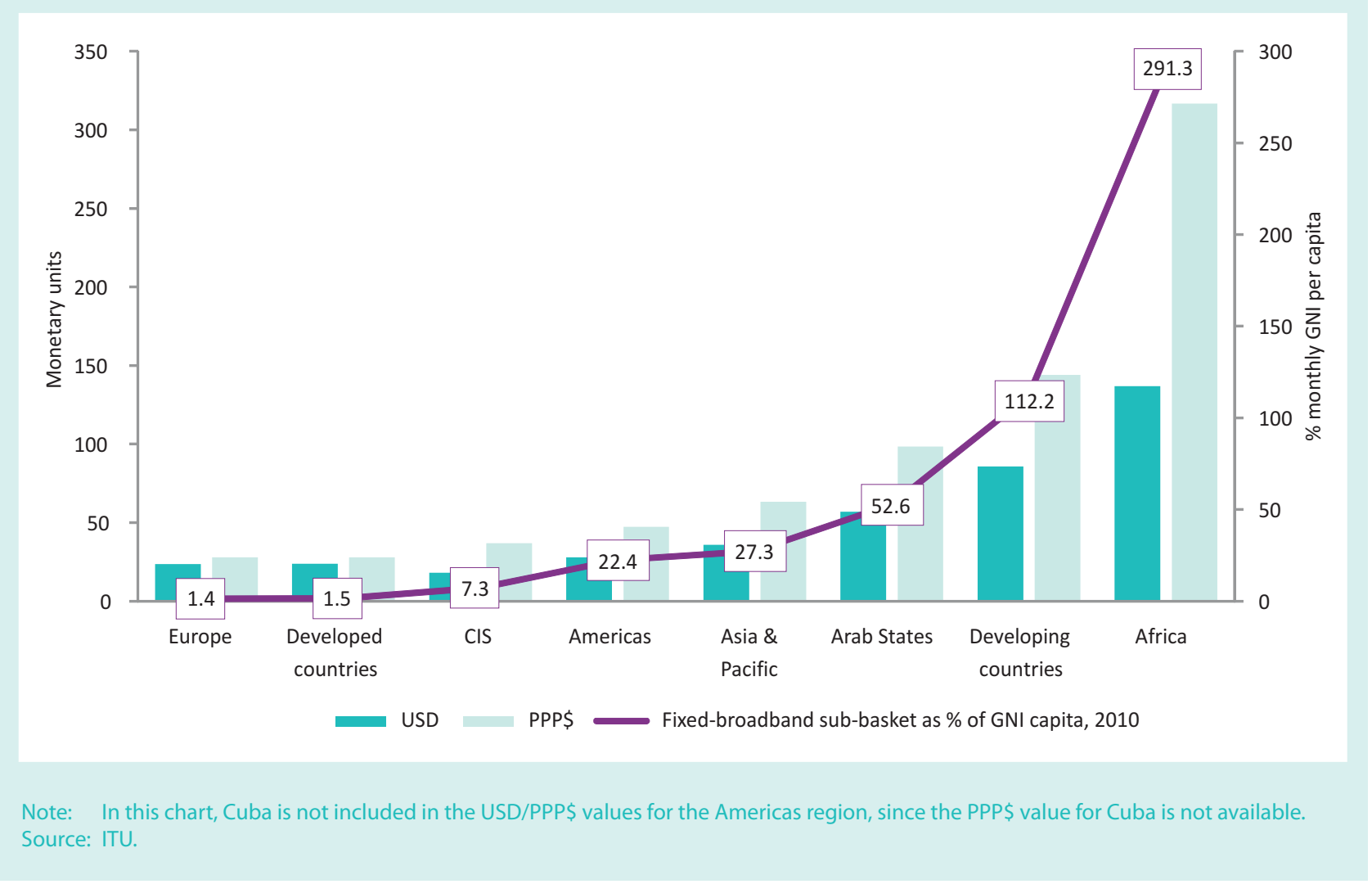




\section{Box 3.4: Inter-modal competition in Morocco}

By the end of 2010, Morocco had over 1.3 million dedicated mobile data subscriptions (using the mobile network via a modem/ dongle), compared with fewer than 500000 fixed-broadband subscriptions. While the former incumbent telecommunication operator Maroc Telecom holds close to 100 per cent of the fixed-broadband market, it holds only 40 per cent of dedicated mobile data subscriptions, a market it shares with two other operators - Wana and Medi Telecom. Fixed-broadband prices have come down by close to 40 per cent between 2008 and 2010 (from USD 19 to 12 for the monthly subscription), and the country has increased its Internet user penetration rate from 33 to 49 per cent. Since less than 0.1 per cent of all Internet subscriptions are narrowband, Internet users in Morocco are almost exclusively broadband users. income. Broadband tariffs also remain very expensive in the Arab States and in Asia and the Pacific, where the fixed-broadband basket stood at 52.6 and 27.3, respectively (Chart 3.9).

The important price divide that separates the world's regions, particularly in terms of relative broadband prices, is highlighted in Chart 3.10. Substantial price drops are needed to make high-speed Internet access affordable and accessible to more people in Africa and in the other developing regions.

\subsection{Comparing mobile-broadband prices - high speed, limited volume}

By 2011, mobile broadband has become a market reality in the majority of the world's countries, with over 150 economies offering $3 \mathrm{G}$ services commercially (compared to 95 in 2007). For an increasing number of people in the world, mobile-broadband access to the Internet is not just complementing fixed-broadband access, but actually constitutes the only access to the Internet. ITU estimates

Chart 3.10: ICT price sub-baskets by region, 2008 and 2010

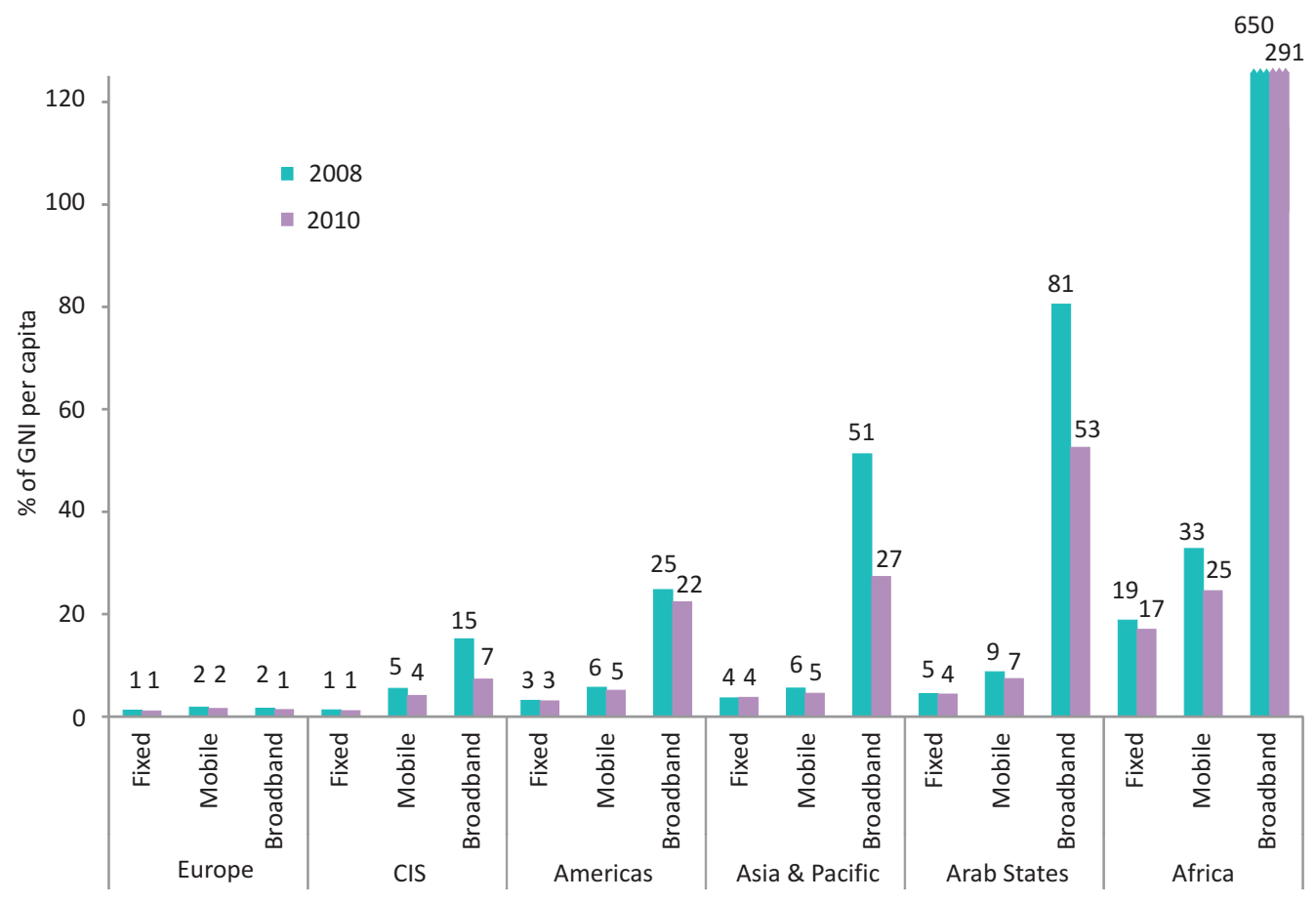


Box 3.5: Both USD and PPP adjusted prices highlight the high cost of fixed-broadband services in developing countries

For analytical purposes it is interesting not only to look at the affordability of ICT services but to also show and compare absolute US dollar values, as well as relative purchasing power parity (PPP) prices, which take into account the local buying power of a national currency.

A comparison of the 2010 USD values shows that for both fixed-telephone and the mobile-cellular services, prices in USD values are on average higher in developed than in developing countries, reflecting lower income levels in the latter group. Fixed-broadband services, however, are on average much more expensive in developing countries - even in USD values - where the fixed-broadband sub-basket is on average more than three times as costly. Broadband prices for 2010 also stand out because they vary much more between countries, from as little as USD 4.8 in Romania to as much as USD 1752 in Cuba. These findings suggest not only a sharp price divide in terms of broadband services but also point to the fact that broadband remains prohibitively expensive.

This finding is also upheld by the comparison of PPP prices: For both fixed-telephone and mobile-cellular tariffs, developed economies have higher PPP prices, reflecting the fact that salaries are higher and products and services cost more than in developing countries. But the gap in prices between developed and developing countries is smaller than in USD terms: In 2010, the fixed-telephone sub-basket cost on average PPP\$ 22.2 in developed countries, compared in PPP\$ 18.3 in developing economies. The mobile-cellular sub-basket in developed countries averaged PPP\$31.9, compared with PPP\$ 25.6 in developing countries. ${ }^{30}$

The situation is different for high-speed Internet access. First, in PPP\$ terms, subscribers in developing countries pay more than those in developed countries. Second, a comparison of 2010 broadband prices shows that - in stark contrast to fixedtelephone and mobile-cellular prices - people in developing countries had to pay five times the price paid in developed countries. The relatively high price for broadband services in developing countries is further highlighted by comparing the price of the three sub-baskets with each other. In developed countries, the three sub-baskets vary between just PPP\$ 22.2 and PPP\$ 31.9, with mobile-cellular being the most expensive sub-basket. In developing countries, the sub-basket values vary between PPP\$ 18.3 and PPP\$ 144.0, with the fixed-broadband sub-basket being the most expensive sub-basket (Chart Box 3.5). At the same time, between 2008 and 2010, fixed-broadband prices in developing countries have decreased considerably, in both PPP\$ and USD, and much more markedly than the other ICT services. While comparisons show that the PPP\$ prices for fixed-telephone and mobile-cellular services have changed little over time, they have come down by 45.5 per cent for broadband services. This compares with a much more moderate price decrease of 10.7 per cent for broadband services in developed countries.

Chart Box 3.5: ICT price sub-baskets by level of development, PPP\$, 2008 and 2010
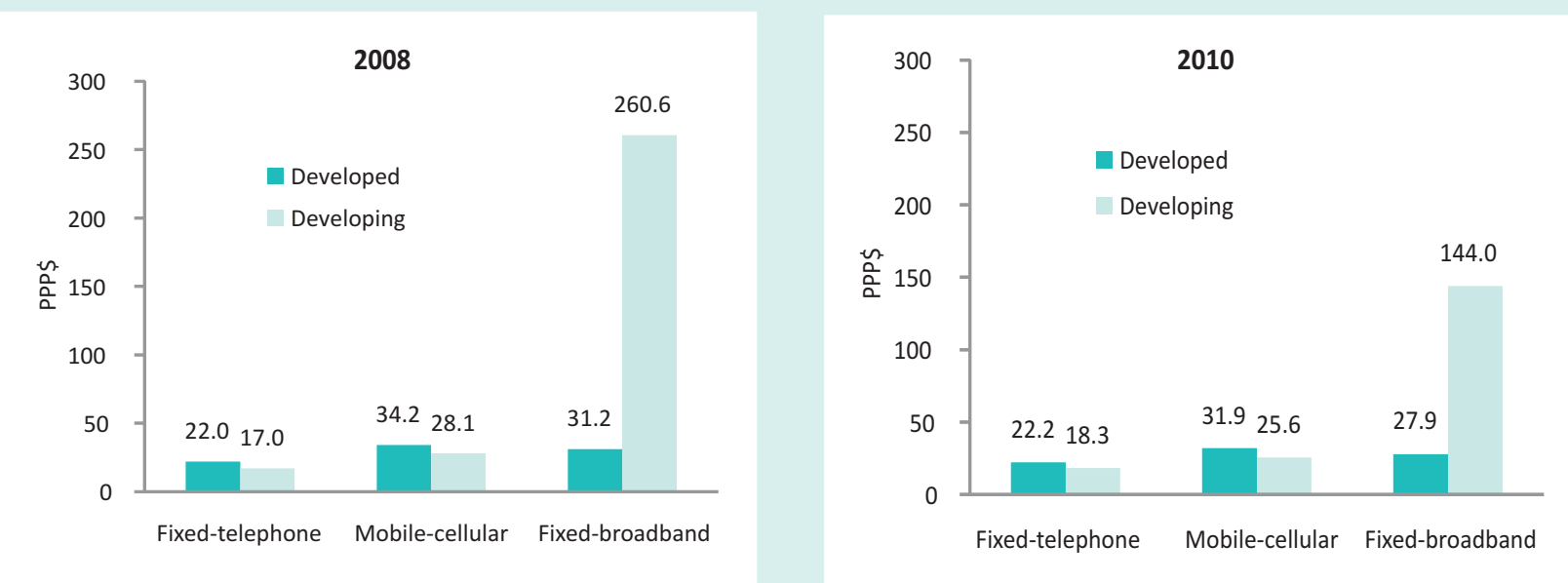

Source: ITU. 
that, by the end of the first quarter of 2011, the number of mobile-broadband subscriptions had surpassed 1 billion - almost twice the number of fixed-broadband subscriptions, up from less than 200000 four years earlier. New technological developments and progress, simplified and user-friendly billing methods and services and improvements in end-user devices (particularly smart phones) have finally made mobile broadband a reality. Many governments have responded to these changes by redefining broadband policies and adjusting targets. Given these developments, it is important to examine mobile-broadband prices, and ITU is considering adding a mobile-broadband sub-basket to the ICT Price Basket.

As opposed to $2 \mathrm{G}$ or $2.5 \mathrm{G}$ networks, the third generation of mobile telephony offers unprecedented bandwidth, allowing users to access the Internet and other high-bandwidth multi-media applications. This means that, besides basic voice and sms/mms services, it provides broadband access to the Internet, previously reserved for users of fixed-broadband technologies.

Mobile-broadband subscriptions refer to active mobilecellular subscriptions that have access to data communications (the Internet) at broadband speeds. The term 'mobile broadband' covers different types of technologies, including WCDMA and CDMA 1xEV-DO. It refers to standard mobile subscriptions (used for data applications, including access to the Internet, via a mobile phone), but also to dedicated data services that use the mobile network and that are purchased separately from voice services, either as a standalone service (modem/ dongle) or as an add-on data package to voice services, which requires an additional subscription.

The multitude of mobile-broadband subscriptions and access devices contributes to the difficulty of understanding and measuring the service, making price comparisons challenging. While the possibility of including a mobile-broadband sub-basket in the IPB has been raised, this will require further discussion and consultation. Since not all countries have launched $3 G$ mobile-broadband services, the inclusion of a mobilebroadband sub-basket would also currently limit the number of countries in the IPB.

Given the importance of mobile-broadband access, particularly in countries where fixed-broadband access is limited, ITU has started to examine mobile-broadband prices for a limited number of economies. Prices for mobile-broadband services were collected directly from operators' websites during the first quarter of 2011. Price data were collected for both standard mobile subscriptions and dedicated data subscriptions (via a modem/dongle), and are based on plans that provide $1 \mathrm{~GB}$ of monthly download volume, which is in line with the fixed-broadband cap used to calculate the fixed-broadband sub-basket of the IPB.

This tariff collection exercise revealed that comparisons face a number of challenges. Operators do not always clearly label their different mobile-broadband services to show whether they refer to standard mobile subscriptions or to dedicated services. In many cases, mobilebroadband services for a standard mobile subscription are only available in combination with other services, such as voice or sms. Often, although services are advertised as including 'unlimited' data volumes, most operators actually limit upload and download volumes by reducing the speed after a certain volume has been exceeded. Many of them only provide this information in a footnote, far from clearly visible for customers, who need to make sure that they read the fine print. In some cases, the speed of mobile-broadband access is not indicated, which further adds to the difficulty of making comparisons. Finally, advertised speeds usually represent a maximum speed rather than an average, so users may end up with a much slower connection than they officially subscribe to and pay for.

A number of conclusions may be drawn based on the tariffs collected for some 20 economies from different regions and with varying development levels (Table 3.9):

- People in developing countries pay relatively more: Prices for a monthly subscription of 1 GB download volume vary considerably in USD, from about USD 4 in Viet Nam and Sri Lanka to over USD 40 in South Africa and Germany, and around USD 80 in Brazil. In relative terms, and compared to income levels, mobile-broadband prices are more expensive in developing than in developed countries, a finding that is in line with the results for the IPB's fixed-broadband tariffs. In India, Mali, Kenya and Brazil, the monthly price for mobile-broadband services exceeds ten per cent of the monthly GNI per capita. In all developed economies included in this analysis, prices correspond to less than two per cent (and most often even below one per cent) of the average income.

- In about half the countries, 1 GB of data is cheaper over the mobile network: A comparison of (postpaid) mobile-broadband and (postpaid) fixed-broadband subscriptions shows that in about half of the countries covered - Australia, Chile, Finland, 
Germany, Kenya, Lithuania, Sri Lanka, United Arab Emirates and Viet Nam - the fixed-broadband $1 \mathrm{~GB}$ subscription is more expensive than the mobile-broadband subscription.

- Mobile-broadband users get more for their money: Based on $1 \mathrm{~GB}$ of data volume, and taking into account the (theoretical) speeds of the different packages, mobile-broadband users get more for their money, since the entry-level mobile-broadband (theoretical) speeds are much higher than those for fixed broadband. Except in Chile and Finland, mobile-broadband speeds far outstrip the speeds offered with the entry-level fixedbroadband subscription in all countries. It is important to note that a comparison based on unlimited plans would yield very different results, since many fixed-broadband packages are truly unlimited, whereas most mobile-broadband plans have a cap. One exception is Finland, where both the standard mobile-cellular broadband and the dongle packages offer truly unlimited data access.

- Mobile-cellular broadband prices depend on the subscription type and cap size, not the end-device: Different price packages for mobile-broadband services reveal that postpaid tariffs tend to be cheaper, usually because operators offer lower tariffs whenever they can count on a predetermined level of consumption and hence revenue, for instance when customers of postpaid subscriptions are tied to a contract for a minimum of either 12 or 24 months (which is often the case). The end-device that is used to access data, on the other hand, is not actually relevant to operators and there should not be any price difference between packages offered for mobile-cellular broadband users or for those that will access the Internet using a modem/dongle. Indeed, operators in a number of countries, including Morocco, India and Mali, offer the same package, regardless of the access device. If price differences exist, this is usually because of a difference in the data capacity that is included in the package, or because the offer is tied to an existing mobile-cellular voice subscription. In Canada and the United States, for example, the advertised price for the standard mobile-cellular data subscription is available only for customers that already have a Rogers/Verizon voice subscription. Operators may also offer different price packages to accommodate different usage patterns. For example, usage volumes tend to be lower for mobile-handset users, and dongle/modem packages often include a greater allowance/cap. In Germany, for example, T-mobile's mobile-broadband package for cellphone users provides high-speed access until 200MB (after which speeds decrease to $64 \mathrm{kbit} / \mathrm{s}$ ), while the dongle subscription includes $3 \mathrm{~GB}$ of data volume. In the Russian Federation, the price for the dongle subscription includes $2 \mathrm{~GB}$, as against only $1 \mathrm{~GB}$ for the standard mobile-cellular data packages.

These findings suggest that, based on a limited (1 GB) amount of data volume, and in comparison with fixedbroadband offers, mobile-broadband packages are competitive in terms of price, and faster in terms of (advertised) speed. At the same time, the mobile-broadband market is still relatively nascent in most countries and expected to grow quickly over the next few years. Increasing economies of scale, inter- and intra-modal competition and further technological advances are likely to help the market mature further, by making services cheaper and faster. An important challenge that operators will need to address is the growing demand for transmission capacity, particularly if mobile-broadband access is to compete with fixed access. The fact that most operators' packages limit access by imposing caps and restricting usage volume highlights the current limitations of mobile-broadband networks - and the need to overcome them. 


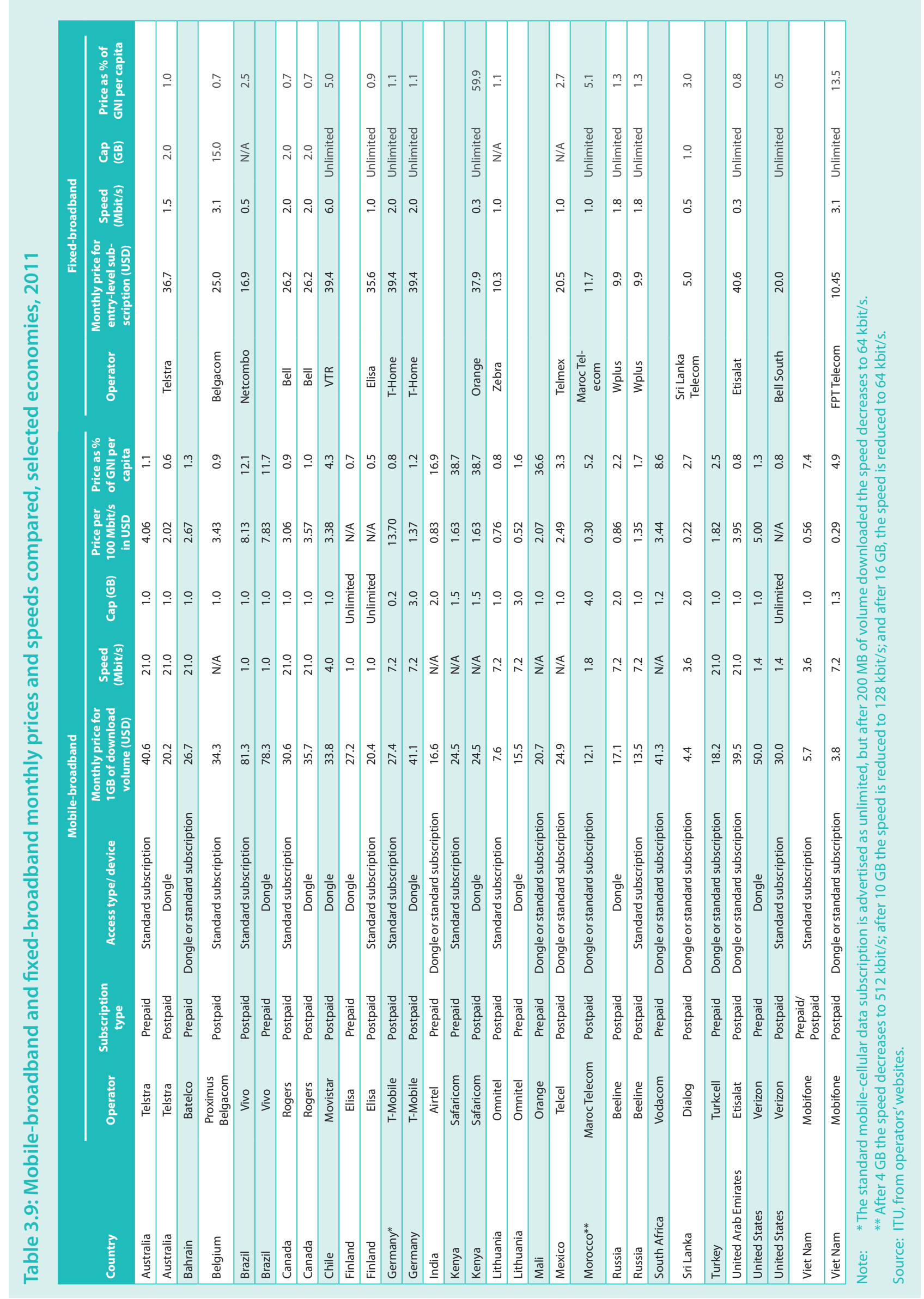




\section{Endnotes}

1 While many governments (usually telecommunication/ICT regulatory authorities) and several regional and international organizations, including OECD and the World Bank, collect and publish price data for selected telecommunication services, these are usually limited to a country, a region or a single telecommunication service. For different examples of prices that are being tracked, see Chapter 6 of ITU (2009).

2 See, for example, http://www.techtree.com/India/News/Kobian Unveils Low-Cost Mobile Phones/551-114330-893.html and http://www.itu.int/ITU-D/ict/newslog/Multi+SIM+Mobile+Phones+Account+For+385+Of+Indian+Phone+Sales.aspx.

3 See, for example, http://www.informationweek.com/news/mobility/smart phones/showArticle.jhtml?articleID=225700597.

4 Fixed broadband, as per the ITU definition in the World Telecommunication/ICT Indicators handbook, is defined as subscriptions to high-speed access to the public Internet (a TCP/IP connection), at downstream speeds equal to, or greater than, $256 \mathrm{kbit} / \mathrm{s}$.

5 The speed of the entry-level broadband plan provided by the operator used in the calculatation of the IPB has increased from $256 \mathrm{kbit} / \mathrm{s}$ in 2008 to $1 \mathrm{Mbit} / \mathrm{s}$ in 2010, in Jamaica, Slovenia, St. Lucia, Pakistan, Panama and Tunisia.

6 Income levels are expressed as gross national income (GNI) per capita.

7 While the ICT Price Basket is a useful tool for assessing the effects of different policies, it is important to remember that not all regulatory changes will have an immediate impact on prices. Certain policies may take some time before they result in any concrete change in tariffs. Others, such as the revision of interconnection charges, may have a more immediate impact.

8 For more information on the choice of the three sub-baskets, refer to the section on methodology.

9 World Bank, USD, Atlas method.

10 The ITU Tariff Indicators Questionnaire has been sent to national statistical contacts once a year, since 2009. Before that, tariffs were collected as part of the regular (long) ITU World Telecommunication/ICT Indicators questionnaire.

11 For this, the average annual UN operational rate of exchange was used.

12 The mobile-cellular sub-basket refers to a 30-call basket, which is the entry-level basket of the 2009 OECD methodology (see OECD (2010a), pp. 13-14), but with the following differences: the 2009 OECD methodology is based on the tariffs of the two largest mobile operators. The ITU mobile-cellular sub-basket uses (only) the largest mobile operator's tariffs. Additionally, the ITU mobile-cellular sub-basket does not take into account calls to voicemail (which in the OECD basket represent 4 per cent of all calls).

13 For the 2008 ICT Price Basket, 2008 PPP conversion factors, the 2008 UN conversion rate and 2008 GNI per capita data were used. For the 2010 IPB, 2009 values were used in all three cases, as 2010 data were not yet available.

14 For example, if country A and country B have the same price in USD for any given ICT service, but in country A prices of other products are in general cheaper (in USD), then applying PPP exchange rates to the ICT service price in country A will make this service more expensive. This is because, compared to country B, in country A the same amount of USD (exchanged into national currency at market exchange rates) can buy more products or services. Therefore, the ICT service in country A is more expensive in terms of what could be bought with that amount in each country. The International Comparison Program (ICP) is the major global initiative to produce internationally comparable price levels. It is overseen by a Global Office housed in the World Bank and is implemented through the national statistical offices of 107 countries. Together with the OECD/Eurostat PPP data, it provides PPP data for all countries of the ICT Price Basket, except for the Bahamas, Cuba, Liechtenstein, Monaco, San Marino and Zimbabwe. For more information on PPP methodology and data, see http://www.worldbank.org/data/icp.

15 The World Bank's Atlas method is used for the Bank's official estimates of the size of economies in terms of GNI converted to current USD. GNI takes into account all production in the domestic economy (i.e. GDP) plus the net flows of factor income (such as rents, profits and labour income) from abroad. The Atlas method smooths exchange-rate fluctuations by using a three-year movingaverage, price-adjusted conversion factor. See: http://econ.worldbank.org/WBSITE/EXTERNAL/DATASTATISTICS/0, contentM DK:20452009 pagePK:64133150 piPK:64133175 theSitePK:239419,00.html.

16 The main reason the IPB does not take into account different packages from different operators is that it is not feasible for most countries to collect and compile price comparisons for several operators and packages.

17 See: http://www.verizonwireless.com/b2c/store/controller?item=planFirst\&action=viewPlanList\&sortOption=priceSort\&typeId=1 \&catId $=323 \&$ sel $=$ ind

18 See: http://www.bob.at/bigbob. Please note that customers need to pay a one-time charge of EUR 15 to be able to use the Big Bob tariff plan.

19 For concrete examples of exceptions and concrete country examples, please refer directly to the sub-basket sections.

20 Prices are relative in two ways: first, the IPB value, on which the ranking is based, is expressed as a percentage of countries' average monthly GNI per capita. Second, the value does not indicate how much citizens need to pay for all of the three ICT services. Rather, it represents an average relative cost, since the sum of the three ICT prices is divided by three. The value should therefore be seen as an indication of cost that is primarily used to compare and benchmark countries with each other.

21 Financial Times, Chief of FCC calls for internet subsidy, 8 February, 2011, see: http://www.ft.com/cms/s/0/4605bf72-3318-11e0-9a61-00144feabdc0.html\#axzz1G0o8Cx48.

22 ITU World Telecommunication/ICT Indicators questionnaire 2011, response from Nauru's Ministry of Transport \& Telecommunications. 
23 The 30 calls are distributed across the different networks (mobile and fixed), at different durations. In total, the 30 calls correspond to 50.87 minutes of calls. For more details on the call distributions and lengths in the OECD/Teligen methodology, see Annex Table 2.1.

24 Costa Rica's mobile market was opened to competition in late 2010 with the assignment of two licenses. The (two) new entrants are expected to start operations at the end of 2011.

25 See http://media.ofcom.org.uk/2011/03/02/average-broadband-speed-is-still-less-than-half-advertised-speed/.

26 See http://www.uswitch.com/broadband/broadband-speeds/.

27 See http://www.seacom.mu/index2.asp.

28 See http://www.wiocc.net/eassy.htm.

29 See allafrica.com, Uganda: Third Internet cable starts operation, 11 August, 2010, at: http://allafrica.com/stories/201008110372.html.

30 The regional Tables 3.5, 3.6 and 3.9 show that all regions have higher PPP\$ prices than USD prices. This is because every regional grouping used in the analysis includes a number of low or lower-income countries, where purchasing-power-parity adjusted dollars are usually higher than USD. 



\section{Chapter 4. Understanding broadband: addressing issues of capacity, speed and quality of service}

\subsection{Introduction}

The ICT for development debate is witnessing an obvious shift: the focus is no longer on the mobile-cellular miracle, but is moving to the need for broadband Internet access. Ambitious policy-makers are trying to set the right regulatory stage while simultaneously calling upon investors, operators and device manufacturers to learn from and leverage the mobile success story. The goal is to roll out high-speed broadband networks and to make broadband Internet access widely available and affordable.

At the same time, there is a growing debate about the meaning and the impact of broadband. Ostensibly a simple term, "broadband" entails a number of complex issues - in terms of technologies, speeds and quality of service. In examining today's broadband developments, there is a growing need to go beyond analysing just the number of broadband subscriptions, which are defined as an Internet connection providing the user with a minimum downstream speed of $256 \mathrm{kbit} / \mathrm{s}$ (see Box 4.1). Other factors, relating to broadband speed and quality in particular, need to be taken into account to determine the uptake - and potential impact - of broadband. These issues are particularly relevant as there are signs that the world is facing a growing divide in terms of the speeds and quality that users are experiencing. This is partly due to increasing differences in the available national and international backbone infrastructure, and in the level of deployment of next-generation access networks (NGAs). ${ }^{1}$ Both high-capacity backbone infrastructure and NGAs are necessary to meet current and future user needs for advanced broadband services.

While second-generation (2G) mobile-cellular services have been identified as a major development enabler, the potential of broadband Internet goes far beyond simple telephony and text messaging. A number of studies have highlighted that broadband is linked to overall economic development. ${ }^{2}$ Broadband is also critical to achieving a number of other development goals, including the Millennium Development Goals (MDG). This is being advocated by the Broadband Commission for Digital Development, which has called upon leaders from the public and private sectors to address the importance of universal access to broadband networks, especially in the achievement of the MDG. ${ }^{3}$

Both the ICT Development Index (IDI) and the ICT Price Basket (IPB) recognize the importance of broadband Internet in the overall ICT development debate. The IDI includes several broadband-related indicators, including mobile-and fixed-broadband penetration, international Internet bandwidth and Internet use. One of the three IPB sub-baskets measures the cost and affordability of fixed-broadband access. These indicators were chosen to benchmark broadband developments because they are readily available and comparable for a large number of countries.

There are high expectations not only that broadband Internet access will become a key development enabler but also that it will be possible to replicate the mobile success story 


\section{Box 4.1: Defining broadband - a moving target}

Although many national regulators and international organizations, including ITU and OECD, define broadband as a connection with downstream speeds greater than, or equal to, $256 \mathrm{kbit} / \mathrm{s}$, there remains much debate as to how fast a connection should be to qualify as broadband, and national definitions vary. ${ }^{4}$ The United States, for example, just recently redefined broadband as a "transmission service that actually enables an end user to download content from the Internet at $4 \mathrm{Mbps}$ and to upload such content at 1 Mbps over the broadband provider's network". Some developing countries, for example Djibouti and Morocco, apply definitions of broadband that set a lower speed (128 kbit/s). However, most national broadband definitions are in line with the ITU/OECD definition.

Specifying a minimum speed for broadband is complicated by the fact that both technologies and services/applications evolve. On the technology side, there are improvements that allow the same technology to provide higher speeds over time, and maximum speeds attained by both DSL and cable services continue to rise. On the services and applications side, users are increasingly accessing data-intensive websites and services, which in theory would require a constant redefining of broadband, which remains a moving target from a user perspective.

Although it is obvious that both content and broadband technologies are evolving rapidly, one of the problems of changing the definition of broadband is that data are then no longer comparable over time, so time series would have to be discontinued. To acknowledge changes in the nature of the Internet (both in terms of content and technology), it seems more useful to analyse and benchmark countries according to broadband technologies, and/or speeds. ITU has collected fixed broadband subscription data by technology for many years, and in 2009 started gathering data by speed, with data collected for subscriptions providing speeds of $256 \mathrm{kbit} / \mathrm{s}$ to less than 2 Mbit/s, $2 \mathrm{Mbit} / \mathrm{s}$ to less than $10 \mathrm{Mbit} / \mathrm{s}$ and $10 \mathrm{Mbit} / \mathrm{s}$ and above. so as to make broadband ubiquitous. This is a prerequisite for moving towards the Internet of Things, i.e. a wholly connected environment where objects such as cars, energy grids or home appliances will automatically exchange information to improve their capabilities and efficiency. ${ }^{6}$ This is starting to happen, with some 81 million machineto-machine (M2M) mobile data connections worldwide in 2010, and a total of 294 million projected for $2015 .{ }^{7}$ Further development and ubiquity of mobile-broadband networks will be necessary in order to achieve such a scenario, and to ensure that no country is left behind.

Another important reason which raises hopes that broadband will become a widespread development tool is the technological advancements made in mobile-cellular technologies themselves. The path from 2G to IMT-2000/3G and now to IMT-Advanced/4G mobile networks is expected to help overcome existing infrastructure barriers, and has already had a major impact on the availability and use of mobile-broadband Internet.

Rapid mobile-broadband developments in the developing countries and increasing reliance on mobile-broadband technologies to address the digital divide make the question of what constitutes broadband particularly pressing. As more and more people come to rely (solely) on mobile-broadband access, operators and regulators are facing a number of new challenges linked not only to the provision of services, but also in terms of backbone infrastructure and international Internet connectivity.

The main objective of this chapter is to look at recent developments in broadband across the world and to address some of the issues which need to be considered in order to understand the development potential of broadband. These issues are linked to the capacity, speed and quality of service that high-speed broadband networks deliver, all of which are affected not only by the national and international Internet backbone infrastructure but also by the broadband access technologies that connect the end user. A more in-depth analysis of broadband will not only highlight substantial differences in broadband services between countries and regions, but also point to the need for governments to identify appropriate measures and indicators to track the real broadband divide.

\subsection{From narrowband to broadband}

As highlighted in Chapter 1 of this report, the number of broadband subscriptions has increased substantially over the last ten years. While fixed broadband was the exclusive means of access for a high-speed Internet con- 
nection until about 2005, the spread of $3 \mathrm{G}$ and higher speed mobile networks across the world has given an increasing number of people the possibility to connect through mobile-broadband networks. As both fixedand mobile-broadband networks and subscriptions are growing, fewer people now rely on fixed-narrowband (usually dial-up) Internet access. The number of dial-up Internet subscriptions started to decrease rapidly in 2007 and, based on current trends, the "death of dial-up" is expected to play out over the next few years. ${ }^{8}$ ITU data show that in Kenya, for instance, the number of dial-up subscriptions has plummeted from over 45000 in 2001 to less than 7000 in 2009. In 2006, over one-third (35 per cent) of households in the Czech Republic accessed the Internet over a narrowband/dial-up connection; only four years later in 2010, nine out of ten connections were broadband connections. ${ }^{9}$ In most developed countries and in a number of developing countries, including Colombia and Senegal, dial-up subscriptions now represent less than ten per cent of all fixed Internet subscriptions.

Mobile broadband ${ }^{10}$ has played an important role in the move from narrowband to broadband high-speed Internet access, and is expected to be instrumental in connecting millions of active people in the developing world. Indeed, the number of active mobile-broadband subscriptions overtook the number of fixed-broadband subscriptions in 2008, and by the end of 2010 more than 150 economies had launched mobile-broadband networks (Figure 4.1). Of these, 109 had launched either HSPA+, LTE and / or WiMAX.

Operators that have launched $3 \mathrm{G}$ services commercially continue to increase coverage. Available data suggest that while $2 \mathrm{G}$ population coverage still exceeds $3 \mathrm{G}$ population coverage in most countries, operators are eager to upgrade mobile networks so as eventually to offer mobile-broadband services to all customers. In Australia, $3 \mathrm{G}$ coverage is on a par with $2 \mathrm{G}$ coverage, with 99 per cent of the population covered. In Qatar and Malaysia, 100 and 95 per cent of the population are covered by a $2 \mathrm{G}$ network, compared with 95 and 81 per cent, respectively, for 3G. In Ghana, just over one-third of the population was covered by a $3 \mathrm{G}$ mobile-broadband signal by the end of 2010 (Table 4.1).

A comparison of the top 25 economies in terms of fixed- and mobile-broadband penetration rates shows that about half of them are included in both categories (Table 4.2). The two countries that were the first to launch $3 \mathrm{G}$ mobile-broadband networks - Japan and the Republic of Korea - today have the highest penetration rate of active mobile-broadband subscriptions. A number of smaller economies that have been able to reach very high fixed-broadband penetration levels, including Liechtenstein, Monaco, Switzerland, the Netherlands and Norway, are not included in the top 25 mobile-broadband list. In contrast, a number of countries from the Arab States region (including the United Arab Emirates and Saudi Arabia) have mobilebroadband penetration rates above 50 per cent, but relatively low fixed-broadband penetration rates (six, ten and two per cent, respectively).

A number of other developing countries have been able to leverage mobile-broadband technologies to overcome infrastructure barriers and to boost competition so as to provide high-speed Internet access to

Table 4.1: Percentage of the population covered by a 2G/3G network, selected countries, 2009 and 2010

\begin{tabular}{|l|c|c|c|c|}
\hline \multirow{2}{*}{} & \multicolumn{2}{|c|}{ 2G population coverage (\%) } & \multicolumn{2}{|c|}{ 3G population coverage (\%) } \\
\cline { 2 - 5 } & $\mathbf{2 0 0 9}$ & $\mathbf{2 0 1 0}$ & $\mathbf{2 0 0 9}$ & $\mathbf{2 0 1 0}$ \\
\hline Australia & 99 & 99 & 99 & 99 \\
\hline Belarus & 99 & 100 & 59 & 67 \\
\hline Belgium & 100 & 100 & 97 & 97 \\
\hline Brazil & 97 & 100 & 55 & 67 \\
\hline Ghana & 75 & 77 & 35 & 36 \\
\hline Malaysia & 95 & 95 & 74 & 81 \\
\hline Qatar & 100 & 100 & 95 & 95 \\
\hline
\end{tabular}




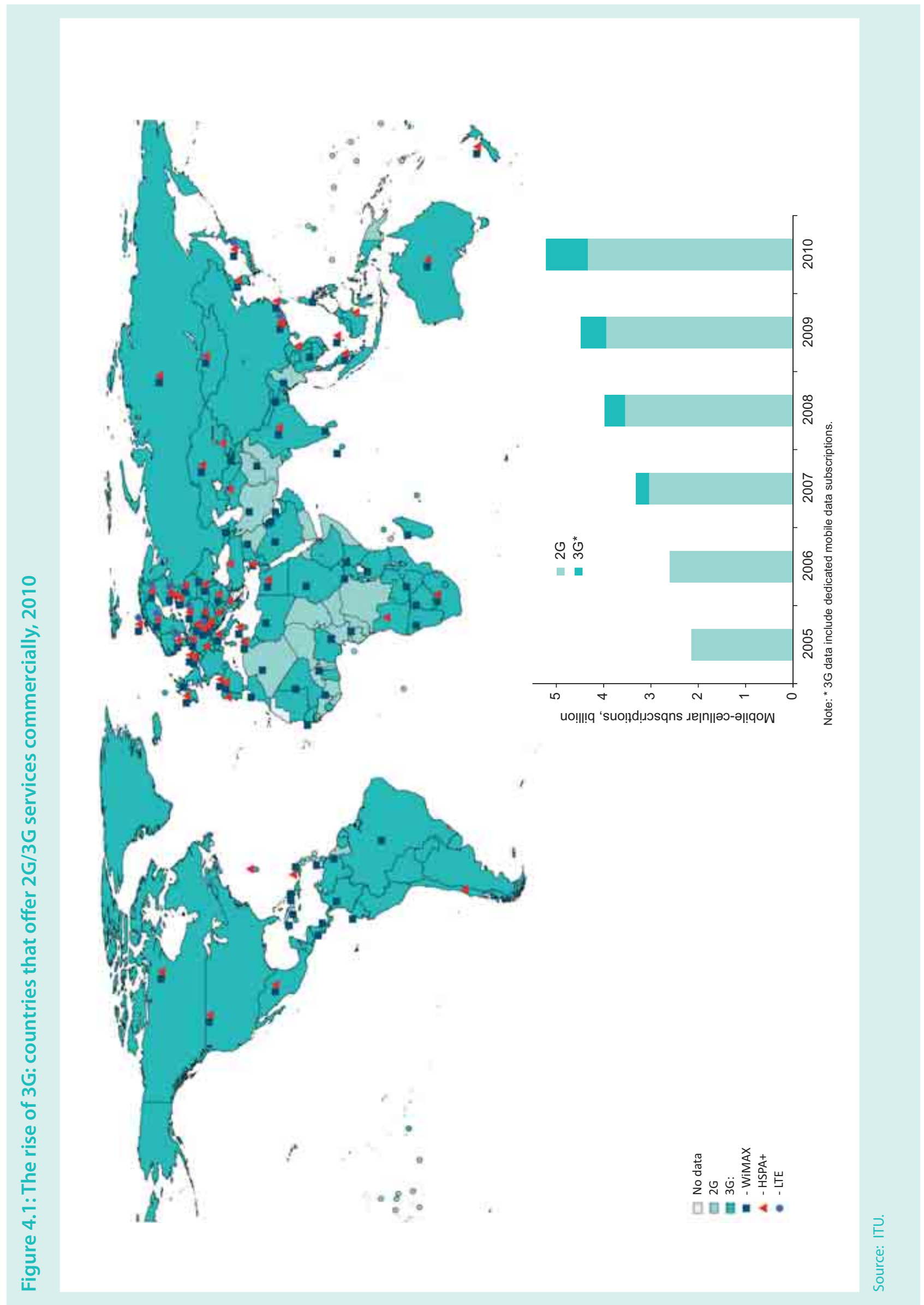


Table 4.2: Top 25 broadband economies, 2010

\begin{tabular}{|l|c|l|c|}
\hline \multicolumn{2}{|c|}{$\begin{array}{c}\text { Fixed-broadband } \\
\text { subscriptions per } \\
100 \text { inhabitants }\end{array}$} & \multicolumn{2}{c|}{$\begin{array}{c}\text { Active mobile-broadband } \\
\text { subscriptions } \text { inhabitants }\end{array}$} \\
\hline Liechtenstein & 63.8 & Korea (Rep.) & 91.0 \\
\hline Dominica & 47.1 & Japan & 87.8 \\
\hline Monaco & 41.9 & Sweden & 84.0 \\
\hline Switzerland & 38.2 & Australia & 82.7 \\
\hline Netherlands & 38.0 & Finland & 78.1 \\
\hline Denmark & 37.4 & Hong Kong, China & 74.5 \\
\hline Korea (Rep.) & 36.6 & Portugal & 72.5 \\
\hline Iceland & 34.6 & Luxembourg & 72.1 \\
\hline Norway & 34.6 & Singapore & 69.7 \\
\hline France & 33.9 & Austria & 67.4 \\
\hline Luxembourg & 32.8 & New Zealand & 66.2 \\
\hline Germany & 31.6 & Kuwait & 63.5 \\
\hline Sweden & 31.6 & Israel & 62.2 \\
\hline Belgium & 31.5 & Brunei Darussalam & 61.4 \\
\hline United Kingdom & 31.4 & Cyprus & 61.3 \\
\hline Hong Kong, China & 30.2 & Italy & 59.4 \\
\hline Canada & 29.8 & UAE & 58.4 \\
\hline Finland & 29.1 & Greece & 58.3 \\
\hline Andorra & 28.9 & Saudi Arabia & 57.8 \\
\hline Malta & 27.5 & Macao, China & 56.1 \\
\hline Japan & 26.9 & United Kingdom & 56.0 \\
\hline United States & 26.3 & Spain & 55.7 \\
\hline Israel & 25.1 & Denmark & 54.7 \\
\hline New Zealand & 24.9 & United States & 54.0 \\
\hline Singapore & 24.7 & Ireland & 47.3 \\
\hline & & \\
\hline
\end{tabular}

previously unconnected areas. For example, in Angola, Cambodia, Indonesia, Kenya, Namibia and Tajikistan, fixed-broadband penetration lies below one per cent, whereas the corresponding figure for mobile-broadband subscriptions stands at six to ten per cent. In South Africa, mobile-broadband services were launched as early as 2005 and operators have started competing for customers by introducing a large number of different mobile-broadband prepaid packages, including promotional offers. ${ }^{11}$ Today, the country has a fixed-broadband penetration rate of 1.5 , compared with a 16.6 per cent penetration in mobile broadband.

Mobile broadband also has the potential to assure seamless Internet connectivity for users when they travel across borders to other countries. Indeed, international roaming services have greatly evolved in recent years, improving the user's experience when accessing mobilebroadband services abroad. However, most often data roaming tariffs are prohibitively high, which greatly deters mobile-broadband usage when roaming (see OECD (2010b) and BEREC (2010)). In the second quarter of 2010, average mobile data roaming prices within the European Union were more than 25 times higher than the corresponding domestic average prices (BEREC, 2010). A growing number of mobile-broadband roamers suffer from so-called "bill shock", i.e. an unexpected increase in their monthly bill and, as a result, many travellers are disconnecting their smartphones or restricting data roaming use when abroad.

Some countries have adopted or are considering the adoption of consumer-protection measures to address the problem. The United States, for example, has discussed the Cell Phone Bill Shock Act of $2011^{12}$ and the European Roaming Regulation was adopted by the European Union in 2009 (European Commission, 2009a). The latter is currently under revision with a view to setting a maximum cap for data roaming prices..$^{13}$ Given the international nature of the service, regulation of mobile-broadband roaming prices requires cooperation between countries, which can make regulation more difficult.

\subsection{Broadband revisited: the importance of capacity, speed and quality}

As the world moves from narrowband to broadband Internet access, it is important to understand the difference that broadband makes in terms of the applications and services that it can deliver. Since many of the opportunities to deliver broadband are ascribed to significant changes in wireless technologies, it is also necessary to identify new challenges in measuring mobile/wireless-broadband developments, and to understand differences between fixed- and mobilebroadband services. A closer look at broadband access technologies will highlight the key issues that affect the way the end user will experience broadband: capacity, speed and quality of service. At the same time, the access technology connecting the user is only one of the broadband building blocks that determine the broadband experience, and it is equally important to look at national and international backbone capacity. All of these are important for the 'broadband for development' discussion, since they directly and indirectly influence the potential impact of broadband. 
There are substantial differences in fixed- and mobilebroadband technologies, with huge variations in the speeds that these technologies can provide. For measurement purposes, in 2005 ITU set a minimum definition for broadband at $256 \mathrm{kbit} / \mathrm{s}$. Today, this may be sufficient for using e-mail and other very basic services, but it is clearly inadequate for delivering data-intensive applications and services. Additionally, some applications may have requirements that involve other quality-ofservice (QoS) parameters. The quality of a voice-over-IP connection, for example, will depend not only on the capacity of a broadband connection but more on the quality of the connection as measured by latency, packet loss and jitter. ${ }^{14}$

The type, quality and speed requirements also depend on the user, and an individual will have very different needs from those of a business or a large organization/institution. One person may also have varying broadband requirements, giving priority to a relatively low-speed, but mobile, broadband connection while 'on the move', yet preferring a higher-speed xDSL or cable connection at home.

Figure 4.2 provides an overview of the broadband technologies that can deliver access to the Internet, at various speeds, at different locations and via various devices. While the fixed (wired)-broadband technologies (xDSL, cable, fibre) provide the highest broadband speed but no mobility, currently available (IMT-2000/3G) mobilebroadband technologies lose out in terms of speed but afford users a higher degree of mobility.

IMT-Advanced/4G technologies, however, which are currently being developed and tested, promise much higher speeds, equal to those delivered over fixed broadband. While a number of operators have launched so-called $4 \mathrm{G}$ services, the speeds achieved by currently available " $4 \mathrm{G}$

Figure 4.2: Fixed (wired)- and wireless-broadband technologies - speed versus mobility

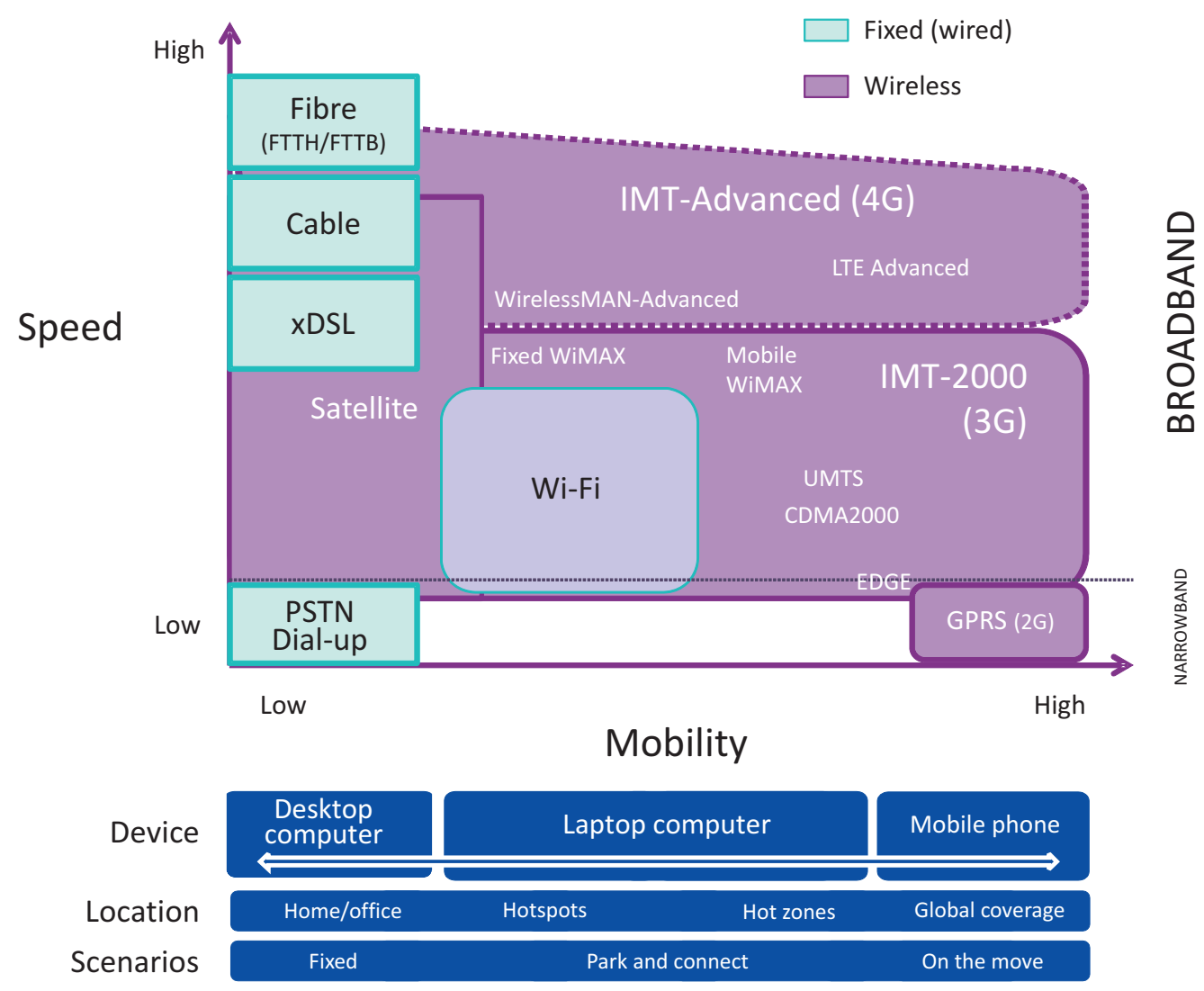

Source: ITU. 
networks" are not in line with the ITU requirement that $4 \mathrm{G}$ should achieve a peak download speed of up to approximately $100 \mathrm{Mbit} / \mathrm{s}$ in a high-mobility environment (e.g. using a mobile phone) and up to $1 \mathrm{Gbit} / \mathrm{s}$ in a lowmobility one (e.g. local wireless access).

Developments in fixed-broadband networks are extending the fibre network from the core, and bringing it closer or direct to the end user. Cable networks are also being upgraded to DOCSIS 3.0, which enables connections at very high speeds, in line with those currently being provided by commercial fibre connections. ${ }^{15}$

The types of technologies and the speeds that they deliver matter because these factors also determine the quality of service and the user experience. In addition, more and more people are relying on a mobilebroadband only connection. Unlike in most developed countries, in developing countries mobile-broadband technologies are not complementing, but rather substituting, fixed-broadband connections, which are lacking in many areas of developing countries. In Kenya, for example, data from the Communications Commission of Kenya (CCK) show that only a very small percentage of the population today relies on fixed Internet access and "Internet subscriptions through GPRS/EDGE and $3 G$ networks $[. .$.$] accounted for 98.8$ per cent of the total subscriptions". In Morocco, the total number of active mobile-broadband $(3 \mathrm{G})$ subscriptions has grown at over 21 per cent in the first quarter of 2011, compared with eight per cent for ADSL subscriptions (the main fixed-broadband technology in the country). As a result, the country's active mobile-broadband subscrip- tions now represent over 75 per cent of all Internet subscriptions. Data from the regulator also show that over 75 per cent of all active mobile-broadband subscriptions are 'data only' subscriptions (or dedicated mobile data subscriptions) that are usually used over a modem or dongle. ${ }^{16}$

Given these developments, it is essential to understand the speed and quality of service that mobile-broadband technologies can deliver in order to cater not only for individual users but also for businesses, government and other public or private organizations. These issues will help ascertain whether mobile broadband can truly replace fixed-broadband Internet access and deliver the same development potential.

User needs depend on the type of user (individual, business, organization) and on the type of service or application that the end user is accessing over the Internet. Table 4.3 highlights the importance of broadband speeds, and points to the limited user experience that someone with a $256 \mathrm{kbit} / \mathrm{s}$ connection (i.e. the minimum speed qualifying as broadband) will get. While it will already take five seconds to view the Google homepage, downloading a $5 \mathrm{MB}$ music track will take over 2.5 minutes. A $20 \mathrm{MB}$ video clip will take over ten minutes to download via a $256 \mathrm{kbit} / \mathrm{s}$ connection, compared with two seconds via a 100 $\mathrm{Mbit} / \mathrm{s}$ connection. Clearly, a minimum broadband connection is not suited to accessing data-intensive sites or applications, or to watching videos, which requires much higher speeds to obtain a minimum of quality and reasonable download times.

Table 4.3: Time needed to download online content at different connection speeds

\begin{tabular}{|l|c|c|c|c|}
\hline \multirow{2}{*}{ Content } & \multicolumn{3}{|c|}{ Actual connection speed (hh:mm:ss) } \\
\cline { 2 - 4 } & $256 \mathrm{kbit} / \mathrm{s}$ & $\mathbf{2 M b i t / s}$ & $10 \mathrm{Mbit} / \mathrm{s}$ & $100 \mathrm{Mbit} / \mathrm{s}$ \\
\hline Google homepage (160 KB) & $00: 00: 05$ & $00: 00: 01^{*}$ & $00: 00: 13$ & $00: 00: 00^{*}$ \\
\hline Music track (5MB) & $00: 02: 36$ & $00: 00: 20$ & $00: 00: 04$ & $00: 00: 00^{*}$ \\
\hline Video clip (20MB) & $00: 10: 25$ & $00: 01: 20$ & $00: 00: 16$ & $00: 00: 02^{*}$ \\
\hline CD / low-quality movie (700MB) & $06: 00: 00$ & $00: 47: 00$ & $00: 09: 20$ & $00: 00: 56$ \\
\hline DVD / high-quality movie (4GB) & $34: 17: 00$ & $04: 29: 00$ & $00: 53: 20$ & $00: 05: 00$ \\
\hline
\end{tabular}




\section{Broadband access technologies}

One way of looking at the speed and quality of broadband access is from the angle of the technology used, since different technologies to which broadband users connect are each associated with maximum speeds. In terms of the last-mile access infrastructure, both fixed (wired) and wireless technologies providing a minimum of $256 \mathrm{kbit} / \mathrm{s}$ are considered as broadband, although major differences in speeds and quality exist, with fixed technologies providing higher access speeds than wireless technologies.

While the dominant fixed-broadband technology worldwide continues to be xDSL (accounting for about 65 per cent of the world's total), ${ }^{17}$ cable modem and fibre optic are also important broadband technologies. Cable networks are practically non-existent in some regions of the world (particularly Africa), but remain an important and growing access technology in others, for example the Americas. In Canada and the United States (Chart 4.1), there are more cable than XDSL subscriptions; in Chile, nearly a half of all broadband connections are through cable; and

\section{Chart 4.1: Broadband subscriptions by technology, United States, June 2010}

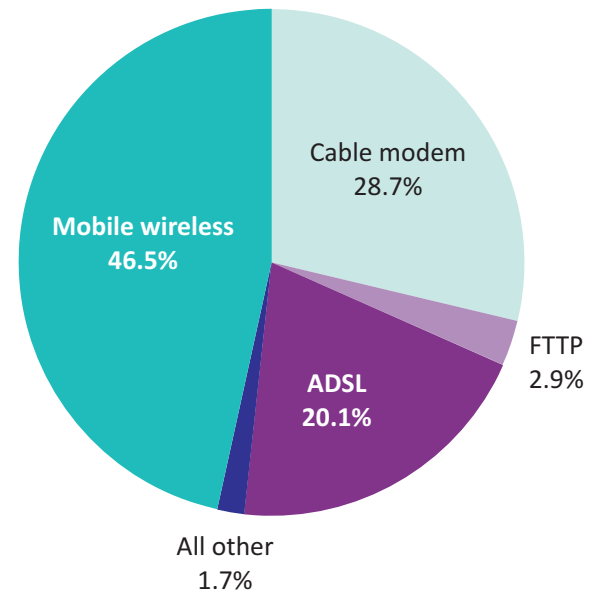

Source: FCC, from http://transition.fcc.gov/wcb/iatd/comp.html Note: Although FCC has recently redefined broadband (see Box 4.1), data in this chart are based on the previous FCC definition of broadband as $200 \mathrm{kbit} / \mathrm{s}$ in at least one direction. in Panama and Colombia, they represent almost one-third of all fixed-broadband subscriptions. The advantage of having both xDSL and cable, as well as other fixed- and mobile-broadband technologies, is that it increases the level of competition based on independent networks.

In Africa, where cable networks do not exist and where only few countries provide fibre access to the home or business, fixed-broadband services are delivered over the fixed-telephone network, through xDSL technology. The very limited availability of the fixed-telephone network, however, effectively limits the uptake of fixed-broadband services.

In an effort to bring an increasing amount of bandwidth and the highest speeds available directly to homes and businesses, many developed countries, and a growing number of developing countries, are promoting fibre deployments, which are superior in terms of the speeds and quality that they can deliver to the end user. Whereas in the Republic of Korea, Japan and some other countries FTTH/B penetration rates are relatively high, fibre connections remain the exception in most countries. Only 26 economies worldwide have more than one per cent of their households/buildings connected to a fibre-optic network. This list is led by a number of developed and developing economies from the Asia and the Pacific region, and includes countries such as Turkey, China, the Russian Federation and the United Arab Emirates (Chart 4.2).

Although FTTH/B broadband connections have the capacity to offer the highest speeds currently available, the actual speeds to which households and businesses subscribe can vary greatly and depend on user needs, as well as on the commercial offers available. At the same time, there are also differences in the speeds provided by different xDSL and cable technologies, with the result that a comparison of technologies only will not provide an exact picture of the situation.

For developing countries, the most significant development in terms of access to broadband networks has been the progress made in wireless, and in particular mobile, broadband technologies and services. Thirdgeneration $(3 \mathrm{G})$ mobile-broadband services have increased the choice for delivering high-speed Internet access to the end user and in many cases created additional facilities-based (inter-modal) competition. 


\section{Chart 4.2: Economies* with the highest penetration of fibre-to-the-home/building + LAN}

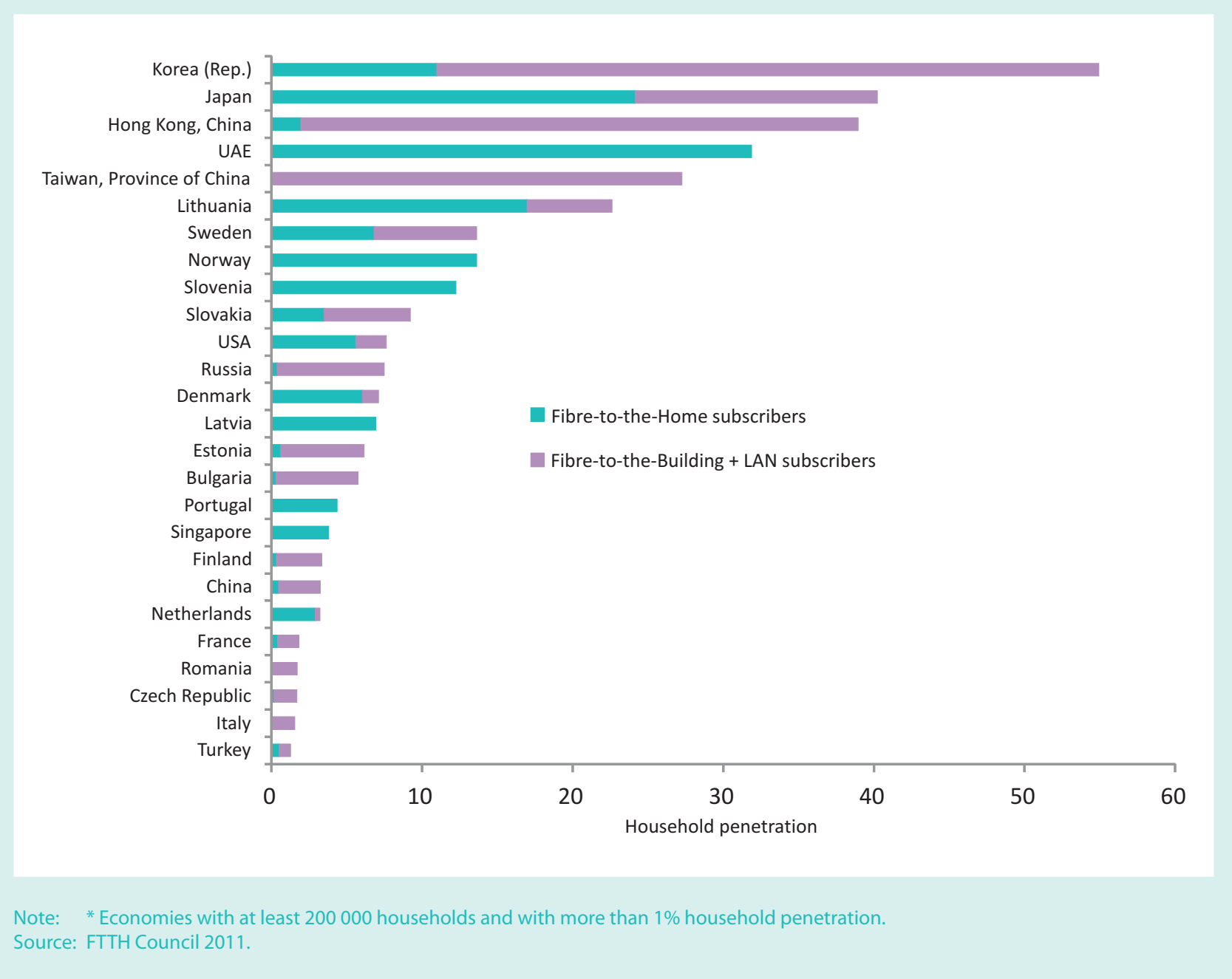

In many countries, mobile operators have secured a considerable chunk of the broadband market. ITU data show that, by December 2010, active mobile-broadband subscriptions represented 56 per cent of all broadband subscriptions in the developing world. At the same time, OECD countries had 306 million fixed (wired)- and 512 million wireless-broadband subscriptions (Chart 4.3). ${ }^{18}$ Almost two-thirds of active wireless-broadband subscriptions in OECD countries are mobile-cellular telephone subscriptions (standard mobile subscriptions) and one-third are dedicated mobile data subscriptions, usually using a modem/dongle (some 174 million, about the same number as DSL subscriptions).

There are a number of points that are worth mentioning when comparing fixed-broadband and mobile-broadband technologies and subscriptions. First, mobile-broadband technologies face a number of speed, capacity and quality challenges that are less of an issue for fixed technologies. While it is possible to duplicate and add a (theoretically) unlimited amount of wires, the quality and speed of mobile-broadband connectivity relies on a limited and shared resource - the radio-frequency spectrum. Although the wireless industry and regulators continue to make devices and network infrastructure more efficient, a limited amount of spectrum means a limited amount of bandwidth, and hence speed. The rapidly growing mobile-broadband market is facing a spectrum crisis, in which there is a risk of demand exceeding wireless network capacity (Box 4.2).

It should also be noted that while mobile broadband is able to overcome important infrastructure barriers, users still need to invest in relatively expensive handsets (or computers, netbooks, tablets, laptops, etc.) in order to be able to take full advantage of high-speed Internet 


\section{Chart 4.3: Broadband subscriptions in the OECD, by technology, December 2010}

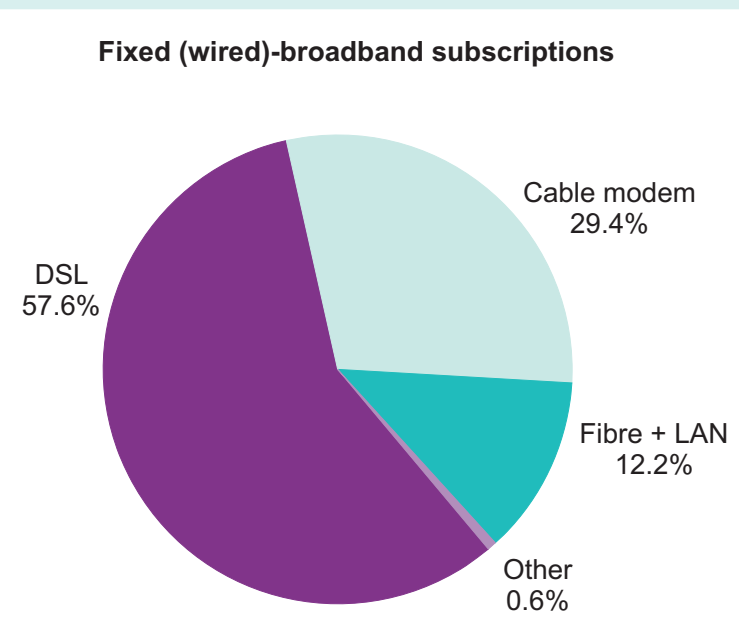

Total subscriptions: 306 million
Wireless-broadband subscriptions

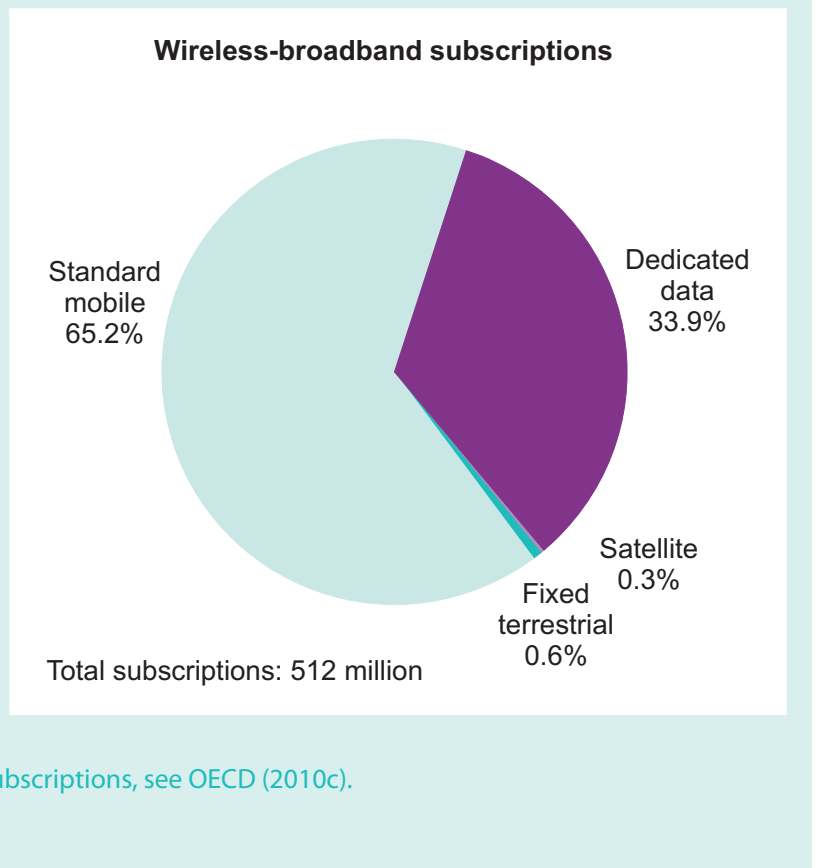

Total subscriptions: 512 million access and the services and applications it can deliver. In other words, mobile-broadband users face a similar cost barrier to fixed-broadband users.

The capacity and speed problems associated with wireless technologies are particularly challenging when mobile-broadband technologies are the only broadband access technology available to end users, which is increasingly the case in many developing countries, particularly outside urban areas. Mobile-broadband networks do not provide equal broadband speeds and capacities compared with fixed networks, and may help to reduce, but not overcome the broadband divide, at least as long as operators impose mobile-broadband caps. It also means that high-end users, particularly organizations and businesses, will continue to rely on fixed infrastructure or require fixed infrastructure if not yet available.

The qualitative differences between fixed-and mobilebroadband services have implications for the comparison of the number of fixed- and mobile-broadband subscriptions. The current capacity and speed of a mobile-broadband subscription does not match that of a fixed subscription, and mobile-broadband subscriptions almost always include data caps, unlike often 'unlimited' fixed-broadband offers. Comparisons between the total number of fixed and mobile subscriptions should therefore be made with caution. Similar caution must also be exercised when making comparisons between fixed-broadband penetration rates (all technologies included), since there are substantial qualitative differences between the different fixed technologies.

Finally, fixed- and mobile-broadband subscriptions cannot always be compared, insofar as one fixed-broadband subscription can easily be (and is often) shared by several people (at home, at work, at school, etc.) whereas mobile-broadband subscriptions - particularly standard mobile-cellular subscriptions - tend to be used by one person only. Dedicated data subscriptions, using a modem/dongle, can be more easily shared.

\section{Broadband speeds}

Another angle for understanding the potential impact of broadband and for measuring and analysing broadband developments is to look at broadband speeds. An increasing number of countries have started collecting fixed (wired)-broadband subscriptions broken down by (advertised) speed. ITU data show that major differences exist between countries (Chart 4.4). By the end of 2010, the Republic of Korea stood out in that it did not actually offer any broadband connection below $2 \mathrm{Mbit} / \mathrm{s}$. In Bulgaria and Portugal, around 
Box 4.2: The spectrum crisis: struggling to keep up the speed, capacity and quality of mobile services

One of the major issues arising from the rapid increase in mobile-broadband subscriptions and data traffic is the spectrum crisis, ${ }^{19}$ a situation where demand exceeds the mobile-cellular network's capacity and which affects mobile operators that are unable to maintain the quality of data services. One example is the problems that smartphone customers have encountered in New York City, where a severely overloaded 3G network has led to dropped calls and slow data speeds..$^{20}$ There are a number of approaches now being adopted to deal with the fact that spectrum is a finite resource that can only accommodate a limited number of users and amount of data.

First, governments are looking into the effective and efficient use of frequencies that will provide mobile operators with sufficient spectrum. This also includes the use of spectrum from the «digital dividend» resulting from the switchover from analogue to digital television broadcasting, ${ }^{21}$ or the refarming of bands to make them available for mobile-broadband services.

Another way to overcome spectrum limitations is to distribute the burden on $3 \mathrm{G}$ mobile-broadband networks by offloading traffic to other networks, including WiFi hotspots and femtocells. More and more operators across the world are taking advantage of offloading and operators are working closely with handset and hardware manufacturers to provide users with a seamless connectivity experience between 3G mobile-broadband and WiFi networks.22
There are also a number of efforts to find innovative technological solutions to the spectrum crunch, such as the use of femtocells, as well as looking into regulatory mechanisms to overcome bottlenecks in mobile-broadband infrastructure. ${ }^{23}$

Finally, operators in developed and developing countries have been turning to metered data plans so as to be able to limit the amount of data transported over mobile-broadband networks. As opposed to fixed-broadband subscriptions, which often offer unlimited access to data, mobile-broadband subscriptions are typically capped. Once specified limits have been exceeded, users have either to pay extra costs, or to accept lower transmission speeds. Few operators around the world now offer truly unlimited $3 \mathrm{G}$ plans and some that did have been forced to change tariff schemes to deal with increased data flows and to protect their networks. In the United States, Verizon announced in June 2011 that it was going to end its USD 30 offer for unlimited data access. ${ }^{24}$ In the Republic of Korea, Korea Telecom has ceased offering unlimited data plans to new customers. ${ }^{25}$ While this approach can help operators deal with overloaded networks, it is not an ideal solution for all users, since it effectively limits the type and amount of services and applications that can be used, which will in turn discourage users from accessing data-intensive services. It seems like a particularly constraining solution for many people in developing countries, and in cases where mobile broadband is the only access technology available. three-quarters of all fixed-broadband subscriptions provide speeds above $10 \mathrm{Mbit} / \mathrm{s}$, and less than five per cent of all subscriptions have speeds of between 256 $\mathrm{kbit} / \mathrm{s}$ and $2 \mathrm{Mbit} / \mathrm{s}$. Romania, the United Kingdom, Denmark and Slovakia also have only very few subscriptions with speeds below $2 \mathrm{Mbit} / \mathrm{s}$, and provide most of their broadband users with higher speeds. In Hong Kong (China) and Singapore, about 40 per cent of all fixed-broadband subscriptions provide speeds of above $10 \mathrm{Mbit} / \mathrm{s}$, but only three to five per cent of subscriptions in Azerbaijan, Cyprus, Turkey and Trinidad and Tobago reach these speeds. Ghana, Mongolia, Qatar, Tunisia, the United Arab Emirates and Venezuela have almost exclusively $256 \mathrm{kbit} / \mathrm{s}$ to $2 \mathrm{Mbit} / \mathrm{s}$ connections.

Comparisons also show that there is a link between fixed-broadband penetration rates, on the one hand, and the speed of subscriptions, on the other, with countries with high penetration rates usually providing higher speeds. Countries that are at an early stage of providing broadband services tend to have mainly lower-speed connections. However, as more and more people use broadband Internet access, there are differences in the type and speed of broadband subscriptions, which highlights that it is not sufficient to compare just the total number of broadband subscriptions. Bulgaria and Portugal, for example, have a lower fixed-broadband penetration rate than many of their European neighbours ${ }^{26}$ but a very high share of very high-speed fixed-broadband connections. This is explained by the advanced stage of deployment of fibre and fast cable networks in these countries. ${ }^{27}$ While in 2010 Germany and the United Kingdom had similar fixed-broadband penetration rates, 59 per cent of the United Kingdom's subscriptions were above $10 \mathrm{Mbit} / \mathrm{s}$, compared with 30 
Chart 4.4: Fixed (wired)-broadband subscriptions by speed, selected economies, 2010

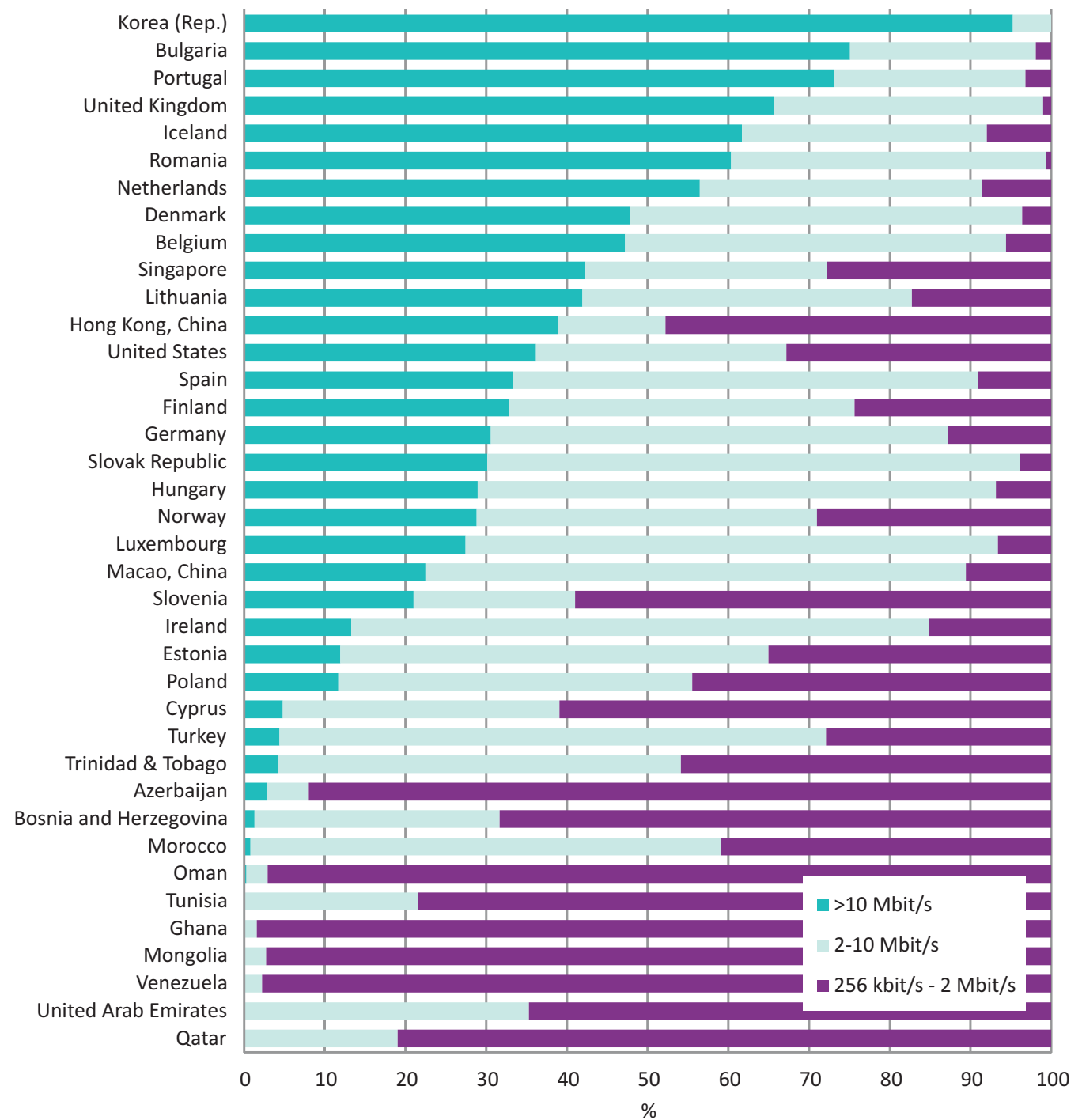

Note: Data from Iceland refer to ADSL connections only, which account for 87 per cent of the market. Norway's speed intervals refer to: $128 \mathrm{kbit} / \mathrm{s}$ to $\leq 2 \mathrm{Mbit} / \mathrm{s} ; 2 \mathrm{Mbit} / \mathrm{s}$ to $\leq 8 \mathrm{Mbit} / \mathrm{s}$; and $>8 \mathrm{Mbit} / \mathrm{s}$. Data from the Netherlands represent $95 \mathrm{per}$ cent of the total broadband subscriptions in the country, and do not include fibre subscriptions, nor data from the smallest operators.

Source: ITU World Telecommunication/ICT Indicators database.

per cent in Germany. Indeed, in the United Kingdom, 99 per cent of all subscriptions are above $2 \mathrm{Mbit} / \mathrm{s}$.

OECD collects data on the fastest advertised broadband speeds (all technologies included) offered by incumbent fixed operators. September 2010 data show great disparities between countries (Chart 4.5). While in Sweden the fastest advertised speed is $1 \mathrm{Gbit} / \mathrm{s}$, operators in Greece and New Zealand offer as a maximum $25 \mathrm{Mbit} / \mathrm{s}$. In
Mexico, the fastest available speed offered by the incumbent is $5 \mathrm{Mbit} / \mathrm{s}$.

In developing countries, maximum advertised speeds tend to be lower than those in most OECD countries (Chart 4.5). Moreover, in some cases, although relatively fast fixed-broadband subscriptions are available, high prices make them unaffordable for a majority of the population. In September 2010, the 
Chart 4.5: Fastest broadband speeds advertised by the incumbent telecommunication operator, Mbit/s, all technologies, OECD and selected non-OECD countries, 2010/11

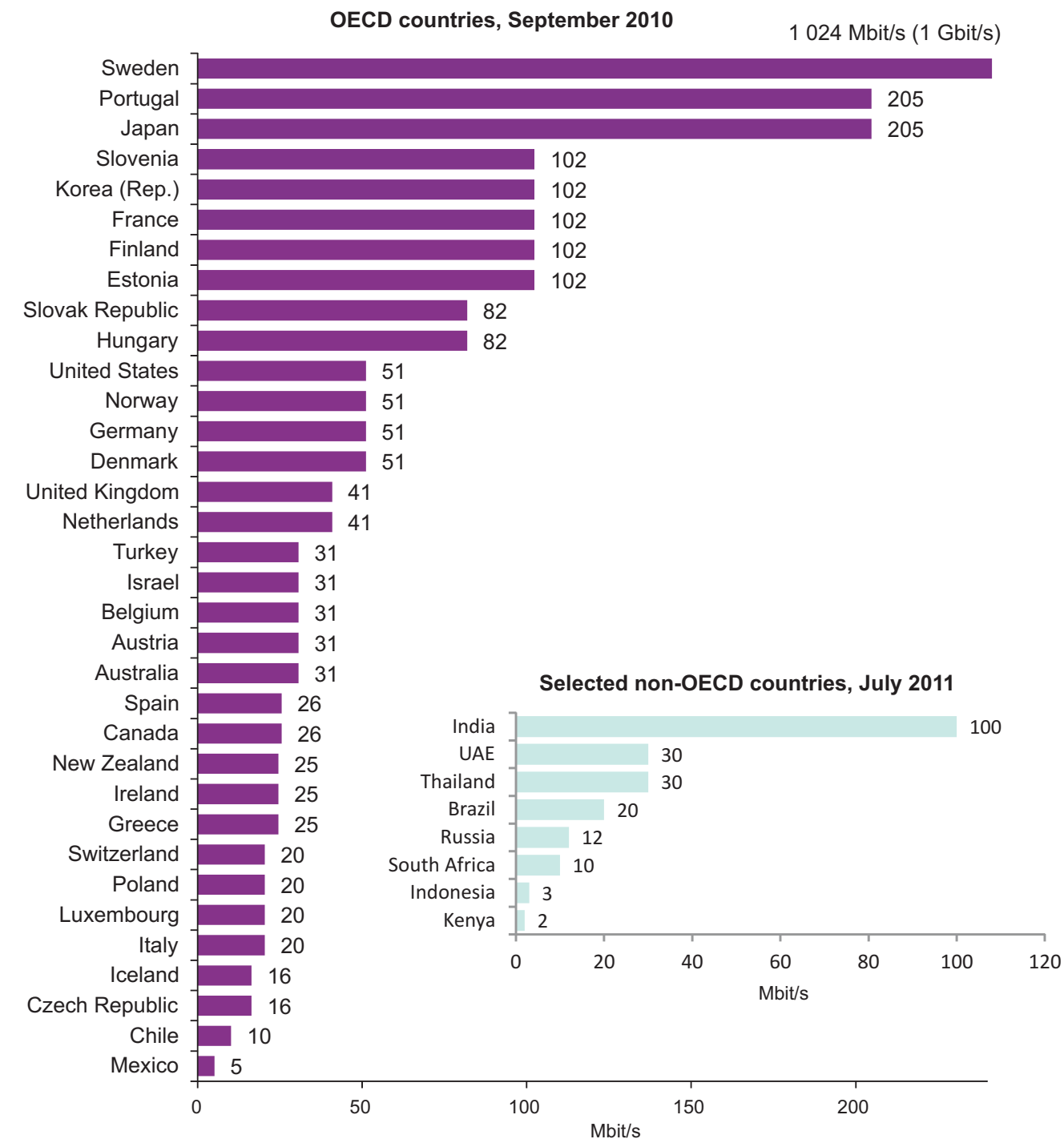

Note: Data do not necessarily reflect the fastest advertised broadband speeds among all operators within the country. For instance, in Brazil cable-broadband provider Net is offering speeds up to $100 \mathrm{Mbit} / \mathrm{s}$, but the incumbent Oi only offers speeds up to $20 \mathrm{Mbit} / \mathrm{s}$.

Source: OECD for all OECD countries. For India, United Arab Emirates, Thailand, Brazil, Russian Federation, South Africa, Indonesia and Kenya, the source is ITU based on data obtained from the website of the largest fixed-broadband provider (in terms of subscriptions) in each country, except for those cases where tariffs were not clearly advertised on the incumbent's website. In particular, data are sourced from the following broadband providers' websites: Oi (Brazil), Wplus (Russian Federation), Telkom (Indonesia), TOT (Thailand), BSNL (India), Telkom/Orange (Kenya), Telkom (South Africa), Etisalat and Du (United Arab Emirates).

median price of a fixed Internet connection between $2.5 \mathrm{Mbit} / \mathrm{s}$ and $15 \mathrm{Mbit} / \mathrm{s}$ in OECD countries ranged from USD 21 to USD $69 .{ }^{28}$ In July 2011, a fixedbroadband Internet connection above $2 \mathrm{Mbit} / \mathrm{s}$ cost more than USD 100 in the United Arab Emirates and Indonesia. In Kenya, the price of a $2 \mathrm{Mbit} / \mathrm{s}$ subscription was also above USD 100. This explains why in several developing countries, including in the United Arab Emirates, most broadband subscriptions offer relatively low speeds, even if higher speeds are available (Telecommunications Regulatory Authority of the United Arab Emirates, 2010). It also suggests that high prices severely limit the potential impact of broadband developments. 
Finally, it is important to note that the actual speed experienced by fixed- and mobile-broadband customers may be much lower than the theoretical and advertised speed.

To truly grasp the potential impact that broadband Internet access can have, and to be able to compare countries, it is therefore important to track and measure actual speeds.

A recent Ofcom study revealed that actual speeds for fixed broadband were only half those advertised, especially for ADSL customers, ${ }^{29}$ and FCC has come to the same conclusion in the United States. ${ }^{30}$ Increasingly, regulators and operators are eager to monitor speeds and establish minimum standards. In Bahrain, for example, the Telecommunications Regulatory Authority publishes quarterly reports measuring average download and upload speeds for fixed connections. ${ }^{31} \mathrm{~A}$ comparison of actual speeds achieved for a $2 \mathrm{Mbit} / \mathrm{s}$ connection between January and March 2011 showed that, during peak hours, the average connection speed was halved, to only $1 \mathrm{Mbit} / \mathrm{s}$. The actual maximum speed achieved during off-peak hours was just above 1.5 Mbit/s (Chart 4.6).

A number of regulators carry out surveys through, or provide links to, third-party applications for meas-

Chart 4.6: Average download speed for $2 \mathrm{Mbit} / \mathrm{s}$ packages, January-March 2011, Bahrain

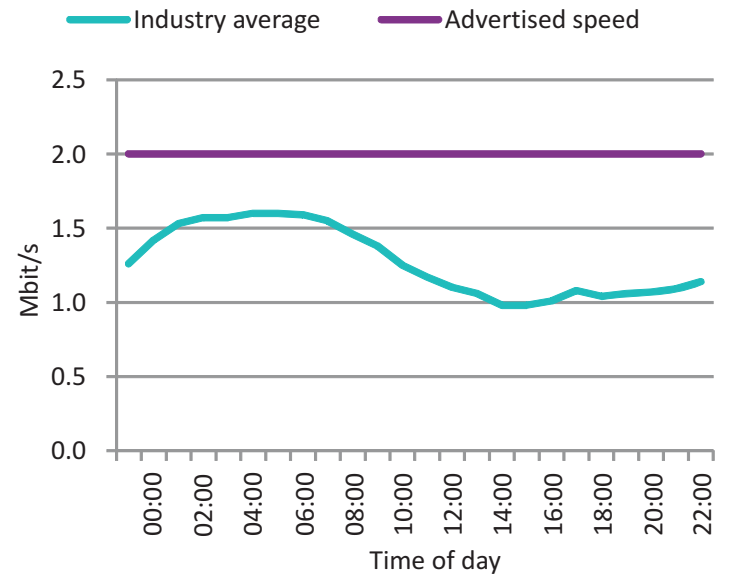

Note: The average is based on a comparison of eight different $2 \mathrm{Mbit} / \mathrm{s}$ packages

Source: Telecommunications Regulatory Authority of Bahrain. uring speed and other quality aspects. ${ }^{32}$ In addition, there are several organizations that publish average download speeds and additional quality metrics. ${ }^{33}$ ITU is currently discussing the collection of new QoS indicators within the ongoing discussions of the Expert Group on Telecommunication/ICT Indicators (EGTI). ${ }^{34}$

Quality-of-service and speed tests are also increasingly becoming available for mobile-broadband services, and regulators in both developed and developing countries are scrutinizing speeds, coverage and quality of service. In the Philippines, where the regulator obliges broadband service providers to publish information on minimum speeds and reliability of fixed- and mobile-broadband services, mobile-broadband tests will be carried out to ensure that operators deliver at least 80 per cent of promised Internet speeds. ${ }^{35}$ In Sri Lanka, the Telecommunications Regulatory Commission carried out field tests on mobile-broadband services and found that only 40-50 per cent of advertised speeds were achieved, and only under ideal conditions. Consequently, it issued a number of guidelines for mobile-broadband operators (Box 4.3).

Increasingly, regulators are putting pressure on operators and introducing new rules to ensure that consumers are able to make informed choices. In the United States, for example, a new bill is under discussion which would oblige mobile operators to provide detailed information on network coverage and reliability, speed, pricing and quality of service. In particular, the bill wants to set $4 \mathrm{G}$ standards so as to inform mobile-broadband users of what they are getting by paying for services advertised as $4 \mathrm{G}^{36}$

In a survey published in early 2011, the United Kingdom Regulator, Ofcom, found that the average mobilebroadband speed was $1.5 \mathrm{Mbit} / \mathrm{s}$ (compared with an average fixed-line broadband speed of $6.2 \mathrm{Mbit} / \mathrm{s}$ ). While mobile speeds could be as high as $2.1 \mathrm{Mbit} / \mathrm{s}$, the speed and quality of service depend to a large extent on $3 \mathrm{G}$ network coverage. The regulator also highlighted that, given lower speeds and data caps, mobile broadband was not suitable for intensive users. The same study found that, in the United Kingdom, 17 per cent of the population was using mobile-broadband services, with seven per cent of broadband users relying solely on a mobile-broadband connection. ${ }^{37}$ In developing countries, many users, including some businesses, rely solely on mobile-broadband access, and operators are adapting mobile-broadband offers and prices to meet demand. In South Africa, for example, 


\section{Box 4.3: Sri Lanka Telecommunications Regulatory Commission's (TRCSL) guidelines on advertising mobile-broadband speeds \\ Following speed tests which revealed that actual mobile- broadband speeds were far below advertised speeds, Sri Lanka's TRCSL concluded that consumers were being misled by false marketing campaigns. To protect customers, the regulator, in May 2011, issued a number of guidelines, including: \\ - Broadband packages should not be advertised without describing the specific delivery technology used. \\ - The speed advertised must be realistic and achievable. The achievable speed must be incorporated in the package and not the theoretical upper limit. \\ - If operators are advertising speeds above $3.6 \mathrm{Mbit} / \mathrm{s}$ in $3 \mathrm{G}$ HSAP or in any future technology, the majority (over 75 per cent) of towers should be capable of supplying the particular speed to the subscribers. \\ - Operators are allowed to advertise any realistic speed above 3.6 Mbit/s by location. In this case, maps and other genuine and correct information must be supplied to customers.}

Source: ITU adapted from TRCSL, May 2011 mobile-broadband operator Cell C recently started offering a range of new mobile-broadband packages, including up to $20 \mathrm{~GB}$ of data volume at speeds up to 21.6 Mbit/s, aimed at high-end users. ${ }^{38}$

\section{Backbone infrastructure}

To bring more people online at high speed, all the building blocks of broadband access need to be in place and adequate bandwidth must be offered for individuals, homes and businesses.

Sufficient access to international Internet bandwidth is a necessary requirement for delivering data-intensive applications and services through a high-speed Internet connection. A competitive bandwidth market, including the liberalization of international Internet gateways and the promotion of multiple international connections, is also important to guarantee reliable connectivity and to bring down ICT service prices that consumers pay.

As highlighted in Chapter 2, international Internet bandwidth has increased tenfold over the last ten years and particularly between 2008 and 2010, when it almost doubled from $29000 \mathrm{Gbit} / \mathrm{s}$ to $59000 \mathrm{Gbit} / \mathrm{s}$ (Chart 4.7). Growth over that two-year period was somewhat stronger in developing countries (54 per cent) compared with developed countries (49 per cent), and between 2005 and 2010 developing countries increased their share of total international Internet bandwidth from 11 to 20 per cent.
A large number of new submarine cables have been built over the last two years, allowing many countries, for example in Africa, finally to join the information society by providing them with necessary international connectivity (Box 4.4).

A regional comparison of international Internet bandwidth per Internet user shows that, while all regions in the world have substantially increased Internet bandwidth per user since 2005, there are great disparities between regions. Europe, in particular, stands out for its very large amount of bandwidth capacity. In 2010, the average European Internet user enjoyed almost $80000 \mathrm{bit} / \mathrm{s}$ of bandwidth, as against $1000 \mathrm{bit} / \mathrm{s}$ for the average African Internet user. Internet users in Asia and the Pacific and the Arab States had on average around $11000 \mathrm{bit} / \mathrm{s}$ at their disposal, compared with 24000 and 27000 in the Commonwealth of Independent States and the Americas, respectively. These figures point to an important bandwidth divide (Chart 4.8).

Annex 4 to this report provides national data on international Internet bandwidth per Internet user and shows that major differences exist not only between regions, but also between countries across the world. In 2010, international Internet bandwidth per Internet user ranged from a high of $683000 \mathrm{bit} / \mathrm{s}$ per Internet user in Hong Kong (China) to 111 bit/s in Nigeria. While Canadian Internet users enjoy on average $54000 \mathrm{bit} / \mathrm{s}$, Mexico's and Peru's online population averages less than $10000 \mathrm{bit} / \mathrm{s}$. If we exclude Canada and the United States, international Internet bandwidth per Internet 


\section{Chart 4.7: Total international Internet bandwidth (in Gbit/s), by level of development, 2000-2010}

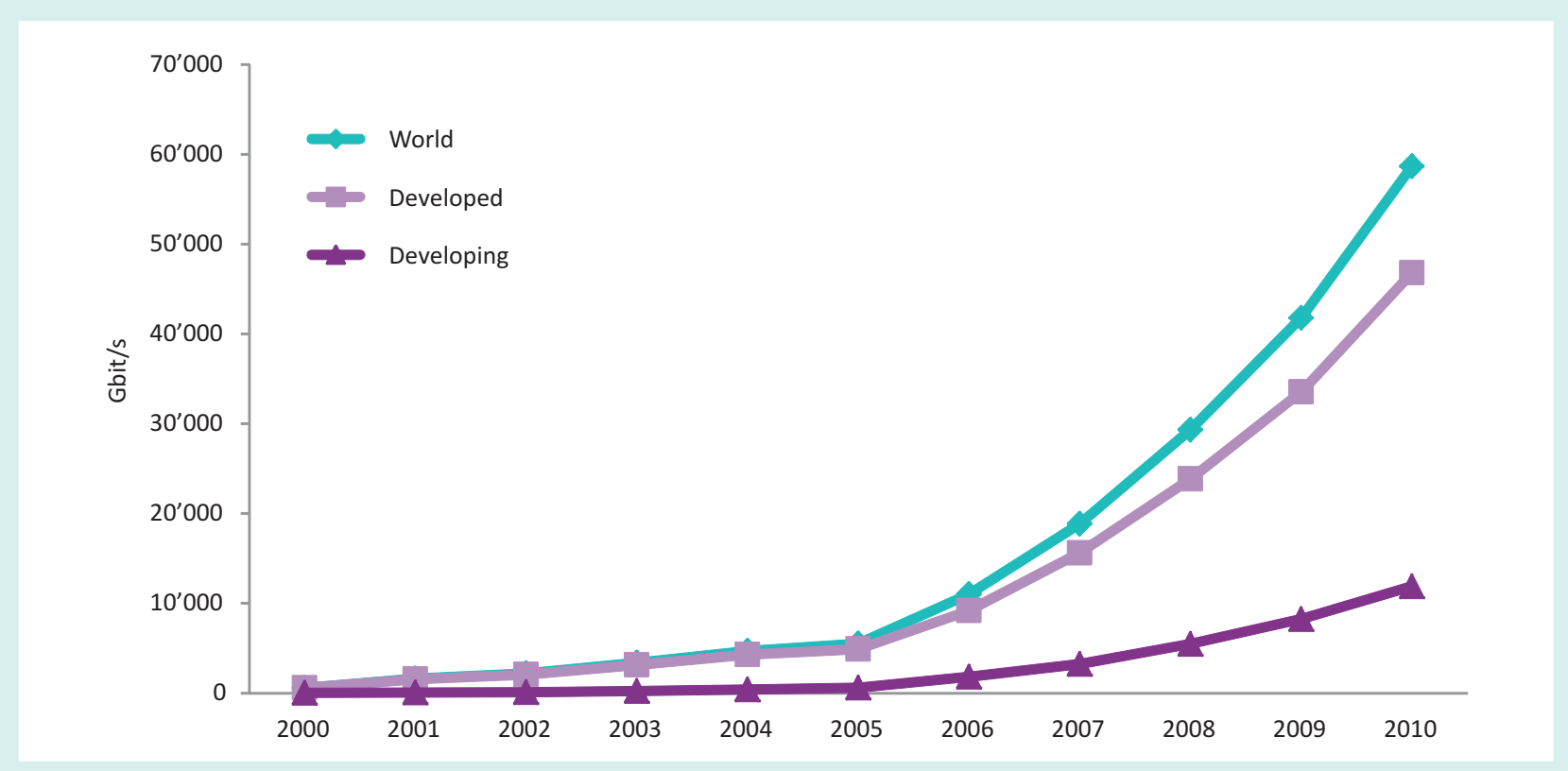

Source: ITU World Telecommunication/ICT Indicators Database.

\section{Box 4.4: Africa joins the global information society}

Africa is an excellent example of how international Internet bandwidth has helped many of the world's poorest nations to come a step closer to joining the information society. Between 2005 and 2010, international Internet bandwidth in Africa increased from 3500 to $82000 \mathrm{Mbit} / \mathrm{s}$, with the greatest growth rate registered between 2009 and 2010. This is mainly the result of a number of new and competing submarine cables that went live in 2010. These include the $10500 \mathrm{~km}$ EASSy cable, which connects Africa to the rest of the world and runs from South Africa to Sudan, with landing points in nine countries and further connections to at least ten landlocked African countries which thus no longer depend solely on satellite access to the Internet. ${ }^{39}$ EASSy also provided Comoros with its first submarine fibre connection to the Internet, and the country's international Internet bandwidth increased from $15 \mathrm{Mbit} / \mathrm{s}$ in 2009 to $166 \mathrm{Mbit} / \mathrm{s}$ a year later.

New submarine cables bringing extra bandwidth to Africa include Main One, Glo One and LION. The West African Cable System (WACS), which will run from South Africa to the United Kingdom, with 15 landing stations on the west coast of Africa, is expected to go live in $2011 . .^{40}$ Other major international connections such as ACE and SAex are planned over the next few years and will provide Africa's Internet users with increased capacities and speeds (see Figure Box 4.4).

New international Internet connectivity has not only increased bandwidth capacity in coastal countries but has effectively allowed Africa's landlocked developing countries to benefit through cross-border backhaul routes. ${ }^{41}$ New national fibre backbone networks have further improved national connectivity and expanded terrestrial transmission networks on the African continent from $466000 \mathrm{~km}$ in July 2009 to $646000 \mathrm{~km}$ by the first quarter of 2011.42 With this, it is estimated that, by early 2011 , 4.4 per cent of Africa's population lived within a $25 \mathrm{~km}$ range of a submarine cable landing station, while 31 per cent lived within $25 \mathrm{~km}$ of an operational fibre node. Some African countries have managed to cover a very high proportion of their population. In Senegal, for example, over 25 per cent live within a $25 \mathrm{~km}$ range of the submarine cable which lands in Dakar, and Sonatel's fibre backone reaches 72 per cent of the population. In Gabon, Gabon Telecom's $3000 \mathrm{~km}$ national fibre backbone is expected to bring some 80 per cent of the population within range $(25 \mathrm{~km})$ of the network, effectively bringing more and more people within reach of high-capacity backbones. ${ }^{43}$

Even though new submarine cables are providing African countries with access to more and cheaper international Internet bandwidth, Africa still lags far behind other regions in terms of the bandwidth available to Internet users. For Africans to benefit from the continent's increased connectivity, operators must acquire greater amounts of international Internet bandwidth, expand and improve core networks, and make network access infrastructure available, as well as affordable. 
Figure Box 4.4: Africa's current and planned undersea cables

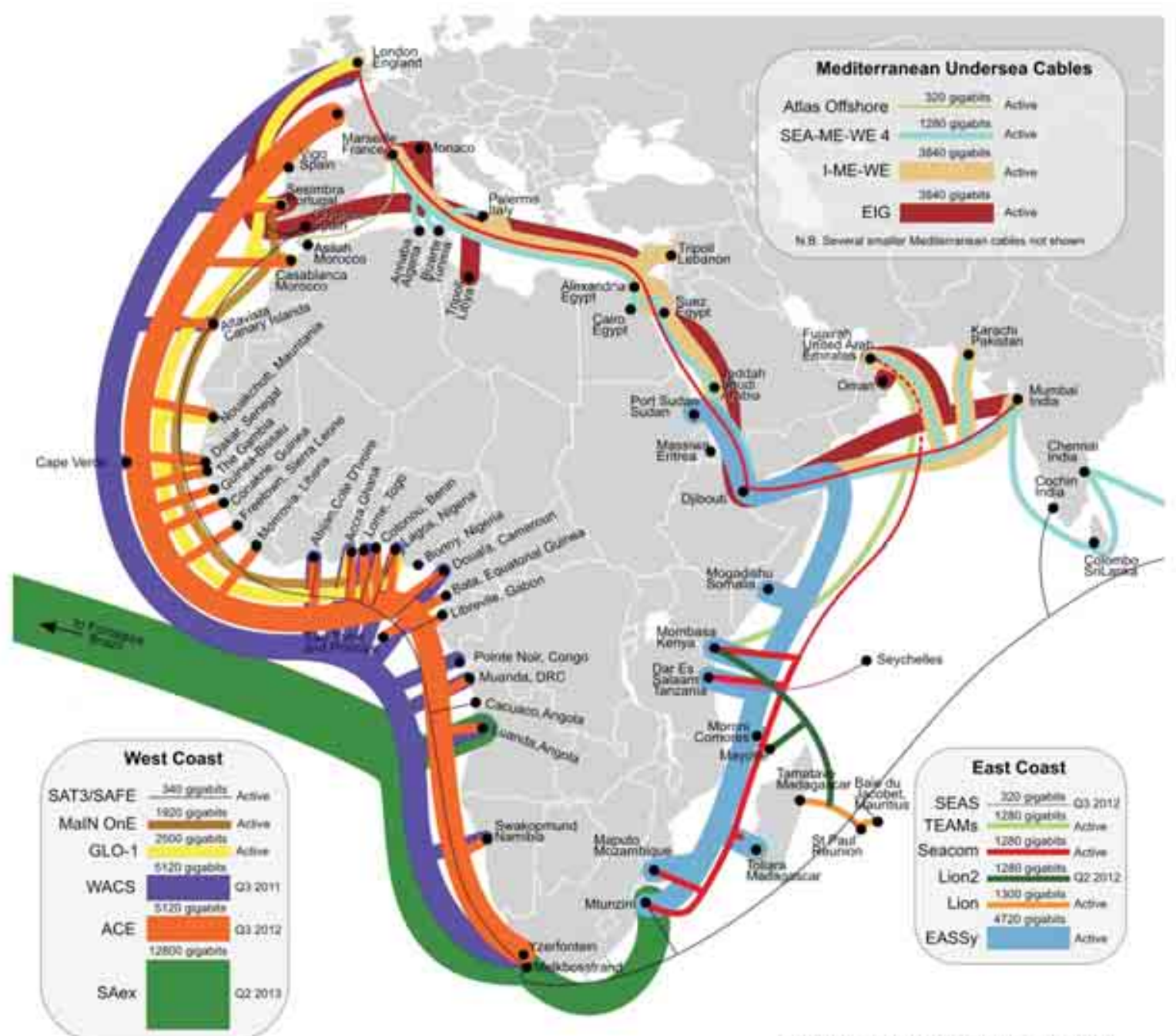

African Undersea Cables (2013)

verven $29 \cdot$ May zol1 5 .

Source: Steve Song, http://manypossibilities.net/african-undersea-cables/.

user in the Americas drops from over 27 000, to less than $13000 \mathrm{bit} / \mathrm{s}$.

A shift from voice to data traffic has had important implications not only for international Internet connectivity but also in regard to the type of national backbone infrastructure needed. First of all, data traffic (created through increased use of the Internet) relies much more on international connectivity than voice traffic, but also requires a different kind of national backbone infrastructure, since Internet and particularly broad- band networks call for high-capacity networks, typically based on fibre-optic cables. Many mobile operators which have effectively become Internet service providers by offering mobile-broadband services are playing an increasingly important role in expanding core networks. ${ }^{44}$ Realizing the importance of a functioning and high-capacity national backbone, many developed and developing countries in the world have been reviewing their backbone strategies and ensuring an upgrade of national backbone networks. For example, Costa Rica's new National Broadband Strategy, which was unveiled in 
Chart 4.8: International Internet bandwidth (bit/s per user), by region, 2005 and 2010
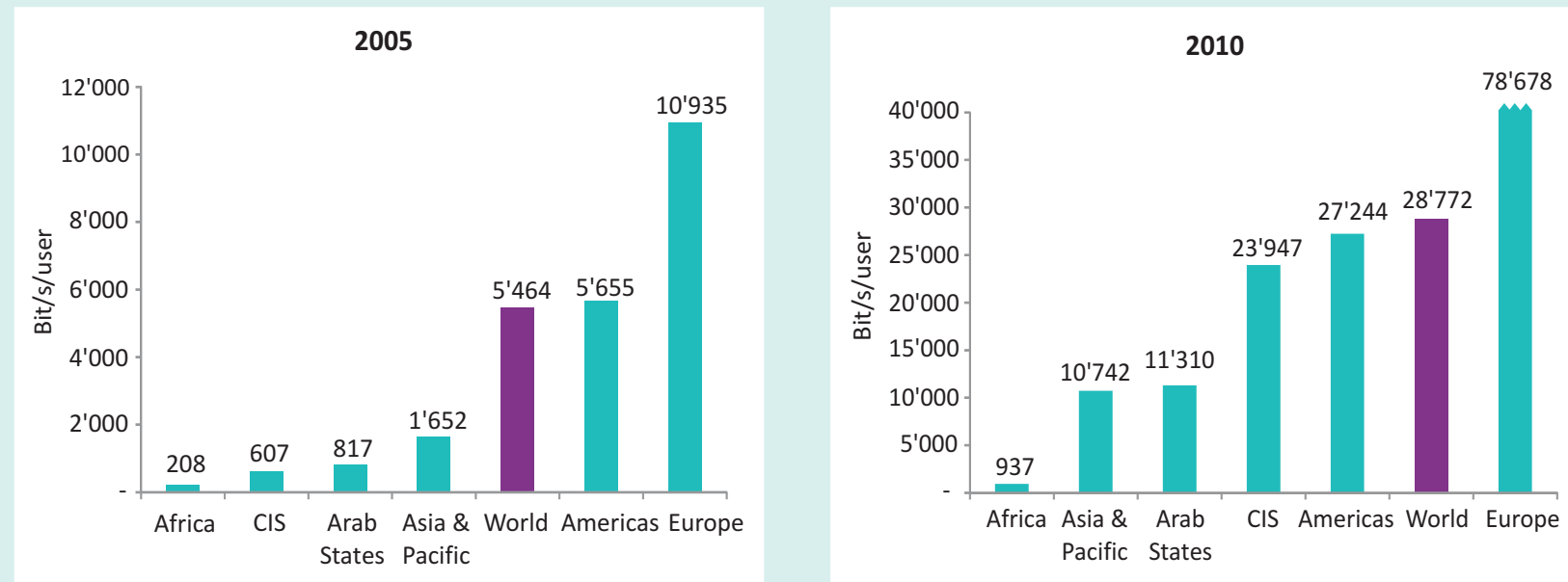

Source: ITU World Telecommunication/ICT Indicators database.

June 2011, includes plans to expand broadband networks to more rural areas of the country. ${ }^{45}$ Other examples of countries that are either planning or already rolling out national broadband - primarily fibre-optic - networks are India,${ }^{46}$ Australia, ${ }^{47}$ Thailand, ${ }^{48}$ Poland, ${ }^{49}$ Argentina ${ }^{50}$ and Uruguay. ${ }^{51}$ Many governments set concrete targets for backbone deployment, often measured in terms of $\mathrm{km}$ of fibre-optic cables, or in terms of the number of cities/localities or households connected.

According to ITU research, as at early 2011 over 70 countries worldwide have formulated a national broadband plan. While there is often a mix of access network technologies, many governments also include targets for deployment of fibre-to-the-home.

Growing and reliable backbone networks are not only allowing operators to transport an increasing amount of data and voice traffic, but are also creating new demand by reducing wholesale (backbone) and retail broadband prices and by providing operators with incentives to attract new customers so as to make their network investments profitable.

\subsection{Conclusions and recommendations}

The last five years have seen great progress in the spread and uptake of broadband technologies and services. Broadband Internet access is becoming more widely available, more affordable and faster. New undersea cables and an extension of national fibre core networks are increasing national and international Internet bandwidth, and a growing number of countries are deploying fibre directly to the home/business. More and more countries in the world have launched $3 \mathrm{G}$ services, and mobile broadband is addressing an important infrastructure barrier, and allowing more people to come online.

With the decline of narrowband (and based on the definition of broadband as a $265 \mathrm{kbit} / \mathrm{s}$ connection to the Internet), almost all Internet users are expected to be broadband users in the near future. At the same time, this chapter has shown that there are major differences in broadband connections, which vary not only in terms of the underlying technology but also in terms of the speed, capacity, price and quality of service they provide. For example, while mobile-broadband services help increase coverage and offer mobility, currently deployed mobile networks and providers usually only allow limited data access, at lower speeds, which makes them unsuitable for intensive users, and in particular for businesses and institutions. In many developing countries, fixed-broadband services are limited to urban areas, and unlimited and very high-speed Internet access remains very expensive. These disparities and issues need to be captured and addressed, in order to track the broadband divide and ensure that users are able to benefit from the potential of broadband.

Governments can take a number of steps to maximize the impact that broadband exerts, and to help understand and measure the broadband divide: 
- Developing countries, in particular where fixedbroadband infrastructure is limited, need to identify broadband policies that leverage the potential of mobile (wireless) technologies. At very least, this means that governments that have not yet done so should allocate and assign $3 \mathrm{G}$ spectrum in order to allow operators to launch $3 \mathrm{G}$ services.

- To increase the capacity and speed of mobile-broadband services, governments need to efficiently allocate and regulate spectrum. User demand for mobile broadband is growing, and more spectrum is needed to meet this demand. Many governments have not yet allocated the 'digital dividend' spectrum in the $700-800 \mathrm{MHz}$ band which can be freed up from the switchover to digital television, and in the 2.5-2.6 GHz band, which ITU has identified as the $3 \mathrm{G}$ extension band. Refarming the $900 \mathrm{MHz}$ and $1800 \mathrm{MHz}$ spectrum, mainly used for $2 \mathrm{G}$ networks, can also help increase spectrum availability for mobilebroadband services.

- The limitations of mobile-broadband networks in terms of capacity and speed need to be taken into consideration, and fixed-broadband technologies, in particular fibre-optic networks, need to be deployed in order to build reliable backbone infrastructure and to cater for data-intensive users (businesses, organizations) and urban areas where Internet users are concentrated. Governments need to review the progress made in terms of privatizing and liberalizing all the building blocks of broadband Internet access, particularly in countries where prices are high and penetration rates remain low.
- Policy-makers need to create an enabling regulatory environment that fosters investment in both fixed-and mobile-broadband networks. To that end, all players (public and private) should face equal and predictable conditions, in order to stimulate competition and private investment in areas that are economically profitable. Governments should leverage the investment made by operators in lucrative areas to extend broadband coverage to other (usually rural and remote) areas, either by promoting public-private partnerships or by directly supporting strategic public investment in broadband networks. Public initiatives need to be carefully designed in order to avoid crowding out private investment. Governments should include the promotion of broadband in the specifications of universal service funds so as to bring high-speed Internet access to underserved areas and to connect more vulnerable groups.

- Governments should set clear targets and monitor progress. To this end, they need to measure developments in fixed- and mobile-broadband subscriptions, 3G-mobile coverage, international Internet bandwidth and fibre-optic backbone infrastructure.

- Policy-makers need to monitor and survey the quality of fixed-and mobile-broadband services, including the difference between advertised and real speeds. Regulators should encourage operators to provide consumers with clear information on coverage, speeds, prices (including data roaming charges) and quality of service, and set QoS standards. 


\section{Endnotes}

1 Next-generation access (NGA) is a term commonly used to refer to FTTx deployments, as well as to the upgrade of cable networks to DOCSIS 3.0. According to the European Commission's definition, NGA networks are "wired access networks which consist wholly or in part of optical elements and which are capable of delivering broadband access services with enhanced characteristics (such as higher throughput) as compared to those provided over already existing copper networks. In most cases NGAs are the result of an upgrade of an already existing copper or co-axial access network," see European Commission (2010).

2 See Booz \& Company (2009), World Bank (2009), McKinsey (2009) and ITU (2011).

3 For more information on the Broadband Commission for Digital Development, see http://www.broadbandcommission.org/.

4 Although under Recommendation ITU-T I.113, broadband is defined as a transmission capacity that is faster than primary rate ISDN at 1.5 or $2.0 \mathrm{Mbit} / \mathrm{s}$, ITU collects end-user data on the number of broadband subscriptions based on a definition of $256 \mathrm{kbit} / \mathrm{s}$, which is in line with the OECD definition.

5 See Federal Communications Commission (2010).

6 ITU's Telecommunication Standardization Sector (ITU-T) is leading several standardization initiatives to promote the development of the Internet of Things. For more information, see http://www.itu.int/en/ITU-T/techwatch/Pages/internetofthings.aspx.

7 M2M figures sourced from Berg Insight, see http://www.berginsight.com/ShowReport.aspx?m m=3\&Id=112.

8 In early 2007, an article in the Economist suggested that it would take a long time for dial-up to die, see: http://www.economist.com/node/8766073. Since then, the number of broadband subscriptions has grown rapidly and dial-up is decreasing in most countries of the world.

9 See Czech Statistical Office (2011).

10 The term "mobile-broadband subscriptions" refers to standard mobile subscriptions with use of data communications at broadband speeds, and dedicated mobile data subscriptions. The term "wireless-broadband subscriptions" includes these subscriptions, plus terrestrial fixed wireless and satellite subscriptions. This distinction between 'wireless broadband' and 'mobile broadband' has been adopted by ITU based on the OECD definition of wireless broadband (OECD, 2010c).

11 According to most mobile operators, promotional offers "are well below cost, which makes them unsustainable in the long run". See: http://www.balancingact-africa.com/news/en/issue-no-555/internet/test-of-article-with/en.

12 See the full text at: http://www.opencongress.org/bill/112-s732/text.

13 See Article 12 in the European Commission's proposal for the new Roaming Regulation (European Commission, 2011a).

14 See, for example, the LirneAsia's Quality of Service Experience reports, which include latency, packet loss and jitter among the parameters analysed: http://lirneasia.net/wp-content/uploads/2009/03/broadband-qose-february-2009-v2.pdf.

15 In a recent trial in the United Kingdom, Virgin Media has been capable of reaching download speeds of up to 1.5 Gbit/s through DOCSIS 3.0 cable technologies. This gives an example of the potential speeds that can be delivered through DOCSIS 3.0. For more details, see: http://mediacentre.virginmedia.com/Stories/Virgin-Media-delivers-world-s-fastest-cable-broadband-2131.aspx.

16 See Communications Commission of Kenya (2010) and Agence Nationale de Réglementation des Télécommunications du Maroc (2011).

17 See Point Topic (2011).

18 "Wireless-broadband subscriptions" refer to standard mobile and dedicated data subscriptions (both of which are included in the ITU term "mobile broadband") and to fixed terrestrial and satellite subscriptions. This distinction between 'wireless broadband' and 'mobile broadband' has been adopted by ITU based on the OECD definition of wireless broadband (OECD, 2010c).

19 See, for example http://www.businessinsider.com/spectrum-crisis-2013-2011-5 and http://www.cellular-news.com/story/49594. php? $=$ h.

20 See http://www.nytimes.com/2009/09/03/technology/companies/03att.html.

21 For more information on the digital dividend and ITU's work in this area, see: http://www.itu.int/net/itunews/issues/2010/01/27. aspx and http://www.itu.int/net/itunews/issues/2010/08/34.aspx.

22 See http://www.tmcnet.com/ngnmag/features/articles/160918-cellular-carriers-onboard-with-wi-fi-offload.htm.

23 See, for example, the use of multiband digital repeaters in Male, the capital of the Maldives, at: http://www.cellular-news.com/story/49664.php?s=h, as well as the UK regulator Ofcom's ruling on spectrum trading, at: http://media.ofcom.org.uk/2011/06/20/mobile-spectrum-trading-given-go-ahead/. Secondary markets for spectrum trading are encouraged at a European level by Article 9b of the EU Better Regulation Directive (European Commission, 2009b). See also Onyeije Consulting LLC (2011).

24 See http://www.macworld.com/article/160639/2011/06/verizon_unlimited_data.html.

25 http://wirelessfederation.com/news/84746-korea-telecom-no-longer-to-offer-unlimited-data-tariffs-south-korea/.

${ }_{26}$ For a detailed analysis of fixed broadband penetration and speeds in Portugal compared to other EU countries, see European Commission (2011b).

27 See recent data from ANACOM, the Portuguese regulator: http://www.anacom.pt/render.jsp? contentId=1072290.

28 See www.oecd.org/sti/ict/broadband. 
29 To a much higher extent than broadband access technologies based on cable and fibre, ADSL is affected by the distance between the end user and the exchange, with the speed decreasing as distance increases.

30 See http://media.ofcom.org.uk/2011/03/02/average-broadband-speed-is-still-less-than-half-advertised-speed/ and http://transition. fcc.gov/Daily Releases/Daily Business/2010/db0813/DOC-300902A1.pdf.

31 See Telecommunications Regulatory Authority of Bahrain (2011).

32 In Thailand, a recent survey carried out by the Telecommunications Consumer Protection Institute (TCI), which operates under the National Telecommunications Commission (NTC), and the Thai Webmaster Association showed that on average customers can download at 71 per cent of the advertised broadband speeds and upload at only 10 per cent. See: http://www.telecompaper.com/news/thai-customers-baffled-by-isp-use-of-up-to-in-speed-claims. The Federal Communications Commission in the United States has a consumer broadband webpage where tests can be run to test speed, latency and jitter. See: http://www.broadband.gov/qualitytest/about/.

33 To measure more than just speed and better understand the quality of services, LirneAsia has developed a Broadband Quality of Service Experience (QOSE) benchmarking methodology, and has tested fixed- and mobile-broadband services in a number of Asian countries and compared results with the United States and Canada. The measure is based on different technical criteria (including speed, packet loss and availability) and helps to objectively measure the quality of a broadband connection. It found that major differences existed not only in terms of the advertised and actual speeds but also in other QoS measures, see:

http://lirneasia.net/wp-content/uploads/2009/03/broadband-qose-february-2009-v2.pdf. Also, Ookla's Net Index provides average download speeds for 170 economies (June 2011). See: http://www.netindex.com/download/allcountries. Akamai compiles performance data for a number of economies. See: "Network Performance Comparison" at: http://www.akamai.com/html/technology/dataviz2.html.

34 See the EGTI online discussion forum at: http://www.itu.int/ITU-D/ict/ExpertGroup/default group.asp.

35 See http://wirelessfederation.com/news/74333-ntc-to-launch-broadband-test-equipment-philippines/.

36 See http://eshoo.house.gov/index.php?option=com_content\&view=article\&id=1009:rep-eshoo-introduces-legislation-to-improveconsumer-information-on-4g\&catid=51:2011-press-releases.

37 See Ofcom (2011)

38 See http://www.telecompaper.com/news/cell-c-offers-bigger-mobile-broadband-bundles.

39 See http://www.eassy.org/.

40 See http://www.itu.int/net/itunews/issues/2010/08/38.aspx.

41 See, for example, Maroc Telecom's project to build a regional fibre-optic network: http://www.telegeography.com/products/commsupdate/articles/2010/02/26/maroc-telecoms-first-phase-of-regional-fibre-backbone-60-complete/.

42 See http://www.africabandwidthmaps.com/?p=2058.

43 See http://www.africabandwidthmaps.com/?p=1735.

44 See, for example, Venezuela's mobile operator Digicel's fibre optic plans: http://www.telegeography.com/products/commsupdate/articles/2011/06/22/digitels-fibre-expanding/.

45 See: $\mathrm{http}: / /$ www.casapres.go.cr/web/index.php?option $=$ com content\&view=article\&id=903:acuerdo-social-digital-hacia-una-sociedad-digital-inclusiva\&catid $=57 \&$ Itemid $=92$.

46 See Telecom Regulatory Authority of India (2011).

47 See Parliament of Australia (2011).

48 http://www.futuregov.asia/articles/2011/feb/21/thailand-lay-down-strategies-connect-government/.

49 See Ministry of Regional Development of Poland and European Commission (2007).

50 More information on the different public initiatives within the "Plan Argentina Conectada" related to fibre-optic deployment is available at Presidencia de la Nación Argentina (2010), and on the website: http://www.argentinaconectada.gob.ar/.

51 See http://www.antel.com.uy/antel/institucional/sala-de-prensa/eventos/eventos-2010/importantes-anuncios-al-presentar-la-nuevaestrategia-de-la-empresa. 



\section{Chapter 5. Increasing Internet use: the role of education, income, gender, age and location}

\subsection{Introduction}

The previous chapters of this report have provided important insights into the development of various ICT infrastructures and technologies, including broadband Internet, as well as countries' progress in improving them. Much less is known about the usage and the users of those technologies. Answers to questions such as who is on the Internet (and who is not), and what they do online, are crucial for policy-makers, businesses, organizations and anyone wanting to reach out to communicate and interact with potential customers, citizens, members and other users of new technologies. Detailed information on the age, the gender and the income levels of Internet users, for example, is not only vital for companies designing their online marketing and e-commerce strategies, but is also important for governments seeking to adapt e-government applications and services. Information on Internet users can moreover point to potential barriers that prevent or discourage people from going online, and thereby help policy-makers address and overcome them.

Most countries in the world have detailed and historic supply-side ICT data, relating to aspects such as telecommunication infrastructure, tariffs or subscriptions to services. There are by contrast relatively little demandside ICT data available, on aspects such as usage of ICTs by individuals, households, businesses, governments, institutions, etc. Nevertheless, an increasing number of countries are now collecting data on ICT use through national surveys, and are producing more reliable and comparable ICT user data, especially concerning individuals and business use. In view of the growing number of Internet users in the world, and the potential impact of Internet use, more attention is now being given to the users of the technologies. In particular, ITU has focused its research on the use of ICTs by households and individuals, while other organizations have been concentrating more on other important users and drivers of ICTs, such as businesses, which are not covered in this report. ${ }^{1}$

Thus, the research reported in this chapter focuses on use of the Internet by individuals. As the chapter will show, the higher rates of usage by people with relatively higher incomes and higher levels of education, in particular in developing countries, suggest that there is ample scope for increasing Internet usage by addressing the skills barriers to Internet use and affordability of the Internet. Both these issues are covered in detail in Chapters 2 and 3 of this publication. The ICT Development Index (IDI) recognizes the role that skills play in the development of the information society through the inclusion of the skills sub-index, and the ICT Price Basket (IPB) provides an important source for understanding the relative price of Internet access.

The observation that Internet use is particularly popular among younger generations suggests that there is great potential for bringing more people online in developing countries, where populations tend to be younger than in developed countries. Governments can exploit the fact that younger people tend to go online easily because the Internet offers relevant content, in the form of educational material and information, and recently largely through social-networking sites and other user-created content. Available data suggest that Internet use tends to be more common among people who are currently in 


\section{Chart 5.1: Percentage of countries collecting data on Internet usage, total and by region}

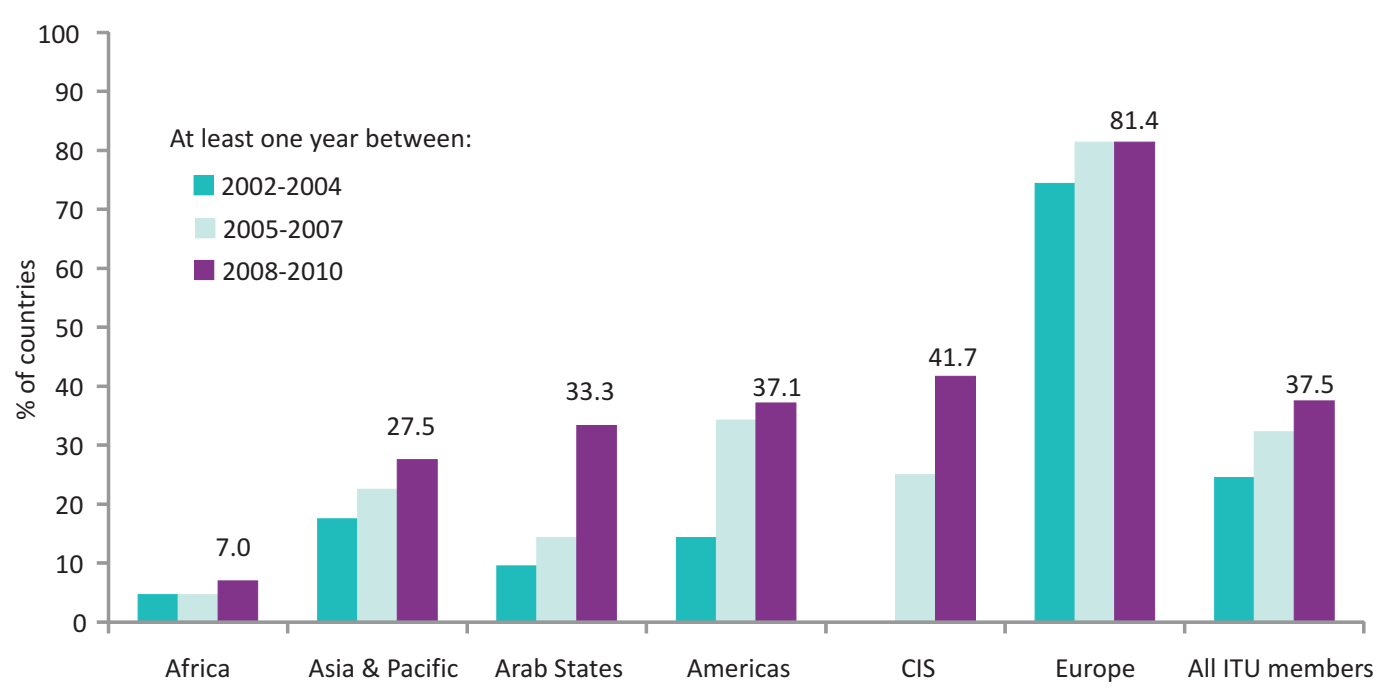

Note: Refers to countries which have collected data on the number of Internet users through official national household surveys. Source: ITU World Telecommunication/ICT Indicators database.

school, so providing Internet access in schools and improving school enrolment may therefore greatly increase Internet take-up in developing countries. ${ }^{2}$

Whereas people with higher incomes tend to use the Internet at home or work, public Internet access facilities play an important role for low-income groups. This is especially true of commercial Internet access facilities (e.g. Internet cafés), which as analysed in this chapter, are the most common location for Internet use in Africa and are widely used in Latin America.

This chapter closely examines and compares Internet user characteristics and behaviour in developed and developing countries, with particular emphasis on Africa. Based on the latest available data, it presents differences in Internet usage according to educational levels, income, location (urban/rural areas), gender and age, and looks at other relevant parameters such as computer or mobile-telephone use. Lastly, it analyses the main activities people engage in on the Internet, with special focus on social networking. Based on the analysis of the data, recommendations are made on how to bridge the digital divide that separates those who are online from those who are not.

As previously mentioned, data on ICT usage are limited, and therefore the analysis in this chapter relies on a limited but representative group of countries that have ICT user statistics. Data were obtained from countries based on national household surveys conducted between 2008 and 2010, and are in line with the core ICT indicators that have been internationally agreed upon under the framework of the Partnership on Measuring ICT for Development. ${ }^{3}$ Since 2005, ITU has been compiling demand-side data collected through household surveys, and an increasing number of countries are reporting them. Despite the progress made, data are still limited for some regions (Chart 5.1), and full harmonization is not always possible, which makes comparisons and benchmarking challenging (see Annex 3 for more details on the methodological issues of demand-side data). To fill some of the gaps, data collected by ITU have been complemented by data from household surveys conducted by Research ICT Africa (RIA) ${ }^{4}$ in 17 African countries at the end of 2007 and beginning of 2008 .

\subsection{From voice to data traffic}

It is useful to compare use of the Internet with use of other key ICTs, in particular computers ${ }^{5}$ and mobile-cellular telephones, so as to understand possible bottlenecks constraining the spread of Internet use, and identify the potential Internet user market. Official data on the level 
of computer usage are particularly interesting, since Internet and computer use are often linked, and because computer usage provides an indication of ICT skills in a country. Mobile penetration levels, on the other hand, do not necessarily provide any indication in regard to ICT skills levels (since fewer skills are needed to use a mobile phone than to use a computer or the Internet), but offer some indication of the demand for ICTs.

In high-income countries, computer and Internet user penetration rates are noticeably similar. In many countries, including Iceland, Norway, Sweden and the Republic of Korea, there is only a relatively small difference between the percentage of the population using a computer and using the Internet (Chart 5.2). In lower-income countries, the discrepancy between computer and Internet user penetration is often greater. In Jordan, for example, around 55 per cent of people used a computer in 2009 , compared with only 26 per cent who used the Internet. In Senegal, computer user penetration in 2009 was more than twice as high as Internet user penetration. In these countries, policy-makers should try to identify bottlenecks to higher Internet user penetration levels, which may include high prices for Internet access, lack of awareness of the benefits of using the Internet, or lack of relevant content. Since more people are using computers than the Internet, ICT skills do not seem to be the main barrier, at least not for those already using a computer.

In Azerbaijan, Morocco and Japan, more people use the Internet than use computers, which can be explained by the prevalence of Internet access through mobile devices. In Japan, for instance, 77 per cent of all Internet users use the mobile phone and Personal Digital Assistants to access the Internet. As smartphone penetration increases in developing countries - where ICT infrastructure has been a major impediment to higher ICT levels - we can expect similar developments in the near future, with

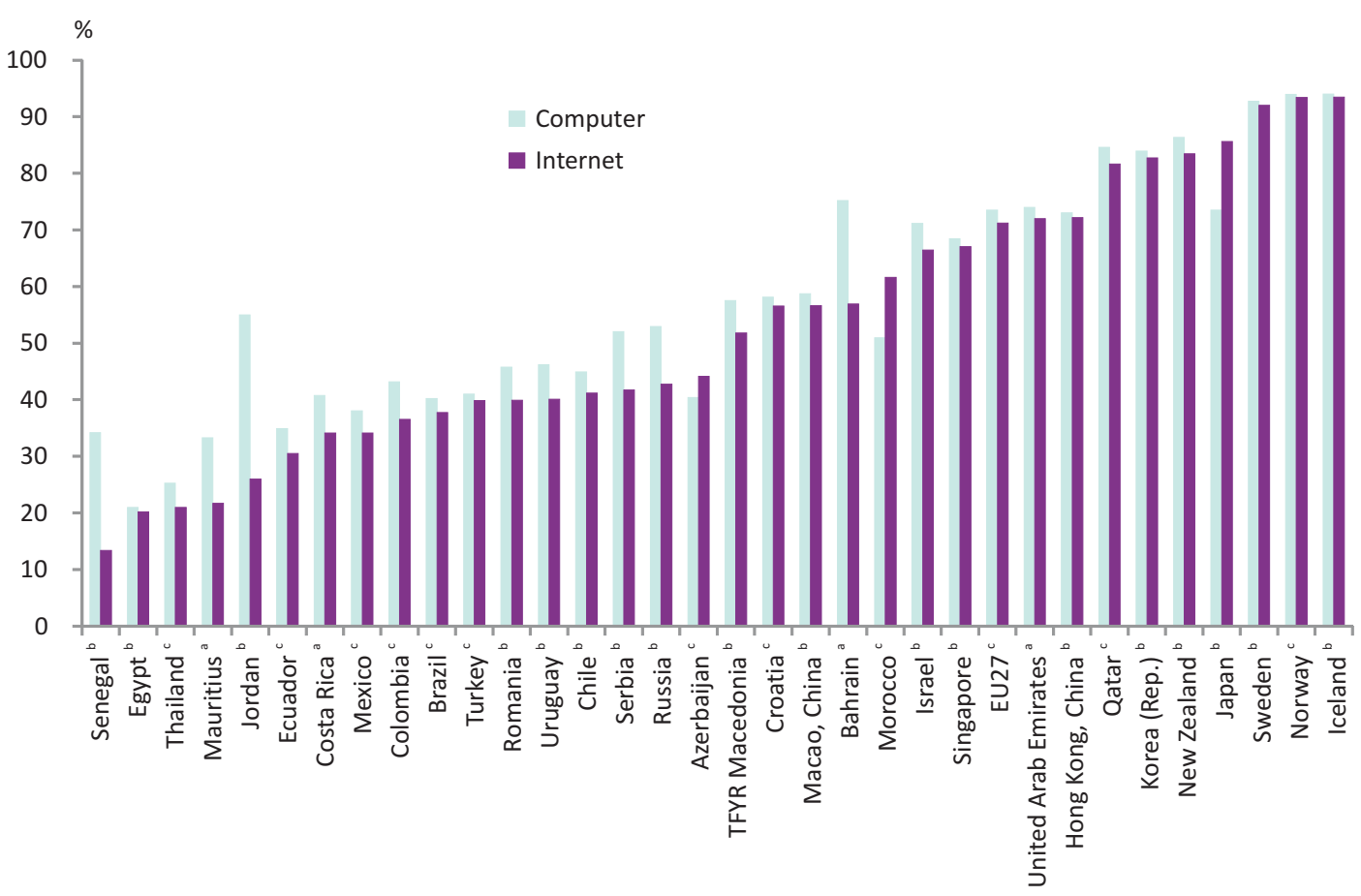

Notes: ${ }^{\text {a }} 2008 ;{ }^{\text {b } 2009 ; ~}{ }^{c} 2010$.

* For most countries that collect ICT usage data broken down by age, information was harmonized to compare (only) the age group 15-74. Exceptions are Colombia (5+), Morocco (12-65) and the United Arab Emirates (15+), as well as some countries where the lower limit of the age range is higher than 15 years of age (see Annex Table 3.1)

EU27 refers to the 27 members of the European Union.

Source: ITU World Telecommunication/ICT Indicators database. 
more people accessing the Internet via a mobile phone than via a computer. This also implies that, in the near future, Internet user penetration levels are likely to exceed computer usage levels.

Since a growing number of users are accessing the Internet through a mobile phone, an analysis of available data on mobile usage can provide further insights into present and future Internet use. Data show that both developed and developing countries have reached relatively high

Chart 5.3: Percentage of individuals aged 15 to $74^{*}$ using a mobile phone, latest available year

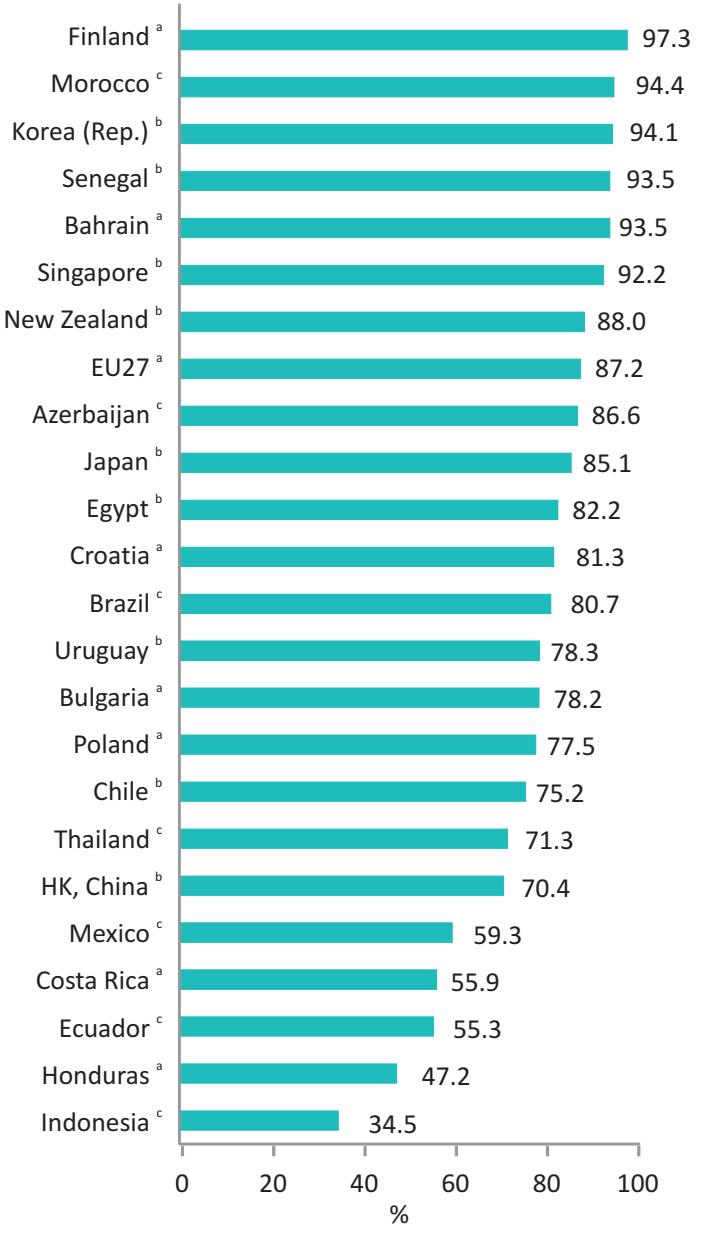

Note: $\quad{ }^{\text {a } 2008 ;}{ }^{\text {b } 2009 ;}{ }^{c} 2010$.

* For most countries that collect ICT usage data broken down by age, information was harmonized to compare (only) the age group 15-74. Exceptions are Morocco (12-65) and some countries where the lower limit of the age range is higher than 15 years of age (see Annex Table 3.1).

Source: ITU World Telecommunication/ICT Indicators database.

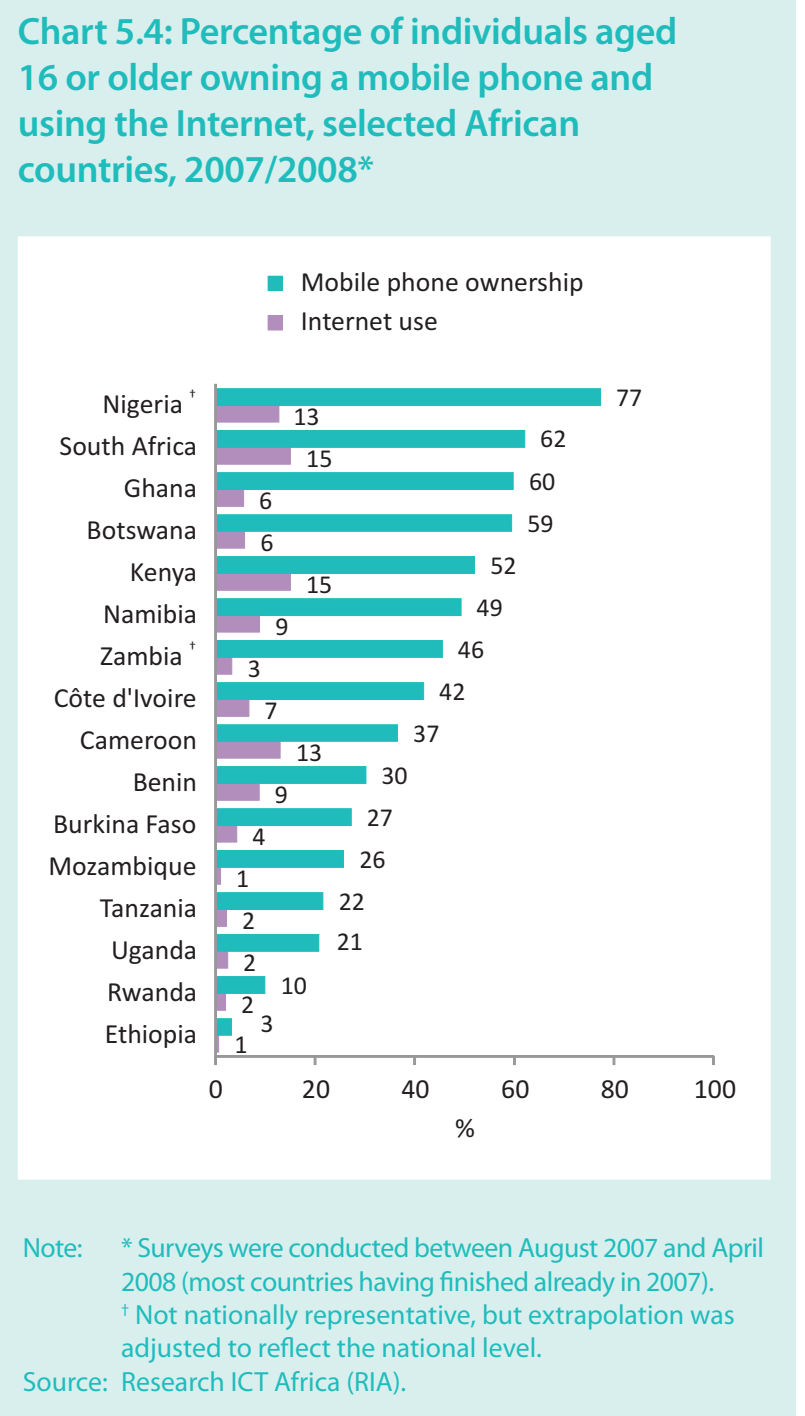

levels of mobile-phone use (Charts 5.3 and 5.4). Even in some of the poorest countries in Africa, including Benin and Côte d'Ivoire, mobile-phone ownership in 2007 had already exceeded 30 per cent.

It is clear that mobile-phone usage is much higher than Internet usage in both developed and developing countries. Within the European Union, for example, even the countries with the lowest mobile-phone user penetration, Portugal and Romania, exceeded 77 per cent in 2008, ${ }^{6}$ when Internet user penetration levels stood at 44 and 32 per cent, respectively. In a number of developing countries, including Egypt, Senegal and Thailand, where fewer than one in four people used the Internet, mobile usage rates exceeded 70 per cent (Chart 5.2 and Chart 5.3).

In those developing countries where Internet user penetration levels remain low because of a lack of fixed Internet 
infrastructure, there is enormous potential to expand the use of the Internet via mobile networks and phones, particularly as competition increases and prices decline. An additional barrier to increased Internet use through mobile phones which needs to be addressed is taxation of handsets. By reducing handset taxation in developing countries with heavy taxation regimes, mobile-broadband adoption could be further promoted (Katz et al., 2010).

A recent example of good practices is Kenya, where a combination of large price reductions and $3 \mathrm{G}$ rollout has resulted in significant increases in mobile Internet penetration (see also Box 2.4 in Chapter 2). The number of mobile Internet subscriptions grew from about 3.2 million at the end of September 2010 to nearly 4.7 million at the end of 2010 - an increase of 46.8 per cent in the space of just three months. ${ }^{7}$ Thanks to this, the gap between Internet and mobile-phone use has been narrowed, and the Communications Commission of Kenya estimates that, by end 2010, over one-quarter of Kenyans were using the Internet, as against 15 per cent in 2008.

Comparing Internet usage in the developed world with that in the developing world, it is clear that the digital divide is to a large extent an Internet divide: whereas demand for voice communication has largely been addressed through mobile telephony, demand for data services is the current major challenge.

\subsection{Education matters}

Data on Internet use by level of education show that Internet usage is much higher among people with higher levels of education. A higher educational level generally also implies higher income and greater computer literacy, both of which are important factors that drive Internet use.

Chart 5.5 shows Internet usage rates according to level of education attained, for a number of developed and developing economies. In all countries, without exception, people having attained higher (secondary or tertiary) educational levels use the Internet more than those with a lower level of education. People with a tertiary education are particularly likely to be online, with Internet user penetration rates in this group exceeding 50 per cent in most countries for which data are available. In many developing countries, including Brazil and Senegal, over 80 per cent of people with a tertiary education are online. Internet use among people with upper secondary educational levels are also relatively high, persistently exceeding national averages. Only in countries with very high overall Internet user penetration levels, such as Norway and Iceland, are Internet use levels similar across all levels of education.

Data suggest that in some developing countries the differences in Internet usage between more and less educated people are even more marked. Indeed, they are striking in a number of countries, such as for instance the Islamic Republic of Iran, Honduras and Paraguay, where over 50 per cent of people having attained tertiary education used the Internet, as against fewer than six per cent of those with primary or lower secondary education. On the other hand, and in addition to the cases of Norway and Iceland already cited, more than 60 per cent of persons having attained primary or lower secondary education were Internet users in the Republic of Korea, Switzerland and New Zealand, and more than 90 per cent of those having attained tertiary education.

Overall, it is important to keep in mind that, in developing countries, the proportion of adults reaching high education levels is relatively low. In Thailand and Brazil, for example, only around ten per cent of the adult population have completed tertiary education. The proportions are even lower in lower-income countries such as Senegal or El Salvador, where only about five per cent of the adult population have completed that level of education. In contrast, in countries such as New Zealand or Norway, this proportion is around 39 per cent. ${ }^{8}$

Additionally, the distribution of incomes seems to play a role, and the difference in Internet usage rates between people with different educational levels appears to be particularly pronounced in countries where incomes are less equally distributed. In El Salvador, the proportion of Internet users among people with tertiary education in 2009 was 11 times higher than among people with primary or lower secondary education. While El Salvador had a Gini coefficient of 49.7 in 2009, Norway, where Internet usage levels vary relatively little between people with different levels of education, had a Gini coefficient of 25.8, indicating a relatively equal distribution of incomes. ${ }^{9}$

Available data for Africa suggest that in this region there is a very strong link between level of education and level of Internet use. Hardly any Africans with only a primary education were using the Internet in $2007 / 2008$, but the majority of those with a tertiary education were online (Chart 5.6). At the same time, there are quite considerable differences in Internet user penetration rates even among 
Chart 5.5: Percentage of individuals* using the Internet, by highest educational level attained, latest available year (2008-2010)

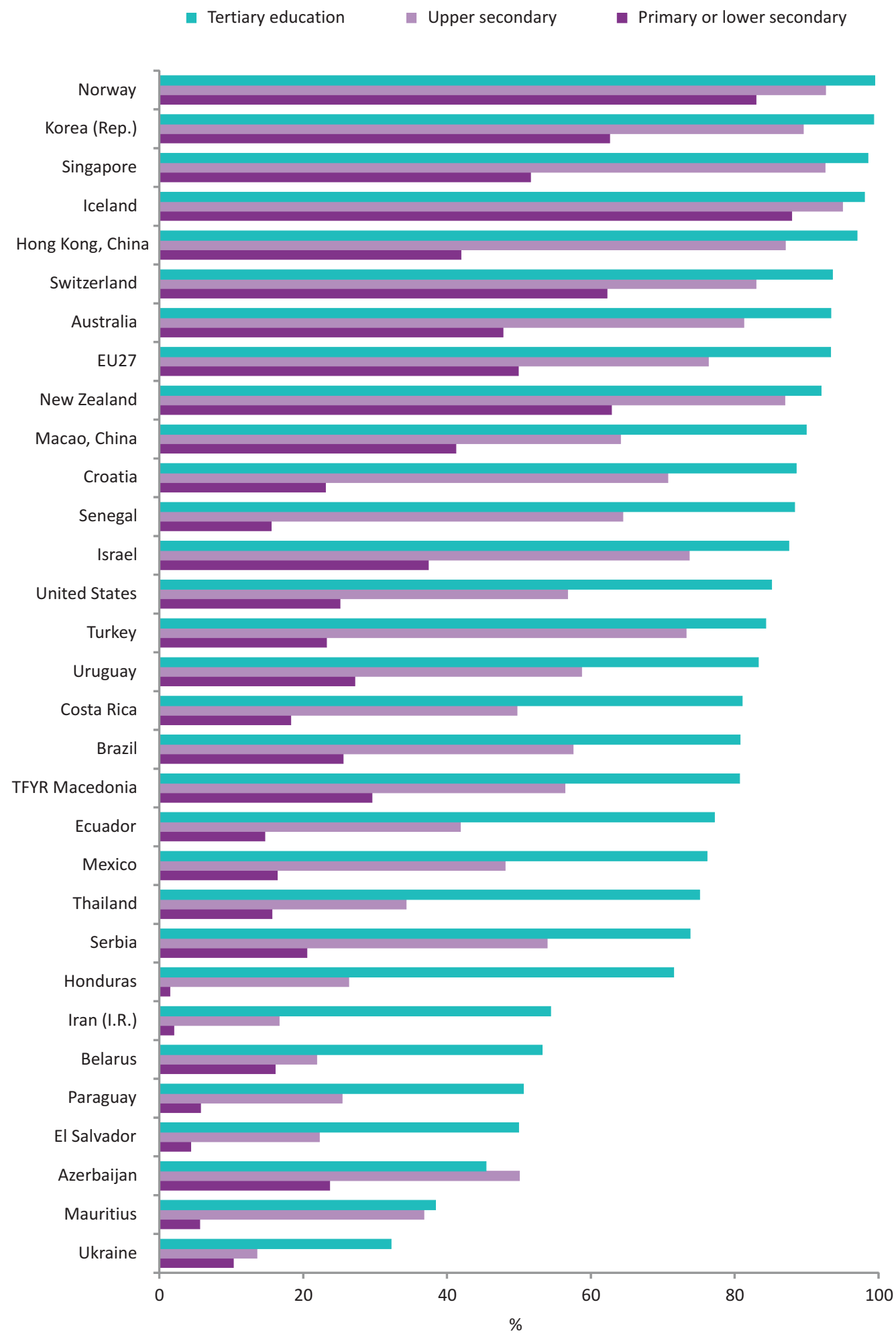

Note: * Age scope varies across countries, see Annex Table 3.1.

Source: ITU World Telecommunication/ICT Indicators database. 
the more highly educated population, ranging from over 90 per cent in Rwanda to less than 20 per cent in Uganda. Rwanda has made ICTs a key development priority, and the country has a number of projects to connect schools and universities, and to equip students with computers and laptops. ${ }^{10}$ These efforts contribute to bringing more students online, even if the overall Internet user penetration rate in Rwanda remains very low (at just over three per cent in 2007 , and less than eight per cent by 2010). Another major barrier in the country that prevents bringing more people online is the low school attendance: gross enrolment ratios ${ }^{11}$ in Rwanda remained very low in 2010, at 26.7 and 4.8 per cent, respectively, for secondary and tertiary education.

Closely related with differences in levels of education, income inequalities are also a major factor for Internet uptake. ${ }^{12}$ Table 5.1, which includes information on income levels in Africa, suggests that one of the key determinants of Internet access is income (or the price of ICTs). In Botswana, for example, only two per cent of the first three quartiles in terms of disposable income access the Internet. In comparison, for people earning in the top quartile, Internet use stood at 19 per cent. Comparisons between countries show that this finding holds true for all countries surveyed in Africa.

Indeed, data on income and educational levels in Africa point to a strong link between how much money people earn and how educated they are. People with tertiary education have a much higher monthly income compared with those who only have a secondary or primary education. Data from RIA (Chart 5.7) show that in South Africa and Namibia, for instance, people with a tertiary education earn more than ten times as much as people with a first

Chart 5.6: Percentage of individuals aged 16 or older using the Internet, by highest educational level attained, selected African countries, 2007/2008*

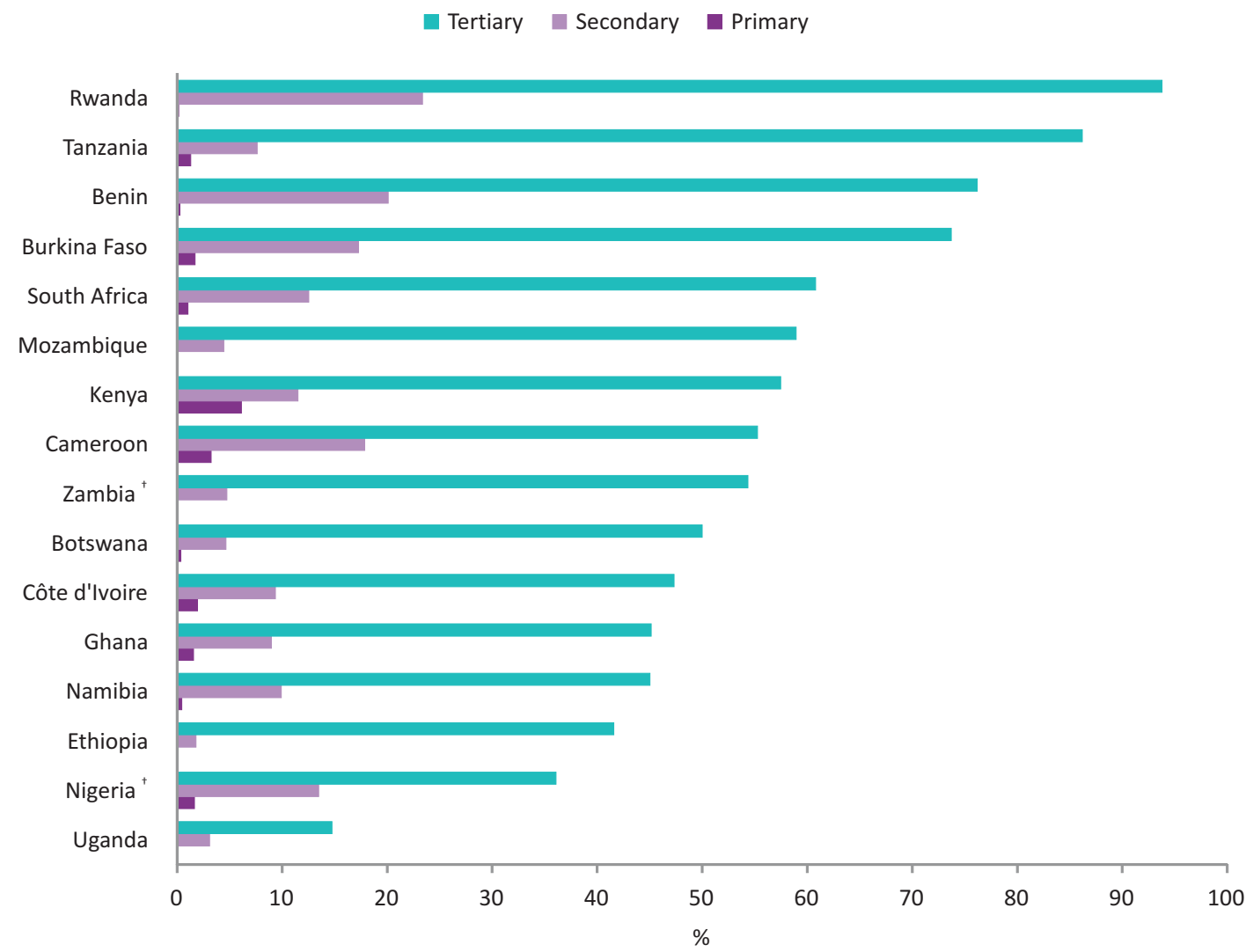

Note: * Surveys were conducted between August 2007 and April 2008 (most countries having finished already in 2007). ${ }^{\dagger}$ Not nationally representative, but extrapolation was adjusted to reflect the national level.

Source: Research ICT Africa (RIA). 
Table 5.1: Percentage of individuals aged 16 and older using the Internet, by income, selected African countries, 2007/2008*

\begin{tabular}{|l|c|c|}
\hline Benin & $\begin{array}{c}\text { Lowest three disposable } \\
\text { income quartiles }\end{array}$ & $\begin{array}{c}\text { Top disposable } \\
\text { income quartile }\end{array}$ \\
\hline Botswana & 6 & 16 \\
\hline Burkina Faso & 2 & 19 \\
\hline Cameroon & 10 & 10 \\
\hline Côte d'Ivoire & 4 & 25 \\
\hline Ethiopia & 0 & 14 \\
\hline Ghana & 5 & 3 \\
\hline Kenya & 9 & 8 \\
\hline Mozambique & 1 & 32 \\
\hline Namibia & 4 & 3 \\
\hline Nigeria ${ }^{\dagger}$ & 10 & 25 \\
\hline Rwanda & 1 & 22 \\
\hline Senegal & 9 & 4 \\
\hline South Africa & 7 & 38 \\
\hline Tanzania & 1 & 4 \\
\hline Uganda & 1 & 13 \\
\hline Zambia ${ }^{\dagger}$ & 1 & 7 \\
\hline
\end{tabular}

Note: * Surveys were conducted between August 2007 and April 2008 (most countries having finished already in 2007). Not nationally representative, but extrapolation was adjusted to reflect the national level.

Source: Research ICT Africa (RIA).

degree. In all other African countries for which data are available, a tertiary education also clearly pays off, and allows people to earn at least twice as much (and often many times more) as people with a primary or secondary education. So far, Internet use in Africa seems to remain the preserve of the highly educated and wealthy elite, in other words those who can afford to use the Internet and who have the necessary skills to do so.

Data from developed countries - where educational levels seem to be less decisive for Internet use - suggest that here, too, affordability plays a key role in increasing Internet use. One of the reasons for the Internet being used more evenly across educational categories in developed countries is that Internet access and usage is cheaper in both absolute and relative terms. At end 2010, unlimited high-speed broadband access in the United States, the United Kingdom and Japan cost less than USD 30 per month, compared with Namibia where it cost over USD 90 for an unlimited 256 kbit/s ADSL.
Based on these findings, there are a number of key trends in the Internet market in developing countries that are likely to narrow the Internet user divide in the short and medium term. First, the spread of mobile Internet access, including mobile-broadband access, will not only address important infrastructure barriers but also help overcome the skills barrier by allowing people to access the Internet via their handsets. The skills needed to use a mobile phone are relatively simple, and since many people today already own and use a mobile phone they have acquired some basic ICT skills, which will make it easier for them to go online.

Second, more and more operators are providing prepaid mobile (broadband) Internet services, which can lower the income barrier. Like in the mobile-cellular market, prepaid Internet services have been introduced so as to allow low-income customers to purchase a limited amount of time or data volumes to access the Internet. That way, people can recharge their airtime to use the 
Chart 5.7: Average monthly income of individuals aged 16 or older, by highest educational level attained, selected African countries, 2007/2008*, USD

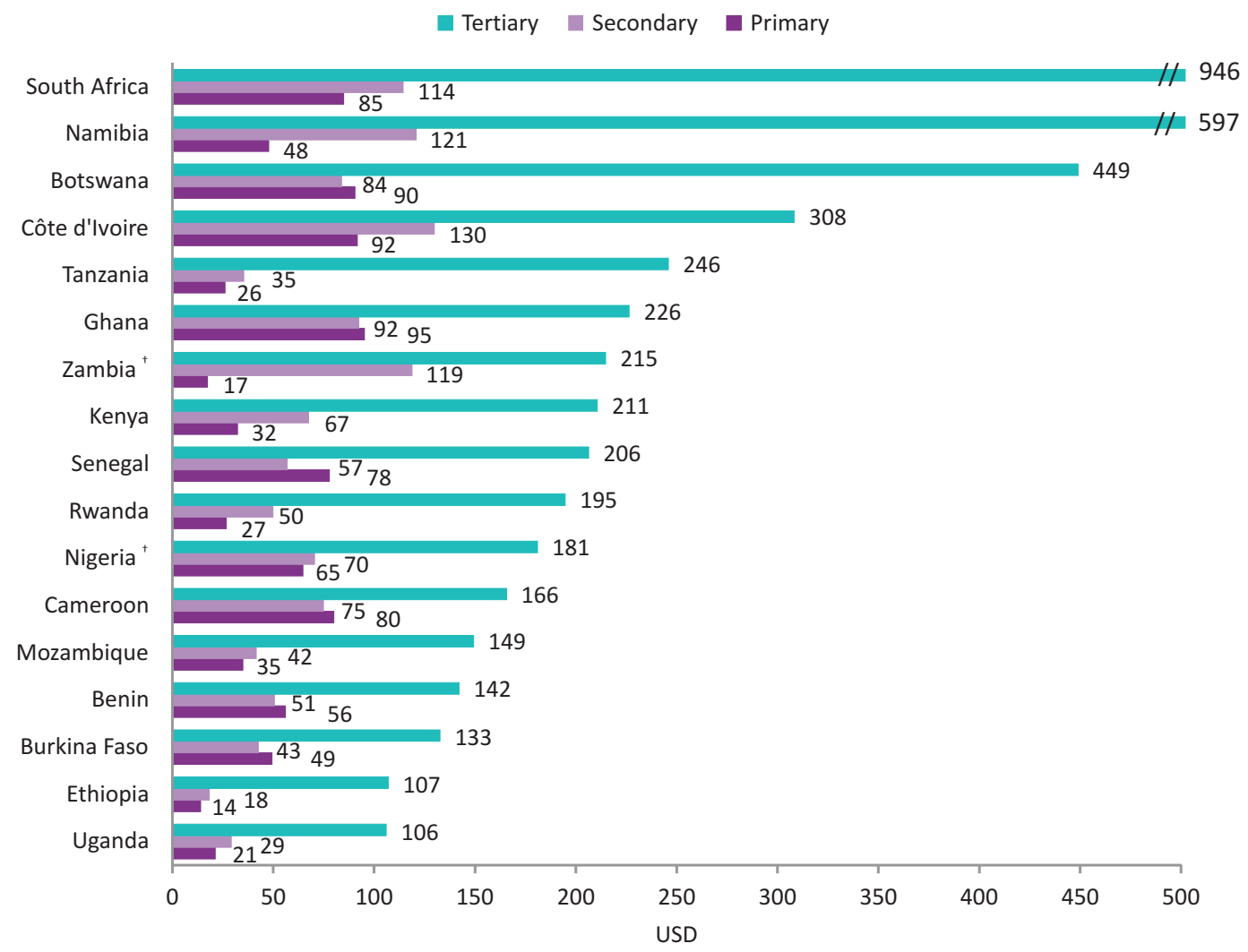

Note: * Surveys were conducted between August 2007 and April 2008 (most countries having finished already in 2007). ${ }^{+}$Not nationally representative, but extrapolation was adjusted to reflect the national level.

Source: Research ICT Africa (RIA).

Internet whenever they have money available. Electricity is also less of an obstacle for mobile Internet use, since the mobile phone can easily be recharged elsewhere than at home, giving users more flexibility.

It is also interesting to look at Internet use among students, i.e. people who are currently enrolled at highereducation institutions (e.g. universities) or attending school. Available data from selected Latin American countries show that Internet use levels are generally higher among young people attending school or university than among those who have already earned a degree (Chart 5.8). In Uruguay in 2009, for example, over 65 per cent of primary students were using the Internet, a higher proportion than among Uruguayans holding a secondary or post-secondary degree. This is linked with the Ceibal project, a plan put in place by the government whereby every pupil and every teacher in all public schools received for free a laptop computer which can be connected to the Internet, at least while in school. ${ }^{13}$ In Brazil, around 90 per cent of people enrolled in tertiary and post-secondary studies were online in 2008, while the country's overall Internet user penetration stood at below 35 per cent.

The reason why a very large proportion of people who are currently studying or enrolled at university are Internet users could be that through their studies they have (perhaps free) access to the Internet. At the same time, students are also more likely to find relevant and useful content on the Internet, including for their studies. Furthermore, they are in a learning environment, which will help them to acquire the necessary skills to use the Internet. 
Chart 5.8: Percentage of individuals using the Internet, by highest education attained or currently studying, selected Latin American countries, latest available year
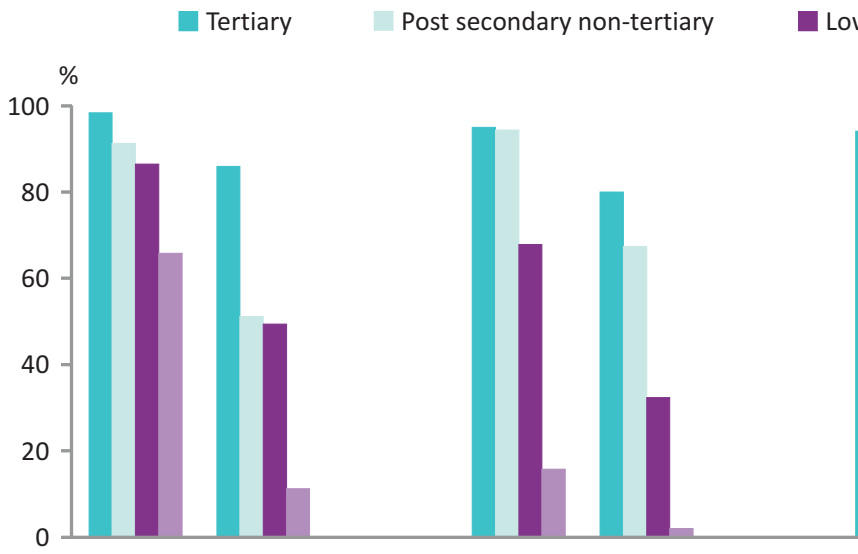

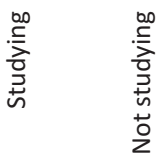

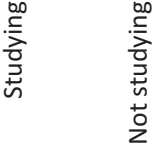

紊

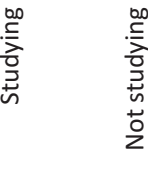

Costa Rica
(2008)

Brazil

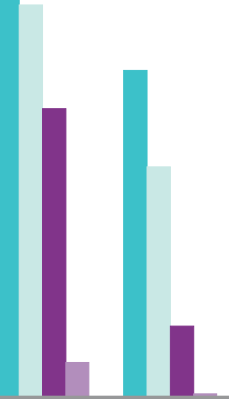

Uruguay
(2009)

$(2008)$

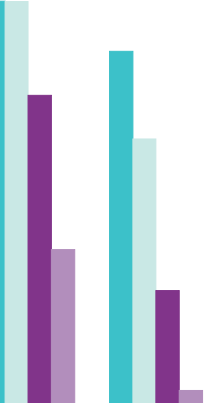

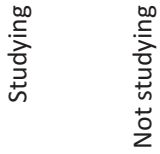

Source: ITU calculation based on OSILAC, ECLAC: http://www.eclac.cl/tic/flash/default.asp?idioma=IN

Further, the lowest Internet user penetration levels are found among those who are not at school and have only completed primary education. People at primary and secondary school are more likely to be online than those who reached those levels of education but are not studying any more. Assuming that people will not stop using the Internet once they have been online, this finding suggests that those currently enrolled at school and university are likely to be future Internet users, too. This in turn implies that Internet user penetration rates are destined to increase, particularly in countries that manage to enrol a large part of their young population and ensure that their educational institutions provide students with Internet access.

\subsection{The gender divide}

Women's access to and use of ICTs can be seen as a means of overcoming gender inequality, in areas such as access to jobs, education or equal wages. At the same time, due to unequal access to the resources that appear to enhance ICT access and usage, women generally have less access to ICTs. Available data from Internet user surveys show that there is still a higher percentage of men than women using the Internet, in both developed and developing countries. Out of all countries with available data, only in New Zealand and Thailand do proportionally more women than men use the Internet, and in these cases the difference is minor (Table 5.2). Marginal differences in favour of men can be seen in Australia, Uruguay, Brazil and Honduras. Quite large differences between the numbers of women and men using the Internet are observed in a number of developing countries, including Azerbaijan, Turkey, Russia and Senegal. Gender-related differences in Internet use do not seem to be tied to development levels, insofar as there is also a relatively large difference, for instance, in Switzerland, where 92 per cent of men use the Internet compared with 86 per cent of women. In the European Union, there is also a clear gender divide, with 74 per cent of men and 69 per cent of women using the Internet.

One explanation for the fact that more men than women are online may be that, in many countries, women earn less and do not have equal access to education. ${ }^{14}$ Indeed, 
Table 5.2: The gender divide: percentage of women and men aged 15 to 74 using the Internet, latest available year

\begin{tabular}{|c|c|c|c|c|}
\hline Country & Reference Year & Women & Men & $\begin{array}{c}\text { Difference } \\
\text { women - men }\end{array}$ \\
\hline Australia & 2009 & 78.2 & 78.7 & -0.4 \\
\hline Azerbaijan & 2010 & 35.5 & 53.4 & -17.9 \\
\hline Belarus & 2010 & 32.0 & 36.3 & -4.3 \\
\hline Brazil & 2010 & 37.5 & 38.0 & -0.5 \\
\hline Chile & 2009 & 39.1 & 43.5 & -4.4 \\
\hline Costa Rica & 2008 & 32.4 & 35.9 & -3.5 \\
\hline Ecuador & 2010 & 29.4 & 31.6 & -2.2 \\
\hline Egypt & 2009 & 17.6 & 22.8 & -5.2 \\
\hline El Salvador & 2009 & 11.6 & 14.0 & -2.4 \\
\hline EU27 & 2010 & 68.5 & 74.0 & -5.4 \\
\hline Honduras & 2008 & 13.1 & 13.1 & -0.1 \\
\hline Hong Kong, China & 2009 & 69.2 & 75.3 & -6.2 \\
\hline $\operatorname{Iran}(I . R)$. & 2009 & 11.7 & 15.4 & -3.7 \\
\hline Israel & 2009 & 64.2 & 68.7 & -4.5 \\
\hline Japan & 2009 & 83.8 & 87.5 & -3.7 \\
\hline Korea (Rep.) & 2009 & 78.5 & 86.9 & -8.4 \\
\hline Macao, China & 2009 & 53.7 & 59.9 & -6.1 \\
\hline Mauritius & 2008 & 20.1 & 23.2 & -3.1 \\
\hline Mexico & 2010 & 32.1 & 36.3 & -4.2 \\
\hline New Zealand & 2009 & 84.2 & 82.8 & 1.4 \\
\hline Paraguay & 2008 & 14.6 & 15.9 & -1.3 \\
\hline Peru & 2008 & 27.8 & 35.5 & -7.7 \\
\hline Qatar & 2010 & 77.8 & 83.6 & -5.7 \\
\hline Russia & 2009 & 38.8 & 47.8 & -9.0 \\
\hline Senegal & 2009 & 9.3 & 18.3 & -9.0 \\
\hline Singapore & 2009 & 63.3 & 71.4 & -8.1 \\
\hline Switzerland & 2010 & 86.0 & 91.9 & -5.9 \\
\hline Thailand & 2010 & 21.6 & 20.3 & 1.3 \\
\hline Turkey & 2010 & 29.9 & 50.1 & -20.2 \\
\hline Ukraine & 2009 & 16.8 & 19.6 & -2.7 \\
\hline Uruguay & 2009 & 39.7 & 40.5 & -0.9 \\
\hline
\end{tabular}

Source: ITU World Telecommunication/ICT Indicators database.

some studies confirm that women often tend to earn less than men even when they have similar qualifications and work experience (Milek et al., 2010). ${ }^{15}$ Lower income levels mean that Internet access is less affordable for women. Additionally, lower educational levels among women would also lead to income differences between the genders.

Examples from Africa (Table 5.3) suggest that a major barrier to bringing more people online is lack of awareness of the existence of the Internet (and, consequently, what it offers), and fewer women than men in Africa know about the Internet. In Botswana and Senegal, for example, 2007 data show that men were much more aware of the Internet and that this was correlated with higher Internet user penetration rates. In Cameroon, where women were as aware (or more aware) of the Internet as men, the gender divide in terms of Internet use was marginal. While lack of awareness can indeed be an important barrier to Internet use, other factors, including lower income and educational levels, are likely to play an important role, too. 
Table 5.3: Knowing about the Internet and using it: the gender divide, 2007/2008*

\begin{tabular}{|c|c|c|c|c|}
\hline \multirow[b]{2}{*}{ Country } & \multicolumn{2}{|c|}{$\begin{array}{l}\text { Individuals aged } 16 \text { and over who } \\
\text { know what the Internet is (\%) }\end{array}$} & \multicolumn{2}{|c|}{$\begin{array}{c}\text { Individuals aged } 16 \text { and over who } \\
\text { use the Internet (\%) }\end{array}$} \\
\hline & Men** & Women ${ }^{* * *}$ & Men $* *$ & Women ${ }^{* * *}$ \\
\hline Benin & 27.8 & 14.6 & 11.9 & 5.3 \\
\hline Botswana & 30.8 & 18.1 & 10.1 & 4.0 \\
\hline Burkina Faso & 8.9 & 9.8 & 3.7 & 6.4 \\
\hline Cameroon & 34.5 & 44.6 & 13.1 & 12.8 \\
\hline Côte d'Ivoire & 19.3 & 13.4 & 8.1 & 4.0 \\
\hline Ethiopia & 10.8 & 6.5 & 0.9 & 0.4 \\
\hline Ghana & 29.7 & 23.4 & 8.1 & 3.2 \\
\hline Kenya & 39.9 & 27.8 & 21.1 & 11.5 \\
\hline Mozambique & 3.8 & 3.7 & 1.0 & 0.9 \\
\hline Namibia & 30.4 & 24.2 & 11.2 & 7.2 \\
\hline Nigeria $^{+}$ & 40.7 & 34.9 & 16.4 & 7.6 \\
\hline Rwanda & 6.4 & 7.0 & 1.8 & 2.1 \\
\hline Senegal & 56.5 & 35.8 & 14.4 & 6.7 \\
\hline South Africa & 56.2 & 47.0 & 20.4 & 11.3 \\
\hline Tanzania & 9.9 & 8.0 & 1.9 & 2.3 \\
\hline Uganda & 9.4 & 3.5 & 3.7 & 1.1 \\
\hline Zambia $^{\dagger}$ & 49.2 & 39.6 & 5.6 & 1.7 \\
\hline
\end{tabular}

Note: * Surveys were conducted between August 2007 and April 2008 (most countries having finished already in 2007).

** As a percentage of men aged 16 or older.

*** As a percentage of women aged 16 or older.

${ }^{\dagger}$ Not nationally representative, but extrapolation was adjusted to reflect the national level.

Source: Research ICT Africa (RIA).

The fact that women tend to use the Internet less than men does not seem to have to do with ICTs as such. Empirical evidence has shown that, under equal conditions of education or employment, there are relatively minor differences between men and women in terms of the use of technologies. ${ }^{16}$ It is thus differences between men and women in areas such as income and education that play a major role in explaining different levels of access to ICTs and their usage. Disparities increase as the technologies and services become more sophisticated and expensive, requiring greater levels of income and education to access and to operate them. ${ }^{17}$

\subsection{The urban/rural divide}

People living in rural areas stand to benefit from ICTs even more than others because ICTs have the potential to deliver services that otherwise might be less available, such as e-health, distance learning, information on agricultural product prices, etc. This is also consistent with the fundamental intent of Target 1 in the Geneva Plan of Action adopted by the World Summit on the Information Society (ITU, 2003), which was formulated precisely to ensure that people living in rural areas are not excluded from the information society.

Evidence shows that there are major differences between rural and urban areas, especially in the use of Internet and computers, with people in rural areas using the Internet less than those in urban areas. While these differences tend to be relatively small in developed, high-income countries, the variations are often substantial in developing countries. The urban/rural divide is much less pronounced in high-income economies, such as Switzerland and New Zealand. Indeed, of those countries for which data are available, New Zealand presents the most uniform penetration of Internet users between urban and rural areas, with only one percentage point difference. In many developing countries, including Morocco, Peru, Colombia, Brazil, Ecuador, Chile, Turkey and Azerbaijan, Internet usage among the urban population is much higher than among people living in rural areas (Table 5.4). 
Table 5.4: Percentage of individuals using the Internet, by urban/rural, latest available year

\begin{tabular}{|c|c|c|c|c|}
\hline Country & Reference Year & Rural & Urban & $\begin{array}{c}\text { Difference } \\
\text { Rural - Urban }\end{array}$ \\
\hline Australia & 2009 & 69.3 & 76.9 & -7.6 \\
\hline Azerbaijan & 2010 & 23.4 & 47.1 & -23.7 \\
\hline Belarus & 2010 & 14.5 & 37.8 & -23.2 \\
\hline Benin & 2007 & 1.2 & 20.7 & -19.5 \\
\hline Botswana & 2007 & 2.9 & 7.9 & -5.0 \\
\hline Brazil & 2010 & 16.0 & 45.4 & -29.4 \\
\hline Burkina Faso & 2007 & 0.5 & 18.7 & -18.2 \\
\hline Cameroon & 2007 & 3.9 & 21.5 & -17.6 \\
\hline Canada & 2009 & 72.9 & 82.6 & -9.7 \\
\hline Chile & 2009 & 16.6 & 42.0 & -25.4 \\
\hline Colombia & 2009 & 9.9 & 36.2 & -26.3 \\
\hline Costa Rica & 2008 & 18.4 & 41.8 & -23.4 \\
\hline Côte d'Ivoire & 2007 & 1.8 & 11.9 & -10.1 \\
\hline Ecuador & 2010 & 12.0 & 37.6 & -25.7 \\
\hline Egypt & 2009 & 14.3 & 30.7 & -16.5 \\
\hline El Salvador & 2009 & 3.1 & 17.0 & -13.9 \\
\hline Ethiopia & 2007 & 0.0 & 4.0 & -4.0 \\
\hline Ghana & 2007 & 2.2 & 10.0 & -7.8 \\
\hline Honduras & 2008 & 2.5 & 18.0 & -15.5 \\
\hline Indonesia & 2010 & 3.8 & 16.1 & -12.3 \\
\hline Iran (I.R.) & 2009 & 3.0 & 15.0 & -12.0 \\
\hline Israel & 2009 & 76.3 & 62.0 & 14.3 \\
\hline Japan & 2009 & 76.0 & 81.3 & -5.2 \\
\hline Kenya & 2007 & 13.5 & 20.9 & -7.4 \\
\hline Korea (Rep.) & 2009 & 69.4 & 84.3 & -14.9 \\
\hline Lithuania & 2010 & 51.5 & 70.1 & -18.6 \\
\hline Mauritius & 2008 & 21.9 & 19.9 & 2.0 \\
\hline Mongolia & 2010 & 2.5 & 16.4 & -13.9 \\
\hline Morocco & 2010 & 40.4 & 75.6 & -35.2 \\
\hline Mozambique & $2007 / 8$ & 0.0 & 4.3 & -4.3 \\
\hline Namibia & 2007 & 4.1 & 18.5 & -14.4 \\
\hline New Zealand & 2009 & 79.1 & 79.8 & -0.7 \\
\hline Nigeria $^{\dagger}$ & 2007 & 10.3 & 22.3 & -12.0 \\
\hline Paraguay & 2008 & 3.1 & 21.8 & -18.7 \\
\hline Peru & 2008 & 7.8 & 38.9 & -31.2 \\
\hline Russia & 2009 & 27.7 & 48.0 & -20.3 \\
\hline Rwanda & 2007 & 0.4 & 9.6 & -9.2 \\
\hline Senegal & 2009 & 2.2 & 18.2 & -15.9 \\
\hline South Africa & 2007 & 4.6 & 21.8 & -17.2 \\
\hline Switzerland & 2010 & 82.5 & 84.5 & -2.0 \\
\hline Tanzania & $2007 / 8$ & 1.8 & 3.3 & -1.5 \\
\hline Thailand & 2010 & 16.5 & 35.1 & -18.5 \\
\hline Turkey & 2010 & 22.1 & 47.3 & -25.2 \\
\hline Uganda & 2007 & 1.6 & 8.1 & -6.5 \\
\hline Ukraine & 2009 & 5.2 & 20.6 & -15.5 \\
\hline United States & 2009 & 64.9 & 69.3 & -4.4 \\
\hline Zambia $^{\dagger}$ & $2007 / 8$ & 5.1 & 3.3 & 1.8 \\
\hline
\end{tabular}

Note: $\quad$ Not nationally representative, but extrapolation was adjusted to reflect the national level.

Source: ITU World Telecommunication/ICT Indicators database and Research ICT Africa (RIA). 
In many African countries, hardly any rural inhabitants were using the Internet in 2007/2008, with Internet use in most countries confined almost exclusively to people living in urban areas. In Burkina Faso, Rwanda, Ethiopia and Mozambique, fewer than one per cent of people in rural areas were using the Internet. Two notable exceptions in Africa are Mauritius and Kenya, where Internet use among rural individuals reached 21.9 and 13.5 per cent, respectively.

For people in many developing countries, in both urban and rural areas, commercial Internet facilities and schools are the main place for accessing the Internet. Chart 5.9 compares location of Internet access in three different regions: Africa, Latin America and Europe. It highlights the importance of public commercial Internet access points, such as Internet cafés, in the developing world. It also shows that these commercial facilities are much more common locations for Internet access than free or government owned and subsidized access points (community facility). Internet use at home is the prevailing practice in Europe (85 per cent of Internet users), and in Latin America (50 per cent of Internet users). However, in Latin America, Internet use at commercial facilities still remains significant, and is es- pecially important for people living in rural areas, who use Internet at home much less than urban users (see country examples in Chart 5.10). As countries progress, there is likely to be a trend towards increasing Internet access at home or through mobile devices, but in the meantime commercially operated public facilities will play a major role in facilitating Internet access in the developing world and in rural areas.

Lastly, the importance of Internet cafés in Africa deserves special attention, all the more so because only eight per cent of African Internet users access the Internet at home, and in some countries barriers to Internet access at home also include a number of bureaucratic obstacles. For example, in Namibia, for a residential fixed-line or ADSL application, Telecom Namibia requires the following documents: identity card or passport, deed of sale or rental agreement, marriage certificate, proof of income, and security deposit. In contrast to the low level of Internet use at home, in Nigeria, for example, 89 per cent of (both urban and rural) Internet users in 2008 accessed the Internet from an Internet café, and 65 per cent in Kenya (75 urban users and 62 rural users). This highlights the importance of such projects as the Kenyan ICT Board's Digital Villages,

Chart 5.9: Location of Internet use aggregated for 17 African countries, 8 Latin American countries and 35 European countries, latest available year

Home Commercial facility W Work Place of education Another person's home Mobile phone Community facility

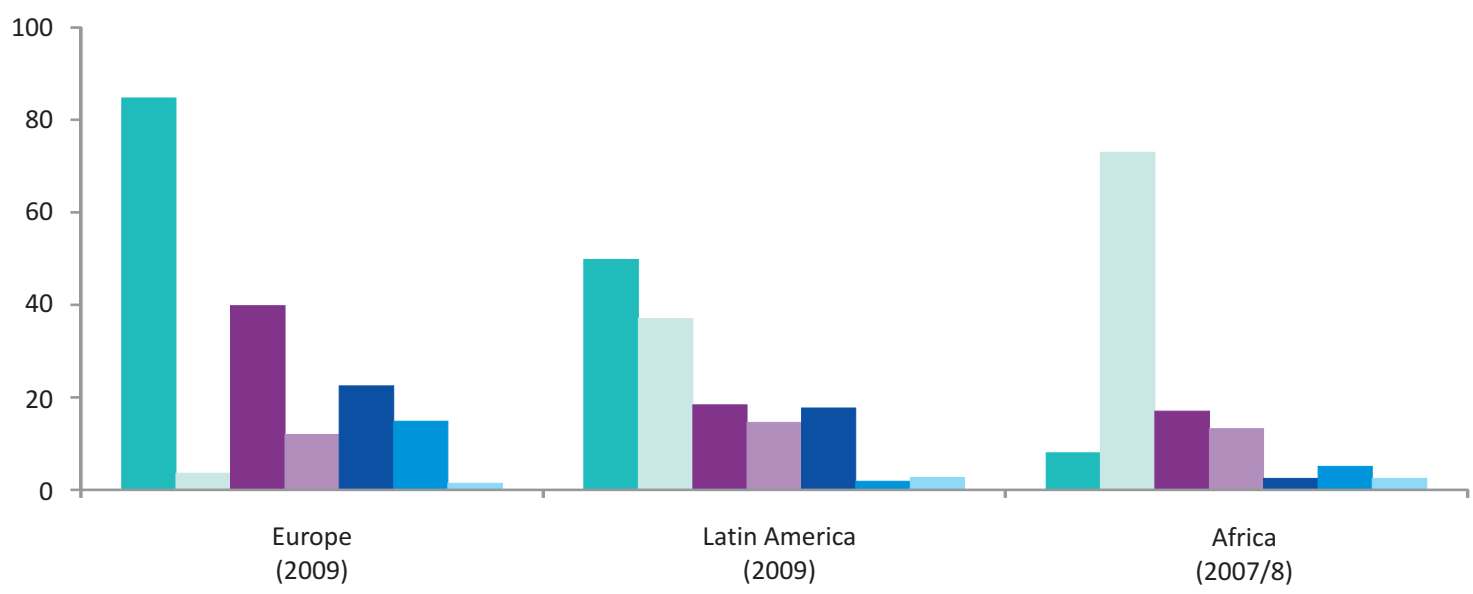

Note: Percentages calculated over the total number of Internet users. Multiple locations are possible. Community facility in the case of Africa refers to a library.

Source: ITU World Telecommunication/ICT Indicators database and Research ICT Africa (RIA). 
Chart 5.10: Percentage of Internet users, by urban/rural, using the Internet at commercial facility (left) and at home (right), selected countries, latest available year
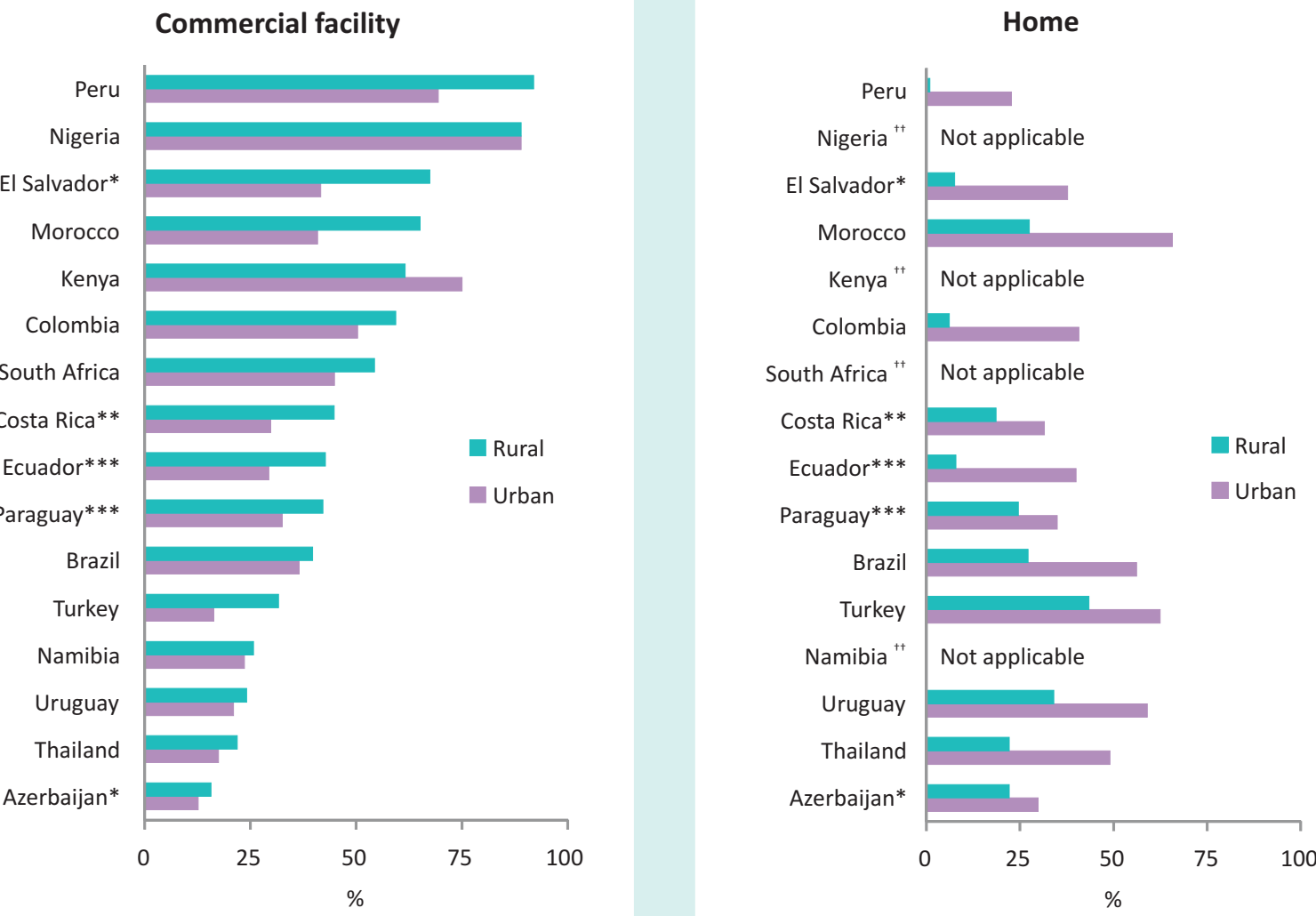

Note: All locations are possible, except for some countries where users were asked only about the most used place $\left(^{*}\right)$, the two most used places $\left.{ }^{* *}\right)$ and the three most used places $\left(^{* * *}\right)$. ${ }^{+t}$ Sample results for use at home non significant at the urban/rural level.

Source: ITU World Telecommunication/ICT Indicators database and Research ICT Africa (RIA).

where entrepreneurs are given loans on a commercial basis to set up Internet cafés. ${ }^{18}$ These findings not only point to the importance of pubic Internet access facilities for bringing more people online, but also suggest that viable business models may be the best solution in areas where people do not have access to the Internet at home.

\subsection{From e-mail to social networks: drivers of Internet use}

The Internet supports a wide variety of uses: from simple communications, such as e-mail, chat or Twitter, to sophisticated real-time video and audio communications; from access to the press in digital format and to authoritative information sources, to blogging, wikis and other user-generated content; from educational and research purposes to online gaming, downloading music and streaming videos; from accessing local government services to checking the balance of a bank account.

Data from both developed and developing economies (Table 5.5) show that communication remains the most popular Internet activity in many countries, and that other activities such as e-government, e-banking and commercial transactions are less common. For many users of all ages, men and women alike, the most prevalent activity is sending and receiving e-mails. In countries such as New Zealand and Chile, over 90 per cent of Internet users use e-mail, and in the European Union the average is also very high, at over 88 per cent.

While a large proportion of Internet users also exploit the Internet for education and learning 


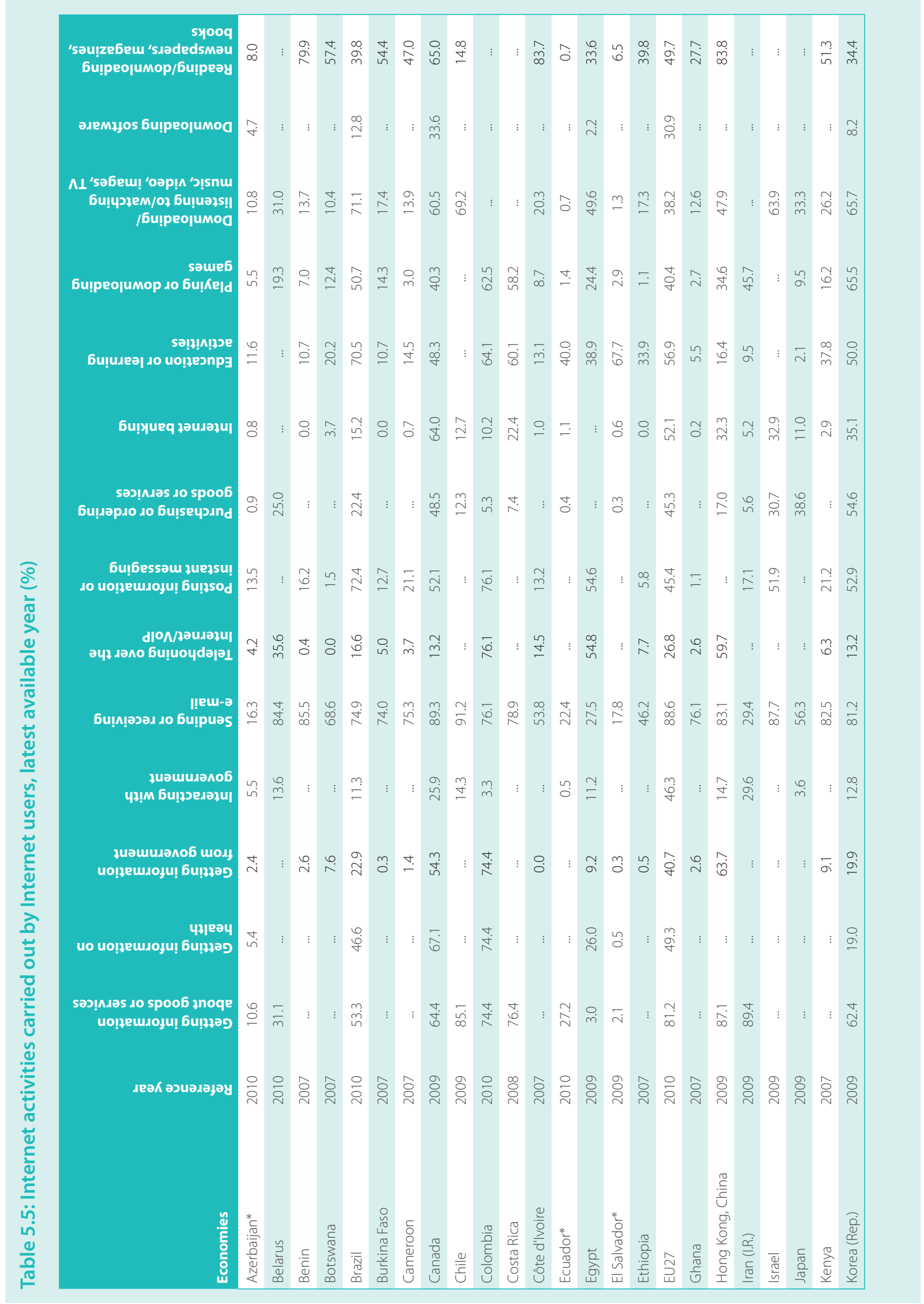




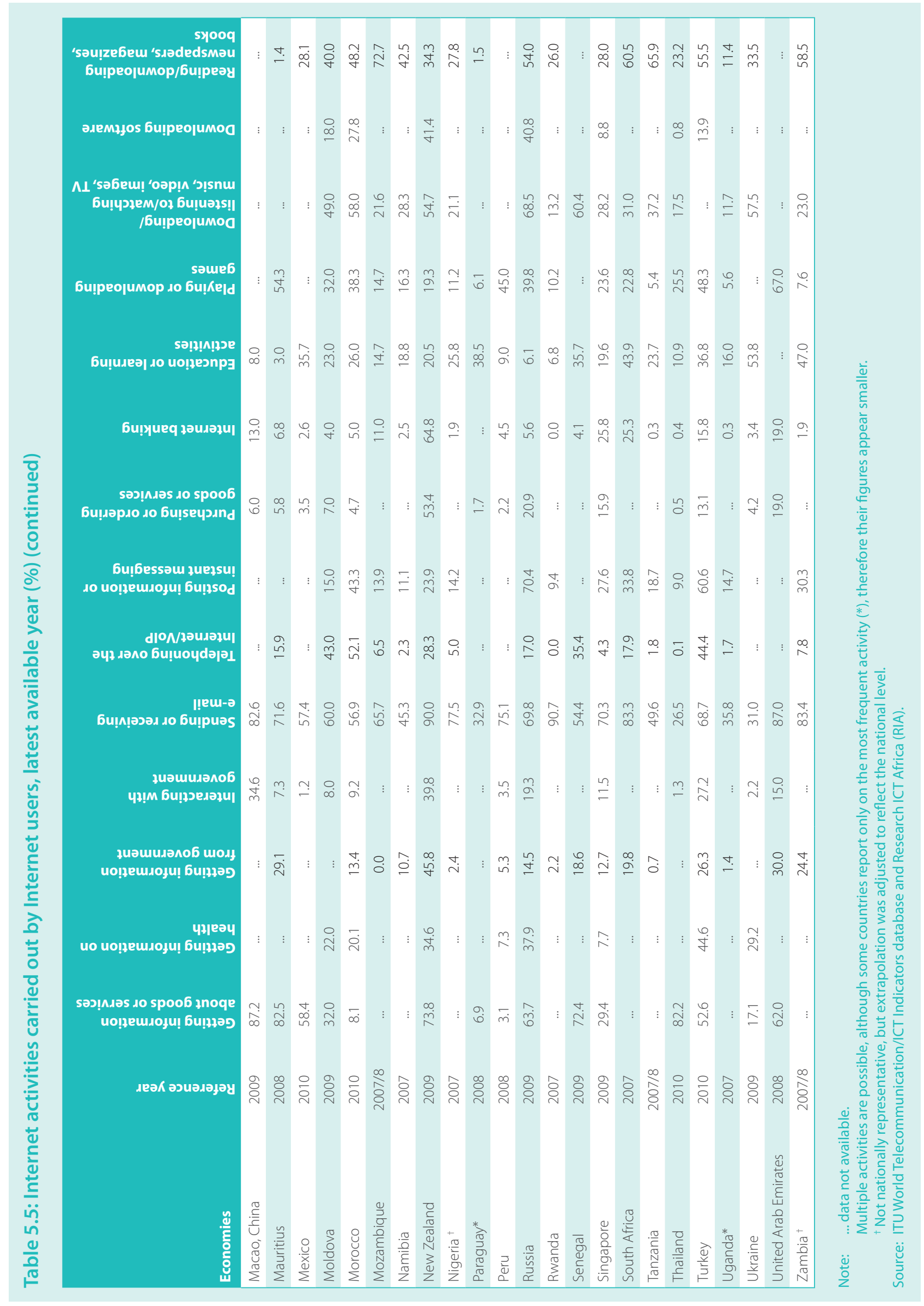


purposes, there are considerable differences across countries. For example, available data from some Latin American countries suggest that around 50 per cent of people using the Internet were going online for - among others - educational purposes in the period of 2009-2010. This can be related to the fact that many users in Latin America are young and are students. The European Union average is also high, at over 52 per cent in 2010, and the figure is similarly high in Ukraine, where over 53 per cent of Internet users accessed the Internet for educational or learning activities in 2009. In Africa, on the other hand, only about 25 per cent of all Internet users employed the Internet for educational purposes in $2007 / 2008$. This may be attributable to a variety of reasons, such as for instance scarcity of suitable content (e.g. in local language, and adapted to each educational level, to people's computer skills, to the type and quality of the connection, etc.) or insufficient information on the educational resources that are available. Improvements in these areas may significantly contribute to extending the benefits of Internet as an e-learning tool to more people in Africa.

A further popular activity in most countries is obtaining information and accessing news, with over 40 per cent of Internet users in many countries across all regions using the Internet for these purposes. Posting information and instant messaging, such as through social media sites, social networking and other usercreated content, is becoming increasingly relevant. In countries for which recent (2009 and 2010) data are available, the proportion of Internet users engaging in these activities has reached very high levels. In Colombia, Brazil and the Russian Federation, for example, over 70 per cent of users reported using the Internet for these activities. The next section examines in detail the relevance of social networking and user-generated content for bringing more people in developing countries online.

An interesting finding from RIA's survey is that almost 25 per cent of individuals using the Internet (in 17 African countries) used it to get information for a friend or family member. This highlights the fact that the Internet benefits not only those who are actually accessing and using it, but others, too, especially in rural areas, where 30 per cent of users employed it for these purposes, as against 20 per cent in urban areas.

The popularity of the Internet for entertainment purposes varies between countries. In countries from the
European Union and from Latin America for which data are available, around 40 per cent of Internet users accessed the Internet to play or download games, as compared with 13 per cent of Internet users in Africa. In the United Arab Emirates and the Republic of Korea, 67 and 65 per cent, respectively, of Internet users play or download games. While these variations may in part be explained by cultural differences between countries, the type of activities that Internet users can carry out is also greatly influenced by the type and quality of the Internet connection (see Chapter 4).

For instance, if e-mailing is by far the most popular Internet activity in Africa, this is probably because it may be comfortably used even with limited bandwidth and low speeds. It must not be forgotten that some Internet users access the Internet via secondgeneration mobile networks, which makes using more data-intensive applications impossible. This may also be one explanatory factor (among others) for the low degree of use of e-government services among African Internet users, because this type of application requires a minimum capacity and speed to offer a good user experience. These conclusions are supported by the differences between rural and urban Internet users, since rural areas usually have lower Internet speeds. Indeed, available data from 2007 and 2008 show that African rural Internet users played online games less than urban Internet users, and used e-banking and e-government services less, too.

However, there are other relevant factors determining the uptake of Internet activities beyond just quality and speed of the user connection. One of these is service availability and the extent to which services are adapted to the user. For example, if only very few Internet users in Africa use the Internet to interact with the government, this may also be because of a lack of relevant e-government services matching the skills and needs of Internet users in each country.

Finally, high levels of online purchasing and Internet banking activities are confined primarily to citizens in developed economies. In New Zealand, Canada and the European Union, for example, the majority of Internet users engage in Internet banking, as compared with much lower levels in most developing countries. Several developing countries lack both a widely established banking system and an outreaching Internet access network, and people's income levels in many developing countries are insufficient for them to have a credit card. 


\section{Social networks}

An important trend that has driven Internet access over the last few years is the growth of social media and networking sites. These provide innovative ways of conveying information, and of reaching a wide audience. They allow people to expand social and business contacts, and facilitate the communication and sharing of content among users, including photos, videos and music. Young people have played a major role in the success of social media and networking sites. Data also suggest that social networking sites have become a key driver of Internet use (see for instance Box 5.1). In some countries over 70 per cent of Internet users are engaging in social networking (specifically posting information and instant messaging) (see Table 5.5).

Livingston $e t$ al. (2011), for example, conducted a faceto-face survey of 25000 young Internet users (between the ages of nine and 16) and their parents in 25 European countries, and found that social networking was the most popular activity among children. Some 38 per cent of children between nine and 12 years old have a social network profile, and 77 per cent of children between 13 and 16 years old.

A comparison of data from Facebook, one of the most popular networking sites in the world, indicates that in some developing countries there are as many Facebook users as Internet users. The comparison between Internet users and Facebook users must however be interpreted with caution, since Internet users are individuals, while Facebook accounts may belong to individuals, companies, etc. (see Box 5.2). Table 5.6 shows a list of selected countries ordered by total number of Facebook accounts, and highlights how they rank in terms of absolute number of Facebook accounts in comparison with other countries

\section{Box 5.1: Social networking as a key driver for bridging the Internet divide in Namibia}

A nationally representative survey conducted by Research ICT Africa in cooperation with the Communications Regulatory Authority of Namibia (CRAN) from June to August 2011 revealed that 81 per cent of Internet users subscribe to a social network application. The survey, which also covered mobile-phone ownership and use, shows that 17 per cent of mobile-phone owners use their mobiles for accessing social networking applications such as Facebook, Twitter, Mixit, etc. Overall, about 23 per cent of mobile-phone owners used their mobiles to browse the Internet. These results suggest that increasing numbers of people are using mobile phones for social networking. Table Box 5.1 shows some additional results of the survey.

The increasing reliance on the mobile phone and the growth in the use of applications that lend themselves to the mobile platform - such as social media - indicate that the mobile phone is a key entry point for Internet adoption in Namibia. The mobile phone is thus not only narrowing the voice gap in Namibia, but is being used to reduce the differences in Internet usage.

Table Box 5.1: Internet and mobile-phone usage in Namibia, 2011 (\%)

\begin{tabular}{|l|l|}
\hline Internet usage & 13.4 \\
\hline Percentage of individuals aged 15 years or older using the Internet & 62.7 \\
\hline Share of Internet users who used the Internet for the first time on a computer or laptop & 37.3 \\
\hline Share of Internet users who used the Internet for the first time on a mobile phone & 80.7 \\
\hline Share of Internet users who are signed up for a social network & 55.7 \\
\hline Share of Internet users who access the Internet using a mobile phone & 56.1 \\
\hline Mobile-phone usage & 22.7 \\
\hline Percentage of individuals aged 15 years or older owning a mobile phone & 17.3 \\
\hline Share of mobile-phone owners who use their mobile for browsing the Internet & \\
\hline Share of mobile-phone owners who use their mobile for accessing social networking applications such as & \\
\hline
\end{tabular}




\section{Box 5.2: How accurate are Facebook user statistics?}

Statistics on the number of Facebook users are widely cited, especially given their impressive growth rates over the past few years, but little is published about how those statistics are compiled or what they actually represent. For example, a comparison of Facebook user data and Internet user data for some developing countries show there to be as many Facebook users as Internet users, whereas it can reasonably be assumed that not every Internet user is also on Facebook. How then can these numbers be explained?

Country-level Internet user statistics are generally collected through official representative national household surveys and reflect the number of individual people in a given country having used the Internet during a certain reference period (for example, the past three/six/twelve months). The survey is often limited to a certain age group (see Annex 3) and does not include Internet use by enterprises, governments or other organizations.

Facebook user statistics for individual countries, on the other hand, are published by several online businesses ${ }^{19}$ which compile the data from Facebook's advertisement page, ${ }_{1}^{20}$ where numbers are to be found on the potential target audience (i.e. users) by country. According to Facebook's Help Centre, "Facebook determines the location of a user based on IP (Internet Protocol) addresses, which can help identify the country or city where a user is physically located." ${ }^{21}$ Based on this information, Facebook"users" should perhaps be called "accounts", given that a single user could be operating several accounts. In addition to a personal account, a user can create an account for a school, business, organization or other group using a different e-mail address (so that there could, in theory, be more Facebook users than people within a country). In addition, while IP addresses make a good proxy indicator for how many accounts exist in a given country, they are not necessarily accurate, given that Facebook users could be accessing their Facebook accounts through servers located in countries other than their home country (for example, in cases where Facebook access might be restricted or where users are travelling). Finally, the question of how "active" the account should be in order to be counted needs to be addressed. How many "dead" accounts are there and are they included in the user statistics?

Until answers to some of these questions are known, Facebook country-level "user"statistics should be treated with caution, particularly when making comparisons with Internet user statistics.
(Facebook ranking). Some developing countries with large populations, such as Indonesia, India and Mexico, are among the top countries in the world in terms of Facebook accounts. In China, the leading social network is Renren, which by end June 2011 had some 124 million activated users. ${ }^{22}$ In Brazil, the leading social network is Orkut. According to a survey by IBOPE, Nielsen Online (2010), as at August 2010 more than 70 per cent of Internet users in the country were visiting Orkut's website at least once a month, and overall 36 million Brazilians were accessing social network sites. It can be thus concluded that social networks are gaining momentum in several developing countries, too. Taking into account that in the developing world only a small proportion of the population has access to the Internet, the popularity of social networks has the potential to become a major incentive for people to go online.

Some social networks such as Renren and Facebook have launched specific platforms to optimize user experience in cases where connection capacity and speed are limited, and to adapt navigation to $2 \mathrm{G}$ mobile access. For instance, as early as December 2009 Renren launched an open platform for mobiles, which allowed access via a WAP browser, with streamlined navigation design. ${ }^{23}$ In May 2010, Facebook launched Facebook Zero, which allows users to access a mobile version of Facebook, but with data-intensive applications, such as pictures, placed an additional click away. Facebook has also collaborated with operators to make sure that there are no data charges associated with Facebook Zero. Pictures, video and audio can still be accessed, but at that point standard data rates become applicable. A notification page appears when users want to access video or pictures telling them that data charges will apply. Innovations such as Renren's mobile platform and Facebook Zero have the potential to foster Internet usage in countries where high-capacity Internet access is limited, and therefore usage is lagging behind.

Chart 5.11 shows that younger generations tend to be more online in all countries, both in the developed and 


\begin{tabular}{|c|c|c|}
\hline $\begin{array}{l}\text { Facebook } \\
\text { ranking }\end{array}$ & Country & $\begin{array}{l}\text { Facebook } \\
\text { accounts } \\
\text { August } 2011\end{array}$ \\
\hline 1 & United States & $154^{\prime} 040^{\prime} 460$ \\
\hline 2 & Indonesia & $39^{\prime} 568^{\prime} 620$ \\
\hline 3 & India & $33^{\prime} 587^{\prime} 640$ \\
\hline 6 & Mexico & $28^{\prime} 150 ' 240$ \\
\hline 7 & Philippines & $26^{\prime} 056^{\prime} 340$ \\
\hline 8 & Brazil & 24'921'480 \\
\hline 14 & Colombia & $15^{\prime} 166^{\prime} 260$ \\
\hline 16 & Thailand & $11^{\prime} 698 ' 220$ \\
\hline 22 & Egypt & 8'506'060 \\
\hline 27 & Sweden & $4^{\prime} 379^{\prime} 680$ \\
\hline 29 & South Africa & 4'281'100 \\
\hline 37 & Nigeria & $3^{\prime} 675^{\prime} 960$ \\
\hline 39 & Romania & $3^{\prime} 562^{\prime} 400$ \\
\hline 47 & Tunisia & $2^{\prime} 641^{\prime} 060$ \\
\hline 71 & Kenya & 1'172'540 \\
\hline 89 & Senegal & $572^{\prime} 500$ \\
\hline 99 & Tanzania & $336 ' 980$ \\
\hline 101 & Uganda & $314 ' 900$ \\
\hline 125 & Zambia & $151 ' 900$ \\
\hline 127 & Botswana & $133^{\prime} 200$ \\
\hline 130 & Namibia & $122^{\prime} 340$ \\
\hline
\end{tabular}

in the developing world. Indeed, younger people are more curious, more interested and more active in some of the most popular Internet activities, such as those related to personal communications, and social networks. The latter have thus become major drivers of Internet adoption, and can be increasingly so in the future, especially in developing countries. Some 47 per cent of the population in developing countries are under 25 years old, while in developed countries only 28 per cent of the total population are below that age. ${ }^{24}$ This represents more than 2.5 billion people under 25 in developing countries, suggesting enormous potential in terms of Internet adoption through the younger generations.

\subsection{Conclusions}

While the voice communication gap has largely been closed through affordable prepaid mobile-telephone services, the key ICT challenge today is to bring more people online, especially from developing countries.
This chapter has shown that the Internet user divide is influenced by gender, education, income and age, and that there are major differences between urban and rural areas. It has also demonstrated that the barriers to Internet use are not necessarily related to infrastructure and access: there is remarkably little difference in terms of usage among highly educated, high-income individuals across the developing and developed world.

The success of prepaid mobile telephony can be replicated. Mobile Internet access and more affordable prepaid Internet will allow less affluent people to gain access to the Internet. They can recharge airtime to use the Internet whenever they have money available, and use a device for Internet access with which they are already familiar. Mobile phones are less expensive and easier to operate than computers. There is a clear trend towards cheaper smartphones, and this will have an impact on mobile Internet use. However, there is still substantial progress to be made in reducing barriers to prepaid mobile broadband, through a range of measures such as lowering cost, reducing taxation and improving access.

There are some gender-related differences in Internet use between countries, but the ICT gender divide seems to depend largely on factors not related to ICT, and so the gender divide can only be addressed by measures aimed at ensuring equal opportunities in terms of income generation and education.

In developing countries, public access facilities, in particular commercially run establishments, play an important role in reducing the Internet access and usage divide in the short to medium term, in the absence of affordable home access. The success of commercially run cybercafés highlights the need to support innovative commercial business models for public access, even if in the long term one may expect to see an increase in Internet access at home, and through personal devices. Public access points, such as cybercafés, will remain critical for countries at the initial stages of Internet uptake, and particularly for rural users. More affordable personal Internet access through mobile phones (and other wireless devices) is likely to reduce the importance of public facilities over time. In the absence of alternatives, however, public access points are often the only means of finding and obtaining information.

There are significant differences in Internet use between urban and rural areas, with fewer rural inhabitants using the Internet. Urban/rural differences are closely linked with 
Chart 5.11: Proportion of individuals* using the Internet, by age group, latest available year (2009/2010)

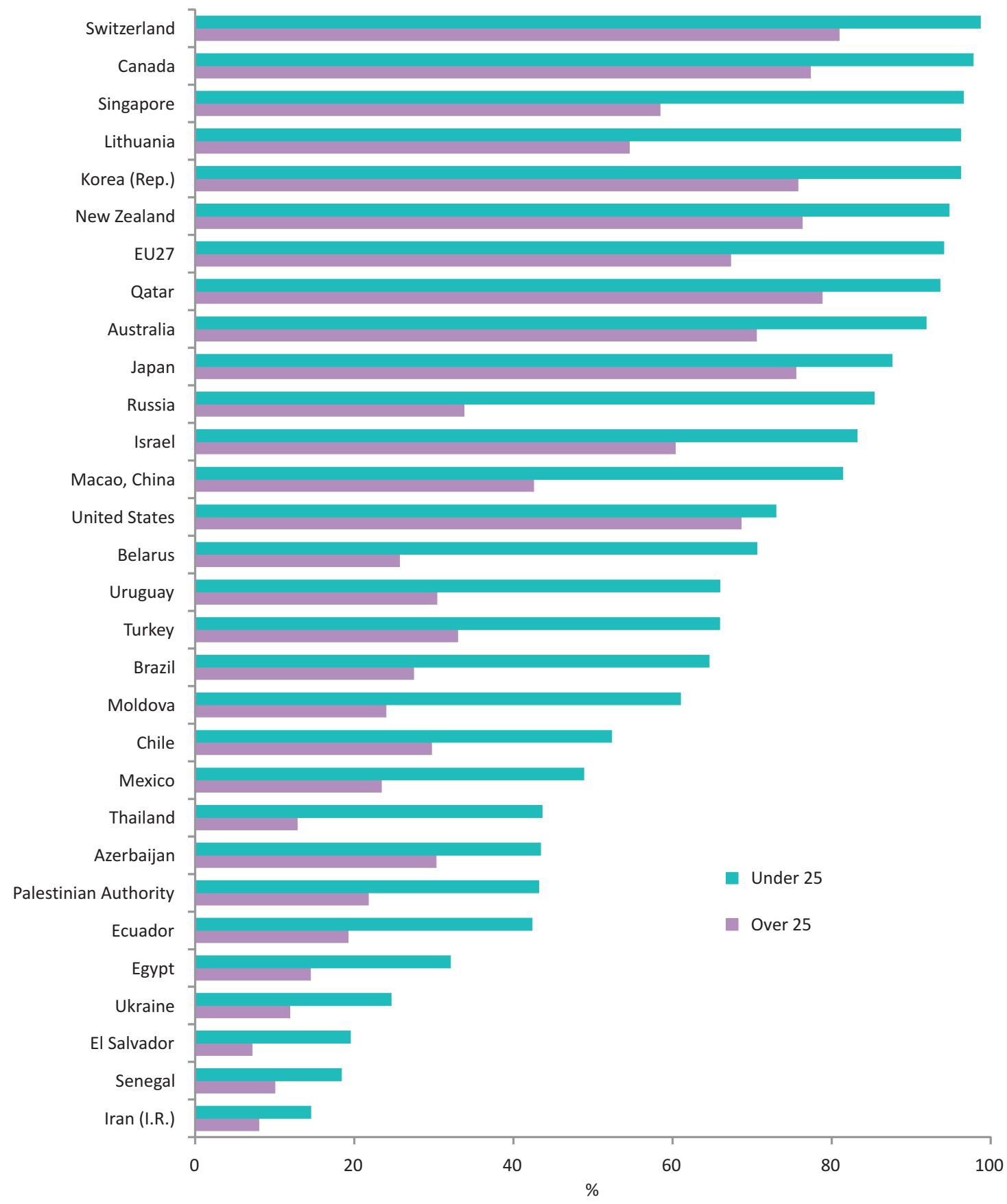

Note: $\quad{ }^{*}$ Minimum and maximum age varies across countries, see Annex Table 3.1.

Source: ITU World Telecommunication/ICT Indicators database

differences in education and income, but they are also attributable to infrastructure and service limitations in rural areas. This is indeed an area for improvement, which could greatly benefit from wireless-broadband technologies.
Most people use the Internet for communication and entertainment purposes, and social networking sites have become a key driver for Internet uptake, particularly for young people, suggesting that relevant 
content is an important factor in bringing more people online. Young people are not only drivers of Internet usage; they also represent a relatively large proportion of the world's population. Developing countries have a large potential Internet user base that could be brought online relatively easily, particularly by connecting schools and other educational institutions. 


\section{Endnotes}

1 For example, UNCTAD collects statistics on the use of ICTs by businesses and on the ICT sector. For more information, see: measuring-ict.unctad.org.

2 ITU has acknowledged the potential of connecting schools in developing countries, and is promoting ICT development for communities through the "Connect a School, Connect a Community" Initiative. More information is available at: http://www.itu.int/ITU-D/sis/Connect_a_school/index.html.

3 For more information on the Partnership on Measuring ICT for Development and its members, see: http://www.itu.int/ITU-D/ict/partnership/index.html and http://new.unctad.org/default 600.aspx.

4 Research ICT Africa is a network of researchers from African countries which conducts ICT studies to support evidence-based and informed policy-making. For more information, see http://www.researchictafrica.net/home.php.

5 According to Partnership on Measuring ICT for Development (2010), a computer refers to a desktop or a laptop computer. It does not include equipment with some embedded computing abilities such as mobile-cellular phones, personal digital assistants (PDAs) or TV sets.

6 Eurostat stopped collecting data on mobile use in 2008.

7 In Kenya, 99 per cent of Internet subscriptions are mobile, including both narrowband (GPRS/EDGE) and 3G mobile. Source: Communications Commission of Kenya (2011).

8 Calculations based on available data from households surveys, for people above 25 years old.

9 The Gini coefficient measures inequality in the distribution of income with a value of 0 expressing total equality and a value of 100 total inequality. Income is hence more equally distributed in Norway than in El Salvador. For Gini values in 2010, see http://hdr.undp.org/en/media/HDR 2010 EN Tables reprint.pdf.

10 ICT development is a major cross-cutting feature of Rwanda's Vision 2020, the country's framework for economic and social development, and for the conversion to a knowledge-based economy. Moreover, the country has taken part in the One-Laptop-per-Child project, see: http://www.connectaschool.org/en/schools/connectivity/devices/section_5.6/case\%20studies/Rwanda.

11 A definition of gross enrolment ratio is provided in Annex 1.

12 For a in-depth analysis of the relation between income and Internet use in Latin America, see Navarro (2011) and Grazzi (2011).

13 Plans for expanding the Ceibal project to private schools, and to increase the availability of Internet access points for connecting the laptops, are also ongoing. More information can be found at: www.ceibal.org.uy.

14 According to UNIFEM, women often earn much less than men, and the average wage gap between women and men in 2008 was 17 per cent. See: http://www.unifem.org/gender issues/women poverty economics/.

152008 data from the United States showed that even with equal education and experience, women only earned 81 per cent of what men earned. See: http://www.time.com/time/nation/article/0,8599,1983185,00.html\#ixzz1UjLJohmE.

16 See Milek et al. (2011) for a study on 17 African countries, Hilbert (2011)for a study including Latin American and African countries and Navarro and Sanchez (2011) for a study on 6 Latin American countries.

17 See Milek et al. (2011) for a more detailed discussion.

18 For more information, see http://www.ict.go.ke/index.php/digitalinclusion/pasha/football.

19 See for example http://www.socialbakers.com/; http://statistics.allfacebook.com/pages; http://www.insidefacebook.com/.

20 http://www.facebook.com/advertising/.

21 http://www.facebook.com/help/?faq $=133609753380850$.

22 See http://ir.renren-inc.com/phoenix.zhtml?c=244796\&p=irol-homeProfile.

23 See http://renren-inc.com/en/news/32.html.

24 United Nations, Department of Economic and Social Affairs, Population Division (2011). World Population Prospects: The 2010 Revision, CD-ROM Edition. 


\section{List of references}

Agence Nationale de Réglementation des Télécommunications du Maroc (2011), 'Tableau de Bord Marché Internet au Maroc', March 2011. Available at: http://www.anrt.net.ma/fr/admin/download/upload/file fr2164.pdf.

BEREC (Body of European Regulators for Electronic Communications) (2010), 'International Mobile Roaming BEREC Report', December 2010. Available at: http://www.erg.eu.int/doc/berec/bor_10_58.pdf.

BEREC (2011), 'Next Generation Access - Collection of factual information and new issues of NGA roll-out', BoR (11) 06b, February 2011. Available at: http://erg.eu.int/doc/berec/bor 11 06b.pdf.

Booz \& Company (2009), 'Digital Highways. The Role of Government In 21st-Century Infrastructure'. Available at: http://www.booz.com/media/uploads/Digital Highways Role of Government.pdf.

Communications Commission of Kenya (2010), 'Annual Report'. Available at: http://www.cck.go.ke/resc/publications/annual_reports/Annual_Report2010.pdf.

Communications Commission of Kenya (2011), 'Quarterly Sector Statistics Report'. Available at: http://www.cck.go.ke/resc/statistics/SECTOR STATISTICS REPORT Q2 2010-11 x2x x3x x2x.pdf.

Czech Statistical Office (2011), 'Information Society in Figures 2011'. Available at: http://www.czso.cz/csu/2011edicniplan.nsf/engp/9706-11.

European Commission (2009a), 'Regulation (EC) No 544/2009 of the European Parliament and of the Council of 18 June 2009 amending Regulation (EC) No 717/2007 on roaming on public mobile telephone networks within the Community and Directive 2002/21/EC on a common regulatory framework for electronic communications networks and services', June 2009. Available at : http://www.eur-lex.europa.eu/LexUriServ/LexUriServ.do?uri=OJ:L:2009:167:0012:0023:EN:PDF.

European Commission (2009b), 'Directive 2009/140/EC of the European Parliament and of The Council of 25 November 2009 amending Directives 2002/21/EC on a common regulatory framework for electronic communications networks and services, 2002/19/EC on access to, and interconnection of, electronic communications networks and associated facilities, and 2002/20/EC on the authorisation of electronic communications networks and services', November 2009. Available at: http://eur-lex.europa.eu/LexUriServ/LexUriServ.do?uri=OJ:L:2009:337:0037:0069:EN:PDF.

European Commission (2010), 'Commission Recommendation on regulated access to Next Generation Access Networks (NGA)', 2010/572/EU, September 2010. Available at: http://eur-lex.europa.eu/LexUriServ/LexUriServ.do?uri=OJ:L:2010:251:0035:0048:EN:PDF.

European Commission (2011a), 'Proposal for a regulation of the European Parliament and of the Council on roaming on public mobile communications networks within the Union', COM(2011) 402 final, July 2011. Available at: http://ec.europa.eu/information_society/activities/roaming/docs/roaming recast11.pdf.

European Commission (2011b), 'Digital Agenda Scoreboard 2011. Portugal. Main market developments', May 2011. Available at: http://ec.europa.eu/information_society/digital-agenda/scoreboard/docs/regulatory/ pt reg dev 2011.pdf.pdf. 
Federal Communications Commission (2010), 'Sixth Broadband Deployment Report', July 2010. Available at: http://transition.fcc.gov/Daily Releases/Daily Business/2010/db0720/FCC-10-129A1.pdf.

Government of Republic of Moldova (2005), 'National Strategy on Building Information Society "e-Moldova”", Chisinau, March 2005. Available at: http://en.e-moldova.md/Sites/emoldova en/Uploads/ strat_ENG.36370AF841D74D74B3969D0FA3FBE6D2.pdf.

Grazzi (2011), 'Patterns of Internet use', in Balboni, M., Rovira, S., Vergara, S. (Eds) ICT in Latin America. A microdata analysis, ECLAC, Santiago. Available at: http://www.eclac.cl/publicaciones/xml/7/43847/R.2172ICTinLA.pdf.

Gulvady, S. (2009), 'Blogging - Redefining Global Modern Journalism: An Omani Perspective', Global Media Journal, Vol. 8, Issue 14, Spring 2009, Article No. 13. Available at: http://lass.calumet.purdue.edu/cca/gmj/sp09/gmj-sp09-gulvady.htm\# edn14.

Hilbert, M. (2011), 'Digital gender divide or technologically empowered women in developing countries? A typical case of lies, damned lies, and statistics', Women's Studies International Forum, 34(5), 479-489.

IBOPE, Nielsen Online (2010), 'Redes de Amigos', Proxxima, October 2010, page 94.

Katz, R.L., E. Flores-Roux, and J. Mariscal (2010), 'The Impact of Taxation on the Development of the Mobile Broadband Sector', GSMA. Available at: http://www.gsmamobilebroadband.com/upload/resources/files/15072010174953.pdf.

Korea Communications Commission (2010), 'Annual Report 2010’, Seoul.

Information Technology Authority, Sultanate of Oman (2008), 'e-Oman'. Available at: http://www.ita.gov.om/ITAPortal/Data/DocLibrary/FID2010921144034803/ITA e.oman eng new.pdf.

ITU (2003), Plan of Action', World Summit on the Information Society outcome documents, Geneva. Available at: http://www.itu.int/wsis/docs/geneva/official/poa.html.

ITU (2009), 'Measuring the Information Society - The ICT Development Index 2009', ITU, Geneva.

ITU (2010a), 'World Telecommunication/ICT Development Report 2010: Monitoring the WSIS Targets,

A mid-term review', ITU, Geneva. Available at: http://www.itu.int/ITU-D/ict/publications/wtdr_10/material/WTDR2010_e v1.pdf.

ITU (2010b), 'Measuring the Information Society 2010’, ITU, Geneva.

ITU (2011), 'The impact of broadband on the economy: research to date and policy issues ', Trends in Telecommunication Reform 2010-2011: Enabling Tomorrow's Digital World, ITU, Geneva.

Livingstone, S., K. Ólafsson, and E. Staksrud (2011), 'Social Networking, Age and Privacy'. Available at: http://www2.lse.ac.uk/media@lse/research/EUKidsOnline/ShortSNS.pdf.

McKinsey (2009), 'Mobile broadband for the masses', McKinsey \& Company, Louvain-la-Neuve.

Milek, A., C. Stork, and A. Gillwald (2011), 'Engendering communication: a perspective on ICT access and usage in Africa', Info, Emerald Group Publishing Limited, 13(3), pp.125-141.

Ministry of Education, Sultanate of Oman (2008), 'ICT and Education in the Sultanate of Oman', Ministry of Education, Sultanate of Oman, 2008. Available at: http://www.moe.gov.om/portal/SiteBuilder/Sites/EPS/ Arabic/MOE/Newest/ICT\%20and\%20education.pdf.

Ministry of Regional Development of Poland and European Commission (2007), 'Operational Programme Development of Eastern Poland 2007 - 2013. National Strategic Development Framework 2007 - 2013’, Warsaw, October 2007. Available at: http://www.mrr.gov.pl/english/european funds 20072013 / european funds 2007 2013/PORPW/Documents/PORPW eng final.pdf. 
Navarro (2011), 'Impact of Internet use on individual earnings', in Balboni, M., Rovira, S., Vergara, S. (Eds) ICT in Latin America. A microdata analysis, ECLAC, Santiago. Available at: http://www.eclac.cl/publicaciones/xml/7/43847/R.2172ICTinLA.pdf.

Navarro, L., and M. Sanchez (2011), 'Gender differences in Internet use', in Balboni, M., Rovira, S., Vergara, S. (Eds), ICT in Latin America. A microdata analysis, ECLAC, Santiago. Available at: http://www.eclac.cl/publicaciones/xml/7/43847/R.2172ICTinLA.pdf.

OECD, European Commission Joint Research Centre (2008), 'Handbook on Constructing Composite Indicators: Methodology and User Guide’, OECD, Paris.

OECD (2010a), 'Revision of the methodology for constructing telecommunication price basket. Working Party on Communication Infrastructure and Services Policy', OECD, Paris. Available at: http://www.teligen.com/publications/oecd.pdf.

OECD (2010b), 'International Mobile Data Roaming', DSTI/ICCP/CISP(2010)12/FINAL, May 2011, Directorate for Science, Technology and Industry, OECD, Paris. Available at: http://www.oecd.org/dataoecd/57/62/48127892.pdf.

OECD (2010c), 'Wireless Broadband Indicator Methodology', March 2010, OECD Digital Economy Papers, No. 169, OECD, Paris. Available at: http://www.oecd-ilibrary.org/science-and-technology/wirelessbroadband-indicator-methodology $5 \mathrm{kmh} 7 \mathrm{~b} 6 \mathrm{sw} 2 \mathrm{~d} 4-\mathrm{en}$.

OFCOM (2011), 'Measuring Mobile Broadband in the UK: performance delivered to PCs via dongles/ datacards', May 2011. Available at: http://stakeholders.ofcom.org.uk/binaries/research/telecoms-research/ bbspeeds2010/Mobile BB performance.pdf.

Onyeije Consulting LLC (2011), 'Solving the capacity crunch. Options for Enhancing Data Capacity on Wireless Networks', Onyeije, Arlington, VA.

Partnership on Measuring ICT for Development (2010), 'Core ICT indicators', Geneva, 2010.

Parliament of Australia (2011), 'National Broadband Network Companies Bill 2010 [Provisions]; and Telecommunications Legislation Amendment (National Broadband Network Measures-Access Arrangements) Bill 2010 [Provisions]', Senate Printing Unit, Canberra, March 2011. Available at: http://www.aph.gov.au/senate/committee/ec ctte/nbn bills/report/report.pdf.

Point Topic (2011), 'World Broadband Statistics: Short Report. Q42010’. Available at: http://point-topic.com/dslanalysis.php.

Post and Telecom Administration in Iceland (2011), 'Statistics on the Icelandic electronic communications market 2010', May 2011. Available at: http://www.pfs.is/upload/files/T\% $\% \mathrm{C} \% \mathrm{~B} 6 \mathrm{lfr} \% \mathrm{C} 3 \% \mathrm{~A} 6 \% \mathrm{C} 3 \% \mathrm{~B} 0 \mathrm{isk} \%$ C3\%BDrsla PFS 2008\%20-\%202010.pdf.

Presidencia de la Nación Argentina (2010), 'Decreto 1552/2010. Créase el Plan Nacional de Telecomunicaciones "Argentina Conectada"”, Boletín Oficial No. 32.016, Buenos Aires, October, 2010. Available at: http://www.argentinaconectada.gob.ar//adjuntos/139/documentos/000/010/0000010892.pdf.

Que, J., V. Hurtado, G. Chawla, and R. Ferreira (2010), 'The rise of Saudi Arabian telecoms: Unrivalled promise and opportunity in a vibrant market', The Delta Perspective, Delta Partners, September 2010. Available at: http://www.deltapartnersgroup.com/our insights/whitepapers/the-rise-of-saudi-telecoms-unrivalledpromise-and-opportunity-in-a-vibrant-market.

Stork, C., and L. Lumingu (2010), 'Measuring competitive pressure using OECD Price Benchmarking Baskets', Available at: http://www.acorn-redecom.org/presentation/acornredecom2010presentationStorkRoom2Session3.pdf.

Swiss Federal Communications Commission (2011), 'Activity Report ComCom 2010', ComCom, Berne. 
Telecommunications Regulatory Authority of Bahrain (2011), 'Broadband Analysis Report', April 2011. Available at: http://www.tra.org.bh/en/marketQuality.asp.

Telecommunications Regulatory Authority of the United Arab Emirates (2010), 'ICT in the UAE Household Survey', 2010. Available at: http://www.tra.gov.ae/download.php?filename=ICT Survey\%20English\%202010.pdf.

Telecom Regulatory Authority of India (2011), 'TRAI's recommendations on "National Broadband Plan", Letter No. 341-18/2011-CA, New Delhi, May 2011. Available at: http://www.trai.gov.in/WriteReadData/ trai/upload/Recommendations/135/Reply DOT Broadband modified.pdf.

World Bank (2009), 'Information and Communication for Development IC4D: Extending reach and increasing impact', Available at: http://go.worldbank.org/DMY979SNP0. 


\section{Annex 1. ICT Development Index (IDI) methodology}

This Annex outlines the methodology used to compute the IDI, and provides more details on various steps involved, such as the indicators included in the index and their definition, the imputation of missing values, the normalization procedure, the weights applied to the indicators and sub-indices, and the results of the sensitivity analysis.

\section{Indicators included in the IDI}

The selection of indicators was based on certain criteria, including relevance for the index objectives, data availability and the results of various statistical analyses such as the principal component analysis (PCA). ${ }^{1}$ The following 11 indicators are included in the IDI (grouped by the three sub-indices: access, use and skills).

\section{a) ICT infrastructure and access indicators}

Indicators included in this group provide an indication of the available ICT infrastructure and individuals' access to basic ICTs. Data for all of these indicators are collected by ITU.

\section{Fixed-telephone subscriptions per 100 inhabitants}

Fixed-telephone subscriptions refers to the sum of active analogue fixed-telephone lines, ISDN voice channel equivalents, fixed wireless local loop (WLL) connections, fixed public payphones and voice-over-broadband (VoB) subscriptions. It includes all accesses over fixed infrastructure supporting voice telephony using copper wire, voice services using Internet Protocol (IP) delivered over fixed (wired)-broadband infrastructure (e.g. DSL, fibre optic), and voice services provided over coaxial-cable television networks (cable modem). It also includes fixed wireless local loop (WLL) connections, which are defined as services provided by licensed fixedline telephone operators that provide last-mile access to the subscriber using radio technology, when the call is then routed over a fixed-line telephone network (and not a mobile-cellular network). In the case of $\mathrm{VoB}$, it refers to subscriptions that offer the ability to place and receive calls at any time and do not require a computer.

\section{Mobile-cellular telephone subscriptions per 100 inhabitants}

Mobile-cellular telephone subscriptions refers to the number of subscriptions to a public mobile-telephone service which provides access to the public switched telephone network (PSTN) using cellular technology. It includes both postpaid subscriptions and prepaid SIM cards that have been active during the past three months. It covers both analogue and digital cellular systems and all mobile-cellular subscriptions that offer voice communications. It excludes subscriptions via data cards or USB modems, subscriptions to public mobile data services, private trunked mobile radio, telepoint, radio paging and telemetry services.

Given the rapid growth in the number of mobile-cellular subscriptions, it would be useful to distinguish between the number of mobile subscriptions and the number of individuals using a mobile phone. Although the latter indicator would be more appropriate for inclusion in the IDI, only a limited number of countries currently collect this information through household surveys. ${ }^{2}$ As more data become available, the number of mobile-phone users should eventually replace the number of mobile subscriptions in the index. 


\section{International Internet bandwidth (bit/s) per Internet user}

International Internet bandwidth refers to the sum of capacity of all Internet exchanges that backbone operators provide to carry Internet traffic. It is measured in bits per second per Internet user. The data compiled by ITU from responses received from countries through its annual questionnaire were supplemented with data from ITU research.

\section{Percentage of households with a computer}

A computer refers to a desktop or a laptop computer. It does not include equipment with some embedded computing capabilities, such as mobile-cellular phones, personal digital assistants or TV sets.

\section{Percentage of households with Internet access at home}

The Internet is a worldwide public computer network. It provides access to a number of communication services, including the World Wide Web, and carries e-mail, news, entertainment and data files, irrespective of the device used (not assumed to be only a computer - it may also be a mobile phone, games machine, digital TV, etc.). Access can be via a fixed or mobile network.

There are certain data limits to this indicator, insofar as estimates have to be calculated for many developing countries which are not yet collecting ICT household statistics (see below on missing data). Over time, as more data become available, the quality of the indicator will improve.

\section{b) ICT use indicators}

The indicators included in this group capture ICT intensity and usage. Data for all of these indicators are collected by ITU.

\section{Percentage of individuals using the Internet}

The percentage of individuals using the Internet indicator is based on results from national household surveys. Today, most developed and larger developing countries are collecting data on the number of Internet users through official household surveys. Data are either provided directly to ITU by the national statistical offices (NSO), or ITU carries out the necessary research to obtain them, for example from NSO websites.

There are certain data limits to this indicator, insofar as estimates have to be calculated for many developing countries which are not yet collecting ICT household statistics (see below on missing data). Over time, as more data become available, the quality of the indicator will improve.

\section{Fixed (wired)-broadband Internet subscriptions per 100 inhabitants}

Fixed (wired)-broadband Internet subscriptions refers to subscriptions to paid high-speed access to the public Internet (a TCP/IP connection). High-speed access is defined as downstream speeds equal to, or greater than, $256 \mathrm{kbit} / \mathrm{s}$. Fixed (wired)-broadband Internet includes cable modem, DSL, fibre and other fixed-broadband technology (such as Ethernet LAN, and broadband over power line (BPL) communications). Subscriptions with access to data communications (including the Internet) via mobile-cellular networks are excluded.

\section{Active mobile-broadband subscriptions per 100 inhabitants}

Active mobile-broadband subscriptions refers to the sum of active standard mobile-broadband subscriptions and dedicated mobile-broadband data subscriptions.

Standard mobile-broadband subscriptions refers to mobilecellular subscriptions with advertised data speeds of $256 \mathrm{kbit} / \mathrm{s}$ or greater and which have been used to set up an Internet data connection via the Internet Protocol in the past three months. The subscription must allow access to the greater Internet via HTTP and must have been used to set up an IP data connection in the past three months. Standard sms and mms messaging does not count as an active Internet data connection, even if the messages are delivered via IP.

Dedicated mobile-broadband data subscriptions refers to subscriptions to dedicated data services over a mobile network which are purchased separately from voice services, either as a standalone service (e.g. using a data card such as a USB modem/dongle) or as an add-on data package to voice services which requires an additional subscription. All dedicated mobile data subscriptions with recurring subscription fees are included as "active data subscriptions" regardless of actual use. Prepaid mobile-broadband plans require active use if there is no monthly subscription. This could also include mobile WiMAX subscriptions.

ITU began gathering data on active mobile subscriptions in 2010. However, only few countries have started collecting data for this indicator. For this reason, ITU uses data from Wireless Intelligence ${ }^{3}$ for active $3 \mathrm{G}$ connections. Wireless Intelligence collects these data 
directly from operators. While ITU has used the Wireless Intelligence data for this year's calculation of the IDI, countries are encouraged to collect this information from operators and to supply it to ITU under its data-collection survey.

\section{c) ICT skills indicators}

Data on adult literacy rates and gross secondary and tertiary enrolment ratios are collected by the UNESCO Institute for Statistics (UIS).

\section{Adult literacy rate}

According to UIS, the "Adult literacy rate is defined as the percentage of population aged 15 years and over who can both read and write with understanding a short simple statement on his/her everyday life. Generally, 'literacy' also encompasses 'numeracy', the ability to make simple arithmetic calculations. The main purpose of this indicator is to show the accumulated achievement of primary education and literacy programmes in imparting basic literacy skills to the population, thereby enabling them to apply such skills in daily life and to continue learning and communicating using the written word. Literacy represents a potential for further intellectual growth and contribution to economic-socio-cultural development of society."

\section{Gross enrolment ratio (secondary and tertiary level)}

According to UIS, "The gross enrolment ratio is the total enrolment in a specific level of education, regardless of age, expressed as a percentage of the eligible official school-age population corresponding to the same level of education in a given school-year." ${ }^{4}$

\section{Imputation of missing data}

A critical step in the construction of the index is to create a complete data set, without missing values. There are several imputation techniques that can be applied to estimate missing data. ${ }^{5}$ Each of the imputation techniques, like any other method employed in the process, has its own strengths and weaknesses. The most important consideration is to ensure that the imputed data will reflect a country's actual level of ICT access, usage and skills.

Given that ICT access and usage are both correlated with national income, hot-deck imputation was chosen as the method for estimating the missing data. Hot-deck imputation uses data from countries with "similar" characteristics. GDP per capita and geographic location were used as the main criteria in identifying countries with similar characteristics. For example, missing data for country A were estimated for a certain indicator by first identifying the countries that have similar levels of GDP per capita and that are from the same region. Then, the indicator that has a known relationship to the indicator to be estimated was considered. For instance, fixed-broadband subscription data of country A was estimated by using fixed-broadband subscription data of country B from the same region with a similar level of GDP per capita and a similar level of Internet subscriptions. The same logic was applied to estimate missing data for all indicators included in the index.

\section{Normalization of data}

Normalization of the data is necessary before any aggregation can be made in order to ensure that the data set uses the same unit of measurement. For the indicators selected for the construction of the IDI, it is important to transform the values to the same unit of measurement, since some of them are expressed as a percentage of the population or households, with a maximum value of 100, while other indicators (although also expressed as a percentage) can have values exceeding 100 , such as mobile-cellular subscriptions or international Internet bandwidth.

There are certain particularities that need to be taken into consideration when selecting the normalization method for the IDI. For example, in order to identify the digital divide, it is important to measure the relative performance of countries (i.e. divide among countries). Second, the normalization procedure should produce index results that allow countries to track progress of their evolution towards an information society over time.

A further important criterion for the selection of the normalization method was to choose one that can be replicated by countries. Indeed, some countries have shown a strong interest in applying the index methodology at the national or regional level. Therefore, certain methods cannot be applied, for example those that rely on the values of other countries, which might not be available to users.

For the IDI, the distance to a reference measure was used as the normalization method. The reference measure is the ideal value that could be reached for each variable (similar to a goalpost). In all of the indicators chosen, this will be 100, except for four indicators: 
- International Internet bandwidth per Internet user, which in 2010 ranges from 101 (bits/s/user) to more than 600000 . To diminish the effect of outliers at the high end of the value scale, the data were first transformed to a logarithmic (log) scale. The ideal value was then computed by adding two standard deviations to the mean of the rescaled values, resulting in a log value of 5.45 .

- Mobile-cellular subscriptions, which in 2010 range from 3.53 to 206 per 100 inhabitants. The ideal value was computed using the same methodology used for the bandwidth data, by adding two standard deviations to the mean. The resulting reference value was 180 subscriptions per 100 inhabitants.

- Fixed-telephone subscriptions per 100 inhabitants range between 0.06 and 64 in 2010. The same methodology was used to compute the reference value, resulting in a rounded value of 60 per 100 inhabitants.

- Fixed (wired)-broadband subscriptions per 100 inhabitants. This is a fairly recent indicator, and values range from zero to 38 per 100 inhabitants. In line with fixed-telephone subscriptions, the ideal value was defined at 60 per 100 inhabitants.
After normalizing the data, the individual series were all rescaled to identical ranges, from 1 to 10 . This was necessary in order to compare the values of the indicators and the sub-indices.

\section{Weighting and aggregation}

The indicators and sub-indices included in the IDI were weighted based on the PCA results obtained when the index was first computed. ${ }^{6}$ Annex Box 1.1 presents the weights for the indicators and sub-indices.

\section{Calculating the IDI}

Sub-indices were computed by summing the weighted values of the indicators included in the respective subgroup.

- ICT access is measured by fixed-telephone subscriptions per 100 inhabitants, mobile-cellular subscriptions per 100 inhabitants, international Internet bandwidth per Internet user, percentage of households with a computer and percentage of households with Internet access at home.

- ICT use is measured by percentage of individuals using the Internet, fixed (wired)-broadband

Annex Box 1.1: Weights used for indicators and sub-indices included in the IDI

\begin{tabular}{|l|c|c|}
\hline & Weights (Indicators) & Weights (Sub-index) \\
\hline ICT access & 0.20 \\
Fixed-telephone subscriptions per 100 inhabitants & 0.20 \\
Mobile-cellular telephone subscriptions per 100 inhabitants & 0.20 \\
International Internet bandwidth per Internet user & 0.20 \\
Percentage of households with a computer & 0.20 \\
Percentage of households with Internet access at home & & 0.40 \\
\hline ICT use & 0.33 \\
Percentage of individuals using the Internet & 0.33 \\
Fixed (wired)-broadband Internet subscriptions per 100 inhabitants & 0.33 \\
Active mobile-broadband subscriptions per 100 inhabitants & \\
\hline ICT skills & 0.33 \\
Adult literacy rate & 0.33 \\
Secondary gross enrolment ratio & 0.33 & 0.40 \\
Tertiary gross enrolment ratio & \\
\hline
\end{tabular}

Source: ITU. 
Internet subscriptions per 100 inhabitants and active mobile-broadband subscriptions per 100 inhabitants.

- ICT skills are approximated by adult literacy rate, secondary gross enrolment ratio and tertiary gross enrolment ratio.

The values of the sub-indices were calculated first by normalizing the indicators included in each sub-index in order to obtain the same unit of measurement. The reference values applied in the normalization were discussed above. The sub-index value was calculated for each country by taking the simple average (using equal weights) of the normalized indicator values.

For computation of the final index, the ICT access and ICT use sub-indices were given 40 per cent weight each, and the skills sub-index (because it is based on proxy indicators) 20 per cent weight. The final index value was then computed by summing the weighted sub-indices. Annex Box 1.2 illustrates the process of computing the IDI for the Republic of Korea (which tops the IDI 2010).

\section{Sensitivity analysis}

Sensitivity analysis was carried out to investigate the robustness of the index results, in terms of the relative position in the overall ranking, using different combinations of methods and techniques to compute the index.
Potential sources of variation or uncertainty can be attributed to different processes employed in the computation of the index, including the selection of individual indicators, the imputation of missing values and the normalization, weighting and aggregation of the data.

Each of the processes or combination of processes affects the IDI value. A number of tests were carried out to examine the robustness of the IDI results (rather than the actual values). The tests computed the possible index values and country rankings for different combinations of the processes mentioned above. Results show that, while the computed index values change, the message remains the same. The IDI was found to be extremely robust to different methodologies - with the exception of some countries, particularly countries in the "high" group.

The relative position of countries included in the "high" group (see Chapter 2) can change depending on the methodology used. Therefore, caution should be exercised when drawing conclusions based on the ranking of these countries. However, the relative position of countries included in the "low" group is in no way affected by the methods or techniques used, and the countries in this group ranked low in all index computations using different methodologies. This confirms the results conveyed by the IDI. 
Annex Box 1.2: Example of how to calculate the IDI value

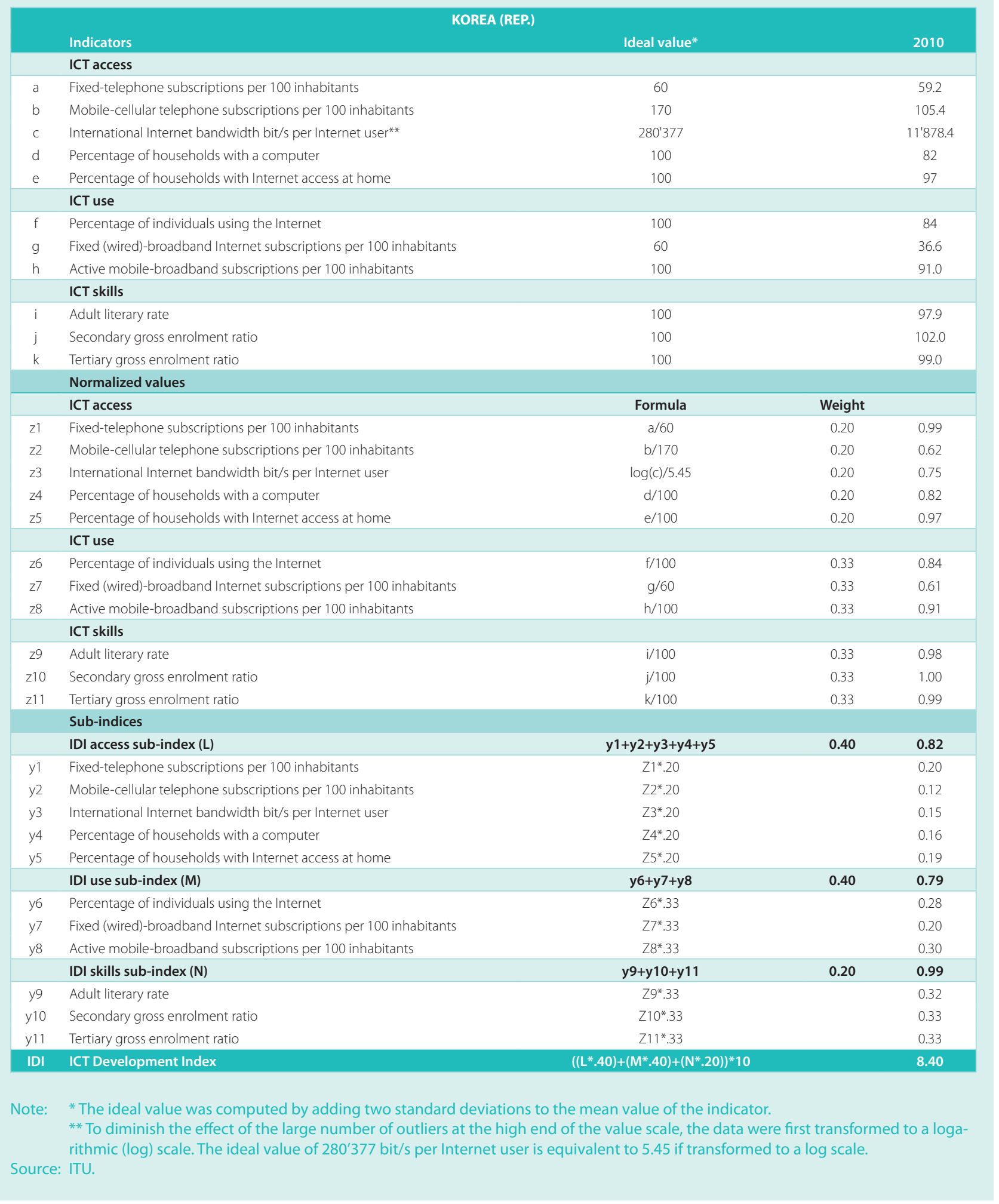




\section{Endnotes}

1 Principal component analysis was used to examine the underlying nature of the data. A more detailed description of the analysis is available in Annex 1 to ITU (2009)

2 As of 2010 the ITU annual data-collection survey, there were 59 economies reporting the data for this indicator.

3 Wireless Intelligence is part of GSM Media LLC, a wholly owned subsidiary of GSMC Limited, the organization behind the GSMA Mobile World Congress and GSMA Mobile Asia Congress, see https://www.wirelessintelligence.com/about/.

4 UIS “Education Indicators: Technical Guidelines”, see http://www.uis.unesco.org/ev.php?ID=5202 201\&ID2=DO TOPIC.

5 See OECD and European Commission Joint Research Centre (2008).

6 For more details, see Annex 1 to ITU (2009). 



\section{Annex 2. ICT Price Basket (IPB) methodology}

\section{Tariff-data collection and sources}

All 2010 tariffs were collected in August 2010, through the ITU Tariff Indicators questionnaire, which was sent to administrations and statistical contacts of all ITU Member States. Through this questionnaire, contacts were also requested to provide 2008 and 2009 tariffs. For those countries that did not reply, tariffs were collected directly from operators' websites. Tariffs were collected from the operator with the largest market share (as measured by the number of subscriptions), either from its website or through direct correspondence. Insofar as, for many countries, it is not clear which Internet service provider (ISP) has the dominant market share, preference was given to tariffs offered by the (former) incumbent telecommunication operator. In some cases, especially when tariffs were not clearly advertised, or described only in the local language, and when ISPs did not respond to queries, alternative ISPs were chosen. All prices were gathered during the second half of 2010, and converted into USD using the 2010 average annual UN operational rate of exchange. Similarly, for countries that did not provide 2008 tariffs, these were collected in the second half of 2008, and converted using the 2008 annual UN operational rate of exchange. ${ }^{1}$

\section{The fixed-telephone sub-basket}

By the end of 2010, the number of fixed-telephone lines stood at around 1.2 billion. Although at the global level the number of fixed-telephone lines has started to decrease since 2006, the ITU ICT Price Basket (IPB) includes a sub-basket for fixed telephony because fixedtelephone access remains an important access technology in its own right in a large number of countries. Additionally, the conventional fixed-telephone line is used not only for dial-up Internet access, but also as a basis for upgrading to DSL broadband technology, which today represents about 63 per cent of all fixed-broadband subscriptions. ${ }^{2}$ While more and more countries are moving away from narrowband/dial-up Internet access to broadband, dial-up Internet access still remains the only Internet access available to many people in developing countries. Since the IPB does not include dial-up (but only broadband) tariffs, and dial-up Internet access requires users to subscribe to a fixed-telephone line, the fixed-telephone sub-basket can be considered a proxy for the price of dial-up Internet access.

The fixed-telephone sub-basket has been developed to capture the average monthly cost of a basic local fixed residential telephone service. Following the methodology of the World Bank's "Price Basket for residential fixed line", it includes the monthly subscription fee plus the cost of 30 three-minute local calls to the same (fixed) network (15 peak and 15 off-peak calls). However, unlike the World Bank's basket, it does not take into consideration the one-time connection charge. This choice has been made in order to improve comparability with the other sub-baskets, which include only recurring monthly charges. If the monthly subscription includes free minutes of calls, then these are taken into consideration and deducted from the total cost of the fixed-telephone sub-basket.

The cost of a three-minute local call refers to the cost of a three-minute call within the same exchange area (local call) using the subscriber's equipment (i.e. not from a public telephone). It thus refers to the amount the subscriber must pay for a three-minute call, and not the average price for each three-minute interval. For example, some operators charge a connection fee for every call, or a different price for the first minute of a call. In this case, the actual amount for the (first) three 
Annex Table 2.1: OECD mobile-cellular low-user call distribution (2009 methodology):

\begin{tabular}{|c|c|c|c|c|c|}
\hline & To fixed & On-net & Off-net & TOTAL & $\begin{array}{c}\text { Call } \\
\text { distribution by } \\
\text { time of day }(\%)\end{array}$ \\
\hline Call distribution (\%) & 17.0 & 56.0 & 26.0 & 100.0 & 100.0 \\
\hline Calls & 5.2 & 16.9 & 7.9 & 30.0 & \\
\hline Peak & 2.4 & 7.8 & 3.6 & 13.8 & 46.0 \\
\hline Off-peak & 1.5 & 4.9 & 2.3 & 8.7 & 29.0 \\
\hline Weekend & 1.3 & 4.2 & 2.0 & 7.5 & 25.0 \\
\hline Duration (minutes per call) & 2.0 & 1.6 & 1.7 & & \\
\hline Duration (total minutes of calls) & 10.4 & 27.0 & 13.4 & 50.9 & N/A \\
\hline Peak & 4.8 & 12.4 & 6.2 & 23.4 & 46.0 \\
\hline Off-peak & 3.0 & 7.8 & 3.9 & 14.8 & 29.0 \\
\hline Weekend & 2.6 & 6.8 & 3.4 & 12.7 & 25.0 \\
\hline Calls & \multicolumn{4}{|c|}{30 calls per month } & \\
\hline SMS & \multicolumn{4}{|c|}{100 SMS per month (50 on-net, 50 off-net) } & \\
\hline
\end{tabular}

Note: N/A: Not applicable.

Source: ITU, based on OECD (2010a).

minutes is calculated. Many operators indicate whether advertised prices include taxes or not. If they are not included, and if the tax rate is advertised, taxes are added to the sub-basket, to improve the comparability of tariffs between countries. The sub-basket does not take into consideration the price of a telephone set.

\section{The mobile-cellular sub-basket}

The mobile-cellular market is the fastest growing telecommunication market and uncontested in terms of subscriber numbers. According to ITU, there were 5.4 billion mobile-cellular subscriptions worldwide by the end of 2010. No other ICT service has ever had the same kind of impact in terms of subscriptions, particularly in the developing world, in so little time.

The mobile-cellular sub-basket is largely based on, but does not entirely follow, the 2009 methodology of the OECD low-user basket. The mobile-cellular sub-basket refers to a 30-call basket, which is the entry-level basket of the 2009 OECD methodology. ${ }^{3}$ Unlike the 2009 OECD methodology, which is based on the tariffs of the two largest mobile operators, the ITU mobile-cellular sub-basket uses (only) the largest mobile operator's tariffs. Additionally, the ITU mobilecellular sub-basket does not take into account calls to voicemail (which in the OECD basket represent 4 per cent of all calls), nor non-recurring charges, such as the one-time charge for a SIM card. ${ }^{4}$ The basket gives the price of a standard basket of mobile monthly usage in USD determined by the OECD for 30 outgoing calls per month in predetermined ratios plus $100 \mathrm{sms}$ messages. ${ }^{5}$ The cost of local short messaging service (sms) is the charge to the consumer for sending a single sms text message within the local exchange area. The basket considers on-net and off-net calls as well as calls to a fixed telephone ${ }^{6}$ and, since the price of a call often depends on the time of day or week it is made, peak, off-peak and weekend periods are also taken into consideration. The call distribution is outlined in Annex Table 2.1.

Prepaid tariffs were chosen because they are often the only payment method available to low-income users, who might not have a regular income and will thus not qualify for a postpaid subscription based service. Rather than reflecting the cheapest option available, the mobile-cellular sub-basket therefore corresponds to a basic, representative package available to all customers. In countries where no prepaid offers are available, the monthly fixed cost (minus the free minutes of calls included, if applicable) of a postpaid subscription is added to the basket.

To make tariffs comparable, a number of rules were applied (Annex Box 2.1).

It should also be noted that there has been a methodological change in the computation of the ICT Price 


\section{Annex Box 2.1: Rules applied to collect tariffs for the 2010 mobile-cellular sub-basket}

1. The OECD 2009 mobile basket for the "30 calls per month basket" is used as a basis for the ITU data collection on mobile-cellular prepaid tariffs.

2. Tariffs are based on the tariffs published by the dominant operator, in terms of the number of subscriptions/market share.

3. If there are several prepaid plans, the plan that is chosen is the one that comes closest to the 30 calls and 100 sms included.

4. Special offers and plans with limited availability (for example those reserved for a limited number of customers) cannot be used.

5. If subscribers can choose "favourite" numbers (for family, friends, etc.) with a special tariff, this special tariff cannot be taken into consideration (irrespective of the quantity of numbers).

6. If prices vary between minutes ( 1 st minute $=$ price $A, 2$ nd minute $=$ price $B, 3 r$ minute $=$ price $C$ ), the sum of the different prices will be divided by the number of different prices (for example: price per minute $=(A+B+C) / 3$ ).

6.1. If only the first minute is different, calculate the average price per minute based on 3 minutes.

6.2. If prices vary beyond 3 minutes, calculate the average price per minute based on 3 minutes.

7. If there is a connection cost per call, then this is taken into consideration in the final formula of the mobile-cellular basket, based on 30 calls.

8. If free minutes/calls/sms are included in the connection fee, then these are taken into consideration and deducted from the number of calls/minutes/sms in the formula that is used to calculate the price basket.

9. If there are different prices for an sms (off-peak vs peak), then the average of both is used.

10. If there are different off-peak tariffs, then the one that is the cheapest before midnight is used.

11. If the only off-peak period is after midnight, then this is not used. Instead, the peak price is applied.

12. If there are different peak tariffs, the most expensive one during daytime is applied.

13. If there are different weekend tariffs, the price that applies Sundays during daytime applies (or the equivalent day in countries where weekends are not on Sundays).

14. If there is no weekend price, the average peak and off-peak price that is valid during the week applies.

15. When the customer can chose between different connection charges that include different amounts of units/minutes, and the price per minute/unit decreases the higher the connection charge, the 'cheapest' refill card is used. If different connection charges exist depending on the validity period, the validity period for 30 days (or closest to 30 days) applies.

16. If calls are charged by call (and not by minute), the mobile-cellular sub-basket formula will be calculated based on 30 calls.

17. Tariffs include taxes.

Basket's mobile-cellular sub-basket, with the result that the values in this report are not strictly comparable with those published in the previous IPB (ITU, 2010b). This change in methodology is due to an update in the OECD low-user basket, which ITU has adopted. In particular, the new (2009) OECD low-user basket includes more calls (30, instead of 25 previously) and more sms (100, instead of 30 previously), so the overall value of the latest IPB is higher.

\section{The fixed-broadband sub-basket}

The discussion on today's information society is increasingly focused on the Internet, which is the single most powerful ICT in terms of access to information and applications. Currently, ITU estimates that one in three people use the Internet; practically all governments and large businesses today are online; and the Internet has transformed the way people communicate. 
To take full advantage of the potential of the Internet, broadband Internet access is indispensable. Many of the most popular applications and services in use today, including many that have the greatest development potential, require a high-speed broadband connection. By the end of 2010, there were 527 million fixed-broadband connections, according to ITU. While it is not possible to know how many people access the Internet over a fixed-broadband connection, more and more of the world's 2 billion Internet users have gone 'high speed'. Indeed, the number of dial-up and narrowband connections is decreasing, and in many countries Internet access is almost exclusively broadband.

The price computed for the fixed-broadband sub-basket gives a broad representation of an entry-level fixedbroadband offer available in an economy. The price is calculated based on a $256 \mathrm{kbit} / \mathrm{s}$ connection and a minimum of 1 Gigabyte (GB) of data. Broadband is considered any dedicated connection to the Internet at speeds equal to, or greater than, $256 \mathrm{kbit} / \mathrm{s}$, downstream. Where several offers are available, preference is given to a $256 \mathrm{kbit} / \mathrm{s}$ connection. Preference is also given to 'unlimited' offers, when these are cheaper than a capped offer (based on $1 \mathrm{~GB}$ of data). If providers set a limit of less than $1 \mathrm{~GB}$ on the amount of data that can be transferred within a month, then the price per additional Gigabyte was used and added to the monthly tariff to calculate the cost of $1 \mathrm{~GB}$ of data per month. Whenever possible, prices are for services over a digital subscriber line (DSL), since this remains the most common access method worldwide. The sub-basket does not include installation charges, modem prices or telephone/line rentals that are often required for a DSL service. The tariff represents the broadband entry-level plan in terms of the minimum speed of $256 \mathrm{kbit} / \mathrm{s}$, but does not take into account special offers - limited in time or to specific geographic areas. The plan does not necessarily represent the fastest or most cost-effective connection, since the price for a higher-speed plan is often relatively cheaper (on account of caps).

\section{A future mobile-broadband sub-basket}

An increasing number of people are accessing the Internet over mobile-broadband connections, and in some parts of the world mobile broadband is the only means of access to the Internet. By the end of 2010, more than 150 countries were offering $3 \mathrm{G}$ services, but many countries, such as India and China, only launched services in 2009, and operators are still in the process of adjusting tariffs and pricing structures to subscribers' needs and usage patterns.

There are two main reasons for not including mobilebroadband prices in the 2010 IPB. First, mobile-broadband services are not yet available in all countries, so the number of countries included in the IPB would have to be reduced. Second, given the relative novelty of the service, pricing structures are changing quite rapidly and vary between countries. Mobile-broadband subscriptions could include the subscription to a USB/dongle which enables a computer to connect to the Internet via a $3 \mathrm{G}$ network; or they could refer to the subscription to the Internet via a mobile-cellular telephone. While both subscriptions use the same high-speed (3G) wireless network, packages and prices differ. Often, access to data and the Internet are also bundled with other services, such as calls or sms, which makes it difficult to separate out the price for data only. These difficulties suggest that some comparisons need to be made and some rules need to be established before a harmonized mobile-broadband sub-basket can be calculated. Finally, it is not clear if this sub-basket should be given the same weight as the other sub-baskets, or whether it should be grouped with the fixed-broadband sub-basket. 


\section{Endnotes}

1 For the 2008 ICT Price Basket, 2008 PPP conversion factors, the 2008 UN conversion rate and 2008 GNI per capita data were used. For the 2010 IPB, 2009 values were used in all three cases, as 2010 data were not yet available.

2 See Point Topic (2011).

3 See OECD (2010a), pp. 13-14.

4 It should also be noted that the previous (2009) mobile sub-basket was based on the 2001 methodology of the OECD low-user basket, which included only 25 calls and $30 \mathrm{sms}$, instead of the 30 calls and $100 \mathrm{sms}$ that are included in the 2009 methodology. The results of the mobile sub-basket and the previous IPB that were published in 2010 are therefore not strictly comparable with the 2008 results published in this report. Since the updated mobile sub-basket methodology includes more calls and more sms, it will be relatively more expensive than the mobile sub-basket published in 2010 .

5 For more details on the OECD/Teligen methodology, see OECD (2010a) pp. 13-14.

6 On-net refers to a call made to the same mobile network, while off-net and fixed line refer to calls made to other (competing) mobile networks and to a fixed-telephone line, respectively. 



\section{Annex 3. Methodological aspects related to household survey results}

Since 2004, the Partnership on Measuring ICT for Development has been striving to achieve internationally comparable and reliable statistics on ICT access and use. The members of the Partnership have been working together in developing and maintaining a core list of ICT indicators which is recommended as a minimum set that could be collected by countries, in particular by national statistics offices (NSO). One of ITU's responsibilities has been to provide guidance and capacity building in the collection of data for the core ICT household indicators, specifically on ICT access by households and ICT use by individuals.

Until 2005, ITU focused on collecting primarily telecommunication infrastructure and market statistics. It thus has historic time-series data on ICT services, including Internet and mobile-cellular subscription data. However, subscription (or supply-side) data have their limitations, particularly when it comes to analysing the uptake and use of ICTs by people and businesses. From 2005, ITU therefore started gathering demand-side data. Collected through household surveys, demand-side data provide in-depth information on ICT use not only in terms of usage levels but also according to socio-demographic and economic characteristics, which in turn can be used to identify ICT divides and barriers. More and more countries have started collecting demand-side ICT data through official household surveys. By end 2010, 34 developing economies had collected data on the number of individuals using the Internet for at least one year between 2008 and 2010 through an official household survey. Chart 5.1 (Chapter 5) provides a more detailed picture of data availability on this indicator by region and over time.

Work has been undertaken by ITU, in cooperation with NSOs, to harmonize questions on ICT access and use by households and individuals. However, full harmonization is not always feasible, and some limitations still exist in regard to comparability of questions or classificatory variables. Additional efforts have been made to try to show harmonized and comparable information as far as possible.

For example, populations taken into account to measure the use of ICT may differ, as not all countries are using the same age range for surveyed individuals (see Annex Table 3.1). For comparison purposes, and whenever possible, the results are shown for the population between 15 and 74 years old. It is expected that more countries will collect data with a broader age scope in the future, so that comparisons can be made at the level of the total population.

In other cases, not all countries with available data for a certain variable can be included in the analysis due to the fact that not all subcategories of a question or a classificatory variable have been surveyed. However, it is expected that this can be corrected in future analyses, as more countries begin to follow the recommendations by the Partnership.

When analysing survey results, it is very important to take into account that, as surveys apply to a representative sample of the population and not the entire population, they incur sampling errors. Results which at first sight look different may be very close or potentially equal when they are compared in light of their standard errors. For example, results that show small differences among classificatory categories need to be read with care, since in some cases they may overlap when confidence intervals are calculated. Non-sampling errors, also referred to as bias, may also occur at any time. This can be due, for example, to sampling frame inadequacies or non-response. 


\begin{tabular}{|c|c|}
\hline Economy/region & Scope \\
\hline Indonesia, I.R. of Iran, Ukraine & All population \\
\hline Korea (Rep.), Macao (China), United States & Population age $3+$ \\
\hline Chile, Colombia, Costa Rica, Ecuador, Honduras, Jordan & Population age $5+$ \\
\hline Japan, Mexico, Peru, Thailand, Uruguay, Egypt & Population age $6+$ \\
\hline Azerbaijan, Nicaragua, Singapore & Population age $7+$ \\
\hline Brazil, El Salvador, Hong Kong (China), Paraguay & Population age $10+$ \\
\hline Morocco & Population age 12-65 \\
\hline Mauritius, Senegal & Population age $12+$ \\
\hline Switzerland & Population age $14+$ \\
\hline Australia, New Zealand, United Arab Emirates & Population age $15+$ \\
\hline EU 27*, Croatia, Iceland, Moldova, Norway, Serbia, Macedonia, Turkey & Population age 16-74 \\
\hline Canada, Belarus, Research ICT Africa & Population age $16+$ \\
\hline Qatar & Population age $18+$ \\
\hline Israel & Population age $20+$ \\
\hline Russia & Population age less than 74 \\
\hline
\end{tabular}

Note: *Although the EU27 data (collected by Eurostat) refer to the age group 16 - 74 years old, some countries collect data for a broader age scope: Italy (all), Germany (10+), Slovenia (10-74), Slovak Republic (12+), Lithuania, Netherlands (12-74), and Norway, Spain and United Kingdom (16+). 


\section{Annex 4. Statistical tables of indicators used to compute the IDI}




\section{Access indicators}

\begin{tabular}{|c|c|c|c|c|c|c|c|c|c|c|c|}
\hline & \multirow[b]{2}{*}{ Economy } & \multicolumn{2}{|c|}{$\begin{array}{c}\text { Fixed-telephone } \\
\text { subscriptions per } \\
100 \text { inhabitants }\end{array}$} & \multicolumn{2}{|c|}{$\begin{array}{c}\text { Mobile-cellular } \\
\text { subscriptions per } \\
100 \text { inhabitants }\end{array}$} & \multicolumn{2}{|c|}{$\begin{array}{l}\text { International Internet } \\
\text { bandwidth } \\
\text { Bit/s per Internet user }\end{array}$} & $\begin{array}{c}\text { Perce } \\
\text { hou } \\
\text { with }\end{array}$ & $\begin{array}{l}\text { ge of } \\
\text { ids } \\
\text { outer }\end{array}$ & $\begin{array}{r}\text { Percen } \\
\text { househ } \\
\text { Inte }\end{array}$ & $\begin{array}{l}\text { ye of } \\
\text { s with } \\
\text { at }\end{array}$ \\
\hline & & 2008 & 2010 & 2008 & 2010 & 2008 & 2010 & 2008 & 2010 & 2008 & 2010 \\
\hline 1 & Albania & 10.8 & 10.3 & 98.7 & 141.9 & 1'581 & 9'709 & 12.0 & 15.6 & 8.8 & 11.7 \\
\hline 2 & Algeria & 8.9 & 8.2 & 78.5 & 92.4 & 913 & $8^{\prime} 120$ & 12.4 & 20.0 & 3.4 & 10.0 \\
\hline 3 & Angola & 0.6 & 1.6 & 37.6 & 46.7 & 545 & 629 & 5.6 & 7.1 & 4.4 & 5.7 \\
\hline 4 & Antigua \& Barbuda & 43.7 & 47.1 & 157.2 & 184.7 & $18^{\prime} 409$ & $16 ' 909$ & 47.0 & 50.9 & 36.0 & 38.0 \\
\hline 5 & Argentina & 24.5 & 24.7 & 117.1 & 141.8 & $17^{\prime} 914$ & $27^{\prime} 494$ & 37.6 & 40.0 & 17.6 & 21.3 \\
\hline 6 & Armenia & 20.3 & 19.1 & 75.9 & 125.0 & $5^{\prime} 666$ & 9'219 & 10.2 & 17.8 & 5.9 & 11.6 \\
\hline 7 & Australia & 43.6 & 38.9 & 102.8 & 101.0 & $9^{\prime} 728$ & $41 ' 361$ & 74.9 & 81.1 & 66.6 & 74.1 \\
\hline 8 & Austria & 39.4 & 38.7 & 129.7 & 145.8 & $41^{\prime} 127$ & $73^{\prime} 744$ & 76.0 & 76.2 & 68.9 & 72.9 \\
\hline 9 & Azerbaijan & 14.7 & 16.3 & 73.2 & 99.0 & 6'703 & 12'387 & 14.6 & 21.5 & 13.9 & 35.3 \\
\hline 10 & Bahrain & 20.9 & 18.1 & 136.9 & 124.2 & $8^{\prime} 121$ & $14^{\prime} 409$ & 87.0 & 87.0 & 57.7 & 74.0 \\
\hline 11 & Bangladesh & 0.9 & 0.6 & 30.7 & 46.2 & 511 & 2'790 & 2.2 & 3.1 & 1.9 & 2.6 \\
\hline 12 & Barbados & 55.1 & 50.3 & 106.1 & 128.1 & $5^{\prime} 525$ & $20^{\prime} 638$ & 53.0 & 61.4 & 43.0 & 51.0 \\
\hline 13 & Belarus & 38.4 & 43.1 & 84.0 & 107.7 & $2^{\prime} 021$ & $22 ' 027$ & 28.5 & 40.8 & 15.6 & 31.2 \\
\hline 14 & Belgium & 44.7 & 43.3 & 107.0 & 113.5 & $52^{\prime} 952$ & $106^{\prime} 008$ & 70.0 & 76.7 & 63.6 & 72.7 \\
\hline 15 & Benin & 1.4 & 1.5 & 43.4 & 79.9 & 1'003 & 2'238 & 2.1 & 2.5 & 0.1 & 0.1 \\
\hline 16 & Bhutan & 3.9 & 3.6 & 36.1 & 54.3 & 980 & 3'343 & 4.7 & 6.4 & 2.8 & 4.9 \\
\hline 17 & Bolivia & 8.2 & 8.5 & 52.4 & 72.3 & 2'099 & 4'271 & 14.7 & 17.0 & 3.3 & 3.9 \\
\hline 18 & Bosnia and Herzegovina & 27.3 & 26.6 & 84.2 & 80.1 & 1'529 & $15^{\prime} 650$ & 28.3 & 33.7 & 12.6 & 18.1 \\
\hline 19 & Botswana & 7.3 & 6.8 & 76.0 & 117.8 & 3'462 & $6^{\prime} 436$ & 4.9 & 6.5 & 1.0 & 2.8 \\
\hline 20 & Brazil & 21.5 & 21.6 & 78.6 & 104.1 & $6^{\prime} 244$ & $12^{\prime} 619$ & 31.2 & 34.9 & 23.8 & 27.1 \\
\hline 21 & Brunei Darussalam & 21.0 & 20.0 & 103.7 & 109.1 & 3'504 & $25^{\prime} 068$ & 72.6 & 79.6 & 65.2 & 71.3 \\
\hline 22 & Bulgaria & 28.8 & 29.4 & 138.3 & 141.2 & $95 ' 326$ & $115^{\prime} 464$ & 28.6 & 35.1 & 25.3 & 33.1 \\
\hline 23 & Burkina Faso & 1.0 & 0.9 & 19.5 & 34.7 & 3'496 & 3'474 & 1.8 & 2.1 & 0.2 & 0.2 \\
\hline 24 & Cambodia & 0.3 & 2.5 & 30.7 & 57.7 & $13^{\prime} 476$ & $28^{\prime} 067$ & 3.7 & 4.3 & 0.2 & 0.4 \\
\hline 25 & Cameroon & 1.4 & 2.5 & 32.8 & 41.6 & 314 & 411 & 4.5 & 5.4 & 1.3 & 1.5 \\
\hline 26 & Canada & 54.8 & 50.0 & 66.3 & 70.7 & $31 ' 296$ & $54^{\prime} 039$ & 79.4 & 83.9 & 74.6 & 78.2 \\
\hline 27 & Cape Verde & 14.7 & 14.5 & 57.0 & 75.0 & 1'590 & $2^{\prime} 083$ & 8.2 & 11.3 & 2.5 & 3.5 \\
\hline 28 & Chad & 0.4 & 0.5 & 17.0 & 23.3 & 150 & 101 & 0.4 & 0.6 & 0.1 & 0.2 \\
\hline 29 & Chile & 21.0 & 20.2 & 88.1 & 116.0 & $10 ' 376$ & $19^{\prime} 140$ & 40.0 & 46.8 & 26.6 & 35.0 \\
\hline 30 & China & 25.6 & 21.9 & 48.3 & 64.0 & 2'133 & 2'389 & 31.8 & 35.4 & 18.3 & 23.7 \\
\hline 31 & Colombia & 17.6 & 14.7 & 91.9 & 93.8 & $8^{\prime} 725$ & $10^{\prime} 245$ & 22.8 & 26.1 & 12.8 & 19.3 \\
\hline 32 & Comoros & 4.1 & 2.9 & 13.2 & 22.5 & 412 & 4'430 & 4.8 & 5.7 & 1.5 & 2.4 \\
\hline 33 & Congo (Dem. Rep.) & 0.1 & 0.1 & 15.9 & 17.2 & 47 & 232 & 0.3 & 0.3 & 0.2 & 0.3 \\
\hline 34 & Costa Rica & 31.8 & 31.8 & 41.7 & 65.1 & $5^{\prime} 284$ & $12^{\prime} 686$ & 34.4 & 41.3 & 14.8 & 24.1 \\
\hline 35 & Côte d'Ivoire & 1.9 & 1.1 & 55.0 & 75.5 & $2^{\prime} 633$ & 7'794 & 1.4 & 1.8 & 0.7 & 1.1 \\
\hline 36 & Croatia & 42.5 & 42.4 & 133.1 & 144.5 & 31'518 & $42^{\prime} 920$ & 52.9 & 60.0 & 45.3 & 56.5 \\
\hline 37 & Cuba & 9.7 & 10.3 & 2.9 & 8.9 & 207 & 231 & 3.3 & 3.4 & 0.5 & 0.6 \\
\hline 38 & Cyprus & 38.4 & 37.6 & 94.4 & 93.7 & 6'584 & $17 ' 098$ & 56.3 & 60.5 & 42.9 & 53.7 \\
\hline 39 & Czech Republic & 23.9 & 20.9 & 132.8 & 136.6 & $30 ' 606$ & $69 ' 245$ & 52.4 & 64.1 & 45.9 & 60.5 \\
\hline 40 & Denmark & 54.1 & 47.3 & 119.3 & 124.4 & $85^{\prime} 583$ & $142^{\prime} 166$ & 85.5 & 88.0 & 81.9 & 86.1 \\
\hline 41 & Djibouti & 1.7 & 2.1 & 13.2 & 18.6 & $24^{\prime} 047$ & $13^{\prime} 416$ & 10.6 & 13.0 & 1.3 & 2.2 \\
\hline 42 & Dominican Rep. & 10.2 & 10.2 & 74.6 & 89.6 & 6'957 & 3'568 & 14.2 & 16.4 & 6.0 & 7.6 \\
\hline 43 & Ecuador & 13.6 & 14.4 & 83.1 & 102.2 & $2^{\prime} 259$ & 6'906 & 22.8 & 27.0 & 7.0 & 11.8 \\
\hline 44 & Egypt & 15.1 & 11.9 & 52.7 & 87.1 & 1'920 & 6'591 & 27.0 & 34.0 & 19.9 & 31.2 \\
\hline 45 & El Salvador & 17.6 & 16.2 & 113.4 & 124.3 & 324 & 1'615 & 10.9 & 14.2 & 4.5 & 7.5 \\
\hline 46 & Eritrea & 0.8 & 1.0 & 2.2 & 3.5 & 119 & 137 & 0.3 & 0.3 & 0.2 & 0.3 \\
\hline 47 & Estonia & 37.1 & 36.0 & 121.0 & 123.2 & $17^{\prime} 946$ & $23^{\prime} 144$ & 59.6 & 69.2 & 58.1 & 67.8 \\
\hline 48 & Ethiopia & 1.1 & 1.1 & 2.5 & 7.9 & 1'399 & 5'357 & 0.5 & 1.4 & 0.1 & 0.3 \\
\hline 49 & Fiji & 15.3 & 15.9 & 71.1 & 116.2 & $6^{\prime} 071$ & 4'900 & 21.1 & 26.8 & 13.4 & 18.8 \\
\hline 50 & Finland & 31.0 & 23.3 & 128.5 & 156.4 & $44^{\prime} 962$ & $107 ' 267$ & 75.8 & 82.0 & 72.4 & 80.5 \\
\hline 51 & France & 56.5 & 56.1 & 93.4 & 99.7 & $45^{\prime} 567$ & $69^{\prime} 596$ & 68.4 & 76.4 & 62.3 & 73.6 \\
\hline 52 & Gabon & 1.8 & 2.0 & 89.6 & 106.9 & 3'331 & $52^{\prime} 083$ & 5.2 & 7.6 & 4.1 & 6.0 \\
\hline 53 & Gambia & 3.0 & 2.8 & 71.3 & 85.5 & 604 & 1'063 & 4.6 & 5.7 & 2.0 & 3.2 \\
\hline 54 & Georgia & 14.1 & 13.7 & 62.7 & 73.4 & $11 ' 368$ & $21^{\prime} 275$ & 6.1 & 18.2 & 5.9 & 16.6 \\
\hline 55 & Germany & 61.0 & 55.4 & 127.9 & 127.0 & $46^{\prime} 688$ & $74^{\prime} 223$ & 81.8 & 85.7 & 74.9 & 82.5 \\
\hline 56 & Ghana & 0.6 & 1.1 & 49.7 & 71.5 & $2^{\prime} 028$ & 1'908 & 6.4 & 9.1 & 0.3 & 0.4 \\
\hline 57 & Greece & 46.5 & 45.8 & 122.2 & 108.2 & $14^{\prime} 460$ & 30'998 & 44.0 & 53.4 & 31.0 & 46.4 \\
\hline 58 & Guatemala & 10.6 & 10.4 & 109.2 & 125.6 & $2^{\prime} 640$ & 3'971 & 14.3 & 15.8 & 2.4 & 3.0 \\
\hline 59 & Guinea & 0.3 & 0.2 & 28.8 & 40.1 & 967 & 1'565 & 1.0 & 1.5 & 0.6 & 1.0 \\
\hline 60 & Guyana & 18.5 & 19.9 & 59.6 & 73.6 & 1'681 & 6'383 & 6.1 & 6.5 & 4.0 & 5.1 \\
\hline 61 & Honduras & 11.3 & 8.8 & 85.0 & 125.1 & 3'566 & $5^{\prime} 932$ & 11.1 & 12.9 & 4.2 & 6.0 \\
\hline 62 & Hong Kong, China & 60.4 & 61.6 & 167.2 & 190.2 & $465^{\prime} 650$ & $683^{\prime} 362$ & 74.6 & 77.3 & 70.9 & 75.7 \\
\hline 63 & Hungary & 30.9 & 29.8 & 122.0 & 120.3 & $10^{\prime} 691$ & 9'974 & 58.8 & 66.4 & 48.4 & 60.5 \\
\hline 64 & Iceland & 64.2 & 63.7 & 108.5 & 108.7 & $17^{\prime} 686$ & 290 '995 & 91.9 & 93.0 & 87.7 & 92.0 \\
\hline 65 & India & 3.2 & 2.9 & 29.1 & 61.4 & 2'837 & 5'825 & 4.4 & 6.1 & 3.4 & 4.2 \\
\hline 66 & Indonesia & 12.9 & 15.8 & 59.8 & 91.7 & 1'349 & $3^{\prime 2} 207$ & 8.3 & 10.8 & 1.9 & 3.9 \\
\hline 67 & Iran (I.R.) & 34.3 & 36.3 & 59.5 & 91.2 & 1'466 & $3^{\prime} 120$ & 22.3 & 33.7 & 14.0 & 20.8 \\
\hline 68 & Ireland & 51.1 & 46.5 & 116.0 & 105.2 & $52^{\prime} 740$ & $64^{\prime} 054$ & 70.4 & 76.5 & 63.0 & 71.7 \\
\hline 69 & Israel & 45.5 & 44.2 & 126.6 & 133.1 & $4^{\prime} 748$ & $8^{\prime} 024$ & 71.0 & 77.0 & 61.8 & 69.0 \\
\hline 70 & Italy & 36.8 & 35.7 & 150.8 & 135.4 & $29^{\prime} 140$ & $61 ' 535$ & 56.0 & 64.8 & 46.9 & 59.0 \\
\hline 71 & Jamaica & 11.6 & 9.6 & 100.1 & 113.2 & 3'115 & $20^{\prime} 967$ & 17.1 & 20.0 & 8.1 & 11.8 \\
\hline 72 & Japan & 38.3 & 31.9 & 87.2 & 95.4 & 7'610 & $15^{\prime} 477$ & 85.9 & 88.5 & 79.8 & 85.4 \\
\hline 73 & Jordan & 8.9 & 7.8 & 90.8 & 107.0 & 3'431 & 6'380 & 39.3 & 51.4 & 13.2 & 22.1 \\
\hline 74 & Kazakhstan & 22.1 & 25.0 & 95.2 & 123.3 & 6'388 & 8'592 & 18.4 & 25.1 & 17.0 & 23.2 \\
\hline 75 & Kenya & 1.7 & 1.1 & 42.4 & 61.6 & 248 & 1'926 & 6.3 & 8.0 & 2.5 & 4.0 \\
\hline 76 & Korea (Rep.) & 51.0 & 59.2 & 95.5 & 105.4 & 6'698 & $11 ' 878$ & 80.9 & 81.8 & 94.3 & 96.8 \\
\hline
\end{tabular}




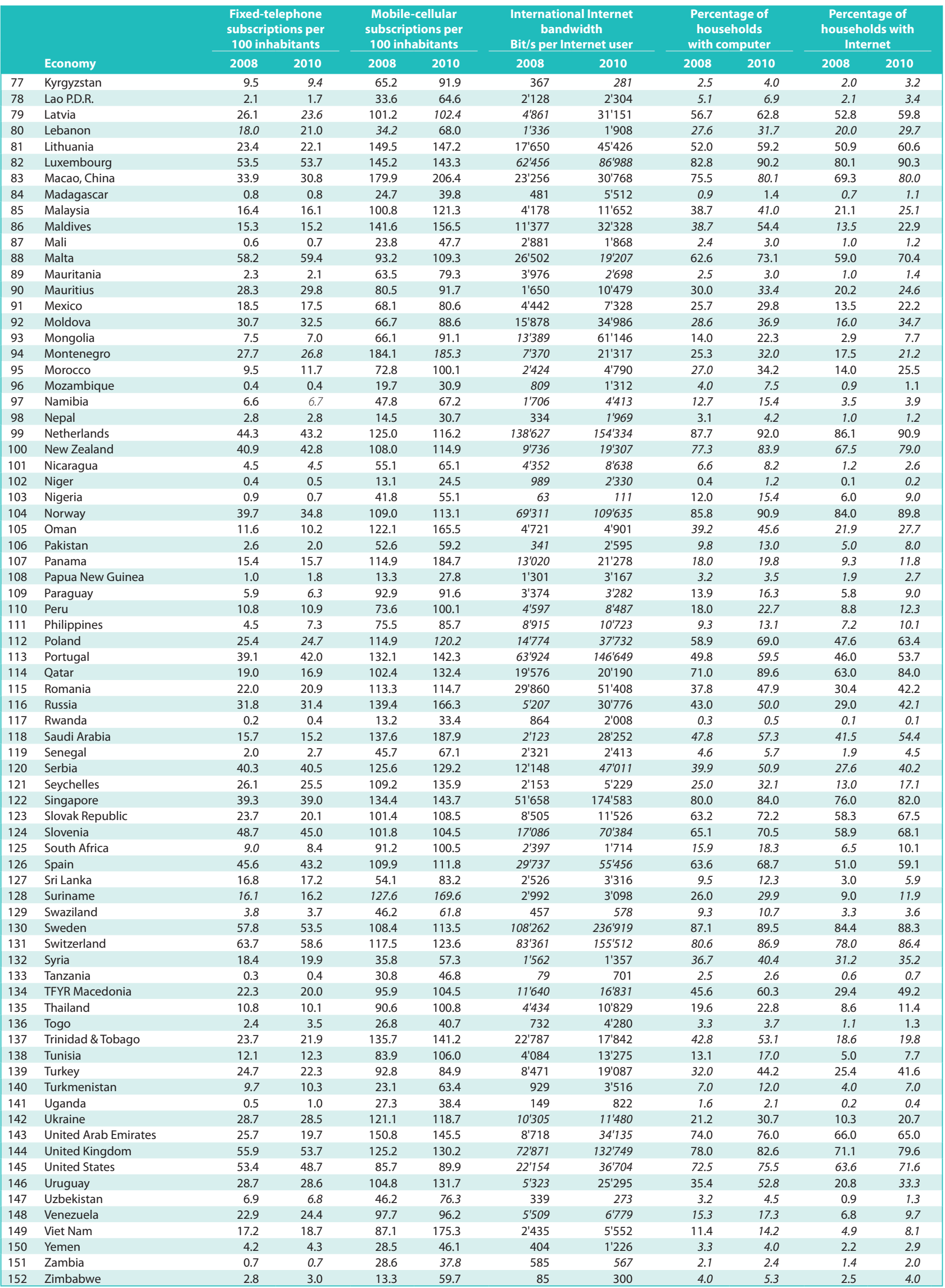

Note: Data in italics refer to ITU estimates.

Source: ITU World Telecommunication/ICT Indicators database. 


\section{Use indicators}

\begin{tabular}{|c|c|c|c|c|c|c|c|}
\hline & \multirow[b]{2}{*}{ Economy } & \multicolumn{2}{|c|}{$\begin{array}{l}\text { Percentage of individuals } \\
\text { using the Internet }\end{array}$} & \multicolumn{2}{|c|}{$\begin{array}{l}\text { Fixed (wired)-broadband } \\
\text { Internet subscriptions } \\
\text { per } 100 \text { inhabitants }\end{array}$} & \multicolumn{2}{|c|}{$\begin{array}{l}\text { Active mobile- } \\
\text { broadband subscriptions } \\
\text { per } 100 \text { inhabitants* }\end{array}$} \\
\hline & & 2008 & 2010 & 2008 & 2010 & 2008 & 2010 \\
\hline 1 & Albania & 23.9 & 45.0 & 2.0 & 3.4 & 0.0 & 0.0 \\
\hline 2 & Algeria & 10.2 & 12.5 & 1.4 & 2.5 & 0.0 & 0.0 \\
\hline 3 & Angola & 3.1 & 10.0 & 0.1 & 0.1 & 0.8 & 5.6 \\
\hline 4 & Antigua \& Barbuda & 75.0 & 80.0 & 14.5 & 17.2 & 0.0 & 0.0 \\
\hline 5 & Argentina & 28.1 & 36.0 & 8.0 & 9.6 & 1.9 & 12.8 \\
\hline 6 & Armenia & 6.2 & 37.0 & 0.2 & 2.7 & 0.0 & 5.2 \\
\hline 7 & Australia & 71.7 & 76.0 & 23.9 & 23.2 & 52.6 & 82.7 \\
\hline 8 & Austria & 72.9 & 72.7 & 20.7 & 23.9 & 26.2 & 67.4 \\
\hline 9 & Azerbaijan & 17.1 & 36.0 & 0.7 & 5.4 & 0.0 & 0.9 \\
\hline 10 & Bahrain & 52.0 & 55.0 & 7.3 & 12.2 & 18.6 & 21.3 \\
\hline 11 & Bangladesh & 2.5 & 3.7 & 0.0 & 0.0 & 0.0 & 0.2 \\
\hline 12 & Barbados & 66.5 & 70.2 & 18.1 & 20.6 & 0.0 & 0.0 \\
\hline 13 & Belarus & 23.0 & 31.7 & 4.9 & 17.4 & 0.2 & 11.6 \\
\hline 14 & Belgium & 71.3 & 79.3 & 27.9 & 31.5 & 12.0 & 23.1 \\
\hline 15 & Benin & 1.9 & 3.1 & 0.0 & 0.3 & 0.0 & 0.0 \\
\hline 16 & Bhutan & 6.6 & 13.6 & 0.3 & 1.2 & 0.3 & 0.3 \\
\hline 17 & Bolivia & 10.8 & 20.0 & 0.8 & 1.0 & 0.1 & 1.4 \\
\hline 18 & Bosnia and Herzegovina & 34.7 & 52.0 & 5.0 & 10.4 & 0.0 & 10.7 \\
\hline 19 & Botswana & 6.3 & 6.0 & 0.5 & 0.6 & 0.0 & 6.3 \\
\hline 20 & Brazil & 33.8 & 40.7 & 5.4 & 7.2 & 1.8 & 10.6 \\
\hline 21 & Brunei Darussalam & 46.0 & 50.0 & 4.4 & 5.4 & 38.4 & 61.4 \\
\hline 22 & Bulgaria & 39.7 & 46.2 & 11.1 & 14.7 & 16.8 & 24.5 \\
\hline 23 & Burkina Faso & 0.9 & 1.4 & 0.1 & 0.1 & 0.0 & 0.0 \\
\hline 24 & Cambodia & 0.5 & 1.3 & 0.1 & 0.3 & 1.1 & 8.9 \\
\hline 25 & Cameroon & 3.4 & 4.0 & 0.0 & 0.0 & 0.2 & 0.9 \\
\hline 26 & Canada & 76.7 & 81.6 & 29.5 & 29.8 & 4.6 & 14.8 \\
\hline 27 & Cape Verde & 20.0 & 30.0 & 1.5 & 3.0 & 0.0 & 0.0 \\
\hline 28 & Chad & 1.2 & 1.7 & 0.0 & 0.0 & 0.0 & 0.0 \\
\hline 29 & Chile & 37.3 & 45.0 & 8.5 & 10.5 & 2.4 & 7.1 \\
\hline 30 & China & 22.6 & 34.3 & 6.2 & 9.4 & 0.0 & 2.0 \\
\hline 31 & Colombia & 25.6 & 36.5 & 3.3 & 5.7 & 1.0 & 5.6 \\
\hline 32 & Comoros & 3.5 & 5.1 & 0.0 & 0.0 & 0.0 & 0.0 \\
\hline 33 & Congo (Dem. Rep.) & 0.4 & 0.7 & 0.0 & 0.0 & 0.0 & 0.0 \\
\hline 34 & Costa Rica & 32.3 & 36.5 & 2.4 & 6.2 & 0.0 & 5.5 \\
\hline 35 & Côte d'Ivoire & 2.0 & 2.6 & 0.1 & 0.0 & 0.0 & 0.0 \\
\hline 36 & Croatia & 50.6 & 60.3 & 11.9 & 18.3 & 20.7 & 39.3 \\
\hline 37 & Cuba & 12.9 & 15.1 & 0.0 & 0.0 & 0.0 & 0.0 \\
\hline 38 & Cyprus & 42.3 & 53.0 & 13.7 & 17.6 & 20.5 & 61.3 \\
\hline 39 & Czech Republic & 63.0 & 68.8 & 17.0 & 14.7 & 13.0 & 27.8 \\
\hline 40 & Denmark & 85.0 & 88.7 & 36.5 & 37.4 & 27.1 & 54.7 \\
\hline 41 & Djibouti & 2.3 & 6.5 & 0.3 & 0.9 & 0.0 & 0.0 \\
\hline 42 & Dominican Rep. & 20.8 & 39.5 & 2.3 & 3.6 & 0.4 & 2.2 \\
\hline 43 & Ecuador & 18.8 & 24.0 & 1.1 & 1.4 & 0.2 & 8.7 \\
\hline 44 & Egypt & 18.0 & 26.7 & 1.0 & 1.8 & 0.8 & 6.4 \\
\hline 45 & El Salvador & 10.1 & 15.0 & 2.0 & 2.8 & 0.8 & 5.0 \\
\hline 46 & Eritrea & 4.1 & 5.4 & 0.0 & 0.0 & 0.0 & 0.0 \\
\hline 47 & Estonia & 70.6 & 74.1 & 21.0 & 24.3 & 4.0 & 8.1 \\
\hline 48 & Ethiopia & 0.5 & 0.8 & 0.0 & 0.0 & 0.0 & 0.3 \\
\hline 49 & Fiji & 12.2 & 14.8 & 1.5 & 1.9 & 0.1 & 1.4 \\
\hline 50 & Finland & 83.7 & 86.9 & 30.4 & 29.1 & 24.3 & 78.1 \\
\hline 51 & France & 70.7 & 80.1 & 28.7 & 33.9 & 23.6 & 35.8 \\
\hline 52 & Gabon & 6.2 & 7.2 & 0.2 & 0.2 & 0.0 & 0.0 \\
\hline 53 & Gambia & 6.9 & 9.2 & 0.0 & 0.0 & 0.0 & 0.5 \\
\hline 54 & Georgia & 10.0 & 27.0 & 2.2 & 5.1 & 9.3 & 18.8 \\
\hline 55 & Germany & 77.9 & 81.9 & 27.5 & 31.6 & 21.2 & 36.4 \\
\hline 56 & Ghana & 4.3 & 8.6 & 0.1 & 0.2 & 0.0 & 0.6 \\
\hline 57 & Greece & 38.2 & 44.4 & 13.3 & 19.8 & 45.1 & 58.3 \\
\hline 58 & Guatemala & 8.3 & 10.5 & 0.7 & 1.8 & 0.7 & 3.7 \\
\hline 59 & Guinea & 0.9 & 1.0 & 0.0 & 0.0 & 0.0 & 0.0 \\
\hline 60 & Guyana & 18.2 & 29.9 & 0.7 & 1.6 & 0.0 & 0.0 \\
\hline 61 & Honduras & 9.6 & 11.1 & 0.0 & 1.0 & 0.7 & 4.2 \\
\hline 62 & Hong Kong, China & 66.7 & 69.4 & 28.3 & 30.2 & 40.3 & 74.5 \\
\hline 63 & Hungary & 56.0 & 65.3 & 16.8 & 19.6 & 15.5 & 29.9 \\
\hline 64 & Iceland & 91.0 & 95.0 & 33.4 & 34.6 & 0.0 & 44.9 \\
\hline 65 & India & 4.4 & 7.5 & 0.4 & 0.9 & 0.0 & 0.9 \\
\hline 66 & Indonesia & 7.9 & 9.1 & 0.4 & 0.8 & 3.4 & 10.3 \\
\hline 67 & Iran (I.R.) & 10.2 & 13.0 & 0.4 & 0.7 & 0.0 & 0.0 \\
\hline 68 & Ireland & 65.3 & 69.9 & 20.3 & 22.8 & 33.0 & 47.3 \\
\hline 69 & Israel & 59.4 & 67.2 & 23.7 & 25.1 & 34.2 & 62.2 \\
\hline 70 & Italy & 44.5 & 53.7 & 18.8 & 22.1 & 50.6 & 59.4 \\
\hline 71 & Jamaica & 23.6 & 26.1 & 3.6 & 4.3 & 0.9 & 7.9 \\
\hline 72 & Japan & 75.4 & 80.0 & 23.8 & 26.9 & 73.2 & 87.8 \\
\hline 73 & Jordan & 23.0 & 38.0 & 2.3 & 3.2 & 0.0 & 2.4 \\
\hline 74 & Kazakhstan & 11.0 & 34.0 & 4.2 & 5.3 & 0.0 & 0.3 \\
\hline 75 & Kenya & 8.7 & 25.9 & 0.0 & 0.0 & 0.1 & 5.6 \\
\hline 76 & Korea (Rep.) & 81.0 & 83.7 & 33.4 & 36.6 & 71.4 & 91.0 \\
\hline
\end{tabular}




\begin{tabular}{|c|c|c|c|c|c|c|c|}
\hline & \multirow[b]{2}{*}{ Economy } & \multicolumn{2}{|c|}{$\begin{array}{l}\text { Percentage of individuals } \\
\text { using the Internet }\end{array}$} & \multicolumn{2}{|c|}{$\begin{array}{l}\text { Fixed (wired)-broadband } \\
\text { Internet subscriptions } \\
\text { per } 100 \text { inhabitants }\end{array}$} & \multicolumn{2}{|c|}{$\begin{array}{l}\text { Active mobile- } \\
\text { broadband subscriptions } \\
\text { per } 100 \text { inhabitants* }\end{array}$} \\
\hline & & 2008 & 2010 & 2008 & 2010 & 2008 & 2010 \\
\hline 77 & Kyrgyzstan & 15.7 & 20.0 & 0.4 & 0.3 & 0.0 & 4.1 \\
\hline 78 & Lao P.D.R. & 3.6 & 7.0 & 0.1 & 0.2 & 0.0 & 0.4 \\
\hline 79 & Latvia & 63.4 & 68.4 & 17.4 & 19.3 & 6.3 & 27.4 \\
\hline 80 & Lebanon & 22.5 & 31.0 & 4.7 & 4.7 & 0.0 & 0.0 \\
\hline 81 & Lithuania & 55.2 & 62.1 & 17.6 & 20.6 & 4.1 & 22.9 \\
\hline 82 & Luxembourg & 82.2 & 90.6 & 29.4 & 32.8 & 64.7 & 72.1 \\
\hline 83 & Macao, China & 49.2 & 56.8 & 23.4 & 24.1 & 0.0 & 56.1 \\
\hline 84 & Madagascar & 1.7 & 1.7 & 0.0 & 0.0 & 0.0 & 0.8 \\
\hline 85 & Malaysia & 55.8 & 55.3 & 4.8 & 7.3 & 8.8 & 27.2 \\
\hline 86 & Maldives & 23.2 & 28.3 & 5.1 & 4.9 & 2.5 & 8.7 \\
\hline 87 & Mali & 1.6 & 2.7 & 0.0 & 0.0 & 0.0 & 1.1 \\
\hline 88 & Malta & 50.1 & 63.0 & 23.0 & 27.5 & 14.3 & 31.0 \\
\hline 89 & Mauritania & 1.9 & 3.0 & 0.2 & 0.2 & 2.2 & 3.1 \\
\hline 90 & Mauritius & 21.8 & 24.9 & 4.1 & 6.3 & 7.0 & 22.1 \\
\hline 91 & Mexico & 21.7 & 31.0 & 6.7 & 10.0 & 1.7 & 8.3 \\
\hline 92 & Moldova & 23.4 & 40.0 & 3.2 & 7.5 & 0.3 & 15.3 \\
\hline 93 & Mongolia & 7.0 & 10.2 & 1.2 & 2.3 & 3.0 & 11.8 \\
\hline 94 & Montenegro & 41.0 & 52.0 & 5.4 & 8.3 & 8.2 & 38.0 \\
\hline 95 & Morocco & 33.1 & 49.0 & 1.5 & 1.6 & 2.3 & 10.0 \\
\hline 96 & Mozambique & 1.6 & 4.2 & 0.0 & 0.1 & 0.0 & 1.5 \\
\hline 97 & Namibia & 5.3 & 6.5 & 0.0 & 0.4 & 0.0 & 7.5 \\
\hline 98 & Nepal & 1.7 & 6.8 & 0.0 & 0.4 & 0.0 & 0.0 \\
\hline 99 & Netherlands & 87.4 & 90.7 & 35.2 & 38.0 & 25.0 & 37.7 \\
\hline 100 & New Zealand & 72.0 & 83.0 & 21.4 & 24.9 & 44.7 & 66.2 \\
\hline 101 & Nicaragua & 5.3 & 10.0 & 0.6 & 0.8 & 0.4 & 3.0 \\
\hline 102 & Niger & 0.7 & 0.8 & 0.0 & 0.0 & 0.0 & 0.0 \\
\hline 103 & Nigeria & 15.9 & 28.4 & 0.0 & 0.1 & 3.1 & 2.9 \\
\hline 104 & Norway & 90.6 & 93.4 & 33.2 & 34.6 & 20.9 & 47.1 \\
\hline 105 & Oman & 20.0 & 62.6 & 1.2 & 1.9 & 5.6 & 10.7 \\
\hline 106 & Pakistan & 15.8 & 16.8 & 0.1 & 0.3 & 0.0 & 0.6 \\
\hline 107 & Panama & 33.8 & 42.8 & 5.8 & 7.8 & 0.0 & 3.4 \\
\hline 108 & Papua New Guinea & 1.2 & 1.3 & 0.0 & 0.1 & 0.0 & 0.0 \\
\hline 109 & Paraguay & 14.3 & 23.6 & 1.4 & 0.6 & 0.3 & 4.1 \\
\hline 110 & Peru & 30.6 & 34.3 & 2.5 & 3.1 & 0.4 & 7.2 \\
\hline 111 & Philippines & 6.2 & 25.0 & 1.2 & 1.8 & 7.0 & 16.6 \\
\hline 112 & Poland & 53.1 & 62.3 & 11.6 & 13.2 & 16.9 & 31.0 \\
\hline 113 & Portugal & 44.1 & 51.1 & 15.4 & 19.4 & 36.7 & 72.5 \\
\hline 114 & Qatar & 38.0 & 69.0 & 7.5 & 9.2 & 6.9 & 28.4 \\
\hline 115 & Romania & 32.4 & 39.9 & 11.5 & 14.0 & 21.3 & 32.8 \\
\hline 116 & Russia & 26.8 & 43.0 & 6.5 & 11.0 & 0.6 & 17.4 \\
\hline 117 & Rwanda & 3.1 & 7.7 & 0.0 & 0.0 & 0.0 & 1.3 \\
\hline 118 & Saudi Arabia & 36.0 & 41.0 & 4.0 & 5.5 & 9.1 & 57.8 \\
\hline 119 & Senegal & 10.6 & 16.0 & 0.4 & 0.6 & 0.0 & 2.6 \\
\hline 120 & Serbia & 35.6 & 40.9 & 6.0 & 8.5 & 6.7 & 19.0 \\
\hline 121 & Seychelles & 40.4 & 41.0 & 3.2 & 7.3 & 2.3 & 4.7 \\
\hline 122 & Singapore & 69.0 & 70.0 & 21.5 & 24.7 & 63.2 & 69.7 \\
\hline 123 & Slovak Republic & 71.3 & 79.4 & 11.1 & 16.1 & 11.8 & 27.0 \\
\hline 124 & Slovenia & 58.0 & 70.0 & 21.1 & 24.4 & 26.2 & 32.8 \\
\hline 125 & South Africa & 8.4 & 12.3 & 0.9 & 1.5 & 5.0 & 16.6 \\
\hline 126 & Spain & 59.6 & 66.5 & 20.1 & 23.0 & 36.0 & 55.7 \\
\hline 127 & Sri Lanka & 5.8 & 12.0 & 0.5 & 1.0 & 2.3 & 9.6 \\
\hline 128 & Suriname & 21.1 & 31.6 & 1.1 & 3.0 & 0.0 & 0.0 \\
\hline 129 & Swaziland & 6.9 & 8.0 & 0.1 & 0.1 & 0.0 & 0.0 \\
\hline 130 & Sweden & 90.0 & 90.0 & 31.4 & 31.6 & 35.4 & 84.0 \\
\hline 131 & Switzerland & 79.2 & 83.9 & 33.8 & 38.2 & 23.2 & 43.8 \\
\hline 132 & Syria & 6.5 & 20.7 & 0.1 & 0.3 & 0.0 & 1.3 \\
\hline 133 & Tanzania & 9.0 & 11.0 & 0.0 & 0.0 & 0.4 & 2.1 \\
\hline 134 & TFYR Macedonia & 46.0 & 51.9 & 8.8 & 12.5 & 0.0 & 20.8 \\
\hline 135 & Thailand & 18.2 & 21.2 & 2.6 & 3.9 & 0.5 & 3.8 \\
\hline 136 & Togo & 4.8 & 5.4 & 0.0 & 0.1 & 0.0 & 0.0 \\
\hline 137 & Trinidad \& Tobago & 34.8 & 48.5 & 6.4 & 10.8 & 0.0 & 0.0 \\
\hline 138 & Tunisia & 27.5 & 36.8 & 2.2 & 4.6 & 0.0 & 1.1 \\
\hline 139 & Turkey & 34.4 & 39.8 & 8.1 & 9.8 & 0.0 & 17.8 \\
\hline 140 & Turkmenistan & 1.8 & 2.2 & 0.0 & 0.0 & 0.0 & 0.0 \\
\hline 141 & Uganda & 7.9 & 12.5 & 0.0 & 0.1 & 0.1 & 0.6 \\
\hline 142 & Ukraine & 10.6 & 23.0 & 3.5 & 8.1 & 1.8 & 4.3 \\
\hline 143 & United Arab Emirates & 72.0 & 78.0 & 9.0 & 10.5 & 29.1 & 58.4 \\
\hline 144 & United Kingdom & 78.4 & 85.0 & 28.2 & 31.4 & 33.8 & 56.0 \\
\hline 145 & United States & 74.0 & 79.0 & 24.8 & 26.3 & 26.9 & 54.0 \\
\hline 146 & Uruguay & 39.3 & 43.4 & 6.8 & 11.4 & 1.4 & 5.7 \\
\hline 147 & Uzbekistan & 9.1 & 20.0 & 0.2 & 0.3 & 0.0 & 3.9 \\
\hline 148 & Venezuela & 25.9 & 35.6 & 4.7 & 5.4 & 8.5 & 20.8 \\
\hline 149 & Viet Nam & 23.9 & 27.6 & 2.4 & 4.1 & 0.0 & 12.8 \\
\hline 150 & Yemen & 6.9 & 10.9 & 0.1 & 0.3 & 0.0 & 0.0 \\
\hline 151 & Zambia & 5.6 & 6.7 & 0.0 & 0.1 & 0.0 & 0.0 \\
\hline 152 & Zimbabwe & 11.4 & 11.5 & 0.1 & 0.3 & 0.0 & 0.7 \\
\hline
\end{tabular}

Note: Data in italics refer to ITU estimates.

* Data provided by Wireless Intelligence. For individual network operator data and forecasts please go to www.wirelessintelligence.com. Source: ITU World Telecommunication/ICT Indicators database. 


\section{Skills indicators}

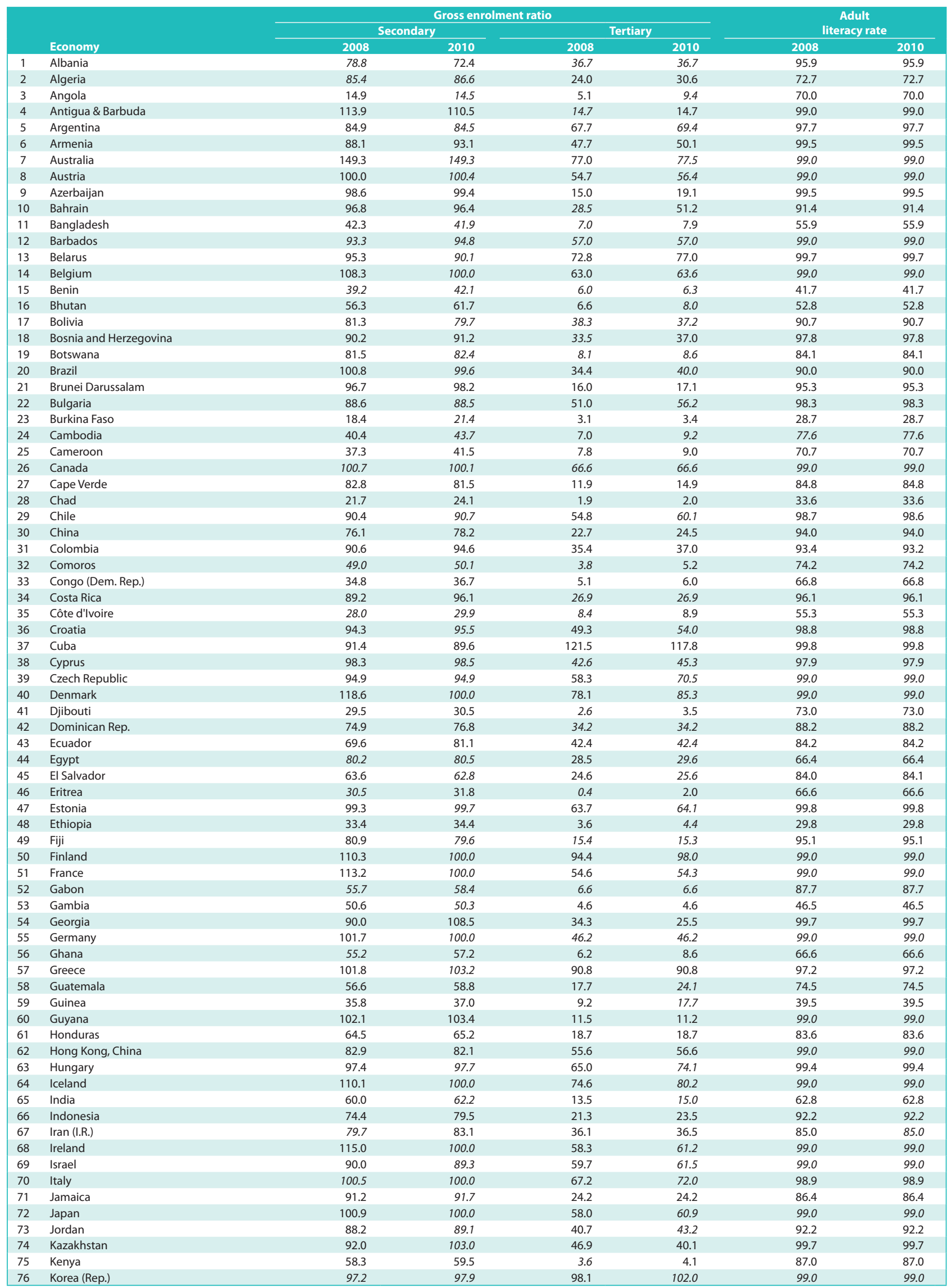




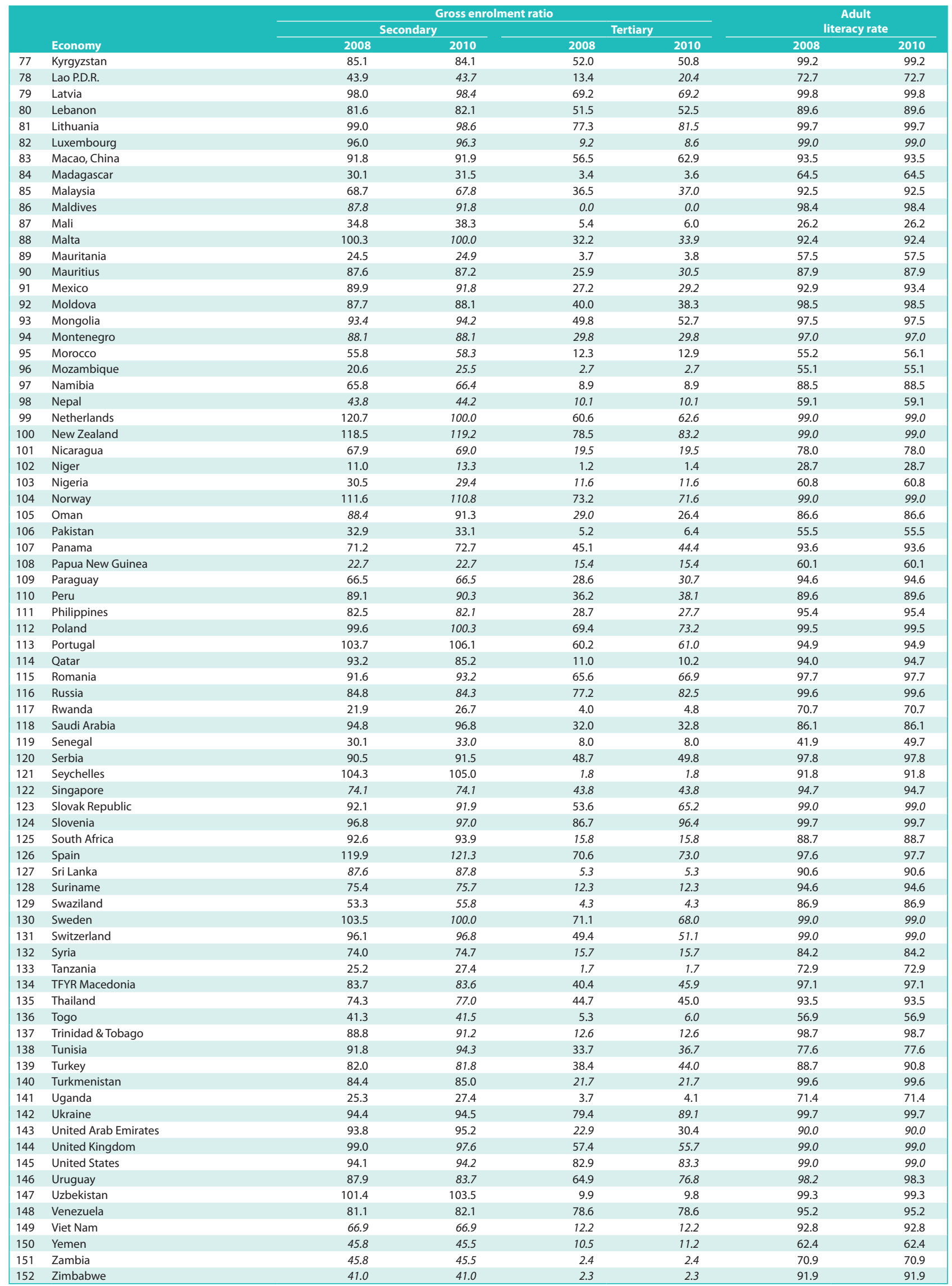

Note: Data in italics refer to ITU estimates.

Source: UIS. Latest available data. 




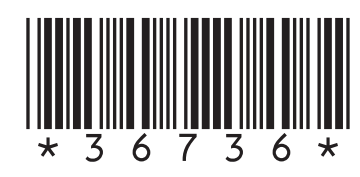

Printed in Switzerland

Geneva, 2011

ISBN 92-61-13801-2

Photo credits: Shutterstock 